\title{
Hormonal Regulation of the Anticoagulant Protein S
}

\author{
Quintin Hughes
}

Supervisors Prof. Jennet Harvey, Dr. Janelle Staton and Dr. Mark Watson

This thesis is a requirement for a postgraduate Doctorate of Philosophy undertaken at the University of Western Australia, School of Surgery and Pathology 
This thesis 'Hormonal Regulation of the Anticoagulant Protein $\mathrm{S}$ ' is a true representation of my own research. All experiments were conducted by myself in the Department of Haematology and the Research Centre, both situated at Royal Perth Hospital, Perth, Western Australia, under the supervision of Dr. Janelle Staton, with the following exceptions. Figures $3.7 \mathrm{C}$ and $3.8 \mathrm{~B}$ were performed by Vanessa Atkinson. The pregnancy cohort DNA obtained from King Edward Hospital detailed in Section 2.1 was extracted by Dr. Anne Bardon while the associated levels of free, total and functional Protein S were determined by Leesa Ivey, Jim Thom and Grace Gilmore.

Data presented in this thesis is to the best of my knowledge and belief original, except where acknowledge in the text, and has not been submitted, either whole or in part, for a degree at this or any other university.

Quintin W. Hughes

April 2007 


\section{ABSTRACT}

Every year thousands of individuals suffer from thrombotic related complications that in some cases can be fatal and every year millions of women take some form of hormonal contraceptive. In some cases, there is a cause and effect relationship between the two as users of the combined oral contraceptive pill have an increased risk of developing a thrombotic event. Increased circulating levels of oestrogen cause a prothrombotic shift in the coagulation cascade resulting from upregulation of several procoagulant proteins and a decrease of key anticoagulant proteins. One of the most oestrogen sensitive anticoagulants is Protein S (PS), a product of the PROS1 gene. PS acts as a cofactor to activated protein C (aPC) and the PS-aPC complex serves to downregulate clot formation by deactivating the tenase and prothrombinase complexes via proteolytic cleavage of activated factors VIII and V, respectively. As such, low PS levels are associated with an increased risk of developing thrombotic disorders such as pulmonary embolism, stroke or coronary thrombosis and deep vein thrombosis. During pregnancy when oestrogen levels increase, a steady decline in PS is evident in the early weeks of gestation and continues to decrease to below the normal range in the 2 nd trimester, remaining there until post-partum. In addition, reduced free and total PS levels are observed in users of the combined oral contraceptive (COC) pill that contains an oestrogen and a progestin. Interestingly, users of 3rd generation COCs have significantly greater reductions of PS than do 2nd generation COC users. The difference between the two forms is the type of progestin, not the oestrogen, which is predominantly ethinyl oestradiol in the majority of commercially available preparations. At present, a mechanism to describe the relationship between oestrogen and/or progesterone associated with the observed in vivo changes in the levels of PS has not been identified. The aim of this thesis was to define the molecular mechanisms involved in the regulation of PS expression by oestrogen and progesterone. In this study, a Combined Single-stranded conformational analysis and Heteroduplex Analysis (CSHA) 
methodology was optimised for screening both PROS1 DNA and mRNA for the detection of mutations. Two patient cohorts were screened, the first comprised patients with abnormally low PS levels while the second was a pregnancy cohort consisting of normal controls and women who experienced greater than normal decreases in their PS levels during gestation. Several mutations were detected including four novel mutations; T101A and G340C both within the PROS1 coding region, g-175a located in the 5 untranslated region and a three nucleotide deletion mapping to intron A. The g-175a variant is of particular interest because its location in the 5'UTR could potentially disrupt binding of transcriptional factors and hormone receptor complexes affecting regulation of the PROS1 promoter. Two other previously described variants were also detected in the 5 UTR, $\mathrm{t}$ $397 \mathrm{c}$ and c-407t. These variants underwent further investigation as both mapped to a potential progesterone response element (PRE) identified using in silico analysis. In addition, a putative putative oestrogen response element (ERE) was identified at positions -526 to -538 within the 5 UTR. The effects of these elements were investigated in transfection experiments. A 950bp fragment of the PROS1 5 UTR was inserted upstream from an enhanced green fluorescence protein (EGFP) reporter gene. The resultant plasmid, denoted pPMTR, was used for transient transfections of the liver and breast carcinoma cell lines, $\mathrm{HuH}-7$ and MCF-7, respectively. Post-transfection treatment with $17 \beta$-oestradiol and a plasmid expressing oestrogen receptor alpha reduced activity of the PROS1 promoter by up to 35\% when the MCF-7 line was used. The response was stronger (reduction of $46 \%$ ) in the HuH-7 cell line. Conversely, PROS1 promoter activity increased (up by 25\%) when the pPMTR vector was transiently transfected into the MCF-7 cells treated with progesterone. The response was reversed in the presence of the progestin receptor antagonist RU486 (activity equivalent to no progesterone control). The level of increased activity was lower when the experiments were repeated in the HuH-7 cell line $(17 \%$ increased activity in the 
presence of progesterone). Subsequent investigation identified a mechanism involving the B-isoform of the progesterone receptor (PR-B) binding to the postulated PRE containing the $\mathrm{t}-397 \mathrm{c}$ and $\mathrm{c}-407 \mathrm{t}$ variants. Introduction of one of the variants, $\mathrm{c}-407 \mathrm{t}$, via site directed mutagenesis, disrupted PR-B binding, reducing the progestin mediated upregulation of the PROS1 promoter. In addition, an electromobility shift assay was performed which established PR-B specific binding to the PRE and further demonstrated that incorporation of the c- $407 \mathrm{t}$ variant reduced binding affinity. This suggested that the area spanning c-407t is involved in direct binding of the progesterone/PR-B complex. Surprisingly, assessment of different progestin isoforms found the level of transcriptional upregulation varied greatly with medroxyprogesterone eliciting a response more than double the effect observed for progesterone. This may explain why users of 3rd generation COCs display a greater reduction in circulating PS levels compared to 2nd generation users. To investigate potential PS interactions with other proteins that could be hormonally regulated, a yeast-2-hybrid (Y-2-H) screen was performed using the PS molecule as a 'bait' against molecules derived from liver and bone marrow cDNA libraries. A clone that contained a portion of another haemostatic protein, Protein Z (PZ) was isolated and confirmed via sequencing. As no full length PZ clones were identified, a second Y-2-H screen was performed once again using the PS molecule as bait and the PZ molecule as the fish. Interaction between the two proteins was shown to be possible via the successful growth of colonies on triple knock out selective media and by positive $\beta$-galactosidase activity. 


\section{PUBLICATIONS}

Prizes

2004 ASTH Medal

2005 MRF Young Scientific Investigator Award

2006 CBSM Oral Presentation Prize

Runner up 2006 ASTH Medal

\section{Complete list of publications}

- Oral Presentation- The $6^{\text {th }}$ Combined Annual Scientific Meeting of the Haematology Society of Australia and New Zealand, the Australian and New Zealand Society of Blood Transfusion, and the Australasian Society of Thrombosis and Haemostasis (HAA) Annual Scientific Meeting, Melbourne, Australia. October 17-20 2004.

- Oral Presentation- Australian Society of Medical Research (ASMR) Medical Research Week Symposium, Perth, Australia. June $7^{\text {th }} 2005$.

- Poster Presentation- XXth Congress of the International Society of Thrombosis and Haemostasis (ISTH), Sydney, Australia. August 16-18 2005 .

- Oral Presentation- The $15^{\text {th }}$ Annual Combined Biological Sciences Meeting (CBSM), Perth, Australia. August $26^{\text {th }} 2005$.

- Oral Presentation- Medical Research Foundation (MRF) Young Investigators Day, Perth, Australia. September $1^{\text {st }} 2005$.

- Oral Presentation- The $7^{\text {th }}$ Combined Annual Scientific Meeting of the Haematology Society of Australia and New Zealand, the Australian and New Zealand Society of Blood Transfusion, and the Australasian Society of Thrombosis and Haemostasis (HAA) Annual Scientific Meeting, Sydney, Australia. October 16-19 2005.

- Oral Presentation- Medical Research Foundation (MRF) Young Investigators Day, Perth, Australia. November $9^{\text {th }} 2005$. 
- Oral Presentation- University Department of Medicine Seminar, Perth, Australia. $25^{\text {th }}$ May 2006.

- Oral Presentation- Australian Society of Medical Research (ASMR) Medical Research Week Symposium, Perth, Australia. June $9^{\text {th }} 2006$.

- Oral Presentation- $11^{\text {th }}$ Congress of the European Hematology Association (EHA), Amsterdam, The Netherlands. June 15-18 2006.

- Oral Presentation- Royal Perth Hospital Department of Haematology Breakfast Meeting, Perth, Australia. June $27^{\text {th }} 2006$.

- Oral Presentation- The $16^{\text {th }}$ Annual Combined Biological Sciences Meeting (CBSM), Perth, Australia. August $18^{\text {th }} 2006$.

- Oral Presentation- University of Western Australia School of Surgery and Pathology Seminar, Perth, Australia. September $29^{\text {th }} 2006$.

- Oral Presentation- The Combined Annual Scientific Meeting of the Haematology Society of Australia and New Zealand, the Australian and New Zealand Society of Blood Transfusion, and the Australasian Society of Thrombosis and Haemostasis (HAA) Annual Scientific Meeting, Hobart, Australia. October $15-18^{\text {th }} 2006$.

Key findings of Chapter 4 have been published in the Journal of Thrombosis and Haemostasis-

- Hughes, Q., Watson, M., Cole, V., Sayer, M., Baker, R. and Staton, J. (2007) Up-regulation of Protein $\mathrm{S}$ by progestins. Journal of Thrombosis and Haemostasis. 5(11) 2243-2249. 


\section{TABLE OF CONTENTS}

TITLE .. $\mathbf{I}$

PREFACE. II

ABSTRACT III

PUBLICATIONS VI

TABLE OF CONTENTS VIII

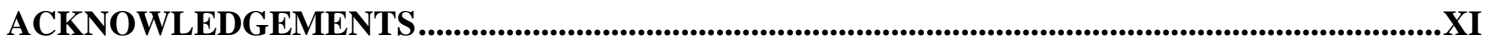

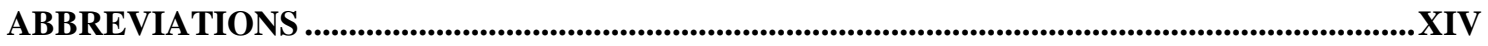

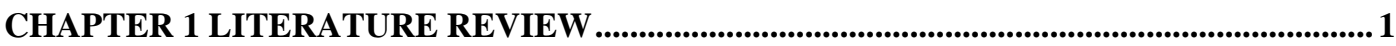

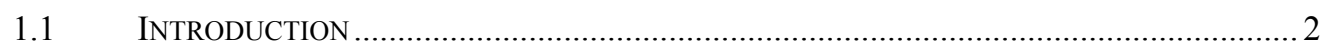

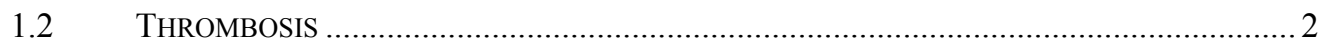

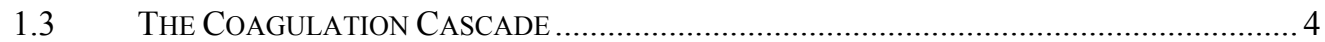

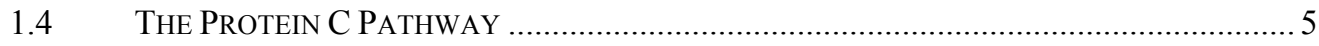

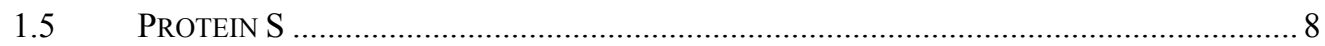

1.6 The ORAL CONTRACEPTIVE PILl .................................................................... 12

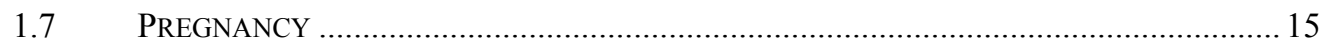

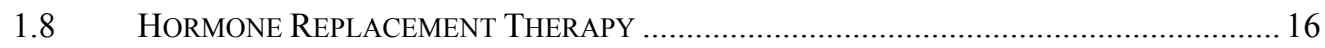

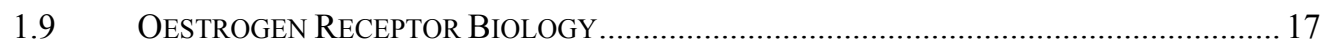

1.10 Progesterone ReCEPTOR BIOLOGY .................................................................. 21

1.11 The EfFect Of Hormones On HaEmostatic Parameters …............................. 23

1.12 The EfFect of Hormones ON ProteIn S........................................................... 25

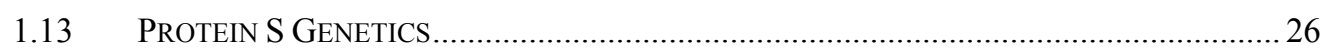

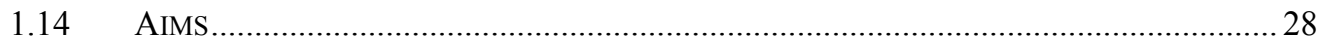

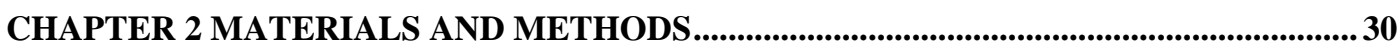

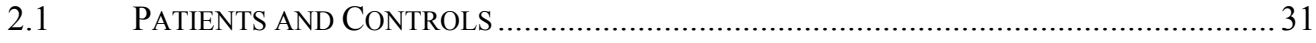

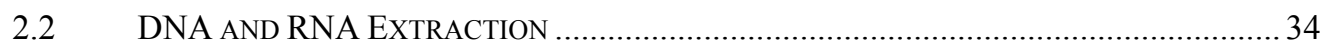


2.3 COMBINED SSCA AND HETERODUPLEX ANALYSIS (CSHA) ................................... 34

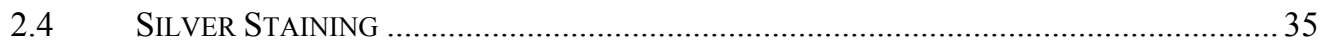

2.5 ISOLATION OF EXON 5 FRAGMENT................................................................. 35

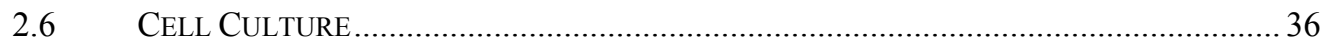

2.7 PlaSMID CONSTRUCTION FOR TRANSIENT TRANSFECTION STUDIES......................... 36

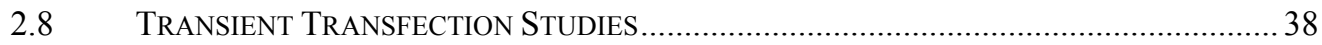

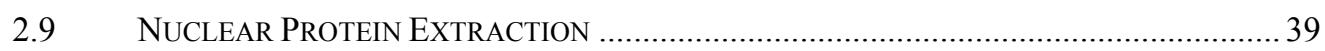

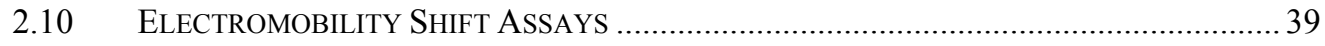

2.11 PlASMID CONSTRUCTION FOR YEAST-2-HYBRID ................................................. 40

2.12 CONFIRMATION OF VECTOR SEQUENCE................................................................ 41

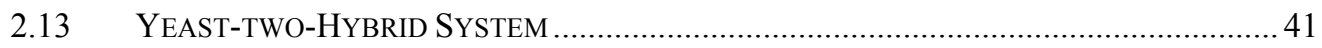

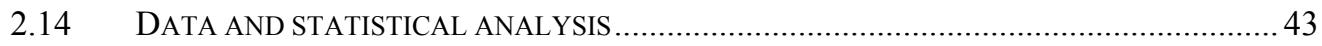

CHAPTER 3 MUTATION ANALYSIS OF THE PROS1 GENE................................................ 44

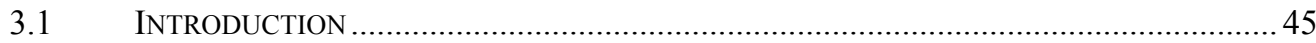

3.1.1 Sensitivity of CSHA Compared to Other Detection Methodologies ...................... 48

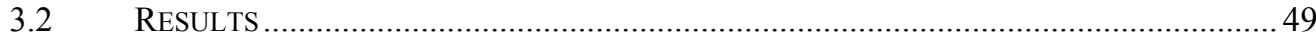

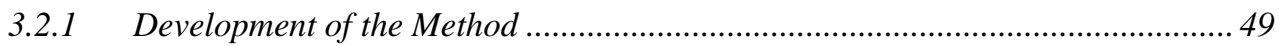

3.2.2 Mutations Identified in the Coding Region ..................................................... 55

3.2.3 Mutations Identified in the 5' Untranslated Region .......................................... 59

3.2.4 Results of mRNA Analysis .......................................................................... 59

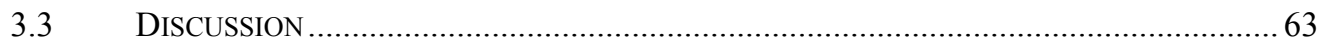

CHAPTER 4 ANALYSIS OF THE PROS1 PROMOTER .................................................. 71

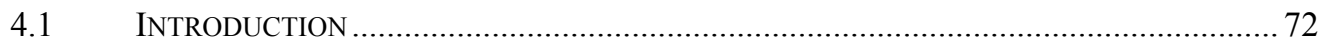

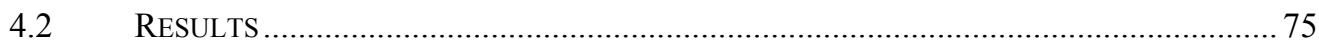

4.2.1 ER $\alpha$ downregulates the PROS1 promoter but not via the ERE consensus

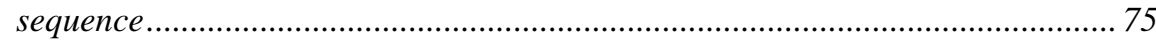

4.2.2 Progesterone upregulates PROS1 promoter activity .......................................... 80

4.2.3 Identification of the PR binding domain within the PROS1 promoter ................. 81

4.2.4 Differential responses to different types of progestins ........................................ 82

4.2.5 Differential response to glucocorticoid......................................................... 82 
CHAPTER 5 IDENTIFICATION OF NOVEL PROTEIN S BINDING PARTNERS

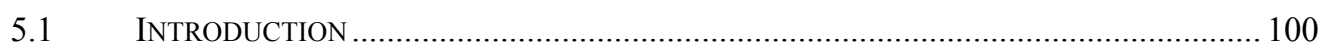

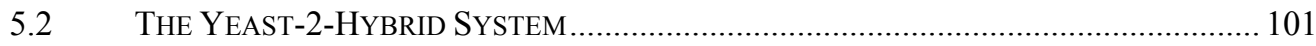

5.2.1 Limitations of the Yeast Two Hybrid Screen ..................................................... 104

5.2.2 MatchMaker Yeast-2-Hybrid System ............................................................. 104

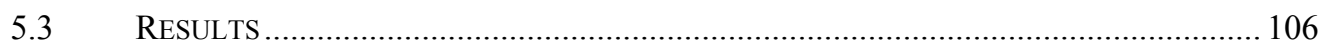

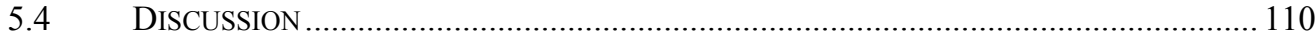

5.4.1 Follow up Studies required to confirm the PS/PZ Interaction ............................ 113

CHAPTER 6 GENERAL DISCUSSION ...................................................................................... 114

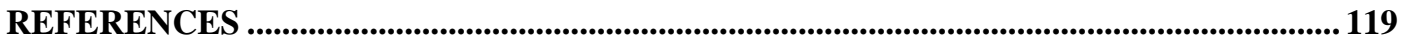

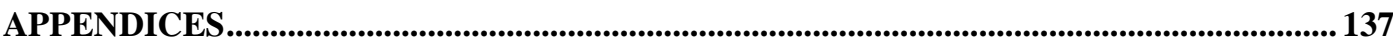




\section{ACKNOWLEDGEMENTS}

First, let me say that Royal Perth Hospital is a great place to do a $\mathrm{PhD}$. So many friendly and helpful people, it's hard to know where to start, but for me, the heart of it is the Research Centre Mob. With people like Marian Sturm, Kay Hudson, Kath Shaw and all the CTTWA crew, how could you ever possibly be glum? Thanks to you all for all your help and advice. Long live the tearoom!

The Research Centre isn't the only source of great people, it seems to me the whole of Level 2 North Block is full of genuine people who are happy offer advice or reagents and provide you with the benefits of their many years of accumulated knowledge. Jim Thom and Grace Gilmore in Coagulation Research; Melinda Higgins, Kerryn Stoner, Rom Kruger and John O'Reilly in Haematology; Jacky Bental, Mark Thomas and Diana Azzam in Anatomical Pathology; Ken Robinson and Amanda Hooper in Biochemistry and all the helpful staff in Immunology.

A special thanks goes to all the people directly associated with my project. Thanks to Ross Baker for supporting my project and importantly for allowing me the freedom to pursue concepts and ideas. My supervisor Janelle Staton has provided the best form of supervision for someone like myself and has tirelessly assisted me throughout my candidature. I am indebted to her and Melissa Sayer, both of whom have three small children and other commitments to contend with, but have always found time for my project.

My other co-supervisor Mark Watson has been invaluable in his provision of advice, reagents and equipment. A genuine good bloke if ever I've meet one. This thesis would 
read quite differently I'm sure if it hadn't been for your input, especially early on in the piece. Thanks Mark.

I would also like to thank my principal supervisor Prof. Jennet Harvey and the School of Surgery and Pathology (particularly Cora D'Souza) for all their help and support throughout my candidature. I will also take this opportunity to thank Prof. Bob Mead of Murdoch University for the support he gave me as a mature age student in my undergraduate days, all those years ago.

A heartfelt thanks to my lab partner Vanessa Cole (now Atkinson!!), who has put up with my insanity and has helped me in countless ways throughout the past few years. A better fellow scientist I could not imagine. Ta and once again, congratulations Mrs. Atkinson!! I extend the same level of appreciation to Julianna Degenaar too, arguably the best RA in the history of science! Thanks heaps Jules!

I will also use this opportunity to thank other past lab buddies too, including Kate Maslen and Leesa Ivey who provided me with important background on the pregnancy cohort, including providing the serum PS levels data.

Thanks to Dr Evan Ingley from the MRF for his help with the Yeast-2-Hybrid work and for providing the pBTM116 vector and FGR clone. Thanks also to other members of the MRF including Dr Andrew Redfern for providing the oestrogen receptor expression vector and Dr Esme Hatchell for supplying me with reagents and advice.

Other researchers I would like to thank for providing me with vital reagents and helpful advice are Dr Yolanda Espinosa-Parrilla and Dr Nuria Sala for providing the PS DNA positive controls referred to in Chapter 3. Thanks to Prof. Christine Clarke, Prof. Pierre 
Chambon and Prof. Tom Ratajczak for providing the progesterone and glucocorticoid expression vectors.

Lastly I would like to thank the people in my personal life. My mother who has, for some unknown reason, always held an unwavering belief in me and my uncle Will and Aunty Ida, who similarly also seem to hold me in high regard? My mates who are more than willing to have a drink (or three) with me when called upon, which of course is very rarely.....

And the biggest thanks goes to Natasha Buzzacott and her beautiful daughter (Queen of the Cheeky Monkeys), Maya. Both of you supported me in many varied and different ways throughout my candidature and I cannot thank you enough. My favourite way to sort out a perplexing problem was to go for a long ride around the lake with The Little One and be instantly reminded that at its core, life should be enjoyed. I will always cherish the time we had together. 


\section{ABBREVIATIONS}

3`UTR 3`Untranslated Region

3AT 3-Aminotriazole

5'UTR 5'Untranslated Region

$\mathrm{Ab} \quad$ Antibody

$\mathrm{aF} \quad$ Activated Factor

AP-1 Activator Protein 1

aPC Activated Protein C

aPC-R Activated Protein C Receptor

AT Antithrombin

ATP Adenosine Tri-phosphate

C4bBP Complement-4b Binding Protein

CMV Cytomegalovirus

COC Combined Oral Contraceptive

CORT Corticosterone

CSHA Combined Single stranded Conformational and Heteroduplex Analysis

dHPLC Denaturing High Performance Liquid Chromatography

DMEM Dulbeccos Modified Eagles Medium

DsRed2 Red Fluorescent Protein

DVT Deep Vein Thrombosis

$\mathrm{E}_{2} \quad 17 \beta$-Oestradiol

EDTA Ethylene diamine tetra acetic acid

EGFP Enhanced Green Fluorescent Protein

EGTA Ethylene glycol tetra acetic acid

EMSA Electro-Mobility Shift Assay

ER Oestrogen Receptor

ERE Oestrogen Response Element

ESR1 Oestrogen Receptor alpha gene

EtOH Ethanol

FCS Fetal Calf Serum

GlcCer Glucosylceramide

HA Heteroduplex Analysis

HEPES N-2-hydroxyethylpiperazine-N`-2-ethanesulfonic acid

His Histidine 


\begin{tabular}{|c|c|}
\hline HNF-3 & Hepatocyte Nuclear Factor-3 \\
\hline HRE & Hormone Response Element \\
\hline HRM & High Resolution Melt \\
\hline HRT & Hormone Replacement Therapy \\
\hline HSPs & Heat Shock Proteins \\
\hline I.M.A.G.E. & Integrated Molecular Analysis of Genomes and their Expression \\
\hline IL-6 & Interleukin-6 \\
\hline $\mathrm{Kb}$ & Kilobase \\
\hline Leu & Leucine \\
\hline LiAc & Lithium Acetate \\
\hline LNG & Levonorgestrel \\
\hline $\mathrm{mM}$ & Milli Molar \\
\hline MPA & Medroxyprogesterone \\
\hline $\mathrm{OC}$ & Oral Contraceptive \\
\hline $\mathrm{P}_{4}$ & Progesterone \\
\hline $\mathrm{PC}$ & Protein $\mathrm{C}$ \\
\hline $\mathrm{PE}$ & Pulmonary Embolism \\
\hline PEG & Polyethylene glycol \\
\hline $\mathrm{pM}$ & Pico Molar \\
\hline Poly (dI-dC) & Poly(deoxyinosinic-deoxycytidylic) acid sodium salt \\
\hline POP & Progesterone Only Pill \\
\hline PR & Progesterone Receptor \\
\hline PRE & Progesterone Response Element \\
\hline Pre-E & Pre-eclampsia \\
\hline PROS1 & Protein S gene \\
\hline PS & Protein S \\
\hline $\mathrm{PZ}$ & Protein $Z$ \\
\hline RU486 & Mifepristone \\
\hline Sp1 & Stimulating protein 1 (transcriptional factor) \\
\hline SSCA & Single Stranded Conformational Analysis \\
\hline STAT-3 & Signal Transducer and Activator of Transcription-3 \\
\hline TAE & Tris acetate EDTA \\
\hline TBE & Tris borate EDTA \\
\hline $\mathrm{TF}$ & Tissue Factor \\
\hline Trp & Tryptophan \\
\hline
\end{tabular}


TSS Transcriptional Start Site

Veh Vehicle

Y-2-H Yeast-2-Hybrid

Yc media Yeast complete media

ZPI Protein Z-dependant Inhibitor

$\alpha 1 \mathrm{ACT} \quad$ alpha-1-antichymotrypsin

$\beta$-Gal beta-galactosidase

$\mu \mathrm{M} \quad$ Micro Molar 


\section{CHAPTER 1}

Literature Review 


\subsection{INTRODUCTION}

Maintenance of haemostasis is a delicate balance between pro- and anti-coagulant forces. In the event of vascular injury, pro-coagulant activation generates rapid clot formation, preventing blood loss. Primarily, the anti-coagulant system serves to regulate the extent of the clot development, but is also important for the prevention of coagulant activation in intact, healthy blood vasculature.

\subsection{THROMBosis}

Thrombosis results from excessive clot formation leading to the blockage of arterial or venous vasculature resulting in stroke, pulmonary embolism (PE) or myocardial infarction, all of which can be fatal. Arterial thrombotic events are characteristic of high shear blood flow conditions generated in the artery. They are often associated with atherosclerotic plaque rupture and will not be discussed in this review. Venous thromboembolism (VTE) aetiology is associated with low or static blood flow that can occur for example in the lower extremities (Line, 2001, Furie and Furie, 2005). Unlike arterial thrombi that consist mostly of activated platelets and fibrin compacted tightly together, venous thrombi often contain red blood cells that result in a clot with comparatively less density (Goel and Diamond, 2002). Several outcomes can occur once a thrombus has formed. The clot can remain localised where it will eventually be cleared via the action of fibrinolytic enzymes released from the endothelium and leukocytes that are recruited to the embolus in response to chemotactic factors (Wakefield et al., 1997, Kolev and Machovich, 2003). However, if the embolus becomes mobilized it can become occluded in the veins of the leg or within the pulmonary arteries resulting in a PE. 
The incidence of VTE, including deep vein thrombosis (DVT) and PE, affect approximately 1 in 1000 adult persons with mortality occurring in an estimated $30 \%$ of cases (Heit et al., 1999b). Furthermore, evidence suggests PE may be the leading undiagnosed cause of death amongst hospitalized patients, many of whom could be saved with standard therapies had the condition been identified (Kroegel and Reissig, 2003). Recent data compiled from six EU member countries estimates that $12 \%$ of all deaths per annum are a result of VTE (Cohen et al., 2007). Across the entire EU statistical data shows the number of VTE-related deaths more than doubles the number of deaths attributed to acquired immunodeficiency syndrome (AIDS), breast cancer, prostate cancer and transport accidents combined (Cohen et al., 2007)

Thrombotic risk factors can have both genetic and environmental origins. Environmental risk factors include age, obesity, cancer, immobility (including extended travel times), surgery, trauma and alterations of hormonal status including pregnancy, hormone replacement therapy and contraceptives (Cushman, 2007). Genetic predisposition to a prothrombotic physiology relate to defects in the pro- and anticoagulants that regulate clot formation via the coagulation cascade (see following section), an example of which is PS deficiency. Inherited PS deficiency occurs in the Caucasian population at a frequency of between 0.03-0.13\% (Dykes et al., 2001), but is much higher in Asians occurring at between $0.48-0.63 \%$ in the Japanese population (Adachi, 2005) and estimated to be as high as $3.7 \%$ in the Thai population (Akkawat and Rojnuckarin, 2005). Although the incidence of PS deficiency overall is low, it is associated with an approximately 10 -fold greater risk of developing venous thromboembolism compared to the general population (Adachi, 2005, Martinelli et al., 2001). 


\subsection{The Coagulation Cascade}

Central to the process of coagulopathy is the coagulation cascade, a complex system that is heavily regulated by both positive and negative feedback loops (Figure 1.1). The coagulation cascade was previously divided into the intrinsic and extrinsic pathways that converged into a common pathway, leading to the generation of thrombin. However, it is now widely accepted that contact activation involving FXII does not play a role in vivo, leaving the tissue factor (TF) initiated extrinsic pathway model which has been altered to include recent discoveries. The TF-initiated model of activation starts with exposure of TF resulting from vascular injury. Strong expression of TF by cells of the tunica adventitia ensures that in the event of damage to vascular lining, TF will be immediately exposed (Weitz, 2001). TF complexes with activated factor VII (aFVII) which is in constant circulation, equating to $1-2 \%$ of the total FVII titre. How FVII is activated and its equilibrium regulated in vivo is still heavily debated but it is thought that unbound, circulating aFVII exhibits little or no proteolytic activity until it is complexed with TF (Komiyama et al., 1990). The aFVII/TF complex catalyses the activation of factors IX and $\mathrm{X}$ (FIX; FX), with aFX able to generate small, but important, quantities of thrombin from prothrombin (Osterud and Rapaport, 1977, Jesty and Silverberg, 1979, Orfeo et al., 2004). The pico molar quantities of thrombin are enough to activate factors V and VIII (FV; FVIII, serving also to cleave the latter from an association with von Willebrand factor which circulates bound to FVIII (Pittman and Kaufman, 1989, Brummel et al., 2002, Fay, 2004). The formation of the tenase complex (aFVIII/aFIX) on negatively charged phospholipids (such as the surface of platelets) generates large quantities of $\mathrm{aFX}$ which bind with aFV to form the prothrombinase complex, also on phospholipid surfaces. The prothrombinase complex dramatically increases prothrombin activation, approximately 300,000-fold greater than that of aFX alone (Nesheim et al., 1979). Positive feedback via thrombin not only 
increases further activation of FV and FVIII, but also activates FXI which in turn yields even greater quantities of FIX and FX.

Control of the coagulation cascade occurs at several levels. Once sufficient aFX has been generated, the initial TF/aFVII pathway is shut down via formation of a quaternary complex composed of TF/aFVII and aFX binding to tissue factor pathway inhibitor (TFPI). Thus TFPI removes TF/aFVII and some of the excess aFX from the activation process (Figure 1.1). However, as the total circulatory TFPI concentration is only $2.5 \mathrm{nM}$ further downregulatory management is necessary for adequate deactivation. The serine protease inhibitor, antithrombin III (ATIII) further downregulates coagulation, via deactivation of thrombin, but also by deactivating several key procoagulant serine proteases, namely aFVII, aFX, aFIX and aFXI (Figure 1.2). The third major component of the anticoagulant system is the activated Protein C (PC) pathway.

\subsection{The Protein C Pathway}

$\mathrm{PC}$ is a serine protease that circulates in an inactive form that is readily activated by thrombin. The process is increased 20,000 times in the presence of membrane bound thrombomodulin and endothelial cell PC receptor (EPCR) which are both expressed on the surface of endothelial cells (Esmon et al., 1982, Stearns-Kurosawa et al., 1996). Activated PC (aPC) deactivates both the tenase and prothrombinase complexes by proteolytically cleaving aFV and aFVIII, respectively (Esmon, 1987). This mechanism is enhanced 20-fold when aPC is bound to its cofactor protein S (PS) (Rosing et al., 1995, O'Brien et al., 2000). Recent studies have identified the additional requirement of inactivated FV for efficient aPC/PS deactivation of aFVIII (Nicolaes and Dahlback, 2002). 


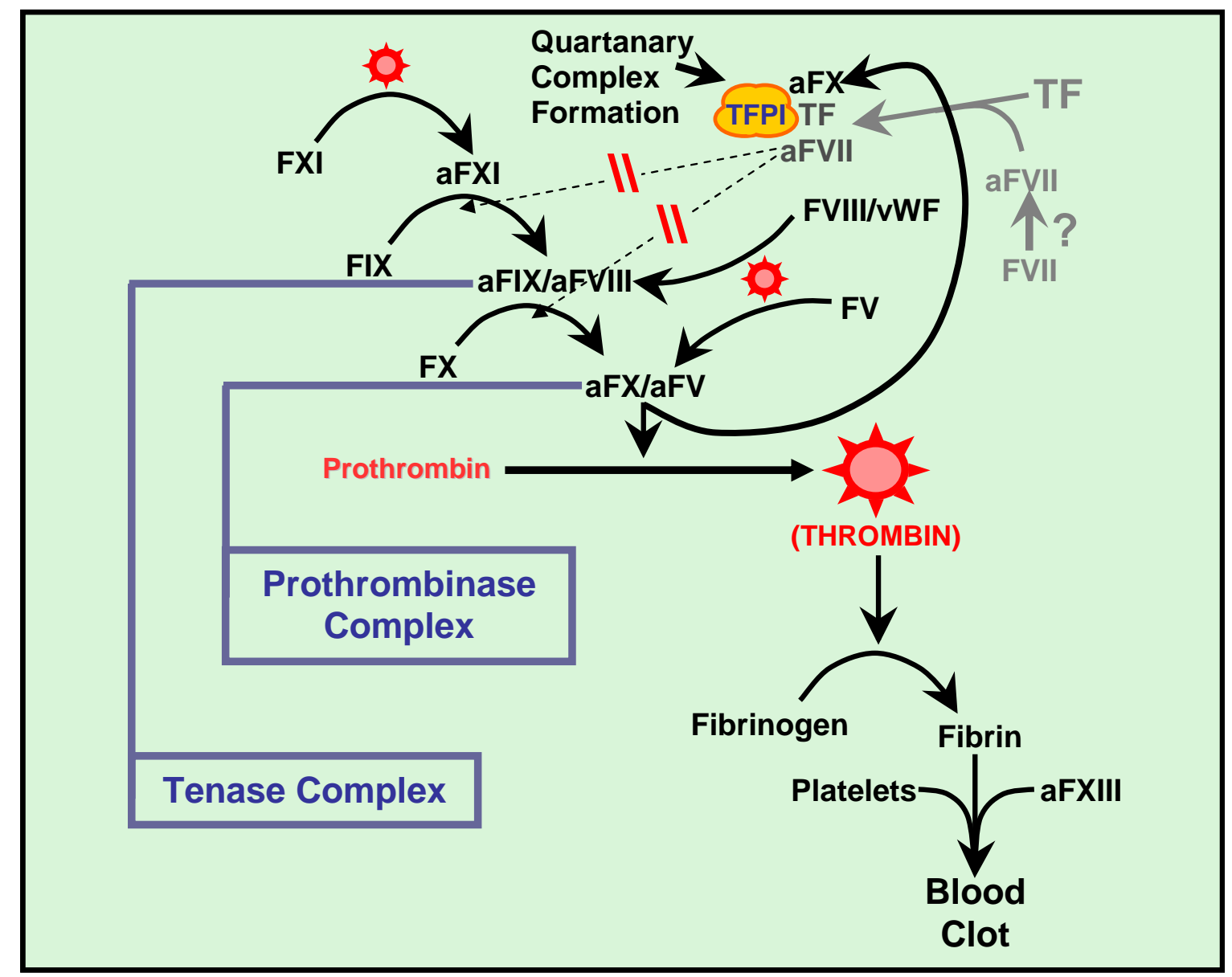

Figure 1.1 Activation of the Coagulation Cascade and Initial Regulation by Tissue Factor Pathway Inhibitor (TFPI) . Exposed TF and aFVII combine to activate FIX and FX. The low levels of aFX generate small quantities of thrombin from prothrombin, enough to activate both FV and FXI and cleave FVIII from VWF leading to the formation of the prothrombinase and tenase complexes. Exponential production of thrombin results leading to cleavage of fibrinogen to fibrin and platelet activation which initiates thrombus formation (blood clot). This process is controlled initially by TFPI which forms a quarternary structure with TF, aFX and aFVII to prevent further activation of FIX and FX. 


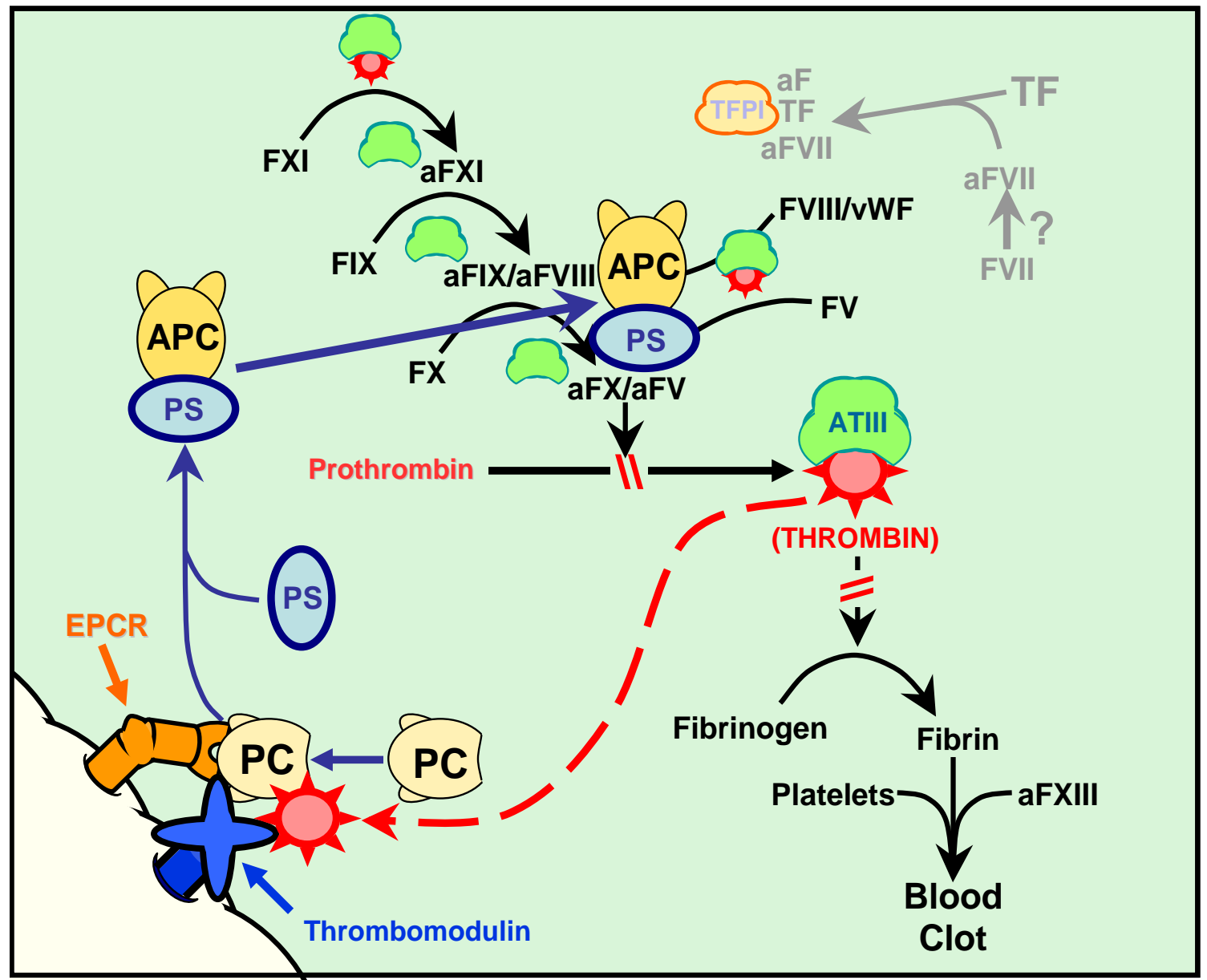

Figure 1.2 Regulation of the Coagulation Cascade by Antithrombin III (ATIII) and the Protein C (PC) Pathway. ATIII deactivates thrombin, aFVII, aFX, aFIX and aFXI. The PC pathway is initiated by the activation of PC (APC) by thrombin, a process that is enhanced 20,000 times by the combination of thrombomodulin and endothelial cell protein $C$ receptor (EPCR) which are both expressed on the surface of endothelial cells. Protein $S$ (PS) binds to APC forming the APC/PS complex enhancing APC inactivation of aFV and aFVIII. 


\subsection{Protein S}

PS has several important functional domains (Figure 1.3). The N-terminus requires vitamin $\mathrm{K}$ to generate a $\gamma$-carboxyglutamic acid rich (Gla)-domain that binds to phospholipids. The Gla-domain (residues 1-45) facilitates binding of the PS molecule to surfaces of activated platelets, platelet microparticles and endothelial cells in the presence of $\mathrm{Ca}^{+2}$ ions localising PS to the source of the thrombus formation. Amino acids 46-74, denoted the thrombin sensitive region (TSR), includes arginine residues at positions $\operatorname{Arg}^{49}, \operatorname{Arg}^{60}$ and $\operatorname{Arg}^{70}$ (Harris and Esmon, 1985, Dahlback et al., 1992, Furie and Furie, 1992, Hackeng et al., 1993). Proteolytic cleavage of all three by thrombin has been demonstrated with an affinity of $\operatorname{Arg}^{49}>\operatorname{Arg}^{70}>>\operatorname{Arg}^{60}$; (Lu et al., 1997, Morboeuf et al., 2000, Borgel et al., 2001, Meijer-Huizinga et al., 1994, Heeb and Griffin, 2002). $\mathrm{Arg}^{60}$ is only cut if $\mathrm{Arg}^{49}$ and $\mathrm{Arg}^{70}$ are unavailable. The TSR is reported to also be important for interaction with aPC (Dahlback et al., 1990b, He et al., 1998). Four epidermal growth factor (EGF)-like domains span residues 75-242. EGF1 and possibly EGF2 are required for aPC binding which directs PS cofactor activity. Like the Gla domain, the 3rd and 4th EGF-like domains bind $\mathrm{Ca}^{+2}$ ions with high affinity (Hackeng et al., 2000, Mille-Baker et al., 2003, Drakenberg et al., 2005). 


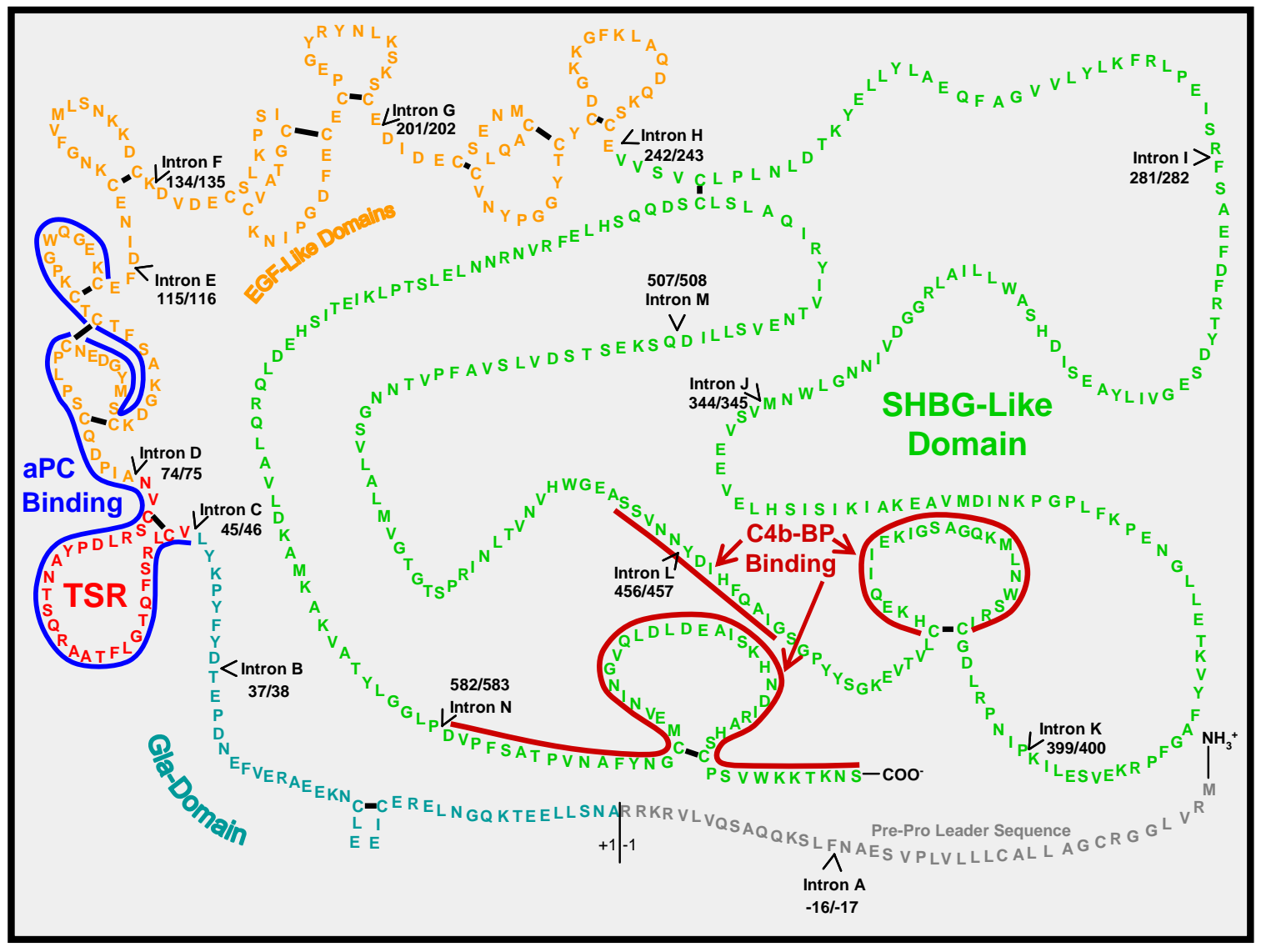

Figure 1.3 Schematic of Protein S highlighting key functional domains. Residues 1-45, $\gamma$-carboxyglutamic acid (Gla) domain; 46-74, thrombin sensitive region (TSR); 75-242, epidermal growth factor (EGF)-like domains; 243-635, sex hormone binding globulin (SHBG)-like domain. Also shown are the regions of PS that are proposed binding sites for activated Protein C (aPC; blue) and C4bbinding protein (C4b-BP, red). Adapted from Greenberg and Davie (2001). 
Unlike the C-terminus of other vitamin K-dependent plasma proteases, which have a serine-protease domain, the large C-terminal of PS (residues 243-635) lacks enzymatic activity (Saposnik et al., 2003). The region is highly homologous with two other plasma proteins, namely another vitamin $\mathrm{K}$ dependant protein, growth arrest-specific gene 6 product (GAS6) and the steroid transporter, sex hormone binding globulin (SHBG) (Gershagen et al., 1991, Gershagen et al., 1987, Villoutreix et al., 1997, Manfioletti et al., 1993). Unlike SHBG, the C-terminus of PS does not bind steroid hormones, nor does it undergo dimerisation with either SHBG or other PS molecules (Villoutreix et al., 1997). Like the TSR, the SHBG domain represents another regulatory domain of PS as it has been shown that it is involved in binding to complement C4b-binding protein (C4b-BP) (Saposnik et al., 2003). Approximately 60\% of PS circulates in the blood bound to the beta chain of the complement C4b-BP. Only the remaining $40 \%$ 'free form' is available for aPC co-factor activity as PS complexed with C4b-BP lacks co-factor activity (Morboeuf et al., 2000).

Recent studies suggest PS to be a multi-functional protein involved in inflammatory and apoptotic processes and, by extrapolation, may have a role in reducing autoimmunity. Anderson et al. (2003) showed that PS is required for the efficient phagocytic clearance of cells that have undergone apoptosis, possibly minimising the risk of autoimmunity (Anderson and Shacter, 2004). Recently Hryszko et al. (2005) proposed a role in the modulation of inflammation after demonstrating that PS suppressed the binding of plasminogen to the surface of THP-1 cells in addition to downregulating their invasive potential. Lastly, a murine model has demonstrated a significant neuroprotective role for PS post ischemic insult (Liu et al., 2003). 
Classification of PS deficiency is based on antigenicity and functionality. The affinity between PS and C4b-BP defines both Type I and III deficiency while Type II is characterised by the strength of PS co-factor activity.

Type I- $\quad$ Low total and free PS levels

Type III- $\quad$ Low free with normal total PS levels

Type II- Low functional activity

The basis for classifying PS deficiency in this way has been criticized as several family studies have identified Type I and Type III deficient individuals within the same kindred, often with the same causative mutation (Zoller et al., 1995, Simmonds et al., 1997, ten Kate et al., 2006). A proposal to restrict classification to either quantitative and qualitative (functional) has yet to ratified (Gandrille et al., 2000). Several groups have suggested reasons to explain the observed discrepancies between Type I and Type III deficiencies and highlight the many confounding factors that affect PS plasma concentration (Zoller et al., 1995, Simmonds et al., 1997, Rezende et al., 2002, ten Kate et al., 2006). PS levels increase with age and differ markedly between the sexes (Henkens et al., 1995, Dykes et al., 2001). It has also been proposed that variation in the concentration of circulating $\mathrm{C} 4 \mathrm{~b}-\mathrm{BP}$ between individuals could influence free PS availability, although this has been disputed (Ceriello et al., 1990, Zoller et al., 1995, Morboeuf et al., 1998). The existence of anti-PS antibodies in individuals suffering from systemic lupus erythematosus and also end-stage renal failure has been demonstrated, although the extent to which they affect the wider population is poorly documented (Song et al., 2000, Molino et al., 2005). Acquired PS deficiency has been reported in cancer patients, although it is unclear whether this is due to a breakdown in the hepatic system, greater turnover, or a direct result of specific chemotherapy agents 
(Battistelli et al., 2005). AIDS patients too experience reduced PS levels that follows disease progression (Dillmon et al., 2005). However, the most widely reported reduction in PS is seen in response to raised oestrogen levels, such as is seen in women who are pregnant or use oral contraceptives (OC).

\subsection{The Oral Contraceptive Pill}

The OC pill became widely available in the 1960 s, although development began several decades prior. In 1940, Sturgis and Albright reported inhibition of ovulation in women who they administered oestrogens to for the treatment of dysmenorrhea (menstrual cramping), but it was progesterone, not oestrogen, that led to the development of the first oral contraceptive. In 1937, a rabbit model study demonstrated ovulation could be inhibited by the administration of progesterone. However, progress stalled due to the labour intensive process of obtaining progesterone; extraction from over 2000 pregnant sow's ovaries yielded only $1 \mathrm{mg}$ of progesterone and it wasn't until 1940 when a chemist named Russell Marker perfected a technique of processing progesterone from the syrup of Mexican yams (Speroff and Darney, 1996).

Further work was required for oral administration of the steroid to be considered, as progesterone is largely inactive when ingested orally (Speroff and Darney, 1996). This issue was overcome in 1951 by Carl Djerassi who engineered and patented the first synthetic progestin from a nortestosterone backbone. Previous studies had shown that removal of the methyl group at $\mathrm{C} 19$ of testosterone resulted in a molecule that lacked androgenic properties, but exhibited progestagenic activity. The new progestin, norethisterone, (17 $\alpha$-ethinyl-19-nortestosterone) orally administered, was 10x more potent than progesterone and was shown to be effective in the treatment of menstrual disorders (Kafrissen and Adashi, 2003, Kovacs, 2003). Within three years, a second 
synthetic progestin, norethynodrel, was patented. Almost identical in structure to norethisterone was tested in a small human trial, resulting in $100 \%$ cessation of ovulation in all 50 of the female participants after administration of $30 \mathrm{mg} /$ day given at days 5 to 25 of their cycle (Rock et al., 1957) (Refer to structural details in Appendices 1-3). Larger clinical trials, carried out in Puerto Rico further supported the initial findings (Pincus, 1958). It was during the Puerto Rican study that the benefits of adding oestrogen were realised when the researchers calculated that the initial supply of norethynodrel contained $1.5 \%$ of the oestrogen mestranol (Appendix 1). When follow up studies using a mestranol-reduced stock were initiated, several of the study participants complained of break-through bleeding. This decision formed the basis for the future of the combined OC (COC) pill. Today there are dozens of COCs available that differ primarily by the type of progestin but also in the oestrogen concentration.

A progestin-only form of oral contraceptive, sometimes referred to as the 'minipill', is a viable alternative for women who are intolerant to oestrogen and is particularly useful for breast-feeding mothers concerned with the use of oestrogen, with only negligible amounts of the progestin entering into the milk supply (Shaaban, 1991).

The mestranol component was soon superseded by ethinyl oestrodial (EE) in an attempt to minimise cardiovascular risks and today the oestrogen component of COCs is almost exclusively EE (Woutersz, 1991, Bloemenkamp, 2005). There are two reasons for this. The first is biological. Early COC preparations that incorporated other estrogens, such as $\beta$-oestradiol $\left(\mathrm{E}_{2}\right)$ or oestradiol valerate $(\mathrm{EV})$, failed due to a high incidence of breakthrough bleeding. This was subsequently shown to be due to a localised, progestinregulated, increase in the expression of 17 beta-hydroxysteroid-dehydrogenase (17HSD; also known as oestradiol dehydrogenase) within the endometrium (Isomaa et al., 1993, Casey et al., 1994). Oxidation of the -OH group by $17 \mathrm{HSD}$ rapidly converts both $\mathrm{E}_{2}$ and 
EV to less potent forms such as estriol (Appendix 1). The ethinyl moiety in EE effectively blocks the 17HSD enzyme, preventing oxidation (Appendix 1) (Wiegratz and Kuhl, 2004). The second reason why EE has dominated as the oestrogen component of both past and present COCs is its lack of patent and therefore there has never been an incentive for the pharmaceutical industry to design newer compounds (Kafrissen and Adashi, 2003).

The use of EE did not substantially reduce the risk of arterial and venous disease. The high concentrations of EE previously used (between 50-100 $\mu$ g) were subsequently lowered to below $50 \mu \mathrm{g}$ in the 1980's and $\leq 35 \mu \mathrm{g}$ EE in the 1990's and are termed low dose COCs. Despite the reduction of EE, COC use is still associated with an increased venous thrombotic risk and possibly even an arterial thrombotic risk (Tanis and Rosendaal, 2003, Rosendaal et al., 2003, Van Den Bosch et al., 2003, Wu et al., 2005).

It is known that PS deficiency is associated with an increased thrombotic risk and it is hypothesised that the oestrogen component of $\mathrm{COC}$ is responsible for the reduction. However, the COC pill contains a second hormonal component, a progestin, and its affect on PS production is less clear.

In contrast to the largely static development of the oestrogens there has been significant evolution of the progestins. Most of the synthetic progestins have been generated from either a progesterone or testosterone parent molecule.

Progesterone has been manipulated to yield $17 \alpha$-hydroxyprogesterone; addition of a hydroxyl group to C17, 19-norprogesterone; removal of the methyl group from C19 and 17 $\alpha$-hydroxy-19-norprogesterone; addition of a hydroxyl group to C17 of 19norprogesterone. Progestins generated from $17 \alpha$-hydroxyprogesterone are classified as 
pregnanes. The hydroxylation of $\mathrm{C} 17$ that creates $17 \alpha$-hydroxyprogesterone produces a hormonally inactive product (Schindler et al., 2003). Esterification of the $\mathrm{C} 17$ generates $17 \alpha$-hydroxyprogesterone acetate which is weakly progestogenic but becomes highly active when a methyl group is attached to C6, creating medroxyprogesterone acetate (Appendix 2).

Testosterone formed the basis for the early synthetic progestins when it was discovered that 19-nortestosterone, created by removing the methyl group at C19, lacked androgenicity but gained progestogenic properties. 19-nortestosterone progestins are classified as either gonanes or estranes as defined by the basic molecular skeleton. The two earliest progestins, norethisterone and norethynodrel are examples of estranes while examples of gonanes are levonorgestrel (part of the 2nd generation COCs), desogestrel and gestodene (both progestin components of 3rd generation COCs). Dienogest is a relatively new progestin with unique properties. Although it is a 19-nortestosterone derivative it lacks the $\mathrm{C} 17$ ethinyl group common to other 19-nortestosterone derivatives, replaced instead by a cyanomethyl group (Kuhl, 2005) (Appendix 3).

\subsection{Pregnancy}

Pregnancy is associated with a shift toward hypercoagulable state due to changes to key components of both the pro- and anti-coagulant pathways, particularly levels of PS which decrease from around 10 weeks. Levels of free PS continue to decline throughout the remainder of gestation, falling to below the normal range for non-pregnant females (not using oral contraceptives) throughout the course of gestation, with the lowest levels evident at delivery (Bremme, 2003, Brenner, 2004). Interestingly, women with a preexisting PS deficiency have an 8-fold greater chance of developing a venous 
thromboembolism as a direct effect of their pregnancy, compared to non-deficient controls (Eldor, 2002).

Levels of both $\mathrm{E}_{2}$ and $\mathrm{P}_{4}$ rise significantly over the course of gestation with serum concentrations of both hormones increased 100-fold at term compared to levels observed in non-pregnant women (Figure 1.4) (Dunn et al., 1981). Circulating levels of $\mathrm{P}_{4}$ rise rapidly in the first 10 weeks, then steadily increase, reaching a maximum at parturition. Other steroids such as testosterone and cortisol are significantly increased during pregnancy (Bammann et al., 1980, Marnach et al., 2003).

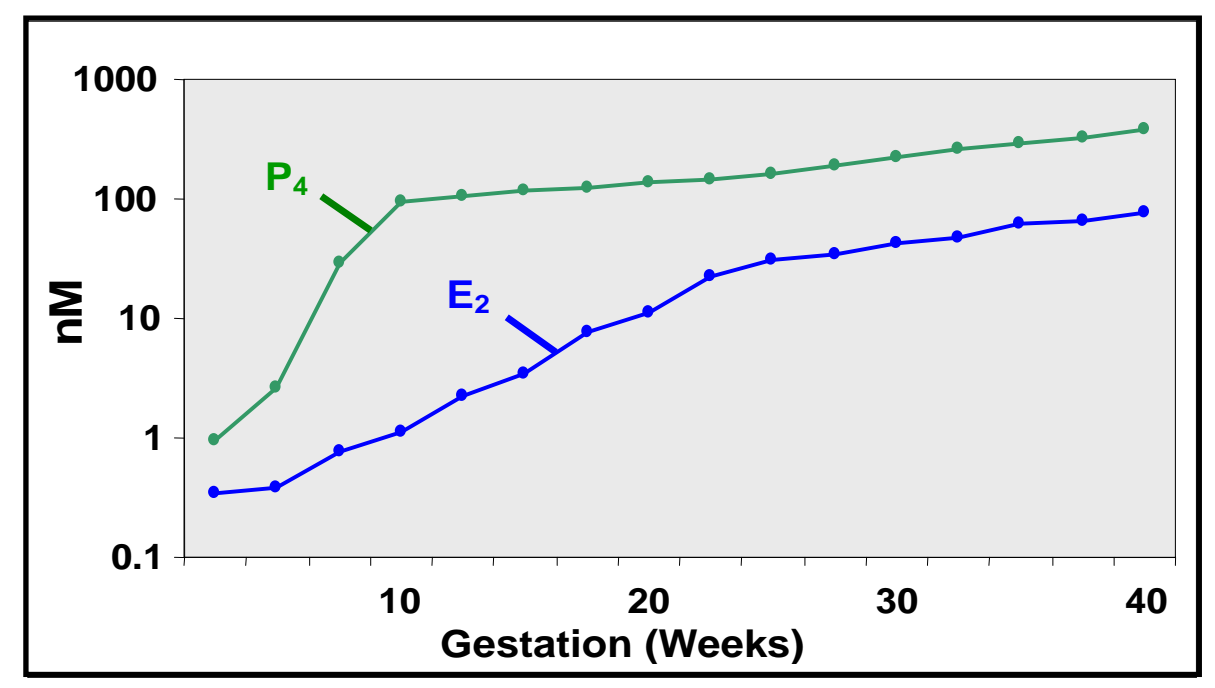

Figure 1.4 Oestrogen and Progesterone Levels During Pregnancy. The serum concentrations of both oestrogen [here 17 $\beta$-oestradiol; $\left(E_{2}\right)$ and progesterone $\left(P_{4}\right)$ ] increase by approximately $100-$ fold at parturition. Adapted from Dunn et al. (1981)

\subsection{HORMONE REPLACEMENT THERAPY}

Unlike the oestrogen component of COCs, the oestrogen component of hormone replacement therapy (HRT) varies. Conjugated equine oestrogen (a mixture of oestrogens extracted from pregnant mare's urine) and esterified oestrogen are used in many preparations as is $17 \beta$-oestradiol $\left(\mathrm{E}_{2}\right)$, both in combination with a progestin and stand alone. Natural oestrogens (like $\mathrm{E}_{2}$ ) are believed to be associated with a lower risk 
of venous thromboembolism than EE, because their effect on haemostasis parameters is weaker (Wiegratz et al., 2004). The progestins included in combined HRT preparations are predominantly medroxyprogesterone or norethisterone. Interestingly, combination HRT is associated with a greater risk of venous thrombosis compared to oestrogen only preparations [Reviewed $\mathrm{Wu}(2005)]$.

\subsection{OESTROGEN RECEPTOR BIOLOGY}

The oestrogen receptor (ER) is the most studied of all the hormone receptors. Its direct involvement in the mediation of oestrogen action was first described by Jensen EV, Jacobsen HI in 1962 (Jensen and Jacobsen, 1962). The last two decades in particular have uncovered several key findings that highlight the complexity of ER biology. Until recently it was thought that there was only one form of ER; ER $\alpha$, which was cloned and sequenced in 1986 (Greene et al., 1986, Green et al., 1986). A decade later, a second ER; ER $\beta$, was cloned from both a rat prostate and ovary and was subsequently identified in humans (Mosselman et al., 1996, Enmark et al., 1997). In this review only ER $\alpha$ will be discussed.

The gene that encodes ER $\alpha$, ESR1, utilises six different promoters (A-F) with each promoter generating a different mRNA transcript in a tissue specific manner. (Flouriot et al., 1998). Expression of ER $\alpha$ in the liver is governed almost exclusively by the $\mathrm{E}$ promoter (Pinzone et al., 2004) which is proposed to be oestrogen inducible, although it has yet to be shown directly. There is circumstantial evidence that supports the theory. For example, it has been shown that levels of E promoter derived ER $\alpha$ mRNAs are higher in the human female liver (Flouriot et al., 1998) who have higher circulating concentrations of oestrogen. A 1999 study by Donaghue et al. examined the oestrogen responsiveness of the $\mathrm{E}$ promoter in vitro using four breast carcinoma cell lines, 
demonstrating increases in mRNA transcripts for three out of the four lines (Donaghue et al., 1999). No studies have examined mRNA expression in liver cell lines.

Distributed in both the nucleus and cytoplasm, unliganded ER $\alpha$ is complexed with heat shock proteins (HSPs) that disassociate when the ER $\alpha$ binds to oestrogen, initiating conformational change causing dimerisation with similarly activated ERs. Dimerised ER $\alpha$ translocates to the nucleus and influences gene expression, either increasing or decreasing transcriptional activity (Htun et al., 1999) (Figure 1.5). Commonly referred to as the classic ER $\alpha$ pathway, the dimerised ER $\alpha$ complex binds to oestrogen response elements (EREs) that initiates the recruitment of additional transcriptional factors directly affecting transcription. In addition to the classical mechanism, there are at least three other distinct pathways whereby $\mathrm{ER} \alpha$ can exert regulatory control over transcription.

Ligand bound ER $\alpha$ interacts with several key transcriptional factors that in turn bind to their cognate promoter recognition sites. Highly GC-rich promoters are often regulated by stimulating protein 1 (Sp1) transcriptional factors which bind to GC rich motifs. Activated ER $\alpha$ is able to form complexes with $\mathrm{Sp} 1$ and subsequently regulate gene transcription. The ER $\alpha$ component itself can either interact indirectly with DNA or interact with ERE or ERE1/2 sequences (Safe, 2001). Upregulation by Sp1/ER $\alpha$ complexes has been widely reported (Duan et al., 1998, Xie et al., 1999, Li et al., 2001, Castro-Rivera et al., 2001, Schultz et al., 2003). Although recent studies have described Sp1/ER $\alpha$ based repression of genes (Kelley et al., 2003, Stossi et al., 2006). 


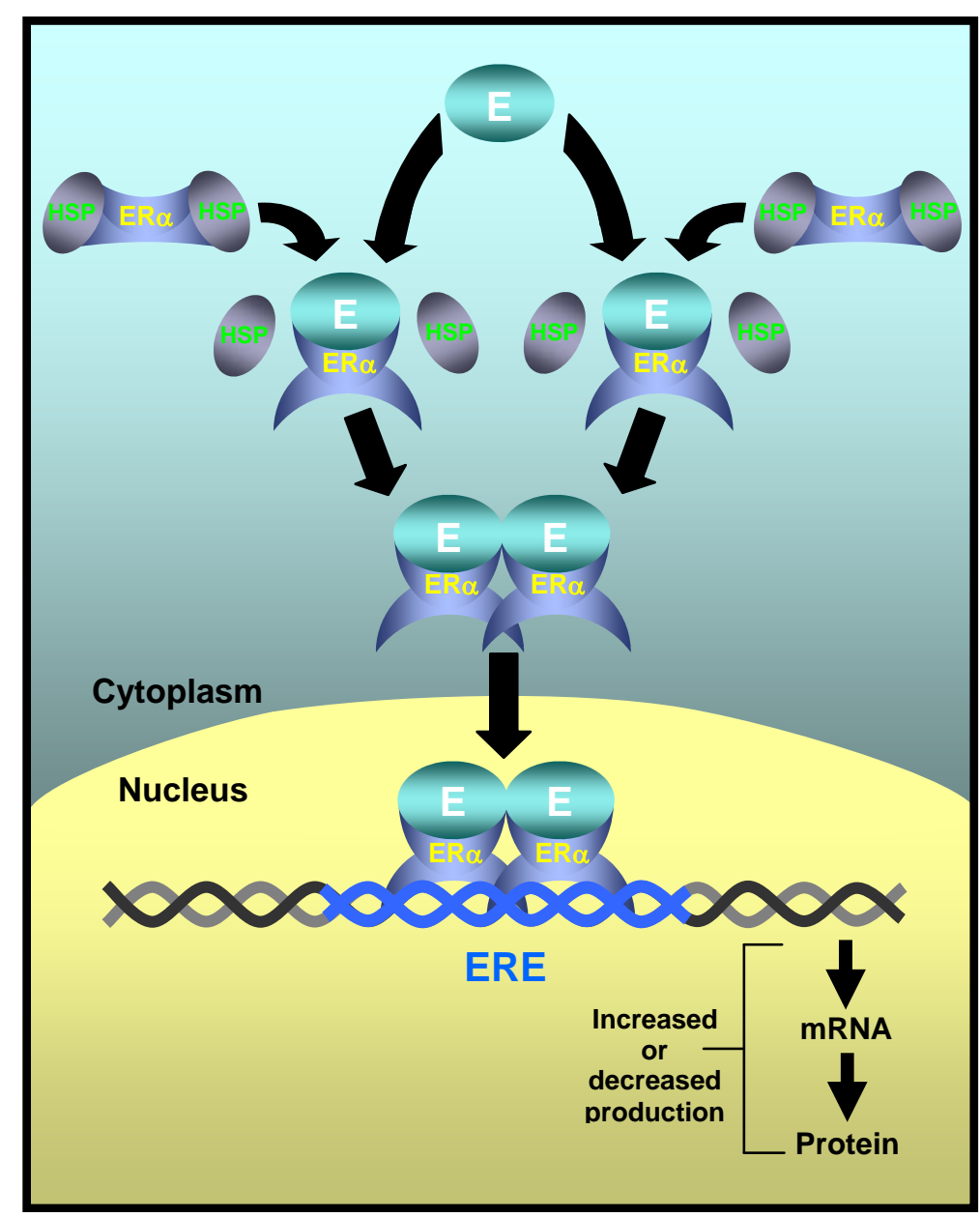

Figure 1.5 The Classic Oestrogen Receptor Pathway. Inactive oestrogen receptor alpha (ER $\alpha)$ bound to heat shock proteins (HSP) circulate in the cytoplasm. Binding to oestrogen $(E)$ initiates a conformational change that dislodges the HSPs and facilitates dimerisation with similarly activated ERo's. Dimerised ERo's enter the nuclear membrane and bind to oestrogen response elements (EREs), regulating gene expression. 
Like the Sp1 mechanism, ER $\alpha$ forms complexes with Jun/Fos transcriptional factors that bind to AP-1 sites within promoters, regulating transcription. Regulation of gene expression by $\mathrm{Jun} / \mathrm{Fos} / \mathrm{ER} \alpha$ complexes also induces or represses gene expression (Kushner et al., 2000).

ER $\alpha$ regulation of ERE-dependant transcription in the absence of oestrogen has also been shown resulting from phosphorylation of the ER $\alpha$ by protein-kinase cascades initiated by growth factors such as EGF and IGF-1 (Ignar-Trowbridge et al., 1993, Ignar-Trowbridge et al., 1995, Lee et al., 1997).

An accumulation of evidence is mounting that suggests ER $\alpha$ can exert rapid, nongenomic regulatory responses via plasma membrane bound ERs. Ligand binding appears to activate phosphorylation cascades and other signalling pathways. These newly identified ER $\alpha$ mechanisms have only recently been identified. 


\subsection{Progesterone Receptor Biology}

The so-called superfamily of hormone receptors refers to a division of receptors that include the progesterone, androgen, and mineral- and glucocortico-steriod receptors (PR, AR, MR, GR, respectively) which share structural similarities and recognise consensus sequence response elements that are different from the ERE consensus sequence. Figure 1.6 details the previously accepted HRE motif as it was thought to be in 1995 (Zilliacus et al., 1995).

\begin{tabular}{|c|c|}
\hline Consensus HRE & 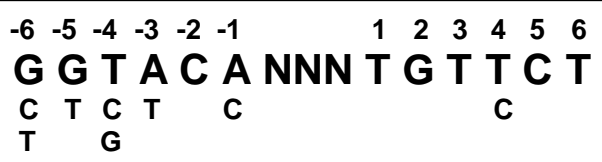 \\
\hline Consensus ERE & $\underset{A}{G}$ G T C A NNN T G A C C \\
\hline
\end{tabular}

Figure 1.6 Hormone Response Element Motifs. Consensus response element sequences for PR, AR, MR and GR (HRE) and for ER (ERE). Subnucleotides denote alternatives for that position. Adapted from Zilliacus et al.(1995). It is now accepted that HREs can be even more complex and diverse in comomposition

However, studies since then have identified multiple variations that make prediction of novel HRE binding sites difficult. A recent paper by Stepanova et al.(2006) addressed the problem by generating an algorithm compiled from the analysis of $>650$ experimentally validated HREs and is available online to screen novel sequences; http://birc.ntu.edu.sg/ pmaria/ (Stepanova et al., 2006). The algorithm generates a value expressed as a similarity coefficient that relates the probability of the sequence entered being a HRE in comparison to the $>650$ experimentally validated elements.

Although not as extensively studied as the ER, research into the superfamily of hormone receptors has increased markedly over the last decade, especially pertaining to their role as transcriptional regulators of gene expression ( $\mathrm{Lu}$ et al., 2006). Investigation of PR 
biology in particular has dominated largely due to its synergistic role with ER in some breast cancers, but also because of its importance in developmental biology (FernandezValdivia et al., 2005, Cordera and Jordan, 2006).

Like the ERs, the PR has two distinct isoforms, PR-A and PR-B (there is a third PR-C isoform but it is largely undescribed, so for the purposes of this review only the PR-A and PR-B isoforms will be discussed). Unlike the ERs, both forms are transcribed from the same gene utilizing different promoters (Kastner et al., 1990). Interestingly, both promoters are $\mathrm{E}_{2}$ responsive; via an $\mathrm{ER} \alpha / \mathrm{Sp} 1$ mechanism for the PR-A expressing promoter and an AP1/Sp1 mechanism for the PR-B promoter (Petz et al., 2004, Flototto et al., 2004).

The PR-A and PR-B isoforms are identical except that PR-B has an additional 164 amino acid $\mathrm{N}$-terminus that accounts for the differences in activation profiles between the two receptors (Takimoto et al., 2003). In vitro studies show that ligand bound PR-B is a stronger transactivator than liganded PR-A and studies using malignant breast cells suggest that it is also the more potent form in vivo (Richer et al., 2002, Tung et al., 2006).

PRs undergo similar conformational change and dimerisation as the ERs once bound to $\mathrm{P}_{4}$ or any other of the many progestin isoforms, where upon they then interact with progesterone response elements (PREs) to regulate gene expression (Tsai et al., 1988, Guiochon-Mantel et al., 1989, Stepanova et al., 2006). However, differences in PR binding affinity in addition to distinct pro- and anti- prostogenic, oestrogenic, and androgenic profiles for each of the different progestins, means that no two progestins exhibit the same transactivational effects [see Schindler et al., (2003)] for a thorough review of progestin biology). This is evident physiologically when contrasting the effect 
of 2nd and 3rd generation COCs, that contain different progestins, on inflammatory markers, lipid metabolism, haemostatic and fibrinolytic parameters, along with thrombotic and cardiovascular disease risk status (Kemmeren et al., 2001b, Kemmeren et al., 2001a, Kemmeren et al., 2004, Baillargeon et al., 2005, van Rooijen et al., 2006, Van Den Bosch et al., 2003, Tanis and Rosendaal, 2003, Tans et al., 2000)

\subsection{THE EFFECT OF HORMONES ON HAEMOSTATIC PARAMETERS}

Variation of most of the procoagulants has been observed in response to OC use, pregnancy or HRT to varying degrees. For example, FVII appears to increase in response to raised oestrogen concentrations, such as the latter stages of pregnancy and HRT (particularly oestrogen only preparations) (Brenner, 2004, Cosman et al., 2005). Like PS, variation in FVII is greatest amongst users of 3rd Generation COCs, but unlike PS, elevated FVII is viewed more as a risk factor for arterial rather that venous thrombosis (Koster et al., 1994, Winkler, 2000, Wiegratz et al., 2004). One study identified an ERE in the promoter region of the FVII gene, but surprisingly found that it repressed, rather than enhanced FVII expression (Di Bitondo et al., 2002). Interestingly, some studies suggest that HRT use correlates with reduced FVII levels in postmenopausal women (Borgfeldt et al., 2004, Collins et al., 2006). It may be a result of this identified ERE repression overcoming a pre-menopause upregulatory mechanism.

A more thoroughly investigated hormonally responsive procoagulant is FIX and its response to testosterone. Haemophilia B results from a deficiency of FIX. One form of Haemophilia B, Haemophilia B Leyden, is in most cases corrected with the onset of puberty. It was this property that lead to the identification of an androgen response element (ARE) in the promoter region of the FIX gene after researchers studied the FIX 
promoter sequences of individuals who did not normalise during puberty. Point mutations that mapped to a specific sequence that subsequent analysis showed was involved in binding to ligand bound AR.

Many of the anticoagulants are influenced by shifts in hormonal balance. The ubiquitous anticoagulant antithrombin (AT) is reported to be regulated by hormones, but it is a contentious issue. Some studies suggest that use of OCs reduces AT levels while other reports indicate little or no change (Norris and Bonnar, 1996, Winkler et al., Tans et al., 2000, Aldrighi et al., 2006). Furthermore, unlike PS, AT levels are not reduced during pregnancy, when both oestrogen and progesterone plasma concentrations are high (Cerneca et al., 1997, Clark et al., 1998). Interestingly though, there has recently been a surge in publications detailing significant AT decreases in postmenopausal women undergoing HRT (Borgfeldt et al., 2004, Al-Farra et al., 2005, Sumino et al., 2005, Sgarabotto et al., 2006).

aPC resistance (aPC-R) is defined as an impaired ability of aPC to deactivate FV. Hereditary aPC-R is linked to the FV-Leiden point mutation which replaces arginine at position 506 with a glutamine (R506Q), destroying the proteolytic cut site. The result is prolonged FV activity and thus greater thrombin activation. In the mid-1990s, acquired aPC-R was reported in pregnant women and women using OCs and, like PS, the use of 3rd generation COCs correlates with a greater impact (Olivieri et al., 1995, Meinardi et al., 1997, Rosing et al., 1997, Rosing et al., 1999, Tans et al., 2000, Alhenc-Gelas et al., 2004, Kemmeren et al., 2004). There is significant debate as to the exact cause of acquired aPC-R; raised FVIII/FVII and reduced PS or phospholipid levels have all been suggested. Recent studies suggest that the expression of a glycosphingolipid, glucosylceramide (GlcCer), may be the causative factor. GlcCer enhances aPC interaction with phospholipid surfaces increasing aPC activity, especially in the 
presence of PS (Yegneswaran et al., 2003, Deguchi et al., 2005). In vitro studies have shown that GlcCer levels are reduced in response to increased oestrogen, thus providing a potential mechanism to describe acquired aPC-R (Shukla et al., 1992).

\subsection{The EFFECT OF HoRMONES ON PROTEIN S}

The most consistent hormonally responsive anticoagulant is PS. Reduction in the circulating levels of both free and total PS are significant for users of oestrogen containing COCs, particularly 3rd generation forms (Kemmeren et al., 2004, Wiegratz et al., 2004). During pregnancy, when oestrogen concentration is markedly raised, levels of free and total PS decrease significantly from the 2nd trimester onwards (Brenner, 2004). Currently, there is debate regarding the impact of HRT on PS levels which may reflect the greater variety of oestrogens used in hormone replacement therapies, or results could be complicated by the phenomenon of increasing PS levels as women get older (Goodwin et al., 2002, Oger et al., 2003, Sgarabotto et al., 2006, Basurto et al., 2006). Nevertheless, in younger women the influence of oestrogens on PS levels is significant. Recent publications also suggest that progestins influence PS levels, with some isoforms clearly associated with increased levels of PS. This provides a possible explanation for the greater impact of 3rd generation COCs on free and total PS compared to 2nd generation COCs (Winkler, 1998, Kemmeren et al., 2004). 


\subsection{Protein S Genetics}

PS is coded for by the PROS1 (or PROS- $\alpha$ ) gene that is located near the centromere of chromosome 3 (3p11.1-q11.2) (Ploos van Amstel et al., 1987). A second psuedogene, designated PROS2 (or PROS- $\beta$ ), shares a 97\% exonic and $95.4 \%$ intronic homology with PROS1 (Gandrille et al., 1997). The PROS1 gene is approximately $101 \mathrm{~Kb}$ in length containing 15 exons that produce approximately $3.3 \mathrm{~Kb}$ of mRNA transcript (Figure 1.7) (Schmidel et al., 1990). Primarily expressed by the hepatocyte, PS mRNA transcripts have also been identified in megakaryocytes and platelets, endothelial cells, osteoblasts, vascular smooth muscle and nervous system cells and Leydig cells located in the testes (Fair et al., 1986, Dahlback, 1991, Stitt et al., 1995). Reflecting the extensive tissue distribution is the diverse number of transcriptional start sites (TSS) that have been identified from the liver and various cell lines (Lundwall et al., 1986, Ploos van Amstel et al., 1990, Malm et al., 1994, Benzakour and Kanthou, 2000, de Wolf et al., 2005). A limited number of studies have investigated the promoter region of PROS1, identifying several transcriptional regulatory motifs including GC-rich motifs that bind the zinc-finger proteins Sp1 and Sp3 and a possible Hepatic Nuclear Factor 3 (HNF3) binding site (de Wolf et al., 2006a, Tatewaki et al., 2003) (Figure 1.7). Recently, a binding site for phosphorylated Signal Transducer and Activator of Transcription 3 (STAT3) protein was identified (de Wolf et al., 2006b) (Figure 1.7). Phosphorylation of STAT3 was shown to be a consequence of interleukin-6 (IL-6) stimulation, previously identified as an activator of PS expression in vitro (Hooper et al., 1995, Hooper et al., 1996, Hooper et al., 1997). To date, identification of any regulatory elements located within the $3^{`}$ untranslated region of the PROS1 gene have not been described. 
tgtggatgatcaaaatgaccccatttgcttttactatcaccatagttcttcctaaagtcctc

attgacttccaggttttggttaatatcttcagggacaactcagtgtctcactgtttctgctt

\section{HNF1}

ctgaacctagggatcctgtcctcttgaaccctggaagttgtcttgaccagtcagagaactge

\section{HNF4}

gttccccacccettcccetttggaaacgtcacactgtggaggaaaagcagcaactagggagc SP1

tggtgaagaaggatgtctcagcagtgtttactaggcctccaacactagagcccatcccccag HNF3

$\downarrow$

SP1

ctccgaaaagcttcctggaaatgtccttgttatcacttccctctcgggctgggcgetggga

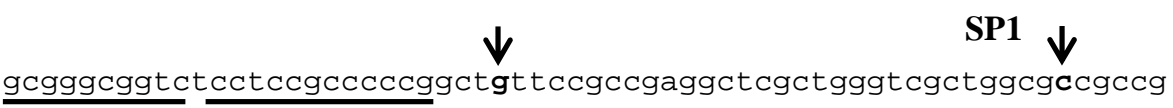

SP1

SP1

cgcagcacggctcagaccgaggcgcacaggctcgcagctccgcggcgcctagcgctccggtc

cccgecgcgacgegccaccgtccetgccggcgectccgcgegcttcgaaATG region
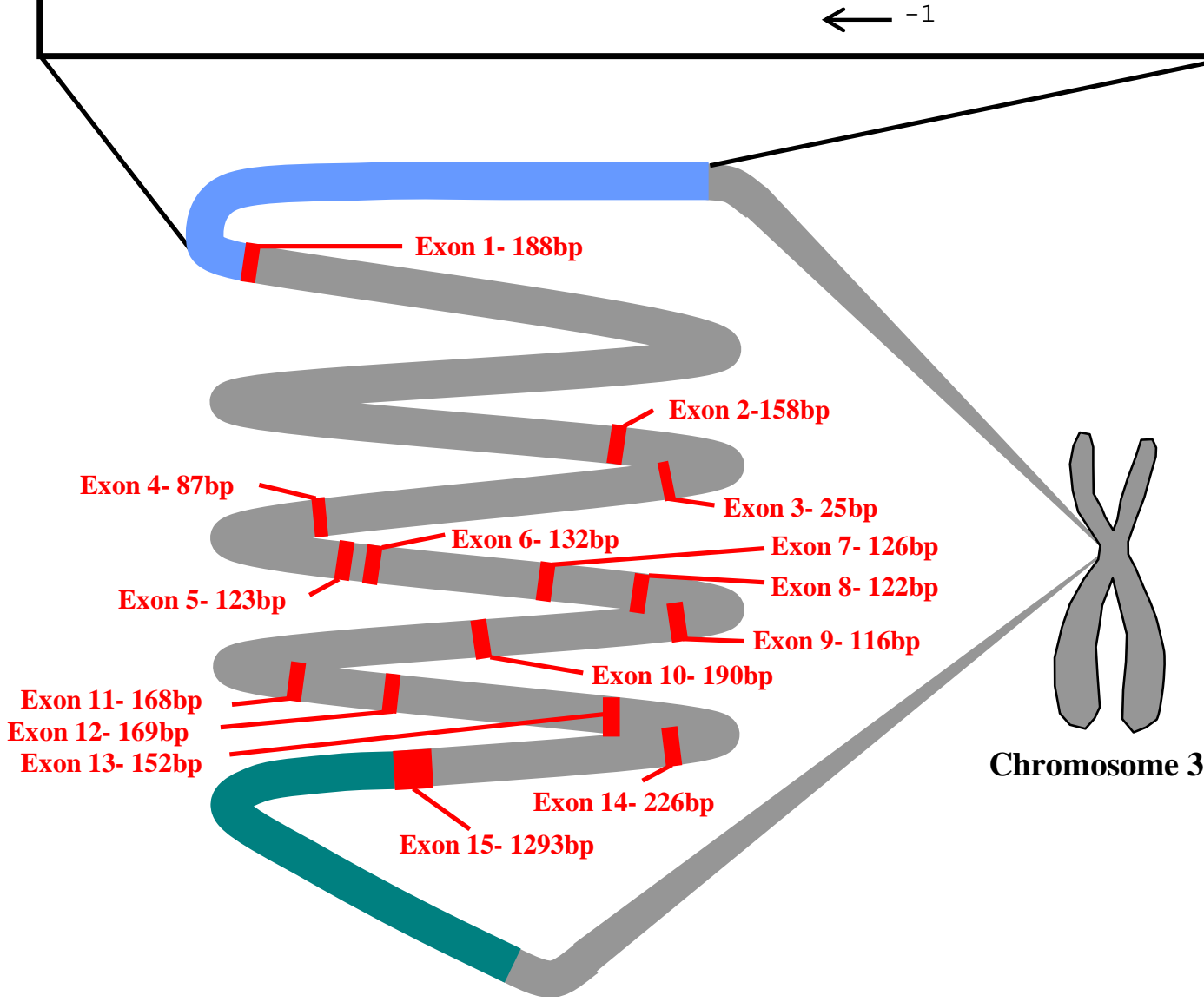

Figure 1.7- Schematic of the PROS1 Gene. PS is encoded by the PROS1 gene that maps near to the centromere of chromosome 3 (3p11.1-q11.2). The PS coding region comprises 15 exons (detailed in red) and 14 introns and is flanked by the 5 and $3^{`}$ untranslated regions (5 ${ }^{`}$ UTR and $3^{\prime}$ UTR). Previously reported transcriptional binding domains located within the promoter region, Sp1, HNF1, HNF3 and HNF4 are shown (Tatewaki et al., 2003, de Wolf et al., 2006a, Hall et al., 2006). Downward arrows denote dominant initiation start sites for various mRNA transcripts derived from human liver samples and various cell lines (de Wolf et al., 2005) 


\subsection{AIMS}

PS deficiency including the acquired form resulting from pregnancy and COC use. In addition, combination of oral contraceptive use with an underlying hereditary PS deficiency increases the underlying risk of developing a thrombotic complication.

Clinically it is well documented that PS levels are influenced by hormonal status, particularly in users of COCs and in pregnant women, where oestrogen and progesterone (or progestin isoforms) are increased. Screening the PROS1 gene and the PROS1 mRNA transcript for mutations may uncover a region or element(s) that are directly or indirectly responsible for the variation of PS. Alternatively, it is possible that the regulation is not occurring at the transcriptional control but is instead determined by a protein-protein interaction of PS with a hormonally regulated binding partner. A detailed examination of all of these factors will facilitate a better understanding of the mechanism that hormonally regulates PS levels. 
Therefore the aims of this thesis are:

- Develop a method to screen the PROS1 gene and the associated mRNA transcript for mutations.

- Investigate the PROS1 gene to identify key hormonally responsive regions that account for the differences in observed levels of circulating PS between users of 2nd and 3rd generation COCs.

- To examine the steroid based mechanisms in the regulation of the identified hormone response elements.

- To identify novel protein binding partners of PS (that may or may not be oestrogen sensitive). 


\title{
CHAPTER 2
}

\author{
Materials and Methods
}




\subsection{Patients ANd Controls}

Sample DNA and RNA was derived from two sources. The first group comprised patients selected by a Senior Haematologist (Dr. Ross Baker) at Royal Perth Hospital (Perth, Western Australia) that had a range of conditions including family history of PS deficiency or unexpected fluctuating free PS levels (determined by a monoclonal free PS antigen enzyme-linked immunosorbent assay- Corgenix; USA) (Table 2.1). The second group consisted of 137 pregnant women recruited from King Edward Memorial Hospital (Perth, Western Australia) that were divided into three subgroups; 48 women who experienced normal pregnancy (controls), 41 women who suffered from preeclamsia (Pre-E) while pregnant and 48 women who suffered gestational diabetes (GD) (Table 2.2). Pre-E was defined as the development of blood pressure greater than $140 / 90 \mathrm{mmHg}$ after 20 weeks gestation, with proteinuria of at least $300 \mathrm{mg} / 24 \mathrm{~h}$ and whose blood pressure returned to normal levels by 3 months post partum without continuing proteinuria (Brown et al., 2000). GD was diagnosed using a 75g oral glucose test and was defined as a fasting blood glucose level greater than $5.5 \mathrm{mM}$ and/or a blood glucose level of $8 \mathrm{mM}$ or more, $2 \mathrm{~h}$ post ingestion. Pregnancy blood samples were collected from women at 32 weeks gestation, and 6 weeks and 6 months post-partum. Total, free and functional PS levels were analysed at each time point using the Liatest Protein S, STA-Liatest Free Protein S and STA-Staclot Protein S tests, respectively (Diagnostica Stago, France). 


\begin{tabular}{|c|c|c|c|}
\hline$\underset{\text { ID }^{\dagger}}{\text { Sample }}$ & Sex & PS Level $(\%)^{\ddagger}$ & Patient History ${ }^{ \pm}$ \\
\hline N41 & M & 77 & Control \\
\hline PS1 & $\mathrm{F}$ & $34-75 \%$ & Fluctuating PS levels Thrombosis in Pregnancy \\
\hline PS2 & $\mathrm{F}$ & 50 & SLE, MI cerebral infarction \\
\hline PS3 & $\mathrm{F}$ & 45 & Severe pre-eclampsia \\
\hline PS4 & $\mathrm{M}$ & 42 & PE \\
\hline PS5 & $\mathrm{F}$ & 52 & Pre-eclampsia \\
\hline PS6 & $\mathrm{F}$ & 114 & Fluctuating PS level \\
\hline PS7 & $\mathrm{F}$ & 81 & DVT, Family history PS def. \\
\hline PS8 & $\mathrm{F}$ & 36 & Recurrent DVT during pregnancy \\
\hline PS9 & $\mathrm{F}$ & 57 & Fluctuating PS level \\
\hline PS10 & $\mathrm{F}$ & 41 & Fluctuating PS level \\
\hline PS11 & $\mathrm{F}$ & 49 & Recurrent pregnancy loss \\
\hline PS12 & $\mathrm{F}$ & 80 & Daughter of PS13 \\
\hline PS13 & $\mathrm{F}$ & 54 & Post Partum PE \\
\hline PS14 & $\mathrm{F}$ & 12 & $\mathrm{PE}$ \\
\hline PS15 & $\mathrm{F}$ & 89 & History of Thrombosis \\
\hline PS16 & $\mathrm{F}$ & 59 & History of thrombosis, DVT \\
\hline PS17 & $\mathrm{F}$ & 24 & Recurrent DVT \\
\hline PS18 & $\mathrm{F}$ & 75 & Family history of DVT \\
\hline PS19 & $\mathrm{F}$ & 38 & PS deficiency, spontaneous miscarriages \\
\hline PS20 & $\mathrm{F}$ & 82 & Persistent DVT in calf \\
\hline PS21 & $\mathrm{F}$ & 78 & Fluctuating PS level \\
\hline PS22 & $\mathrm{M}$ & 37 & PS deficiency \\
\hline PS23 & M & 22 & Family history of PS deficiency, DVTx2, MI \\
\hline PS24 & $\mathrm{F}$ & 128 & History of Thrombosis \\
\hline
\end{tabular}

Table 2.1 Details of the PS Deficient Cohort- The cohort was generated from patients selected by a Senior Haematologist (Dr. Ross Baker) at Royal Perth Hospital (Perth, Western Australia) who had a range of conditions including family history of PS deficiency or fluctuating free PS levels; ‡ PS levels mean \% of free antigenic PS (normal 50\%-150\%); SLE= Systemic Lupus Erythematosus; $\mathrm{MI}=$ Myocardial Infarction; $\mathrm{PE}=$ Pulmonary Embolism; DVT= Deep Vein Thrombosis. 


\begin{tabular}{|c|c|c|c|c|c|c|c|c|c|c|c|}
\hline \multicolumn{4}{|c|}{ Control (C) } & \multicolumn{4}{|c|}{ Gestational Diabetes (GD) } & \multicolumn{4}{|c|}{ Pre-eclampsia (Pre) } \\
\hline & \multicolumn{3}{|c|}{ PS Level $(\%)^{\ddagger}$} & & \multicolumn{3}{|c|}{ PS Level (\%) ${ }^{\ddagger}$} & & \multicolumn{3}{|c|}{ PS Level (\%) ${ }^{\ddagger}$} \\
\hline $\mathrm{N}=46$ & V1 & V3 & dV3-V1 & $\mathrm{N}=33$ & V1 & V3 & dV3-V1 & $\mathrm{N}=38$ & V1 & V3 & dV3-V1 \\
\hline C192 & 49 & 90 & 41 & GD401 & 42 & 87 & 45 & Pre211 & 49 & 68 & 19 \\
\hline C256 & 58 & 117 & 59 & GD407 & 53 & 111 & 58 & Pre255 & 49 & 103 & 54 \\
\hline C268 & 42 & 86 & 44 & GD408 & 45 & 99 & 54 & Pre270 & 59 & 111 & 52 \\
\hline C269 & 47 & 87 & 40 & GD410 & 30 & 82 & 52 & Pre271 & 49 & 90 & 41 \\
\hline C273 & 54 & 68 & 14 & GD412 & 36 & 107 & 71 & Pre275 & 61 & 123 & 62 \\
\hline C278 & 59 & 93 & 34 & GD413 & 52 & 102 & 50 & Pre288 & 34 & 106 & 72 \\
\hline C279 & 47 & 87 & 40 & GD414 & 47 & 51 & 4 & Pre290 & 45 & 111 & 66 \\
\hline C280 & 51 & 87 & 36 & GD416 & 40 & 84 & 44 & Pre292 & 59 & 116 & 57 \\
\hline C281 & 56 & 86 & 30 & GD417 & 48 & 82 & 34 & Pre296 & 76 & 125 & 49 \\
\hline C282 & 44 & 116 & 72 & GD419 & 47 & 80 & 33 & Pre297 & 68 & 145 & 77 \\
\hline C286 & 51 & 106 & 55 & GD420 & 49 & 91 & 42 & Pre301 & 40 & 98 & 58 \\
\hline C287 & 47 & 96 & 49 & GD421 & 38 & 86 & 48 & Pre307 & 58 & 99 & 41 \\
\hline C298 & 70 & 139 & 69 & GD422 & 50 & 125 & 75 & Pre309 & 77 & 74 & -3 \\
\hline C299 & 59 & 97 & 38 & GD423 & 54 & 104 & 50 & Pre311 & 37 & 51 & 14 \\
\hline C303 & 46 & 115 & 69 & GD424 & 46 & 80 & 34 & Pre312 & 57 & 118 & 61 \\
\hline C304 & 59 & 100 & 41 & GD431 & 44 & 101 & 57 & Pre313 & 49 & 88 & 39 \\
\hline C314 & 46 & 87 & 41 & GD433 & 34 & 68 & 34 & Pre321 & 64 & 99 & 35 \\
\hline C315 & 55 & 106 & 51 & GD436 & 40 & 99 & 59 & Pre324 & 33 & 62 & 29 \\
\hline C316 & 58 & 103 & 45 & GD437 & 46 & 81 & 35 & Pre326 & 44 & 89 & 45 \\
\hline C318 & 59 & 92 & 33 & GD438 & 46 & 120 & 74 & Pre327 & 47 & 86 & 39 \\
\hline C319 & 54 & 93 & 39 & GD439 & 32 & 66 & 34 & Pre333 & 84 & 136 & 52 \\
\hline C320 & 46 & 77 & 31 & GD440 & 51 & 91 & 40 & Pre341 & 51 & 133 & 82 \\
\hline C322 & 49 & 106 & 57 & GD441 & 46 & 85 & 39 & Pre342 & 55 & 104 & 49 \\
\hline C323 & 51 & 67 & 16 & GD442 & 46 & 81 & 35 & Pre344 & 61 & 116 & 55 \\
\hline C325 & 51 & 97 & 46 & GD443 & 39 & 73 & 34 & Pre347 & 62 & 88 & 26 \\
\hline C330 & 43 & 76 & 33 & GD444 & 39 & 120 & 81 & Pre349 & 76 & 141 & 65 \\
\hline C334 & 50 & 65 & 15 & GD446 & 43 & 84 & 41 & Pre354 & 61 & 126 & 65 \\
\hline C335 & 49 & 135 & 86 & GD448 & 50 & 126 & 76 & Pre363 & 52 & 96 & 44 \\
\hline C337 & 61 & 96 & 35 & GD453 & 63 & 99 & 36 & Pre370 & 53 & 122 & 69 \\
\hline C345 & 68 & 96 & 28 & GD456 & 43 & 88 & 45 & Pre373 & 48 & 80 & 32 \\
\hline C346 & 57 & 93 & 36 & GD457 & 40 & 87 & 47 & Pre375 & 62 & 81 & 19 \\
\hline C352 & 68 & 131 & 63 & GD460 & 44 & 78 & 34 & Pre376 & 46 & 79 & 33 \\
\hline C353 & 62 & 114 & 52 & GD462 & 44 & 101 & 57 & Pre380 & 57 & 113 & 56 \\
\hline C356 & 49 & 77 & 28 & & & & & Pre381 & 33 & 106 & 73 \\
\hline C357 & 47 & 64 & 17 & & & & & Pre390 & 54 & 106 & 52 \\
\hline C362 & 58 & 119 & 61 & & & & & Pre391 & 47 & 63 & 16 \\
\hline C364 & 50 & 77 & 27 & & & & & Pre392 & 56 & 63 & 7 \\
\hline C366 & 57 & 86 & 29 & & & & & Pre393 & 51 & 89 & 38 \\
\hline C368 & 125 & 135 & 10 & & & & & & & & \\
\hline C371 & 49 & 68 & 19 & & & & & & & & \\
\hline C377 & 43 & 98 & 55 & & & & & & & & \\
\hline C379 & 64 & 89 & 25 & & & & & & & & \\
\hline C385 & 56 & 93 & 37 & & & & & & & & \\
\hline C387 & 49 & 79 & 30 & & & & & & & & \\
\hline C388 & 54 & 91 & 37 & & & & & & & & \\
\hline C389 & 61 & 75 & 14 & & & & & & & & \\
\hline
\end{tabular}

Table 2.2 Details of the Pregnancy Cohort- The pregnancy cohort consisted of 137 pregnant women recruited from King Edward Memorial Hospital (Perth, Western Australia) that were divided into three subgroups; 48 women who experienced normal pregnancy (controls $=C$ ), 41 women who suffered from pre-eclamsia while pregnant (Pre-E) and 48 women who suffered gestational diabetes (GD); $¥$ PS levels mean \% of free antigenic PS (normal 50\%-150\%); 


\subsection{DNA AND RNA EXTRACTION}

DNA and RNA were extracted from leukocytes obtained from citrated whole blood samples. DNA was obtained using a standard salt based extraction method that has been previously described (Wang et al., 1994). Total RNA was obtained using a commercially available reagent, Ultraspec (Fisher Biotec, Australia) following manufacturers instructions.

\subsection{COMBINED SSCA AND HETERODUPLEX ANALYSIS (CSHA)}

The Combined Single-stranded conformational analysis and Heteroduplex Analysis (CSHA) method was performed using DNA and RNA derived from the 2 patient groups and builds on the method designed by (Espinosa-Parrilla et al., 2000a). DNA samples were used to amplify the coding sequence of the PROS1 gene and part of the 5 UTR using primers detailed in Appendix 4 and Taq DNA Polymerase (Invitrogen, Australia). RNA samples were reverse transcribed using Superscript II (Invitrogen, Australia) and random primers (Promega, Australia) according to manufacturers instructions which was then used to generate five PCR fragments using Taq DNA Polymerase (Invitrogen, Australia). Primers for amplification of cDNA were designed to span exon/exon boundaries (Appendix 4). The resultant fragments were cut with combinations of restriction enzymes (Appendix 5). Both the DNA and RNA PCR products were diluted 1:4 as follows: $5 \mu \mathrm{L}$ PCR product, $10 \mu \mathrm{L}$ of $\mathrm{ddH}_{2} 0$ and $5 \mu \mathrm{L}$ of CSHA loading dye $(95 \%$ formamide; $100 \mathrm{mM} \mathrm{NaOH} ; 20 \mathrm{mM}$ EDTA $\mathrm{pH} 8.0 ; 0.05 \%$ bromophenol blue), overlaid with mineral oil then heat denatured at $96^{\circ} \mathrm{C}$ for 5 minutes. The samples were immediately snap frozen in crushed dry ice and incubated for 1 minute, followed by thawing at $4^{\circ} \mathrm{C}$ immediately prior to loading. A $10 \mu \mathrm{L}$ volume of each mixture was loaded into individual wells of a CSHA gel $(16 \mathrm{~cm} \times 16 \mathrm{~cm} \times 0.75 \mathrm{~mm}$ Biorad Protean 
II); matrix composed of 12\% 49:1 (acrylamide:bis-acrylamide) (ICN Biomedicals), 5.0\% glycerol (BDH) and 0.5xTBE [45mM TRIS (ICN Biomedicals); 44.5mM boric acid (BDH); 10mM EDTA (BDH)] with 1\% ammonium persulfate (APS) (Sigma) and $0.1 \%$ N,N,N',N'-tetra-methylethylenediamine (Biorad). Samples were electrophoresed at $4^{\circ} \mathrm{C}$ in $0.5 \mathrm{x}$ TBE buffer for 12 to 16 hours at $300 \mathrm{~V}$. The system was verified by identifying known mutations derived from DNA samples kindly provided by Prof. Yolanda Espinosa-Parrilla (Centre de Genètica Mèdica i Molecular, Institut de Recerca Oncològica (IRO), Barcelona, Spain).

\subsection{SILVER STAINING}

A standard silver staining technique was used to visualise the CSHA polyacrylamide gels. Briefly, post electrophoresis gels were immersed in a $10 \% \mathrm{EtOH}$ solution with shaking $(3 \mathrm{~min})$, followed by a wash step $\left(\mathrm{H}_{2} \mathrm{O}\right)$. This process was repeated with $1 \%$ nitric acid (3min) then again with $0.1 \% \mathrm{AgNO}_{3}(10 \mathrm{~min})$. The silver ion was reduced with a $0.05 \%$ formaldehyde $/ 3 \% \mathrm{Na}_{2} \mathrm{CO}_{3}$ solution until bands became visible and the reaction terminated with $10 \%$ acetic acid.

\subsection{ISOLATION OF EXON 5 FRAGMENT}

The identification of a SSCA shift in an exon 5/6 product derived from a patient sample presented a problem vis-à-vis was the shifted band a product of exon 5 or exon 6 . Therefore, to elucidate which exon to sequence, a total of $54 \mu \mathrm{L}$ Pst I cut exon 5/6 PCR product was combined with $12.5 \mu \mathrm{L}$ of $10 \mathrm{x}$ loading dye $(30 \%$ glycerol; 1 xTAE buffer; $\mathrm{ddH}_{2} 0 ; 0.05 \%$ bromophenol blue) and loaded into a superwell of a $3 \%$ agarose gel (Scientifix) in the absence of ethidium bromide (initial experiments showed that ethidium bromide interfered with SSCA formation). The products were electrophoresed 
in 1 XTAE buffer for $6 \mathrm{~h}$ at $120 \mathrm{~V}$. The gel was removed, divided into three and the two peripheral segments stained in a $0.1 \%$ ethidium bromide solution for 15 minutes. The ethidium bromide stained gel segments were then viewed using a UV light source to determine the location of the two bands corresponding to the exon 5 and exon 6 fragments. These were marked by notching the gel. Realignment of the stained segments with the non-stained segment identified the location of the corresponding bands on the non-stained segment and these were excised and gel purified (GelClean; MOBIO, Australia) following manufacturers instructions. Both wild and mutated separated products were analysed via CSHA.

\subsection{Cell Culture}

The breast carcinoma cell line MCF-7 (kindly provided by Dr. Jacqueline Bentel, Royal Perth Hospital, Western Australia) and the liver carcinoma cell lines HuH-7 and HepG2 (kindly provided by Dr. Mark Watson, Royal Perth Hospital, Western Australia) were maintained in Phenol Red Free Dulbecco Modified Eagle Medium (DMEM; MultiCel, Australia) supplemented with 10\% FCS, 1x nonessential amino acids (MultiCel, Australia), 1mM sodium pyruvate (MultiCel, Australia), 100U/mL penicillin and $0.1 \mathrm{mg} / \mathrm{mL}$ streptomycin (Gibco/Invitrogen, New Zealand) at $37^{\circ} \mathrm{C}$ with $5 \% \mathrm{CO}_{2}$.

\subsection{Plasmid Construction FOR TRANSIENT TRANSFECTION STUDIES}

The backbone of the pPTMR construct was derived from a previously designed vector, pKH2 containing an EGFP reporter gene (a gift from Dr. Mark Watson, Royal Perth Hospital, Australia). The 950bp fragment of the PROS1 promoter was amplified with the high-fidelity polymerase pfu-Turbo (Stratagene USA) (see Appendix 6 for primer sequences). The PCR product and $\mathrm{pKH} 2$ were digested with EcoRI and XhoI (Promega, 
Australia). pKH2 was dephosphorylated and the 950bp PROS1 promoter sequence introduced via ligation with T4 DNA Ligase (Promega, Australia). A CMV/DsRed2 cassette (Clontech, USA) was introduced in order to produce a constitutively expressed DsRed2 signal to generate a baseline against which the PROS1 promoter controlled EGFP levels could be normalized. Briefly, the CMV/DsRed2 cassette was excised from pDsRed2-NI (Clontech, USA) with SspI and VspI (Promega, Australia) and the VspI 3' overhang blunted with T4 DNA Polymerase (Promega, Australia). The cassette was then isolated from the parent backbone via gel extraction (GelClean; MOBIO, Australia). The PROS1 promoter/EGFP vector was cut with SspI (Promega, Australia), dephosphorylated (Antarctic Phosphatase; New England Biolabs, UK) and the CMV/DsRed2 cassette introduced using T4 DNA Ligase (Promega, Australia). The pPMTR(-406) vector was generated via site directed mutagenesis. Briefly, using pfuTurbo (Statagene, USA) the c-406t PCR product and the pPMTR(-ERE) vector were generated using pPMTR as the template, using site directed mutagenesis primers and primers designed to flank the proposed ERE, respectively (see Appendix 6 for primer details). The PCR product lacked the ERE motif and was ligated with T4 DNA Ligase (Promega, Australia) to form pPMTR(-ERE). The pPMTR(AvrII/DraIII-del) plasmid was generated via restriction enzyme digest of the parent pPMTR vector with AvrII and DraIII (both New England Biolabs, USA). The overhangs were 'flushed' with T4 DNA polymerase (Promega, Australia) and the product isolated via an agarose gel extraction (GelClean; MOBIO, Australia). The isolated product was ligated with T4 DNA Ligase. The pPMTR(BclI/AvrII) plasmid was constructed using the same parameters except that BclI (Promega, Australia) was used in place of DraIII. Additionally, as BclI is dam sensitive a dam- pPMTR was used, derived from a plasmid preparation using methylation negative E-coli K12 strain ER2925 (dam- and dcm-; New England Biolabs, USA). The pPMTR(-AvrII) plasmid was generated by restriction enzyme digestion of 
pPMTR with AvrII followed by incubation with 25U of Mung Bean Nuclease. The resultant product was ligated with T4 DNA Ligase creating a ctagg deletion of the cctagg AvrII cut site.

\subsection{Transient Transfection STUdiES}

Constructs were transiently transfected using Transfectin (Biorad, Australia) according to the manufacturers instructions in 12-well plates. Cells were seeded at a density of 4.0 and $2.0 \times 10^{5}$ cells/well for MCF-7s and $\mathrm{HuH}-7 \mathrm{~s}$, respectively. Where specified, plasmids were co-transfected with vectors expressing either progesterone receptor isoform A (PR-A; a gift from Prof. Christine Clarke from the Westmead Institute, Australia), isoform B (PR-B; a gift from Prof. Pierre Chambon from the Institut de Génétique et de Biologie Moléculaire et Cellulaire, France), or oestrogen receptor alpha (ER $\alpha$; a gift from Dr. Andrew Redfern from the Western Australian Institute for Medical Research, Australia). Where appropriate, media was supplemented with hormone; 1,5 or $10 \mathrm{nM} \beta$-oestrodial $\left(\mathrm{E}_{2}\right.$; Sigma, Australia) or $20 \mathrm{nM}$ progesterone $\left(\mathrm{P}_{4}\right.$; Sigma, Australia), medroxyprogesterone acetate (MPA; Sigma, Australia), D(-)norgestrel (LNG; Sigma, Australia), corticosterone (CORT; Sigma, Australia) and $10 \mu \mathrm{M}$ of the progesterone antagonist mifepristone (RU486; Sigma, Australia) delivered using an ethanol vehicle (final concentration $0.5 \% \mathrm{EtOH}$ ) $5 \mathrm{~h}$ post-transfection, followed by incubation for $24 \mathrm{~h}$ at $37^{\circ} \mathrm{C}, 5 \% \mathrm{CO}_{2}$. For all transfection procedures, experimental variables were assessed in triplicate. Following incubation, wells were aspirated and the cells washed with $1 \times$ PBS prior to resuspension in $1 \mathrm{x}$ PBS containing $1 \%$ bovine serum albumin and $0.2 \% \mathrm{NaN}_{3}$. Expression levels of EGFP and DsRed2 were measured using an EPICS Coulter flow cytometer at an excitation of $488 \mathrm{~nm}$ and emissions detected at 505-545nm and 605-635nm for EGFP and DsRed2, respectively. The CMV/DsRed2 
cassette was tested in isolation to determine if addition of hormones and/or cotransfection with the plasmids expressing ER $\alpha$ or PR-B affected expression of the internal control.

\subsection{NuClEAR PRotein EXTRACTION}

Nuclear proteins were extracted from $1 \times 10^{8} \mathrm{MCF}-7$ cells that had been transiently transfected with the pPR-B expression vector after a $24 \mathrm{~h}$ exposure to $20 \mathrm{nM} \mathrm{P}$. Briefly, cells were washed twice in 1xPBS then resuspended in $4 \mathrm{~mL}$ cold Buffer A $(10 \mathrm{mM}$ HEPES, pH 7.9; 10mM KCl; 0.1mM EDTA; 0.1mM EGTA). Note- All Buffers were supplemented with protease inhibitors, specifically, $0.5 \mathrm{mM}$ dithiothreotol, $1 \mathrm{mM}$ $\mathrm{Na}_{3} \mathrm{VO}_{4}$ and $1 \mathrm{x}$ Complete Protease Inhibitor (Roche Diagnostics, Australia) and incubated on ice for $20 \mathrm{~min}$. Post incubation $250 \mu \mathrm{L}$ of $10 \%$ NP-40 was added. The mixture was vortexed briefly then centrifuged for $1 \mathrm{~min}$ at $13000 \mathrm{rpm}$. The supernatant was removed and the pellet was resuspended in $1 \mathrm{~mL}$ cold Buffer $\mathrm{C}$ (20mM HEPES, pH 7.9; $0.42 \mathrm{M} \mathrm{NaCl} ; 1 \mathrm{mM}$ EDTA; 1mM EGTA; 20\% glycerol) and rocked vigorously for $30 \mathrm{~min}$ at $4^{\circ} \mathrm{C}$. Centrifugation at $13000 \mathrm{rpm}$ for $5 \mathrm{~min}\left(4^{\circ} \mathrm{C}\right)$ followed and the supernatant was aliquoted into volumes for storage at $-80^{\circ} \mathrm{C}$.

\subsection{ELECTROMOBILITY SHIFT ASSAYS}

Oligonucleotides for the PRE investigation were purchased (Geneworks, Australia) and were as follows: CONSENSUS PRE- sense 5' GAT CCT GTA CAG GAT GTT CTA GCT ACA 3' and antisense 5' TGT AGC TAG AAC ATC CTG TAC AGG ATC 3';

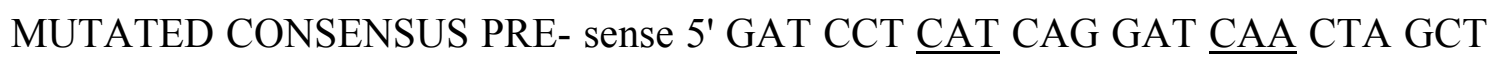

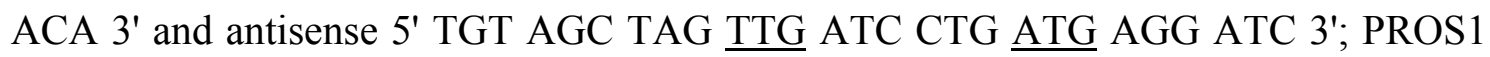
PRE- sense 5' TGA ACC TAG GGA TCC TGT CCT CTT GAA 3' and antisense 5' 
TTC AAG AGG ACA GGA TCC CTA GGT TCA 3'; PROS1 -407 MUTANT PREsense 5' TGA ACC TAG GGA TTC TGT CCT CTT GAA 3' and antisense 5' TTC AAG AGG ACA GㅁA TCC CTA GGT TCA 3'; AP1 CONSENSUS- sense 5' CGC TTG ATG AGT CAG CCG GAA 3' and antisense 5' TTC CGG CTG ACT CAT CAA GCG 3' (all Geneworks, Australia). The AP1 probe was included as an Ab control. The $5^{\prime}$ termini of the sense oligonucleotides were end labelled with ${ }^{32} \mathrm{P}$ using a standard kinase reaction (Promega, Australia) following manufacturers instructions utilising $[\gamma-$ ${ }^{32}$ P] ATP (Perkin Elmer, Australia). The labelled oligonucleotides were annealed to their cognate sequences to form the radiolabelled probes. Unlabelled competitor probes were also produced. Appropriate probes (50pmol unlabelled competitor probe and/or $5 \mathrm{pmol}{ }^{32} \mathrm{P}$-labelled probe) were incubated for $20 \mathrm{~min}$ at $4^{\circ} \mathrm{C}$ in $1 \mathrm{x}$ Dignam Buffer D [20mM HEPES (pH 7.9), 20\% glycerol, 0.1M KCl, 0.2mM EDTA supplemented with $0.5 \mathrm{mM}$ dithiothreotol, $1 \mathrm{mM} \mathrm{Na} \mathrm{NaO}_{4}$ and $1 \mathrm{x}$ Complete Protease Inhibitor (Roche Applied Science, Australia)] with $1 \mu \mathrm{g}$ of PR-B positive nuclear protein extract, with $1 \mu \mathrm{g}$ of Poly dI•dC (Sigma, Australia). Where indicated, $5 \mu \mathrm{g}$ of mouse anti-human PRB (sc-811 X; Santa Cruz, USA) was added. A 5\%, 29:1 acrylamide/bis-acrylamide gel matrix was used to electrophorese the samples for $3 \mathrm{~h}$ at $200 \mathrm{~V}\left(4^{\circ} \mathrm{C}\right)$ in $0.5 \mathrm{x}$ TBE. After drying, the gels were exposed to X-ray film for $24 \mathrm{~h}$ at $-80^{\circ} \mathrm{C}$ and the film developed using standard techniques.

\subsection{PLASMID CONSTRUCTION FOR YEAST-2-HYBRID}

The coding region of PROS1 was amplified from an I.M.A.G.E clone (MGC:9207 IMAGE:3909023; Geneservice, UK) with pfu Turbo (Stratagene, USA) using primers incorporating BamHI and PstI (Promega, Australia) restriction enzyme sequences (See Appendix 6 for primer details). The 'bait' vector pBTM116 (Bartel and Fields, 1995), a 
gift from Dr. Evan Ingley from the Western Australian Institute for Medical Research, was also cut with BamHI and PstI, dephosphorylated with Antarctic Phosphatase (NEB, UK) and gel extracted (MoBio, Australia). The PROS1 fragment was ligated (T4 DNA Ligase; Promega, Australia) in downstream from the LexA-BD coding sequence, inframe, to generate the LexA-BD/PS fusion protein. The PS/pBTM116 vector was used to screen a combined liver and bone marrow cDNA library (see below). A positive interaction was identified that yielded a clone containing a partial sequence of the haemostatic protein $\mathrm{Z}(\mathrm{PZ})$. Therefore, to confirm the interaction the coding sequence of PZ (IMAGE:30915254 MGC:103872; Geneservice, UK) was introduced into the 'fish' vector pGADT7 (Clontech, USA) via a method identical to that of the pBTM116/PS procedure, except that ClaI and BamHI (Promega, Australia) restriction sequences were incorporated into the primers to match the corresponding cut sites in the pGADT7 vector (see Appendix 6 for primer details). The resultant pGADT7/PZ contained the PZ coding sequence downstream and in-frame, from the Gal4-AD to facilitate expression of a Gal4-AD/PZ fusion protein.

\subsection{CONFIRMATION OF VECTOR SEQUENCE}

All vectors were purified from cultures using a Qiagen Maxiprep Kit and the sequences confirmed by DNA sequencing using an ABI Prism 373048 capillary sequencer (Applied Biosystems). See Appendix 6 for primer details.

\subsection{YEAST-TWO-HYBRID SYSTEM}

The pBTM116/PS vector was used to screen combined liver and bone marrow cDNA libraries (Clontech, USA). Briefly, $1.5 \mu \mathrm{g}$ of pBTM116/PS was introduced into competent L40 yeast cells, that lack tryptophan (Trp), leucine (Leu) and histidine (His) 
expression (a gift from Dr. Evan Ingley) using a previously described method based on the LiAc/PEG protocol (Gietz et al., 1992). The transformation mix was plated out on $\mathrm{Yc}^{-\mathrm{Trp}}$ agar plates (Yc agar was $0.17 \%$ yeast nitrogen base; $37.85 \mathrm{mM}\left(\mathrm{NH}_{4}\right)_{2} \mathrm{SO}_{4} ; 0.11 \mathrm{M}$ glucose; with or without $0.1 \mathrm{mM}$ tryptophan, $0.1 \mathrm{mM}$ histidine or 0.7 leucine; all Sigma, Australia). 100 colonies were assessed for both $\beta$-galactose ( $\beta$-Gal) activity and negative growth on $\mathrm{Yc}^{- \text {Trp,-His }}$ agar plates. The $\beta$-Gal activity was assessed using the following assay. Briefly, selected colonies were grown on $\mathrm{Yc}^{-\mathrm{Trp}}$ plates until visible to the naked eye and transferred to a nitrocellulose membrane, prior to emersion in liquid $\mathrm{N}_{2}$ to fix. The membrane was then soaked in Z-buffer $\left(0.06 \mathrm{M} \mathrm{Na} 2 \mathrm{HPO}_{4} ; 0.04 \mathrm{M}\right.$ $\mathrm{NaH}_{2} \mathrm{PO}_{4} ; 0.01 \mathrm{M} \mathrm{KCl} ; 0.001 \mathrm{MgSO}_{4}$; all Sigma, Australia) supplemented with $0.03 \mathrm{M} \beta-$ mercaptoethanol (Sigma, Australia) and 2.78M X-gal (Promega, Australia ) immediately prior to use. The membrane was incubated at RT until the characteristic blue colour indicating positive colonies was detected. A $\beta$-Gal positive/Yc ${ }^{-H i s, T r p ~}$ negative colony was selected for a large scale transformation of the combined liver and bone marrow cDNA libraries. A total of $250 \mu \mathrm{g}$ of each library was used to transform the L40 ${ }^{\text {pBTM116/PS }}$ cells, based on the LiAc/PEG methodology of (Gietz et al., 1995). Positives were selected for growth on $\mathrm{Yc}^{-\mathrm{Trp} \text {-His,-Leu }}$ agar plates, $\beta$-Gal positivity and for total growth inhibition in the presence of $10 \mathrm{mM} \mathrm{3-aminotriazole,} \mathrm{a} \mathrm{His} \mathrm{inhibitor,} \mathrm{to}$ account for any 'leaky' His activity. Plasmids were extracted from positive colonies and the cDNA inserts sequenced (see Appendix 6 for primer details). A 'fish' (pACT2) vector containing a partial fragment that corresponded to the PROZ gene that encodes PZ necessitated performing a follow up small scale PZ/PS transformation. Therefore, competent L40s were co-transformed with the pBTM116/PS and pGADT7/PZ to determine whether there was actually an interaction. Controls were; pACT2/Fgr and pBTM116/GPVI-tail, to generate a positive interaction between protein tyrosine kinase Fgr and glycoprotein VI-tail that has been shown previously in our laboratory (gifts 
from Julianna Degenaar). They were constructed using similar PCR based techniques (see Sarich 2002) insert free pGADT7/pBTM116 vectors.

\subsection{DATA AND STATISTICAL ANALYSIS}

Flow cytometer data generated from the transient transfection work (Section 2.8) was analysed using the following calculation. In order to express the PROS1 promoter controlled EGFP signal as a percentage each sample was normalized against the DsRed2 signal.

$$
\begin{aligned}
& \left(\mathrm{MFI}^{\#} \mathrm{EGFP} \mathrm{MFI}^{\#}\right. \text { DsRed2)x100=\% expression } \\
& { }^{\#} \mathrm{MFI}=\text { Mean Fluorescence Intensity }
\end{aligned}
$$

An average of the triplicates per variable, derived from three separate experiments, was calculated and expressed as a change in expression compared to the untreated (Vehicle; EtOH) for the respective vectors. Where indicated, a two-tailed Student's T-test was used to calculate $p$-values. Standard error mean (SEM) used to represent error where indicated in graphical interpretation of data. 


\section{CHAPTER 3}

\section{Mutation Analysis of the PROS1 Gene}




\subsection{INTRODUCTION}

Genetic analysis of the PROS1 gene has been the focus of a number of studies, resulting in the identification of a large number of mutations and probable polymorphisms (Gandrille et al., 1997, Gandrille et al., 2000). A small percentage of mutations have been characterised in vitro and found to be causative for PS deficiency. These include the replacement of cysteine by arginine at amino acid position 474 (C474R) (Yamazaki et al., 1996), G441C, Y444C (Espinosa-Parrilla et al., 2000b), V-24E, G295V, H623P (Rezende et al., 2002), R314H, P375Q and D455Y (Okada et al., 2006) which have all been linked with Type I deficiency. Definitive linkage of mutations with Type II deficiency has been demonstrated for T103N (Giri et al., 2000) which is proposed to interfere directly with aPC binding. A deletion of I203 and D204 in the 4th Gla domain (Baroni et al., 2006) has also been proposed to interfere with aPC binding. Other mutations that are likely to alter PS conformation, C80Y and $\mathrm{R} 275 \mathrm{C}$, have also been defined as causative for Type II deficiency, due to the probable disruption of the molecules secondary structure via the removal and introduction of the cysteine residues, respectively, altering sulphur-sulphur bond pairing (Okada et al., 2006). The limitations of the methodologies used to assess the mutant forms in vitro makes definitive classification of Type III deficiencies difficult, but cross-matching the patient's data with experimental results allows a measure of certainty.

Polymorphisms within the PROS1 gene have also been described. The K196E (formally known as K155E, or Tokushima variant) has a high prevalence in the Japanese population (frequency $=0.009$ ) where it is a risk factor for DVT (Miyata et al., 2006, Kimura et al., 2006). Another, polymorphism S460P, otherwise known as the Heerlen mutation, has a frequency Caucasian populations in the range of 0.005-0.009 (Heeb et al., 2004, Gandrille et al., 2000). There is ongoing debate as to whether the Heerlen 
variant is a risk factor for thrombosis (Denis et al., 2005, Heeb et al., 2004, Koenen et al., 2004).

To date, no mutations have been linked to a cis-element that could form the basis for a mechanism to explain how PS is hormonally regulated. In this study, PS deficient patients were selected from two sources; individuals presenting with low or unexplained fluctuating free PS levels and a cohort of pregnant women who had suffered preeclampsia or gestational diabetes while pregnant. To identify potential causative mutations of PROS1 DNA, exonic sequences and a large portion of the promoter region were screened using Combined Single-stranded conformational analysis and Heteroduplex Analysis (CSHA). CSHA exploits the change, or changes, in sequence composition arising from the nucleotide substitutions, deletions or insertions. Figure 3.1 details the process involved. Briefly, PCR product is generated from a target sequence with a given size range of 100 to $300 \mathrm{bp}$ (larger sequences can be screened by cutting them into smaller fragments with restriction enzymes). The double stranded PCR product is heat denatured and rapidly cooled, producing single-stranded conformers (single-stranded DNA folded back on itself) and heteroduplexes (single-stranded DNA that has reannealed with complimentary strands and also mutated sequence). The secondary structure of the single-stranded conformers is determined by the nucleotide composition of the sequence. A single base change can dramatically alter the tertiary folding, forming a conformer that migrates through a matrix at a different rate to that of a wild type sequence. Heteroduplexes can be formed when a wild type sense strand reanneals with a mutated antisense strand, forming a 'kink' where the mismatched basepairs are. This too can effect the migration of the heteroduplex compared to that of the reannealed wild and mutated double-stranded products. 


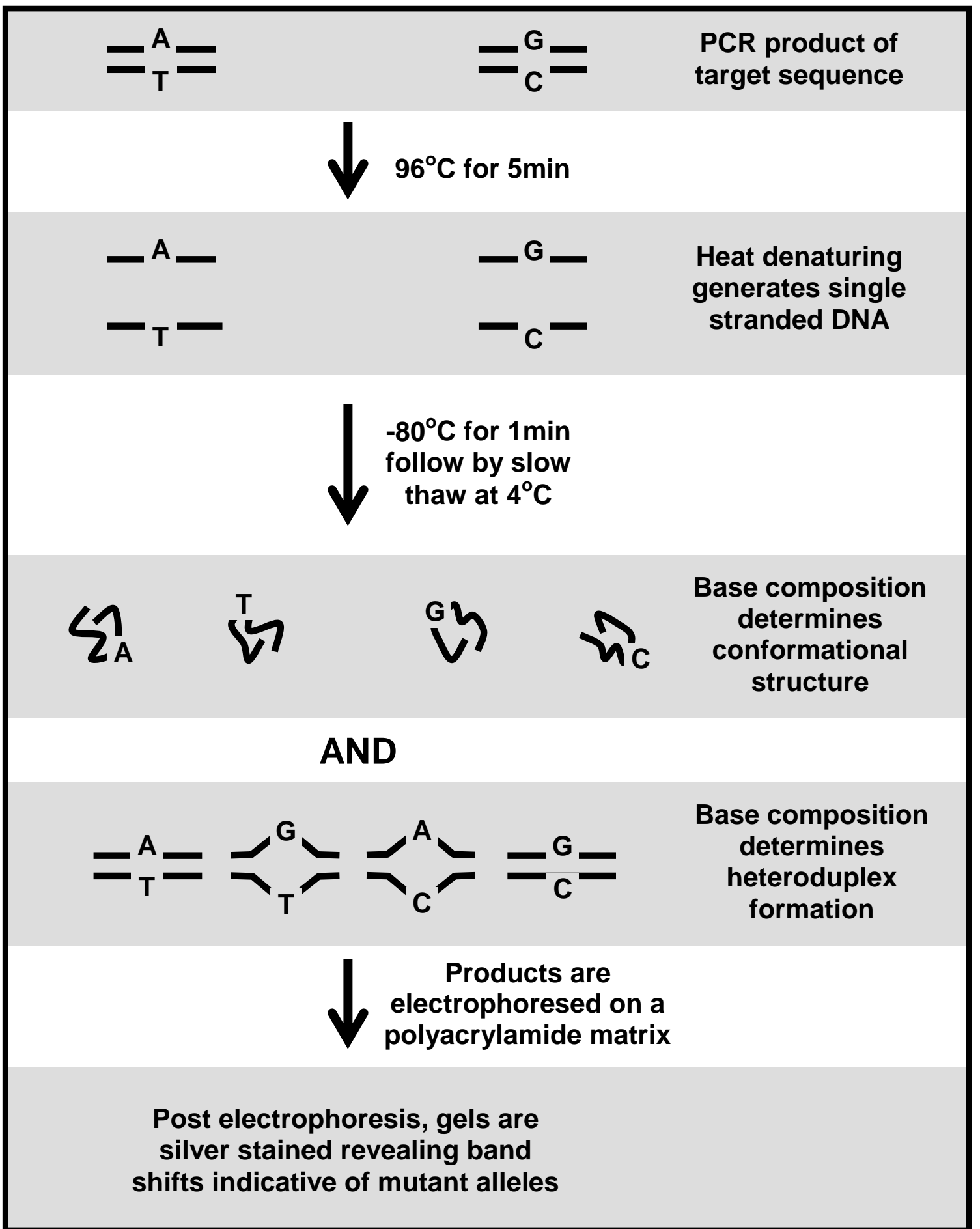

Figure 3.1 A Schematic of the CSHA Methodology- PCR product is heat denatured at $96^{\circ} \mathrm{C}$ for $5 \mathrm{~min}$ to separate the sense and anti-sense strands prior to snap freezing on dry ice $\left(-80^{\circ} \mathrm{C}\right)$. Samples are slowly thawed at $4^{\circ} \mathrm{C}$. The process generates both single stranded DNA conformers (single stranded DNA that has folded back on itself) and heteroduplexes (DNA that has re-annealed with complimentary strands). Differences in base composition alter conformers and generate mismatched heteroduplexes, both of which can migrate at different rates when electrophoresed on polyacrylamide gel matices. 
The development of CSHA methodology was designed with a particular emphasis on the promoter region of the PROS1 gene, as it is a known 'hotspot' for hormonal regulation in many other genes, particularly via hormone receptor/response element interactions (Beato et al., 1996, DeMayo et al., 2002, Wan and Nordeen, 2003, O'Lone et al., 2004, Schoneveld et al., 2004).

The CSHA method was further modified to facilitate screening of PROS1 RNA to enable the detection of splice site variants and as a cross-check for the sensitivity of the DNA screen. In addition, several studies have identified hormone influenced posttranslational mRNA degradation and protection processes that regulate cytoplasmic levels of particular mRNA transcripts, regulating protein translation (Ing, 2005).

This study is first to screen the PROS1 gene and the associated mRNA transcript with the sole aim of identifying potential hormonally responsive elements, by identifying variants that alter hormonal responsiveness. The decision to derive the nucleic acids from two separate sources, the low PS group and the highly hormonal pregnancy cohort, increases the power of the study.

\subsubsection{Sensitivity of CSha Compared to Other Detection Methodologies}

Empirical determination of the exact sensitivity of CSHA based on published literature is problematic, given the extensive variability in experimental conditions used by different groups. Earlier publications focused exclusively on single-stranded conformational analysis (SSCA) with mutation detection sensitivities ranging from $69 \%$ (Choy et al., 1999) to 97\% (Sheffield et al., 1993). However, groups that have 
combined SSCA with heteroduplex analysis on the same gel matrix have reported sensitivities close to 100\% (Espinosa-Parrilla et al., 2000a, Rossetti et al., 1995).

Other detection platforms include denaturing high performance liquid chromatography (dHPLC), high resolution melt curve analysis (HRM) and the 'gold standard' for novel mutation detection, direct DNA sequencing. Several studies report that dHPLC can detect mutations with a $100 \%$ accuracy, however this method requires extensive optimisation of column and running conditions and has a high rate of false positives (Ravnik-Glavac et al., 2002, Colosimo et al., 2003, Chou et al., 2005). Preliminary studies suggest that HRM is a highly stringent methodology, but most studies acknowledge the problems associated with detecting A:T or T:A base changes due to the minimal change in thermal stability between wild and mutated alleles (Chou et al., 2005). DNA sequencing represents the most stringent platform for detecting novel mutations, but the cost is unreasonably expensive for screening large cohorts.

\subsection{RESULTS}

\subsubsection{DeVelopment of the Method}

Several parameters were optimised for the PROS1 CSHA including, gel matrix composition, denaturing and quenching temperatures and electrophoretic conditions including, temperature and time.

Figure 3.2 details the comparison of 29:1 and 49:1 gel matrices (both supplemented with $5.0 \%$ glycerol $)$ for 3 and 6 hour time periods at $290 \mathrm{~V}\left(22^{\circ} \mathrm{C}\right)$ for a standard $150 \mathrm{bp}$ PCR product. Longer running times resulted in greater band separation and were deemed more preferable.

Running temperatures were assessed in combination with sample denaturing times and quenching conditions (Figure 3.3). Two running temperatures were assessed, $4^{\circ}$ and 
$22^{\circ} \mathrm{C}$. The denaturing times were 2,5 and 10 minutes with both dry ice $\left(-70^{\circ}\right)$ and wet ice $\left(4^{\circ} \mathrm{C}\right)$ used to quench the samples. The gel matrix used was $12 \%(49: 1) 5 \%$ glycerol. Both gels were electrophoresed for 4 hours at $400 \mathrm{~V}$. Denaturing times was not observed to affect band migration or resolution. Dry ice improved band resolution and was therefore selected for future procedures. The greatest variability was evident in the temperature used for electrophoresis. The $4^{\circ} \mathrm{C}$ temperature results showed a similar separation to $22^{\circ} \mathrm{C}$ for the upper single-stranded conformer banding, but differed in migration distance for the heteroduplex bands. Therefore, $4^{\circ} \mathrm{C}$ was selected for future studies as it allowed greater running times without the loss of the heteroduplex information.

Increased running times and voltages were also assessed, including 4, 6 and $8 \mathrm{~h}$ runs and a range of voltages from $150 \mathrm{~V}$ through to $400 \mathrm{~V}$ (results not shown). Following assessment of the various parameters tested, the best conditions were considered to be a matrix composed of $12 \% \quad 49: 1$ (acrylamide:bis-acrylamide), 5.0\% glycerol with electrophoresis performed at $300 \mathrm{~V}$ for between 12-16 hours (exon dependent) at a constant $4^{\circ} \mathrm{C}$.

Positive controls for each exon fragment (samples containing known mutations, kindly donated Dr. Espinosa-Parrilla) were tested with the optimised parameters to confirm the ability of our CSHA method to detect mutations. CSHA detection of each of these positive controls is illustrated in Figures 3.4 and 3.5. 


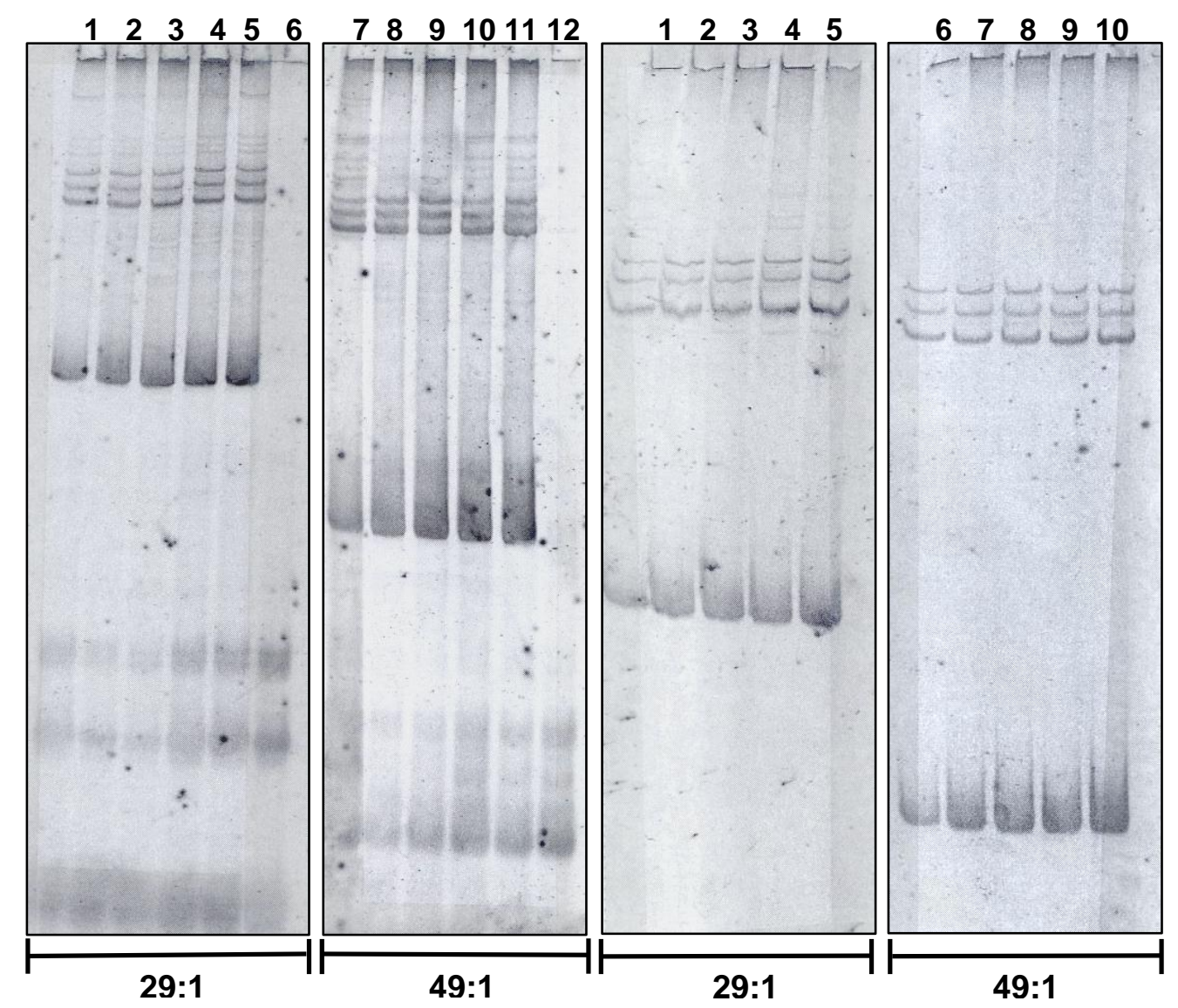

Figure 3.2 Comparison of 29:1 and 49:1 Gel Matrixes Over 3 and 6 Hour Run Times- a) Lanes 1 to 5 and 7 to 11: Replicate control samples electrophoresed at $290 \mathrm{~V}\left(22^{\circ} \mathrm{C}\right)$ through $29: 1$ and 49:1 acrylamide:bis-acrylamide gel matrices, respectively for 3 hours. Lanes 6 and 12: Negative controls. b) Lanes 1 to 5 and 6 to 10: Replicate control samples electrophoresed at $290 \mathrm{~V}\left(22^{\circ} \mathrm{C}\right)$ through 29:1 and 49:1 acrylamide:bis-acrylamide gel matrices, respectively for $6 \mathrm{~h}$. 


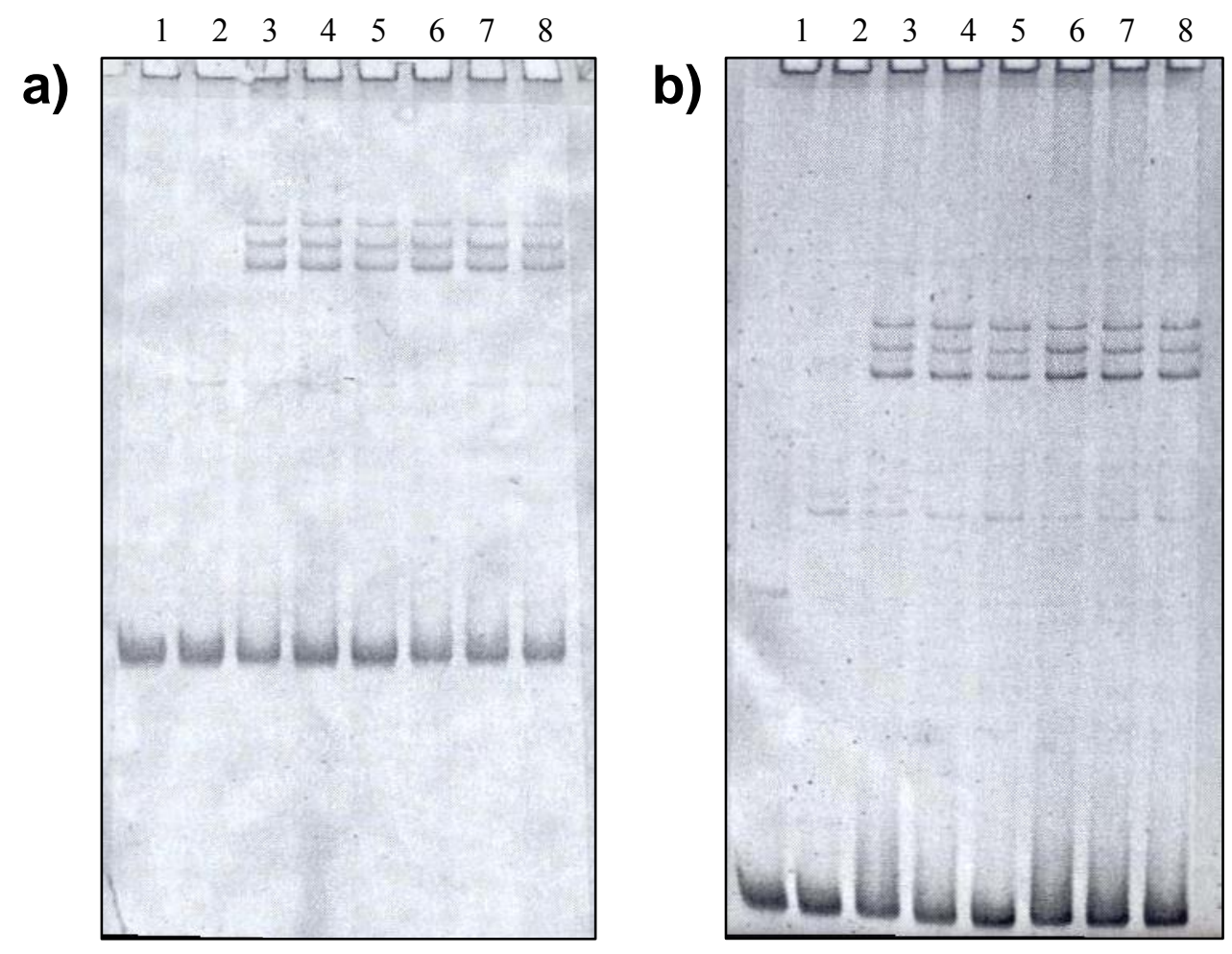

Figure 3.3 Assessment of a) $4^{\circ} \mathrm{C}$ and b) $22^{\circ} \mathrm{C}$ Running Temperature Utilising Various Denaturing and Quenching Parameters- Lane 1: Undenatured sample minus loading dye. Lane 2: Undenatured sample with loading dye. Lanes 3, 4 and 5: Control sample denatured at $96^{\circ} \mathrm{C}$ for 2, 5 and 10 minutes, respectively, and quenched in normal ice. Lanes 6, 7 and 8: Control sample denatured for at $96^{\circ} \mathrm{C}$ for 2,5 and 10 minutes, respectively, and quenched in dry ice. 


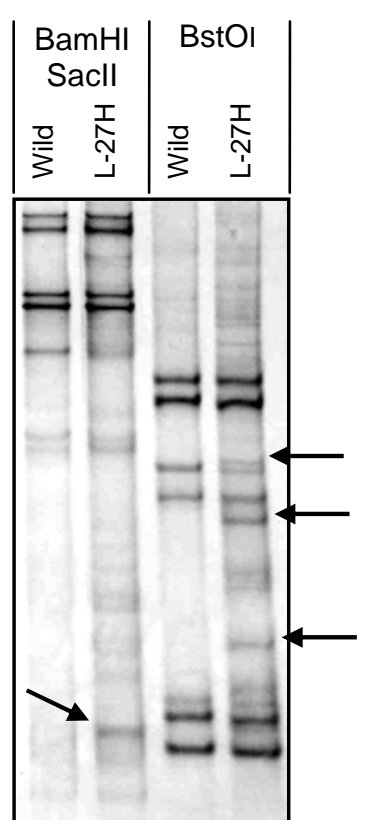

Promoterl Exon 1

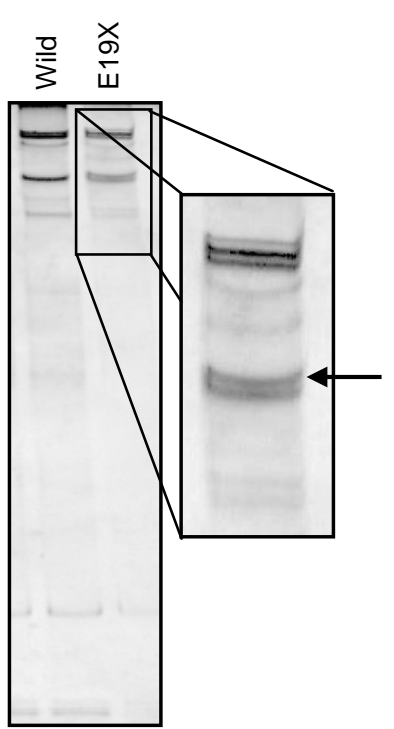

Exon 2

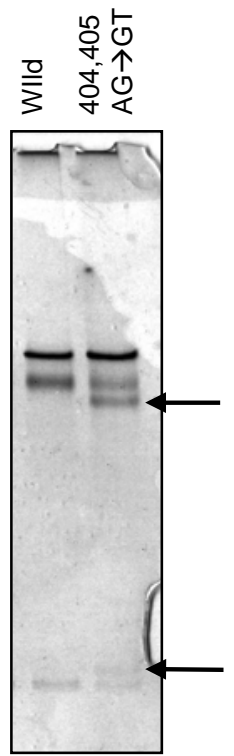

Exon 3

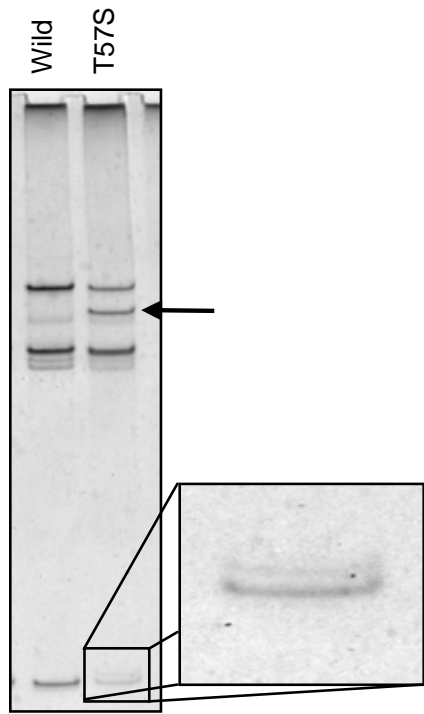

Exon 4

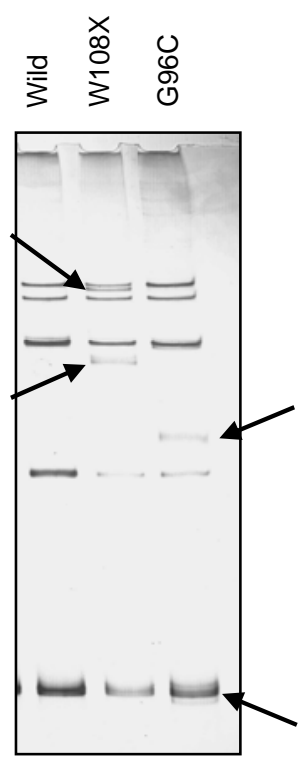

Exons 5/6

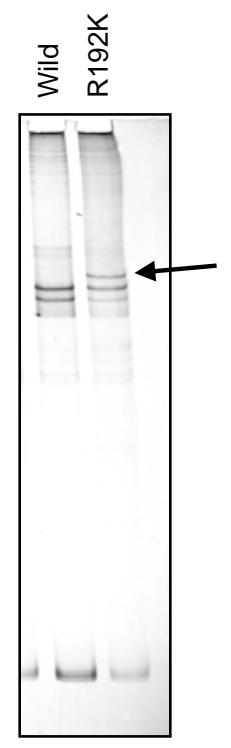

Exon 7

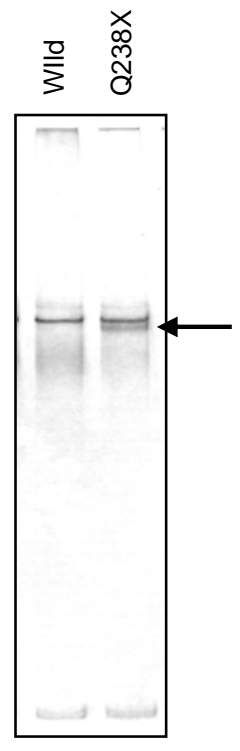

Exon 8

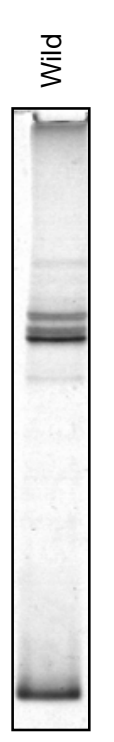

Exon 9

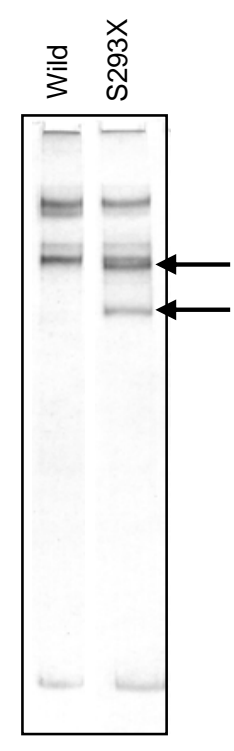

Exon 10

Figure 3.4 CSHA Analysis of Exons 1-10. CSHA analysis of PROS1 exons 1-10 illustrating banding patterns produced by wild-type (Wild) sequences as well as known mutant controls (Gifts from Dr.Espinosa-Parrilla). Note- The large 778bp promoter/exon1 fragment is subjected to two separate restriction enzyme regimes to cut the PCR product into CSHA compatable sizes (BamHI/Sacll and BstOI). Using two different regimes minimizes the possibility of missing possible base changes in or around a cut site. No exon 9 variant sequences were available. Bands corresponding to variant sequences are indicated (arrows). 


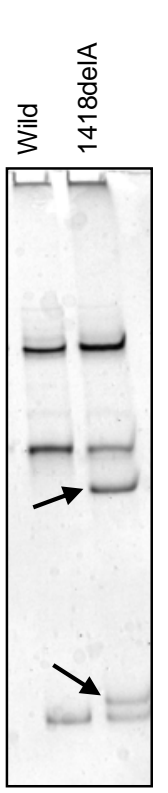

Exon 11

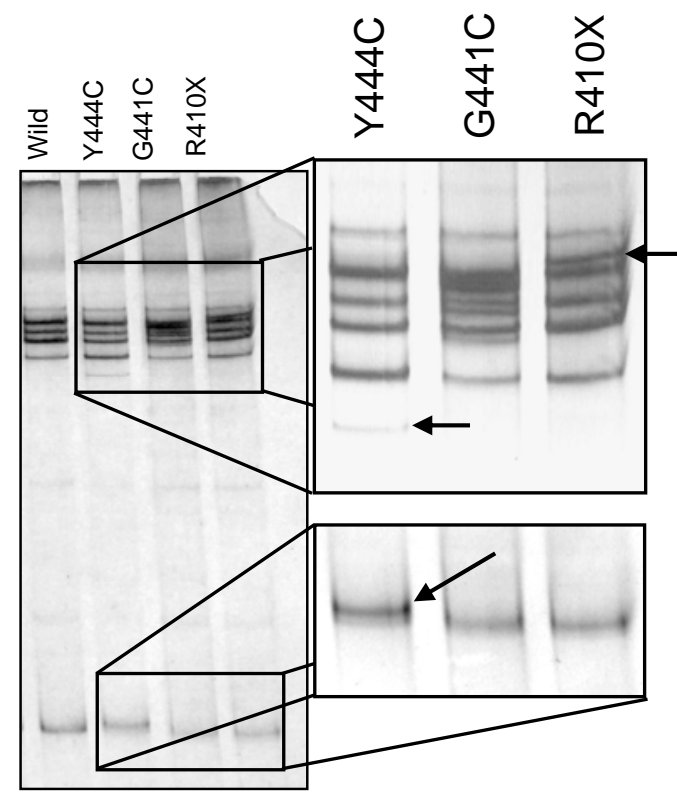

Exon 12

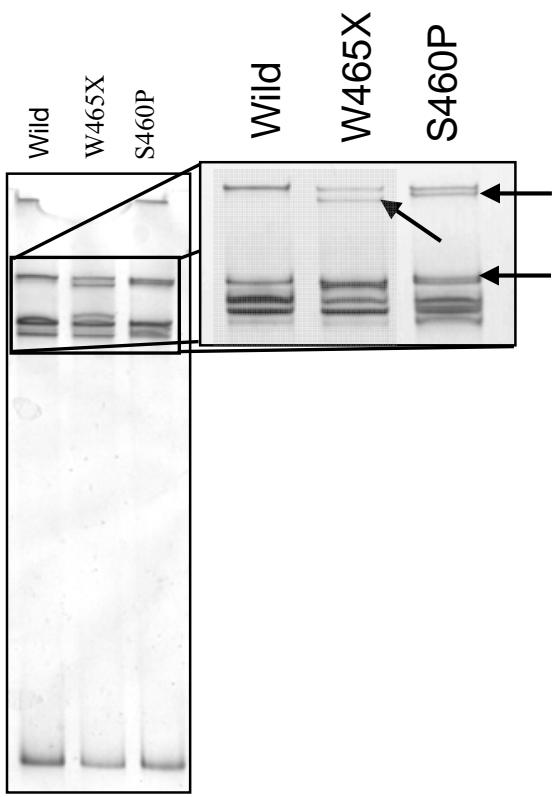

Exon 13

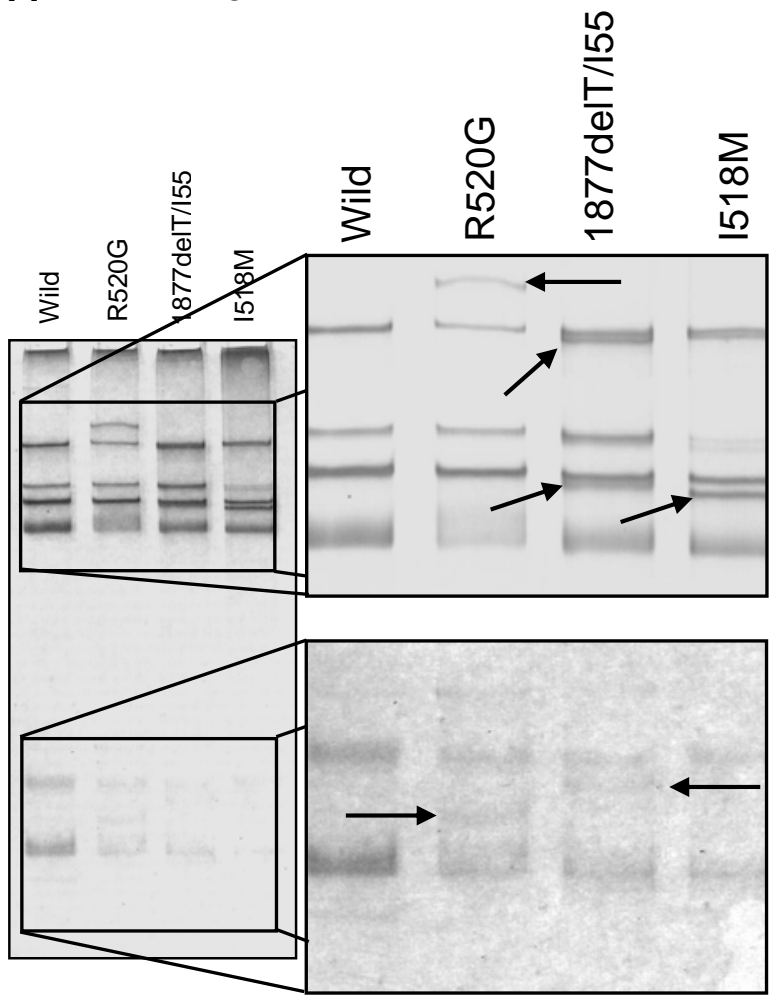

Exon 14

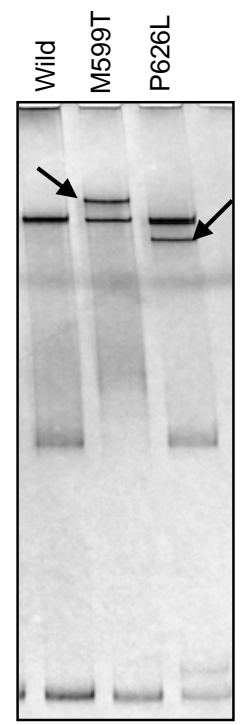

Exon 15

Figure 3.5 CSHA Analysis of Exons 11-15. CSHA analysis of PROS1 exons 11-15 illustrating banding patterns produced by wild-type (Wild) sequences as well as known mutant controls (gifts from Dr Yolanda Espinosa-Parrilla). Bands corresponding to variant sequences are indicated (arrows). 


\subsubsection{Mutations Identified in the Coding Region}

Following confirmation of our CSHA system to adequately detect DNA mutations we then tested our patient samples for the presence of any mutations within their PROS1 gene. Two novel mutations were identified in exonic coding regions (Figure 3.6A). The first was identified in exon 5/6 obtained from a patient with severe PS deficiency. To identify the exon that corresponded to the band shift the two fragments were isolated after restriction enzyme digestion (see section 2.5 Chapter 2) and re-analysed (Figure 3.6B). The mutation mapped to the exon 5 fragment. Sequencing identified an act $\rightarrow$ gct point mutation creating a threonine to alanine change at position 101 (T101A). T101A is located within the EGF1 domain, a domain important for the co-factor function of PS as it is part of the region that binds to aPC.

The second point mutation, ggt $\rightarrow$ tgt, was identified in exon 10 and changes a glycine to a cysteine at position 340 (G340C; Figure 3.7). The G340C mutation maps to within the SHBG-like domain of the carboxy terminal.

In addition to the two novel findings, other previously described polymorphisms were identified; R192K (Gandrille et al., 1997) [PS Deficient cohort, patient PS3], and S460P (Heerlen mutation) (Bertina et al., 1990); in both cohorts [PS Deficient cohort, patients PS16, PS19, PS21 and PS22 and the Pregnancy cohort, patient GD416]. The K196E polymorphism, commonly found in the Japanese population, was not identified in either cohort. All of the control mutations were detected. A schematic highlighting the location of each of these mutations is seen in Figure 3.8. 


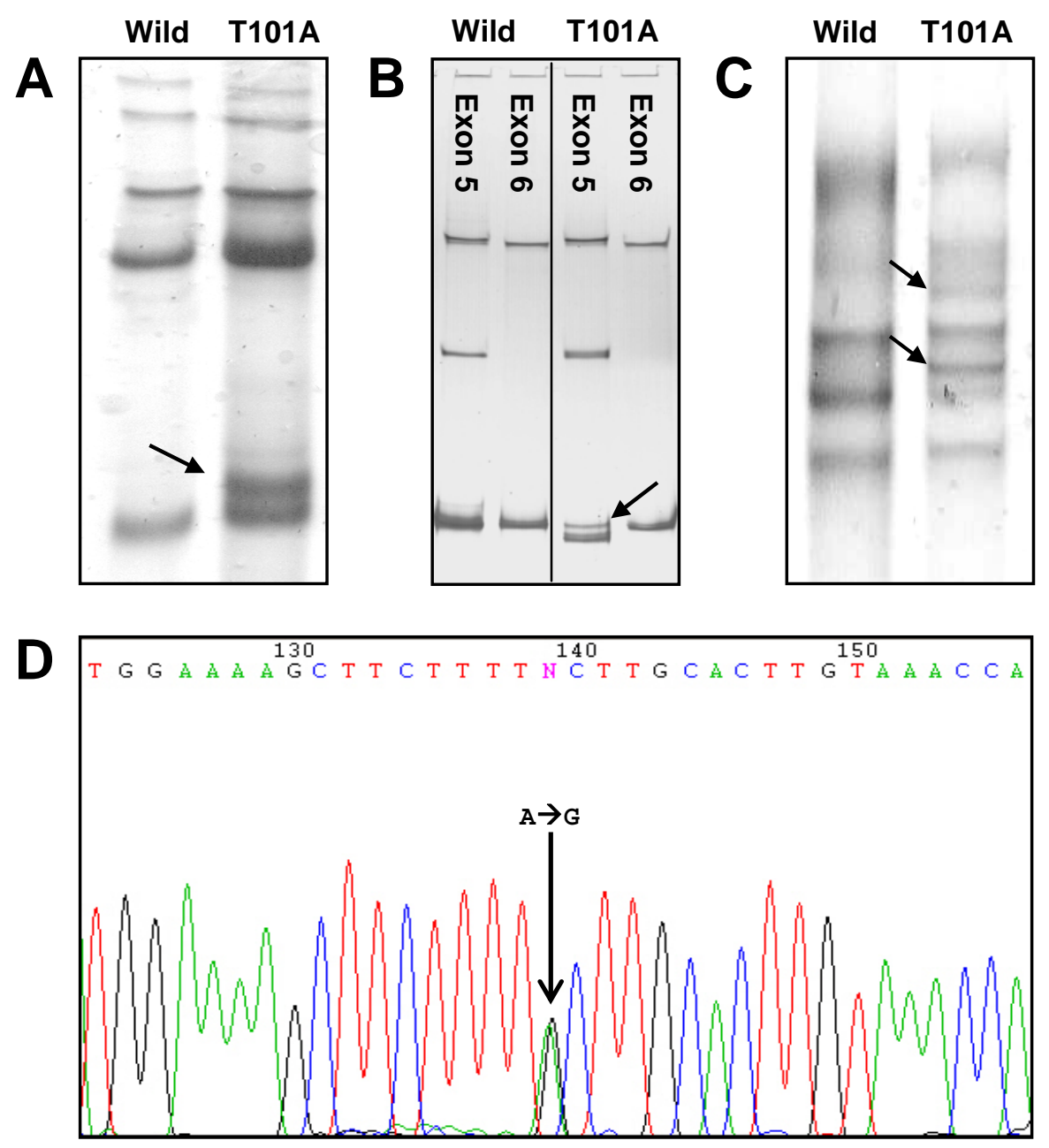

Figure 3.6 Identification of a novel mutation affecting the 1st EGF-like domain. A) Silver stained CSHA gel image showing the band shift for a novel mutation identified in the exon $5 / 6$ screen of the patient's DNA. B) A separation method showed that the shift mapped to exon 5 (see text for details). D) Sequencing of exon 5 revealed an act $\rightarrow$ gct point mutation that changes the threonine to an alanine (T101A). C) The T101A mutation was also identified after CSHA was performed on the patient's RNA. 


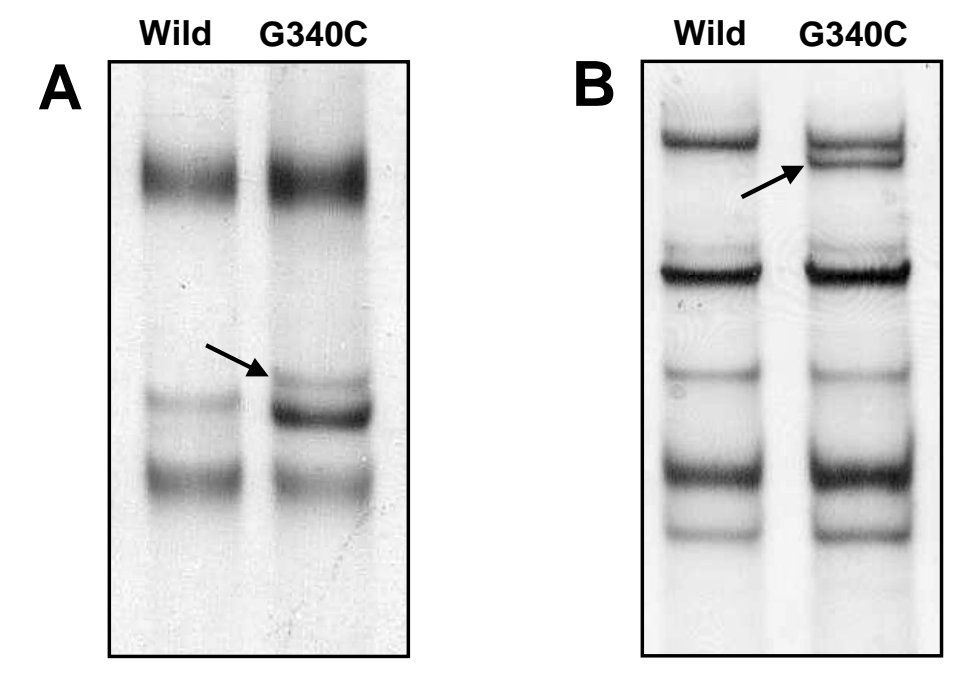

C

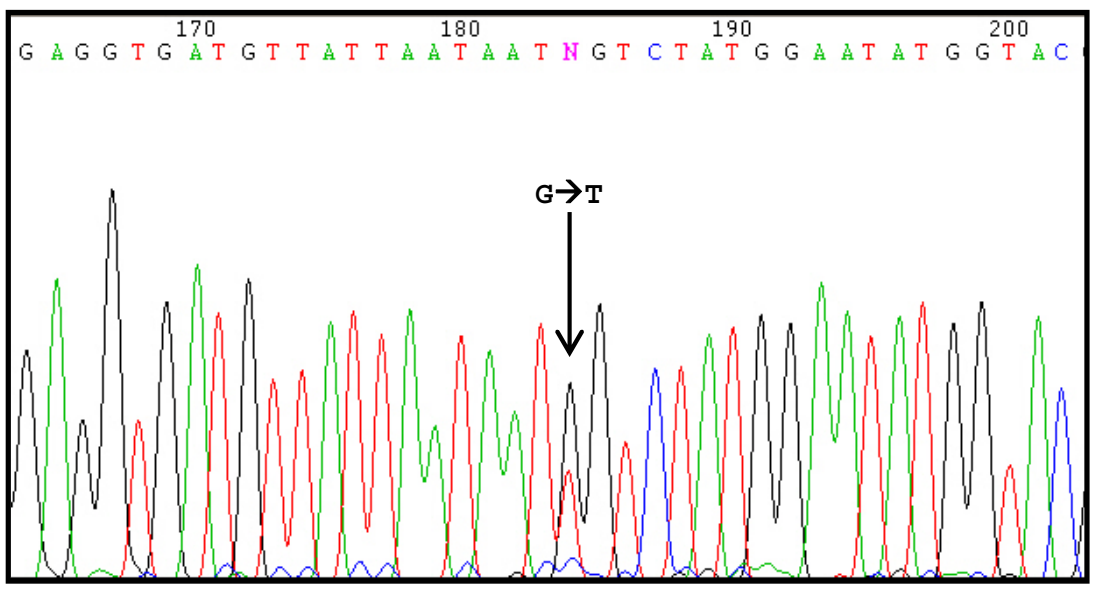

Figure 3.7 Identification of a second novel mutation affecting the SHBG-like domain. A) Silver stained CSHA gel image showing the band shift for a novel mutation identified after screening exon 10 of the patient's DNA. C) Sequencing of exon 10 revealed a ggt $\rightarrow$ tgt point mutation that changes the glycine to a cysteine (G340C) that can be clearly identified in the chromatogram. B) The G340C mutation was also identified after CSHA was performed on the patient's RNA. 


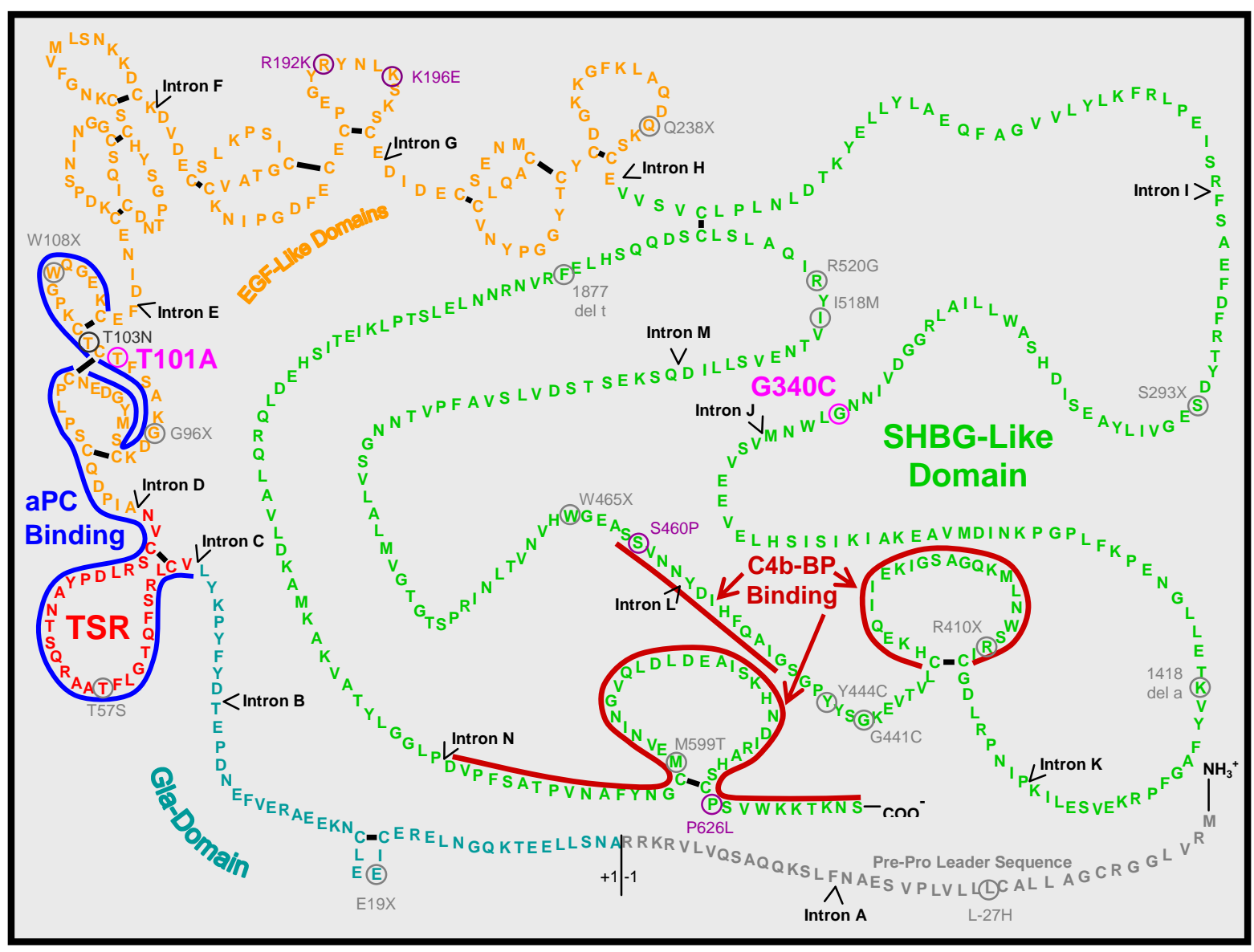

Figure 3.8 Mutations identified in the coding region of protein S. A schematic of the PS showing the location of the two novel mutations, T101A in exon 5 and G340C in exon 10 (highlighted in pink) and previously reported polymorphisms K196E, R192K, S460P and P626L that map to exon's 6, 7, 13 and 15, respectively (highlighted in purple). The previously confirmed Type II PS mutation T103N is shown two residues downstream from T101A. Highlighted in grey (and purple) are the Espinosa-Parrilla controls that were used to validate the CSHA method. Adapted from (Greenberg and Davie, 2001). 


\subsubsection{Mutations Identified in the 5' Untranslated Region}

In order to determine whether clinical observations were due to mutations found within the PROS1 promoter region, CSHA was performed on 950bp upstream from the PROS1 start codon. Three single nucleotide changes were identified in the $5^{\prime}$ untranslated region (5'UTR), one was a novel finding while the other two have been previously described. The novel variant, 175 bases upstream from the start codon, changes the guanine to an adenine (g-175a) (Figure 3.9A).

The remaining two variants have been previously reported. The nucleotide substitutions c-407t (Espinosa-Parrilla et al., 2000a) and t-397c (Espinosa-Parrilla et al., 1999), are only 10 bases apart from each other (Figure 3.9B and C) and were identified separately in two women from the Pregnancy Cohort who developed greater than normal, acquired PS deficiency while pregnant.

\subsubsection{RESULTS OF MRNA ANALYSIS}

The CSHA methodology was also used to test cDNA converted patient mRNA samples. Analysis of PS deficient patient mRNA samples identified a heterozygous splice variant. CSHA analysis alone did not identify the mutation. The splice variant was easily identifiable after electrophoresis of the PCR products on an agarose gel (Figure 3.10A). Sequencing of the PCR product resulted in a chromatogram that developed a dual signal at the exon 2-3 junction. Extraction of the wild-type signal enabled extrapolation of the mutated signal that was subsequently identified as exon 1; thus the mutant allele lacks exon 2 (Figure 3.10B).

No additional findings were identified in the remaining patient mRNA samples. However, the two novel mutations T101A and G340C were re-detected using the 
mRNA CSHA protocol (Figures 3.6C and 3.7B) suggesting that the technique is sensitive for analysis of patient mRNA. 


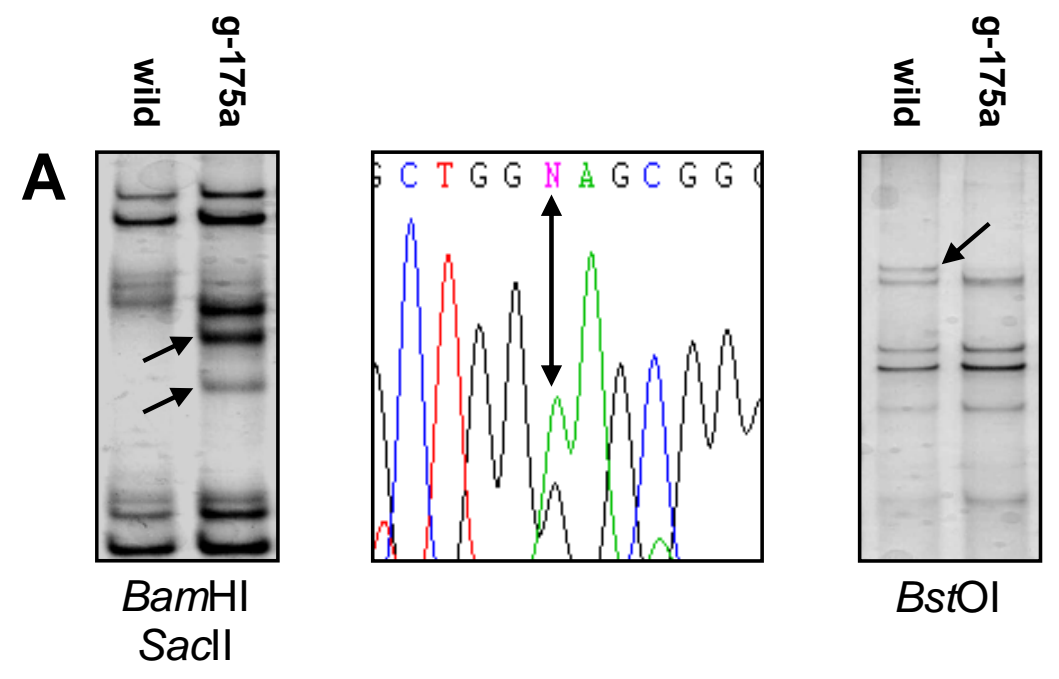

B
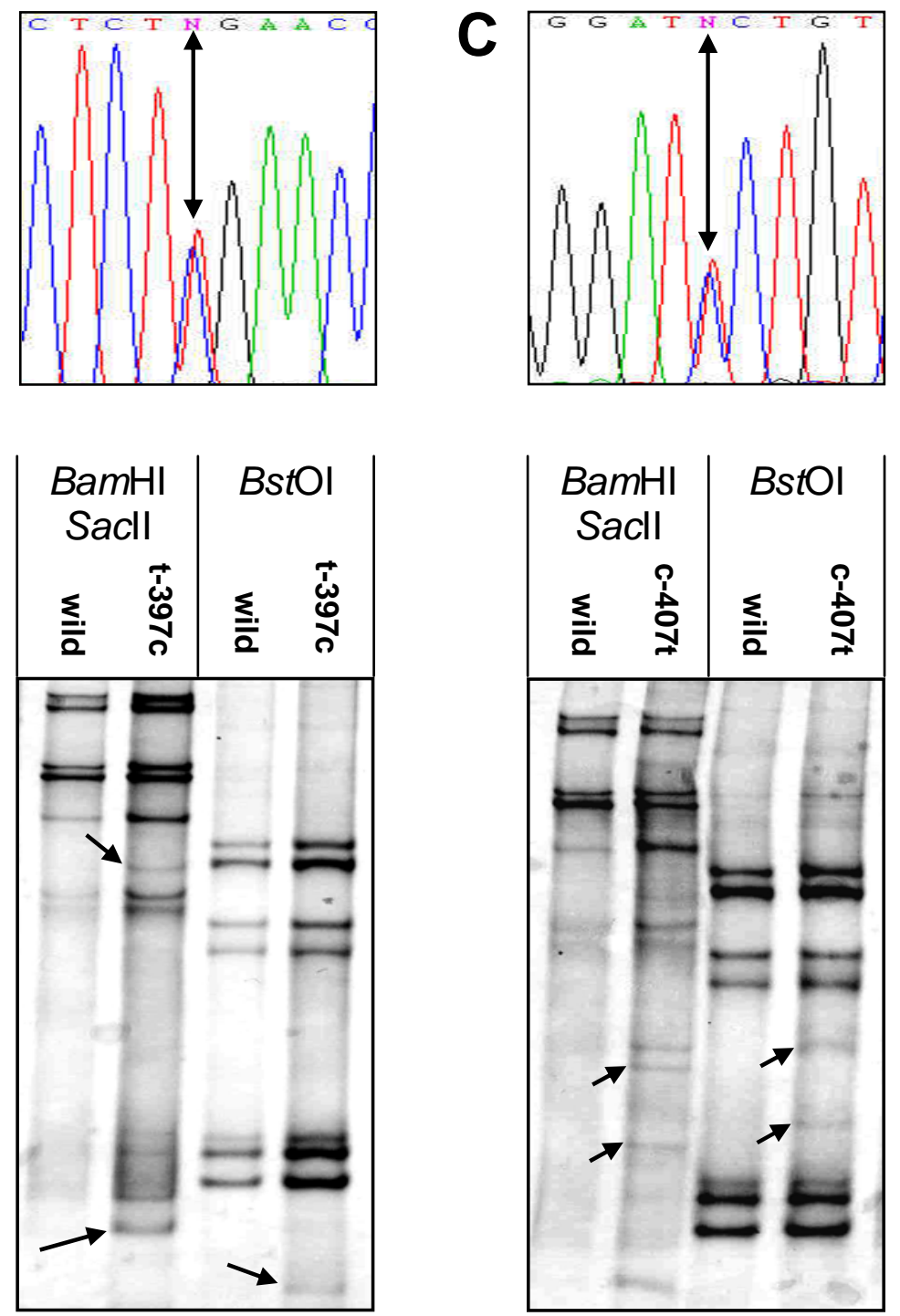

Figure 3.9 Point changes identified in the promoter region of PROS1 using CSHA. Two restriction enzyme regimes (BamHI in combination with Sacll, and BstOI) were used for CSHA of the combined PROS1 promoter and exon 1 region. (A) A novel $g \rightarrow a$ point mutation was identified 175 bases upstream from the ATG start codon; g-175a. Two previously identified variants t-397c (B) and c$407 \mathrm{t}(\mathrm{C})$ were also identified. 


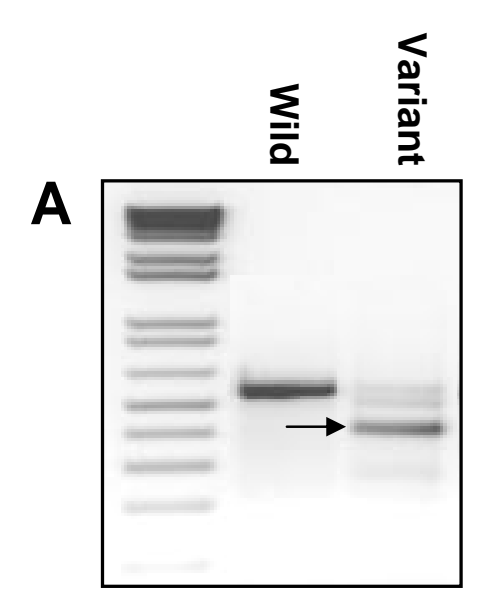

B

Exons 1 (Top line) \& 2 (bottom line)

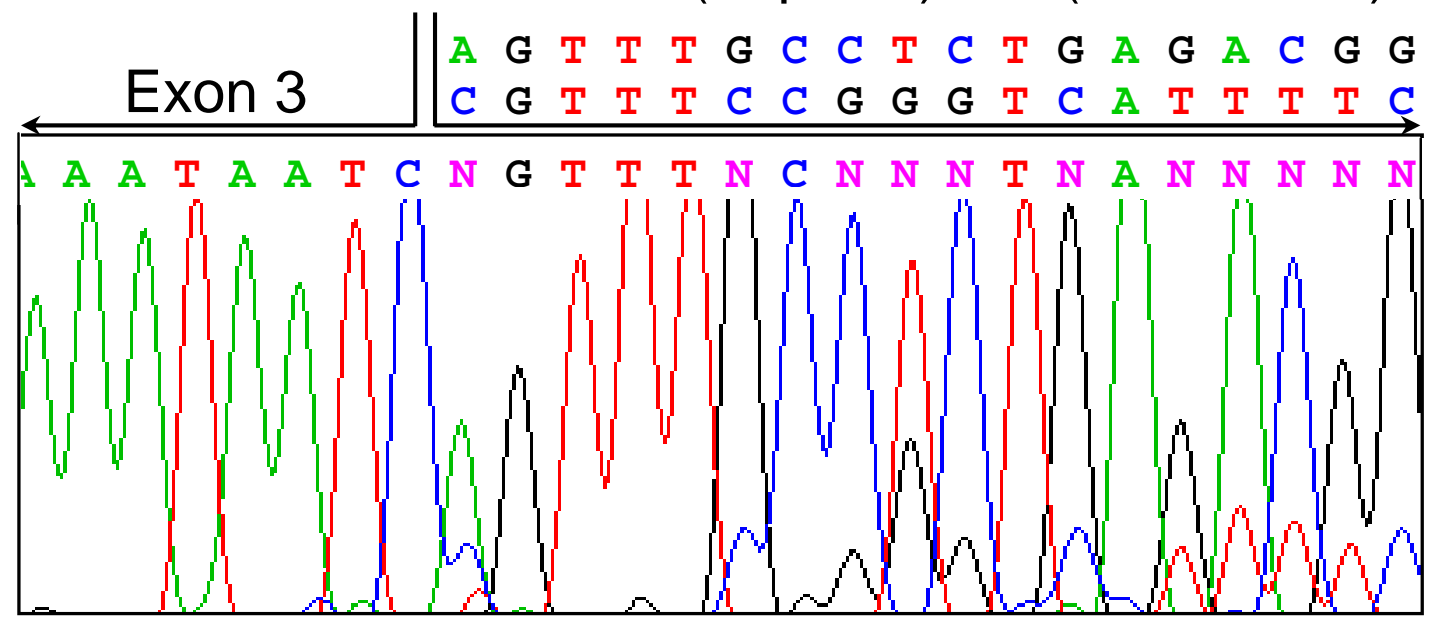

Figure 3.10 Detection of a splice variant by analysis of PROS1 mRNA. A splice abnormality was initially identified from the direct analysis of PROS1 mRNA that had been converted to CDNA, PCR amplified and electrophoresed in an agarose gel (A). The smaller product indicates the mutant allele. Sequencing revealed a dual signal initiating at the exon $2 / 3$ boundary (B). Extrapolation of both signals reveals that the mutant form lacks exon 2. 


\subsection{Discussion}

The sensitivity of DNA CSHA technique was confirmed with the successful identification of all the positive controls supplied by Dr. Espinosa-Parrilla (Figures 3.4 and 3.5). The inclusion of RNA CHSA enabled the identification of possible splice variations, such as the splice variant that results in the deletion of exon 2 (Figure 3.10), but also provided a means of 'cross-checking' a patient's DNA, increasing the power of the CSHA method. Screening of DNA using single stranded conformational analysis (SSCA) in isolation is reported to have a sensitivity of around $90 \%$ with increasing sensitivity gained from using either two or more gel matrices and/or by varying the electrophoretic conditions (Jaksch et al., 1995, Gross et al., 1999, Hayashi and Yandell, 1993, Espinosa-Parrilla et al., 2000a). The combination of SSCA with heteroduplex analysis (the CSHA method) further increases sensitivity (Espinosa-Parrilla et al., 2000a). Direct evidence of this is seen in this study with the novel T101A finding, identifiable only by a heteroduplex shift in the initial DNA CSHA and by the nonheteroduplex bands in the RNA CSHA. The size of the fragments used for CSHA greatly affects sensitivity (Hayashi and Yandell, 1993). Cutting the large fragments amplified for use in the RNA CSHA with two different restriction enzyme (RE) regimes generated fragments small enough for analysis. This approach was used for the promoter/exon1, the exons 5/6 and exon 15 fragments. Secondly, the RE's were selected to ensure that the cut sites in the first regime differed in proximity to the cut sites of the second regime. This minimised the possibility of missing any mutations localised in or around a particular cut site. Thus, by combining the RNA CSHA with the DNA CSHA one sample effectively undergoes three different analyses, increasing the overall sensitivity of the technique. The exception is the promoter region which is not assessed via RNA CSHA (however, PCR samples used for CSHA of the promoter region were 
also treated with two separate RE conditions, which increased the sensitivity for the PROS1 promoter region DNA CSHA). Using the multiple parameter approach set this CSHA study apart from that of the Espinosa-Parrilla group study in which they relied on differential gel matrices to increase the CSHA sensitivity (Espinosa-Parrilla et al., 2000a). The method used in this present study is less labour intensive as only one gel matrix is required for all the DNA and RNA screening.

The CSHA method identified 3 novel mutations located within the promoter, in exon 5 and exon 10 of the PROS1 gene, respectively. The heterozygous T101A mutation is probably a qualitative mutation, the basis of the rare Type II deficiency and is unlikely to interfere with any endocrine based mechanism. Nevertheless, it represents an important finding as only one other Type II mutation has been described in the EGF1 domain, T103N, two residues downstream from T101A. The T103N mutation has been characterised with the mutant form exhibiting approximately $50 \%$ less co-factor activity compared to the wild type (Giri et al., 2000). Similar studies will have to be completed with T101A to determine whether or not it is a functional mutation that directly interferes with aPC binding. Interestingly, the T101 residue is highly conserved across species while the T103 is only found in the human and monkey forms of PS (Table 3.1). The patient (PS2), a 34yr old female, had a history of systemic lupus erythrematosus and had suffered both a myocardial infarction and a stroke. Analysis of the patients functional PS status was not carried out due to prophylaxis with warfarin.

The second novel mutation identified in the coding region of PROS1, G340C (PS23), was also heterozygous and is located in the C-terminal SHBG-like domain of PS. As with the T101A mutation, it is unlikely to be involved in an endocrine response. Like T101 the G340 residue is highly conserved across several species (Table 3.2). Introduction of an additional cysteine could interfere with disulphide bond formation, 
important for the tertiary structure organisation of the protein (Simmonds et al., 1996)

[Figure 3.6- the cysteine residue di-sulphide bridging is a hypothetical representation.] The exact structure of PS has proved elusive due to difficulties associated with crystallising the PS molecule (Gandrille et al., 2000)]. Given the even number of cysteines within the structure of PS, it is possible that the introduction of an additional sulphur residue could disrupt the structure of the PS molecule. Similarly, di-sulphide bridges could be formed with other proteins preventing the mutated protein from being exported into the cytoplasm or causing the incorporation of a secondary protein into the structure. This has been previously suggested for the R474C mutation located in exon 13, where the addition of a cysteine creates a protein with a greater molecular weight compared to the wild-type in non-reducing conditions (Yamazaki et al., 1996).

The third novel finding was the heterozygous g-175a mutation (numbering relative to the ATG start codon) identified in the $5^{`}$ untranslated region of PROS1. The mutation was identified in a patient who experienced persistent low free PS levels which is likely to be a result of a defective transcriptional initiation process. Two studies have reported that either nucleotides $-173,-174$ or -175 form the starting point for transcription initiation of PROS1 mRNA synthesis in the liver and the human hepatoma cell line, HepG2 (Ploos van Amstel et al., 1990, Hall et al., 2006). Although multiple transcriptional start sites (TSSs) have been described for PROS1, the $-173 / 74 / 75$ transcript appears to be a highly expressed form in the liver, the principle organ for PS expression (Soria and Bertina, 1997, de Wolf et al., 2005, Hall et al., 2006). Therefore, the substitution of a guanine for an adenine may inhibit or even prevent mRNA initiation at the TSS, reducing the numbers of PROS1 mRNA transcripts and consequently, lowering levels of circulating PS. 


\begin{tabular}{|c|c|c|c|c|c|c|c|c|c|c|c|c|c|c|}
\hline \multirow{2}{*}{ Species } & \multicolumn{14}{|c|}{ Amino Acid Sequence } \\
\hline & $90 \quad 91 \quad 92$ & 93 & 94 & $95 \quad 96$ & $\begin{array}{lll}97 & 98 & 99\end{array}$ & & 01 & & 103 & & 105 & & 107108 & 109110 \\
\hline Human & Y M S & C & K & $D G$ & $\mathrm{~K} A \mathrm{~S}$ & $F$ & $T$ & C & $\mathbf{T}$ & C & $\mathrm{K}$ & $\mathrm{P}$ & G W & $\mathrm { Q } \longdiv { \mathrm { G } }$ \\
\hline Monkey & Y M S & C & $\mathrm{K}$ & $D G$ & $\mathrm{~K} A \mathrm{~S}$ & $\mathrm{~F}$ & $\mathbf{T}$ & C & $\mathbf{T}$ & C & $\mathrm{K}$ & P & G W & $\mathrm{Q} \mathrm{G}$ \\
\hline Bovine & $\mathrm{F} M \mathrm{~T}$ & C & $\mathrm{K}$ & $D G$ & Q A T & $F$ & $\mathbf{T}$ & C & I & C & $\mathrm{K}$ & S & G W & Q G \\
\hline Porcine & $\mathrm{F} M \mathrm{~T}$ & C & $\mathrm{K}$ & $D G$ & Q A M & $F$ & $\mathbf{T}$ & C & I & C & $\mathrm{K}$ & $\mathrm{S}$ & G W & $E G$ \\
\hline Rabbit & $Y L N$ & C & $\mathrm{K}$ & $D G$ & Q A T & $\mathrm{F}$ & $\mathbf{T}$ & C & I & C & $\mathrm{K}$ & $P$ & $G W$ & $\mathrm{Q} \mathrm{G}$ \\
\hline Mouse & $Y L A$ & C & Q & $D G$ & $Q A A$ & $F$ & $\mathbf{T}$ & C & $\mathrm{F}$ & $\mathrm{V}$ & $\mathrm{K}$ & $P$ & GW & $\mathrm{Q}$ G \\
\hline
\end{tabular}

Table 3.1 Threonine 101 is highly conserved across species. The threonine residue at position 101 (T101) is conserved across a variety of species, whereas T103, the location of the previously described T103N Type II mutation, is homologous only with the monkey sequence.

Amino acid numbering shown for Human PS.

\begin{tabular}{|c|c|c|c|c|c|}
\hline \multirow{2}{*}{ Species } & \multicolumn{5}{|c|}{ Amino Acid Sequence } \\
\hline & 329330331332333334 & 34335336 & 337338339 & 340 & 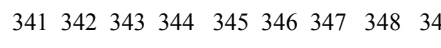 \\
\hline Human & $\begin{array}{llllll}\mathrm{K} & \mathrm{I} & \mathrm{T} & \mathrm{T} & \mathrm{G} & \mathrm{G}\end{array}$ & $\mathrm{J} \mathrm{DV}$ & I $\mathrm{N} \mathrm{N}$ & $G$ & 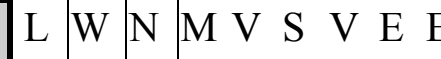 \\
\hline Monkey & $\begin{array}{llllll}K & \mathrm{I} & \mathrm{T} & \mathrm{T} & \mathrm{G} & \mathrm{G}\end{array}$ & J $\mathrm{D} \quad \mathrm{I}$ & I $\mathrm{N} \mathrm{N}$ & G & 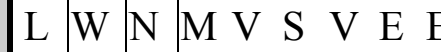 \\
\hline Bovine & \begin{tabular}{ll|llll}
$\mathrm{K}$ & $\mathrm{M}$ & $\mathrm{T}$ & $\mathrm{T}$ & $\mathrm{G}$ & $\mathrm{G}$
\end{tabular} & $\mathrm{J} \mathrm{K} \mathrm{V}$ & I $\mathrm{N} \mathrm{D}$ & G & 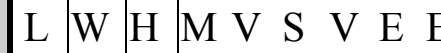 \\
\hline Porcine & $\begin{array}{llllll}\mathrm{K} & \mathrm{I} & \mathrm{T} & \mathrm{T} & \mathrm{G} & \mathrm{G}\end{array}$ & $\mathrm{J} / \mathrm{R} \mathrm{V}$ & I $\quad \mathrm{N} \quad \mathrm{D}$ & G & 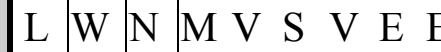 \\
\hline Rabbit & \begin{tabular}{ll|llll}
$\mathrm{Q}$ & $\mathrm{I}$ & $\mathrm{T}$ & $\mathrm{T}$ & $\mathrm{G}$ & $\mathrm{G}$
\end{tabular} & $\mathrm{J}$ Q V & I $\mathrm{N} \mathrm{D}$ & G & 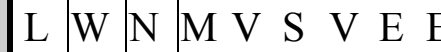 \\
\hline Mouse & \begin{tabular}{ll|llll}
$Q$ & $\mathrm{I}$ & $\mathrm{T}$ & $\mathrm{T}$ & $\mathrm{G}$ & $\mathrm{G}$
\end{tabular} & $\mathrm{J}$ V & I $\mathrm{N} \mathrm{N}$ & $G$ & 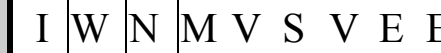 \\
\hline
\end{tabular}

Table 3.2 Glycine $\mathbf{3 4 0}$ is highly conserved across species. The glycine residue at position 340 (G340) is conserved across a variety of species. The G340C mutation introduces an additional cysteine that may affect protein structure or cause cross binding with secondary proteins.

Amino acid numbering shown for Human PS. 
The region surrounding position -175 is also very GC-rich and has recently been characterised as a strong cis-acting element that binds the ubiquitous $\mathrm{Sp} 1$ transcription factor (de Wolf et al., 2006a). As detailed in Section 1.9, Sp1 can form the basis of a hormonal response mechanism via interaction with ligand bound $\mathrm{ER} \alpha$ and has also been shown to exert similar transcriptional control via interaction with PR (Owen et al., 1998, Safe, 2001, Safe and Kim, 2004).

Analysis of PS deficient patient mRNA not only confirmed the T101A and G340C mutations, it also re-detected the common PROS1 polymorphism S460P (Heerlen mutation). The frequency of the Heerlen mutation in the PS deficient cohort (frequency $=0.167)$ was similar to previous reports that examined PS deficient patients who had suffered a venous thrombotic event (Espinosa-Parrilla et al., 2000a, Borgel et al., 1996). The low prevalence of the Heerlen mutation in the pregnancy cohort (frequency $=0.007)$ correlates with previously published data that has examined the frequency of the Heerlen mutation in the general population (Duchemin et al., 1995) and is not surprising given that the pregnancy cohort was not associated with a thrombotic predisposition.

The other advantage of the mRNA analysis was that it facilitated the identification of splice variants such as the apparent exon 2 splice mutation identified in a patient with severe PS deficiency (Figure 3.10). The truncated splice variant needs to be isolated and expressed to confirm that it is the cause of the PS deficiency. Exon 2 encodes the GlaDomain required for binding of PS to phospholipid surfaces such as the surface of platelets. Therefore, this mutation could be classified as causative for a Type II 
deficiency. The patient was receiving warfarin therapy so no functional data was available for PS.

The disadvantage of the DNA/RNA CSHA system is that it fails to detect large heterozygous deletions of the PROS1 gene, whether partial or whole gene deletions, as amplification of the PCR, from DNA or cDNA only requires one complete allele to generate a product. A 2005 study (Johansson et al., 2005) used single nucleotide polymorphisms (SNPs) and microsatellite markers to screen for large heterozygous deletions of the PROS1 in a cohort of PS deficient families. They identified large scale deletions as the causal factor in $18 \%$ of PS deficient families recruited into their study that would have otherwise been unidentified. At the time of writing this thesis, a third detection tier has been added to the DNA/RNA CSHA methodology, multiplex ligationdependent probe amplification (MLPA; http://www.mrcholland.com/pages/indexpag.html; accessed October 2007). Briefly, MLPA analysis uses sets of adjacent probes that are ligated together to prime a standard fluorescently labelled PCR product. Each probe set generates a unique sized fragment due to 'stuffer' sequences that are incorporated into the probe design. Fluorescence intensity is compared with known controls to distinguish allele frequency. 


\begin{tabular}{|c|c|c|}
\hline \multicolumn{3}{|c|}{ PS Deficient Cohort } \\
\hline Sample ID & Mutation & $\begin{array}{r}\text { Patient History } \\
\end{array}$ \\
\hline N41 (Control) & None Detected & Control \\
\hline PS1 & None Detected & Fluctuating PS levels Thrombosis in Pregnancy \\
\hline PS2 & T101A^ & SLE, MI cerebral infarction \\
\hline PS3 & R192K $^{\#}$ & Severe pre-eclampsia \\
\hline PS4 & None Detected & $\mathrm{PE}$ \\
\hline PS5 & None Detected & Pre-eclampsia \\
\hline PS6 & None Detected & Fluctuating PS level \\
\hline PS7 & None Detected & DVT, Family history PS def. \\
\hline PS8 & None Detected & Recurrent DVT during pregnancy \\
\hline PS9 & -68 to -70 del att ${ }^{\wedge}$ & Fluctuating PS level \\
\hline PS10 & None Detected & Fluctuating PS level \\
\hline PS11 & None Detected & Recurrent pregnancy loss \\
\hline PS12 & None Detected & Daughter of PS13 \\
\hline PS13 & $\mathrm{g}-175 \mathrm{a}^{\wedge}$ & Post Partum PE \\
\hline PS14 & None Detected & $\mathrm{PE}$ \\
\hline PS15 & None Detected & History of Thrombosis \\
\hline PS16 & $\mathrm{S} 460 \mathrm{P}^{\dagger}$ (Heerlen) & History of thrombosis, DVT \\
\hline PS17 & None Detected & Recurrent DVT \\
\hline PS18 & None Detected & Family history of DVT \\
\hline PS19 & $\mathrm{S}^{2} 60 \mathrm{P}^{\dagger}$ (Heerlen) & PS deficiency, spontaneous miscarriages \\
\hline PS20 & None Detected & Persistent DVT in calf \\
\hline PS21 & 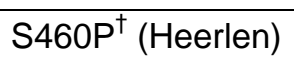 & Fluctuating PS level \\
\hline PS22 & $\mathrm{S} 460 \mathrm{P}^{\dagger}$ (Heerlen) & PS deficiency \\
\hline PS23 & G340C^ & Family history of PS deficiency, DVTx2, MI \\
\hline PS24 & None Detected & History of Thrombosis \\
\hline \multicolumn{3}{|c|}{ Pregnancy Cohort } \\
\hline Sample ID & Mutation & \\
\hline Pre326 & $c-407 t^{\forall}$ & Greater than normal reduction in PS while pregnant \\
\hline Pre390 & $t-397 c^{\exists}$ & Greater than normal reduction in PS while pregnant \\
\hline GD416 & $\mathrm{S} 460 \mathrm{P}^{\dagger}$ (Heerlen) & Gestational Diabetes \\
\hline
\end{tabular}

Table 3.3- Mutations detected within the two cohorts studied- Note- the Pregnancy Cohort has been abridged to show only those patients where mutations were identified. Four novel mutations (denoted ${ }^{\wedge}$ ) were identified in the PS Deficient Cohort; $9-175 a$ a nucleotide substitution located in the 5 UTR; T101A a missense mutation that maps to exon 5; G340C a missense mutation that maps to exon 10; and -68 to -70 del att and 3 base deletion mapping to Intron A. Previously reported mutations R192K (Gandrille et al. 1997), PS3; S460P (Heerlen; Bertina et al. 1990), PS16, PS19, PS21, PS22 and GD416; and two point mutations identified in the 5 'UTR, c-407t (Espinosa-Parrilla et al. 2000) and t-397c (Espinosa-Parrilla et al. 1999) that were identified in the Pregnancy Cohort. 
While regions of the PROS1 coding region and 5 promoter were screened using CSHA, the 3 'untranslated ( 3 '-UTR) region of the PROS1 gene was not included in the screening process. Hormonal control of mRNAs via enhancement or protection of nuclease targeted degradation of the $3^{\prime} \mathrm{UTR}$ has been demonstrated for several genes and may well be occurring in PROS1 (Staton and Leedman, 1998, Staton et al., 2000, Balmer et al., 2001). However, the promoter is often a key region for hormone based regulation and the three variants detected using the CSHA method can be further investigated to ascertain if they form part of some hormone responsive regions. Particularly the $\mathrm{t}-397 \mathrm{c}$ and $\mathrm{c}-407 \mathrm{t}$ variants which are further examined in the following chapter. 


\section{CHAPTER 4}

\section{Analysis of the PROS1 Promoter}




\subsection{INTRODUCTION}

As detailed in Chapter 1, acquired PS deficiency has been reported in individuals with raised oestrogen levels, arising during pregnancy or in individuals using combined oral contraceptives (COCs), particularly the 3rd generation forms (Comp et al., 1986, Malm et al., 1988, Oruc et al., 2000, Tans et al., 2000, Mackie et al., 2001, Kemmeren et al., 2004, Uchikova and Ledjev, 2005). The fall in PS levels may be one reason why users of 3rd generation COCs have a 6 to 9 times greater risk of developing VTE compared to non-users and approximately double the risk associated with users of 2 nd generation COCs (Middeldorp, 2005). The prothrombotic shift results from upregulation of several key components of the procoagulant and fibrinolytic systems in combination with a down-regulation of the anticoagulation system, in particular reduced PS levels and increased aPC resistance. Previous investigations into the molecular mechanisms influencing these changes have focused on promoter regions of genes of the procoagulant and fibrinolytic systems (Farsetti et al., 1995, Brady et al., 1998, Heit et al., 1999a, Farsetti et al., 2001, Smith et al., 2004). The work discussed in this Chapter represents the first attempt to study hormonal regulation of the PROS1 promoter that governs the production of PS.

Regulation of gene expression by transcriptional factors operating via interaction with the promoter regions of genes is well reported [Reviewed by Metivier et al. (2006)]. As discussed in Chapter 1, the hormone receptor class of transcriptional factors are highly active in regulating gene expression via direct and indirect interaction with specific motifs located in the promoter regions of a vast array of genes. A haemostatic example is the gene that encodes FIX (F9). Experimental work performed in the 1990s identified an androgen response element (ARE) in the promoter of the F9 gene following investigation of a form of Haemophilia B known as Haemophilia B Leyden (Morgan et 
al., 1997, Brady et al., 1998, Heit et al., 1999a). FIX levels of patients with the Leyden form of Haemophilia B are low prior to the onset of puberty, but increase to within, or close to, normal ranges by the end of puberty. A subclassification form of Haemophilia B Leyden, Haemophilia B Brandenberg, fails to respond during puberty and was found to be due to a missense mutation within the ARE motif that disrupted the binding of the androgen receptor.

The FIX ARE mechanism is an example of a cis-element acting to increase promoter activity. As PS production is decreased in response to $E_{2}$ the primary focus in this study is to identify an element that suppresses, rather than increases, promoter activity. An initial screen of the PROS1 promoter sequence using an online software program (Dragon ERE Finder; http://sdmc.lit.org.sg/ERE-V2/index; accessed 1st November 2005) identified a potential oestrogen response element (ERE); positions -526 to -538 relative to the ATG start codon, that could act as a repressor. The majority of previously described EREs generate an increase in promoter output in response to $\mathrm{E}_{2}$, but there are several reports of EREs that have inhibitory functions (Online databasehttp://defiant.i2r.a-star.edu.sg/projects/Ergdb-v2/index.htm; accessed 1st November 2005) particularly when in conjunction with other transcriptional factors such as Sp1 (Stossi et al., 2006).

However, the identification of the previously described variants $t-397 \mathrm{c}$ and $\mathrm{c}-407 \mathrm{t}$ using the CSHA method detailed in Chapter 3 suggests the possibility of a secondary cis-element that acts to increase activity of the PROS1 promoter (Stossi et al., 2006, Espinosa-Parrilla et al., 1999, Espinosa-Parrilla et al., 2000a). This hypothesis will be discussed later in this Chapter. 
To assess the potential transcriptional properties of the PROS1 promoter, the pPMTR vector was created that contained the first $950 \mathrm{bp}$ of the promoter region fused to an enhanced green fluorescent protein (EGFP) reporter gene. The vector also contains an additional reporter gene DsRed2, constitutively expressed by a cytomegalovirus promoter (CMV). This chimera was included to produce a baseline signal against which the change in expression of the EGFP signal could be normalised to. Subsequent modifications and deletions of the PROS1 sequence within the pPMTR vector were performed to analyse particularly structural domains. 


\subsection{RESULTS}

\subsubsection{ER $\alpha$ DOWNREGULATES THE PROS1 PROMOTER BUT NOT VIA THE ERE CONSENSUS SEQUENCE}

A potential ERE motif spanning nucleotides -526 to -538 was identified in the PROS1 promoter. The sequence (5’ gatcaaaatgacc $\left.3^{\prime}\right)$ differs from the 'classical ERE' motif- 5' ggtcannntgacc $3^{`}$ only at the second position. To determine whether the presence of this motif was required for oestrogen sensitivity, we constructed three plasmids. One containing the wildtype promoter (pPMTR), a second containing the same promoter but lacking the ERE sequence (pPMTR(-ERE)) and a third with a large deletion that lacked the $3^{\prime}$ terminal sequence of the ERE plus an additional 111 downstream bases (pPMTR(BclI/AvrII-del). All three were used in transient transfection experiments (See Figure 4.1 for details).

Breast carcinoma MCF-7 cells were cotransfected with $2 \mu \mathrm{g}$ pPMTR and 100ng pER $\alpha$ and the activity of the PROS1 promoter measured. In the presence of excess ER $\alpha$ transcriptional activity of the PROS1 promoter was downregulated by $20 \%(p=0.002)$. This downregulation was extended to $35 \%$ with the addition of $10 \mathrm{nM} \mathrm{E}_{2}(p=0.001)$ (Figure 4.2A). When the cotransfection experiments were repeated using pPMTR(ERE) in place of pPMTR, the presence of excess ER $\alpha$ again resulted in a $20 \%$ downregulation of PROS1 promoter activity $(p=0.01)$, which further diminished to $40 \%$ with the addition of $10 \mathrm{nM} \mathrm{E}_{2}(p=0.01)$ (Figure 4.3A). Cotransfection experiments using the larger deletion plasmid pPMTR(BclI/AvrII-del) yielded similar results with a $19 \%$ $(p=\mathrm{n} / \mathrm{s})$ downregulation in the presence of excess ER $\alpha$ that decreased to $41 \%$ with the addition of $10 \mathrm{nM} \mathrm{E}_{2}(p=0.002)$ (Figure 4.3D). 
Interestingly, the cotransfection of pPMTR(-407), which contains the c-407t PROS1 variant, with the $p E R \alpha$ vector resulted in a $35 \%$ decrease in PROS1 activity $(p=0.002)$ which further reduced to $50 \%$ with the addition of $10 \mathrm{nM} \mathrm{E}_{2}(p=0.004)$. Both responses were significantly different compared to the wildtype vector pPMTR $(p=0.01$ and $p=0.01$, respectively) (Figure 4.3B). A similar result was evident for the pPMTR(AvrII/DraIII-del) vector, with the addition of the pER $\alpha$ vector decreasing activity by $36 \%(p=0.02)$ which further reduced to $47 \%$ with the addition of $10 \mathrm{nM} \mathrm{E} 2$ ( $p=0.004)$. However, only the comparison of the wildtype $\mathrm{pER} \alpha+10 \mathrm{nM} \mathrm{E}_{2}$ with the deletion $\mathrm{pER} \alpha+10 \mathrm{nM} \mathrm{E}_{2}$ was significant $(p=0.01)$ (Figure 4.3C).

The $E_{2}$ and $E R \alpha$ responses were significantly more pronounced when transfections were performed in the liver carcinoma cell line HuH-7. Cotransfection with $2 \mu \mathrm{g}$ pPMTR, 100ng ER $\alpha$ plus $10 \mathrm{nM} \mathrm{E}_{2}$ (as used in the MCF-7 cell line) suppressed PROS1 activity to levels below detectable limits. Maintaining pPMTR at $2 \mu \mathrm{g}$ but reducing the ER $\alpha$ vector to $20 \mathrm{ng}$ and $\mathrm{E}_{2}$ to $1 \mathrm{nM}$ reduced the activity of the promoter by $46 \%$ compared with no treatment $(p=0.002)$ (Figure $4.2 \mathrm{~B})$, suggesting that the oestrogen response was much greater in the liver cell line. 
cacgatcaggagttcagaaccagcctggccaacatggtgaaaccctgtctctactaaaaata caaaaaactagccaggcatggtggcaggcgcctgtaatcccacctactcaggaggctgaga caggagaatcacttgaacccgggaggtggaggttgcagtgagccgaaattgcgccactgt tc tccagcctgggcgacagagtgagactctgtctcaaaaaaaaaaaaaaaattttttaaatt aataaataggtagatgtatagatagatattcactttcaactgaagtctttatcggagcaaga tttttttaaggtagattattctaatattcccttctttcttcatgttctttacattattt tatgcctgtatggcatacaagaccgaaaaacatgtggatgatcaaatgaccccatttgct K Bc/I $\rangle$

tttactatcaccatagttcttcctaaagtcctcattgacttccaggtttggttaatatctt cagggacaactcagtgtctcactgtttctgcttctgaacctagggatcctgtcctcttgaac

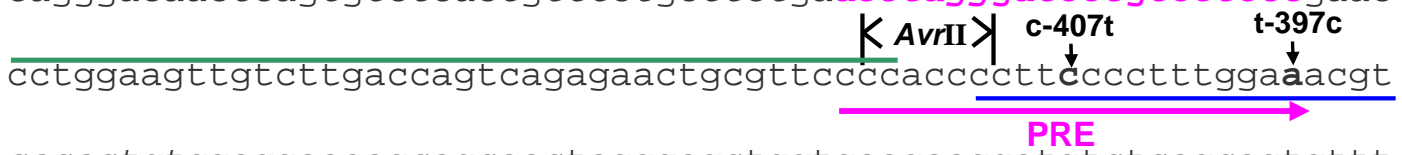
cacactgtggaggaaaagcagcaactagggagctggtgaagaaggatge ${ }^{\text {PE }}$ ctcagcagtgtt K DraIII $>$ actaggccttcaacactagagcccatcccccagctccgaaaagcttcctggaaatgtccttg

ttatcacttcccetctcgggctgggcgctgggagcgggcggtctcctccgccccoggctgtt

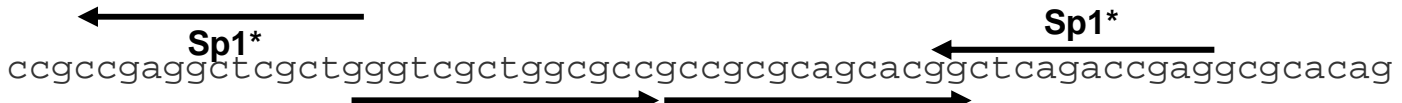

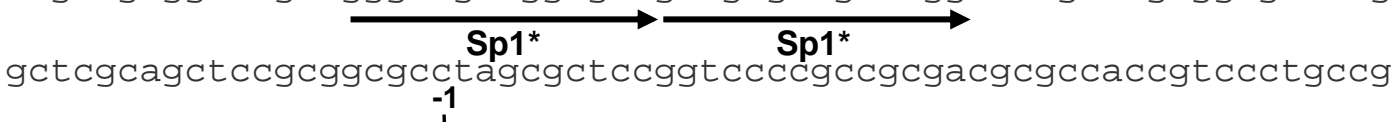
gcgcctccgcgcgettcgaà $\rightarrow$ Translational start

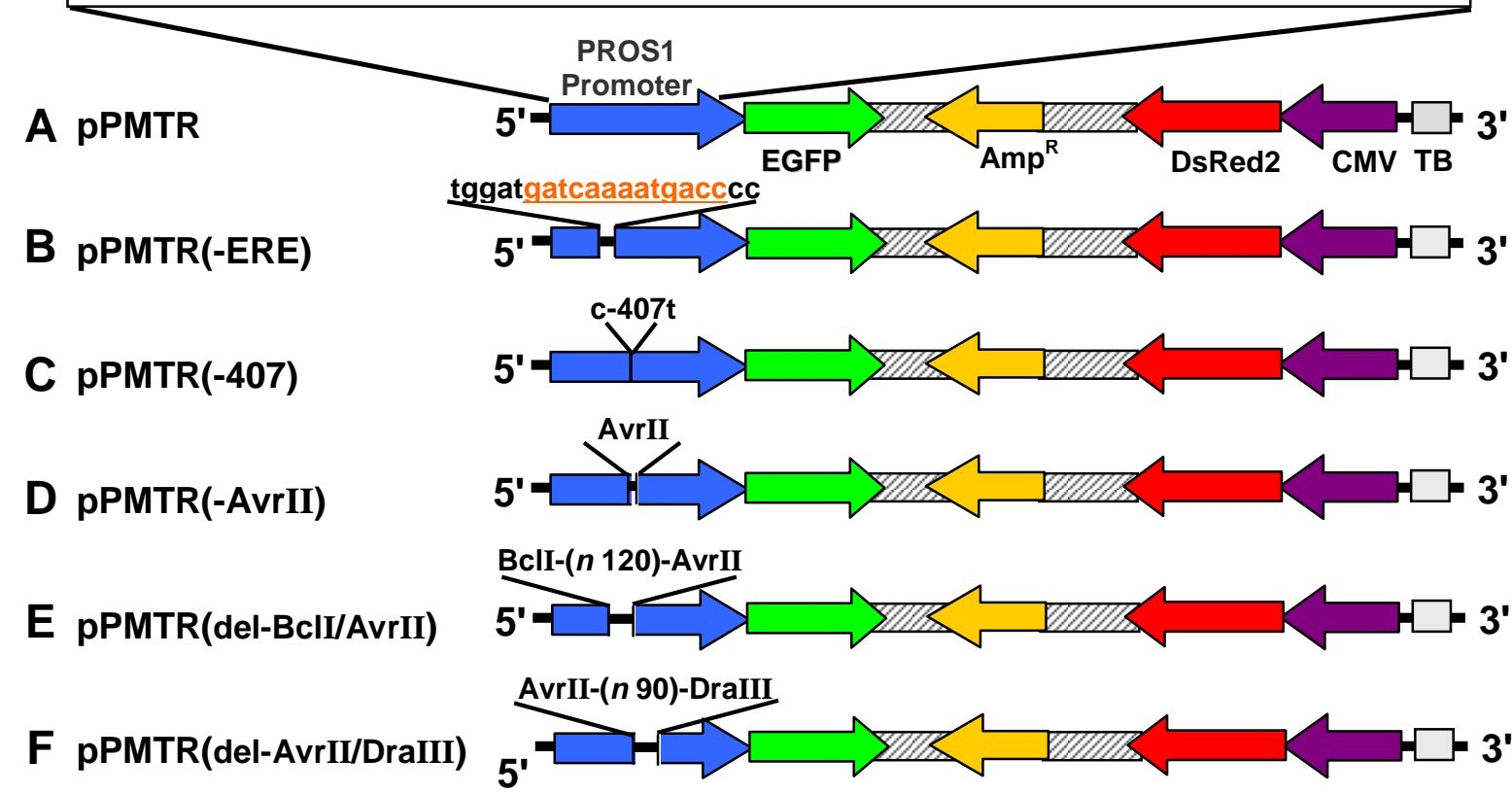

Figure 4.1 Schematics of the six vectors used for the transient transfection procedures. The blow up details the 950bp sequence from the PROS1 promoter. Two point mutations, c-407t and t-397c, are shown flanking the PRE half site. Also shown is the putative ERE identified using the Dragon ERE Finder online software and Sp1 binding sites postulated by de Wolf et al. (2006). (A) pPMTR vector, 950bp wild type PROS1 fragment that includes the putative ERE and proposed PRE motifs; (B) pPMTR-ERE vector, 950bp PROS1 fragment without ERE (underlined); (C) pPMTR(-407) vector, 950bp PROS1 fragment with c-407t mutation introduced; (D) pPMTR(-AvrII), 950bp PROS1 fragment without AvrII sequence; (E) pPMTR(del-BclI/AvrII), 950bp PROS1 fragment without intervening 120bp sequence between the Bc/I and AvrII cut sites (blue line); (F) pPMTR(del-AvrII/DraIII), 950bp PROS1 fragment without intervening 120bp sequence between the AvrII and DraIII cut sites (orange line)

ERE, oestrogen response element; PRE, progesterone response element; EGFP, enhanced green fluorescence protein coding sequence; $A m p^{R}$, ampicillin resistance coding sequence; DsRed2, coding sequence for red coral fluorescence protein (DsRed2); CMV, cyclomegalovirus promoter; TB, trancriptional blocker. 


\section{MCF-7}

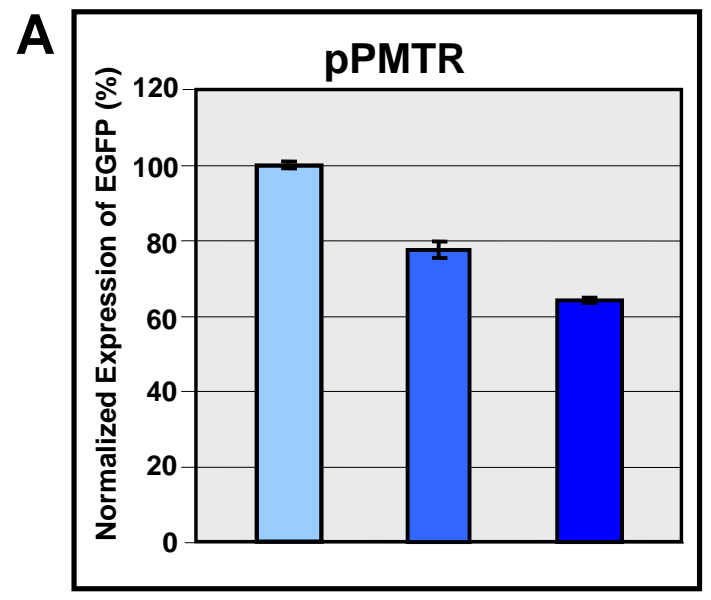

pPMTR MCF-7 Statistical Analysis

\begin{tabular}{|c|c|c|}
\hline pPMTR & pPMTR & $\begin{array}{c}\boldsymbol{p}- \\
\text { value }\end{array}$ \\
\hline Vehicle & Vehicle + 20ng pER $\alpha$ & 0.002 \\
\hline Vehicle & $1 \mathrm{nM} \mathrm{E}_{2}+20 \mathrm{ng} \mathrm{pER} \alpha$ & 0.001 \\
\hline +20ng pER $\alpha$ & $1 \mathrm{nM} \mathrm{E}_{2}+20 \mathrm{ng} \mathrm{pER} \alpha$ & 0.01 \\
\hline
\end{tabular}

Vehicle

$+100 \mathrm{ng} \mathrm{pER} \alpha$

10nM $E_{2}+100 n g$ pER $\alpha$

\section{HuH-7}

B

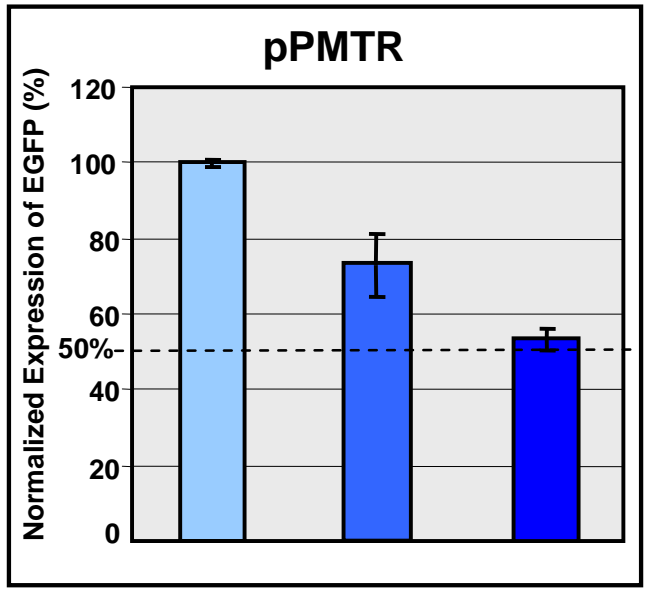

pPMTR HuH-7 Statistical Analysis

\begin{tabular}{|c|c|c|}
\hline pPMTR & pPMTR & $\begin{array}{c}\boldsymbol{p}- \\
\text { value }\end{array}$ \\
\hline Vehicle & Vehicle $+p E R \alpha$ & 0.002 \\
\hline Vehicle & $10 \mathrm{nM} \mathrm{E}_{2}+\mathrm{pER} \alpha$ & 0.001 \\
\hline$+\mathrm{pER} \alpha$ & $10 \mathrm{nM} \mathrm{E}_{2}+\mathrm{pER} \alpha$ & 0.01 \\
\hline
\end{tabular}

Vehicle

$+20 \mathrm{ng} \mathrm{pER} \alpha$

1nM $E_{2}+20 n g p E R \alpha$

Figure 4.2 PROS1 promoter is downregulated by oestrogen MCF-7 cells were transfected with (A) pPMTR with either no treatment (Vehicle), 100ng of $p E R \alpha$ vector, or 100ng pER $\alpha$ plus $10 \mathrm{nM} \mathrm{E}_{2}$. (B) Huh-7 cells were transfected with pPMTR with either no treatment, 20ng of $\mathrm{pER} \alpha$ vector, or 20ng $\mathrm{pER} \alpha$ plus $1 \mathrm{nM} \mathrm{E}_{2}$. In all experiments activity of the PROS1 promoter was measured as a percentage of EGFP expression normalized against constitutive DsRed2 expression over a 24h period. 
A

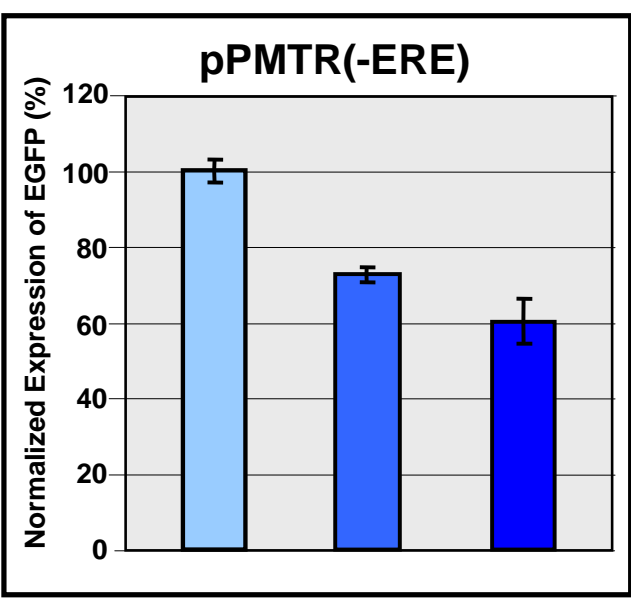

pPMTR(-ERE) Statistical Analysis

\begin{tabular}{|c|c|c|}
\hline pPMTR & pPMTR(-ERE) & $\begin{array}{c}\boldsymbol{p} \text { - } \\
\text { value }\end{array}$ \\
\hline Vehicle $+\mathrm{pER} \alpha$ & Vehicle $+\mathrm{pER} \alpha$ & $\mathrm{n} / \mathrm{s}$ \\
\hline $10 \mathrm{nM} \mathrm{E} \mathrm{E}_{2}+\mathrm{pER} \alpha$ & $10 \mathrm{nM} \mathrm{E} \mathrm{E}_{2}+\mathrm{pER} \alpha$ & $\mathrm{n} / \mathrm{s}$ \\
\hline
\end{tabular}

B

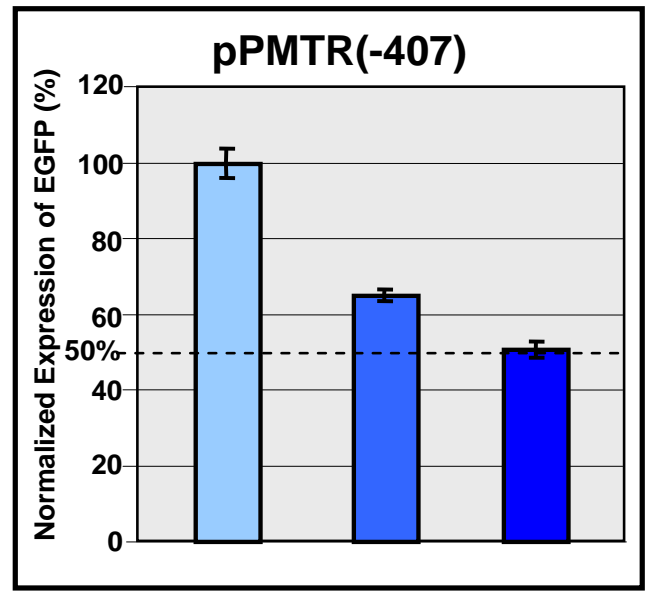

pPMTR(-407) Statistical Analysis

\begin{tabular}{|c|c|c|}
\hline pPMTR & pPMTR(-407) & $\begin{array}{c}\boldsymbol{p} \text { - } \\
\text { value }\end{array}$ \\
\hline Vehicle $+p E R \alpha$ & Vehicle $+p E R \alpha$ & 0.01 \\
\hline $10 n M E_{2}+p E R \alpha$ & $10 n M E_{2}+p E R \alpha$ & 0.01 \\
\hline
\end{tabular}

C

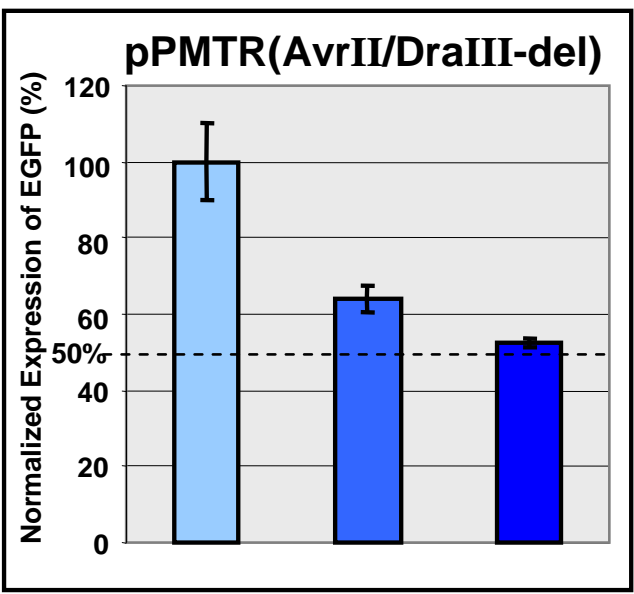

pPMTR(AvrII/DraIII -del) Statistical Analysis

\begin{tabular}{|c|c|c|}
\hline pPMTR & $\begin{array}{c}\text { PPMTR(AvrII/ } \\
\text { DraIII-del) }\end{array}$ & $\begin{array}{c}\boldsymbol{p}- \\
\text { value }\end{array}$ \\
\hline Vehicle $+\mathrm{pER} \alpha$ & Vehicle $+\mathrm{pER} \alpha$ & $\mathrm{n} / \mathrm{s}$ \\
\hline $10 \mathrm{nM} \mathrm{E} \mathrm{E}_{2}+\mathrm{pER} \alpha$ & $10 \mathrm{nM} \mathrm{E} \mathrm{E}_{2}+\mathrm{pER} \alpha$ & 0.01 \\
\hline
\end{tabular}

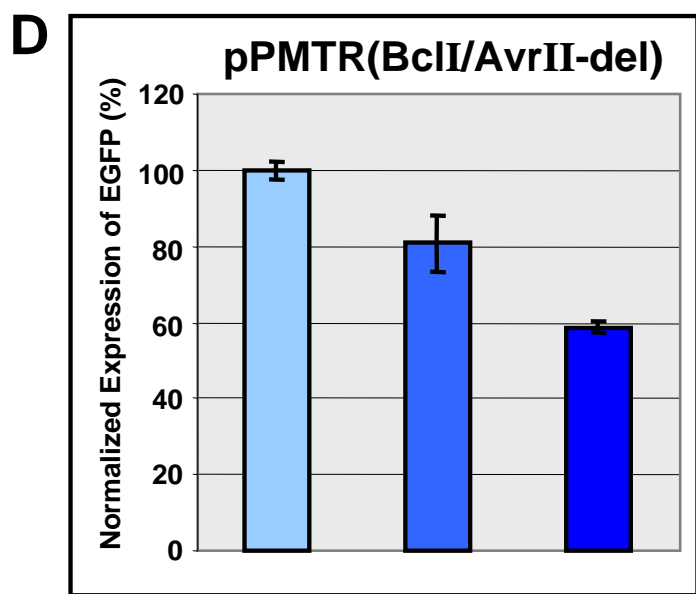

pPMTR(BclI/AvrII-del) Statistical Analysis

\begin{tabular}{|c|c|c|}
\hline pPMTR & $\begin{array}{c}\text { pPMTR(BclIl } \\
\text { AvrII-del) }\end{array}$ & $\begin{array}{c}\boldsymbol{p}- \\
\text { value }\end{array}$ \\
\hline Vehicle $+\mathrm{pER} \alpha$ & Vehicle $+\mathrm{pER} \alpha$ & $\mathrm{n} / \mathrm{s}$ \\
\hline $10 \mathrm{nM} \mathrm{E}_{2}+\mathrm{pER} \alpha$ & $10 \mathrm{nM} \mathrm{E}_{2}+\mathrm{pER} \alpha$ & $\mathrm{n} / \mathrm{s}$ \\
\hline
\end{tabular}

Figure 4.3 Manipulation of the PROS1 promoter alters oestrogen response. MCF-7 cells were transfected with (A) pPMTR(-ERE), (B) pPMTR(-407), (C) pPMTR(BclI/AvrII-del) and (D) pPMTR(AvrII/DraIII-del) with either no treatment (Vehicle) $\square$, 100ng of pER $\alpha$ vector $\square$, or 100ng pER $\alpha$ plus $10 \mathrm{nM} \mathrm{E}_{2} \square$. In all experiments activity of the PROS1 promoter was measured as a percentage of EGFP expression normalized against constitutive DsRed2 expression over a $24 \mathrm{~h}$ period. 


\subsubsection{Progesterone UPREgUlates PROS1 PROMOTER ACTIVITY}

The wildtype pPMTR vector was used to test the effect of the progestin component of the COC pill on PROS1 transcriptional activity. MCF-7 cells were transiently transfected with pPMTR and incubated in the presence of $20 \mathrm{nM}$ progesterone $\left(\mathrm{P}_{4}\right)$. Expression of the EGFP reporter gene was measured and analysis indicated the presence of $\mathrm{P}_{4}$ upregulated the PROS1 promoter activity by $25 \%(p=0.0003)$. When this experiment was repeated in the presence of the progesterone receptor modulator, RU486, the effect was abolished (Figure 4.4A). This finding suggested that the mechanism driving the upregulation involved a progesterone receptor (PR). As there are two PR isoforms, PR-A and PR-B, the aim was to confirm that the pPR-B isoform was the only form involved in the response. MCF-7 cells were cotransfected with $2 \mu \mathrm{g}$ pPMTR, 100ng PR isoform plus or minus 20nM $\mathrm{P}_{4}$. The PR-B isoform increased transcription of the PROS1 promoter $(p=0.004)$ while the PR-A isoform did not exhibit any significant change (Figure 4.4B).

Analysis of the EGFP reporter gene expression using the MCF-7 cell line, indicated PROS1 promoter activity increased by $35 \%$ when cotransfected with 100 ng of the pPRB expression vector in the presence of $20 \mathrm{nM} \mathrm{P}_{4}(p=0.01)$ (Figure 4.5A). The effect of progesterone and PR-B on PROS1 transcriptional activity were also measured in $\mathrm{HuH}-7$ cells using the same parameters. In the liver cell line upregulation of PROS1 promoter activity was weaker; $17 \%$ in the presence of $20 \mathrm{nM} \mathrm{P}_{4}(\mathrm{p}=0.008)$, increasing to $25 \%$ when cotransfected with 100ng of pPR-B $(p=0.04)$ (Figure 4.5B). 


\subsubsection{IDENTIFICATION OF THE PR BINDING DOMAIN WITHIN THE PROS1 PROMOTER}

The $\mathrm{t}-397 \mathrm{c}$ and c-407t PS variants were detected using the CSHA method as discussed in Chapter 3. It was hypothesized that these variants may interfere with PR-B binding. To test this hypothesis, MCF-7 cells were transiently transfected with either the wild type pPMTR or pPMTR(-407) vectors. Initial results indicated the c-407t mutant exhibited an impaired ability to respond to increased $\mathrm{P}_{4}$. These experiments were repeated with the addition of $100 \mathrm{ng} \mathrm{pPR}-\mathrm{B}$ in the presence or absence of $20 \mathrm{nM} \mathrm{P} \mathrm{P}_{4}$ The promoter activity of pPMTR(-407) did not significantly increase when 100ng pPR-B was added ( $2 \%-407$ variant vs $17 \%$ wild type; $p=0.01)$. The addition of $20 \mathrm{nM} \mathrm{P}_{4}$ to the cotransfection recovered some of the promoter responsiveness, but it was still significantly less than that of the wild type (17\% -407 variant vs $35 \%$ wild type; $p=0.001$ ) (Figure 4.6). Analysis of the pPMTR(AvrII/DraIII-del) that lacks most of the proposed PRE (including nucleotides -397 and -407), demonstrated a similar response. There was no increased activity with the pPR-B cotransfection ( $0 \%$ AvrII/DraIII-del vs $17 \%$ wild type; $p=0.003$ ) but there was a degree of recovery in the presence of additional $\mathrm{P}_{4}(18 \%$ AvrII/DraIII-del vs 35\% wild type; $p=\mathrm{n} / \mathrm{s}$ ) (Figure 4.7). Results for the pPMTR(-AvrII) plasmid that has the deletion of nucleotides -411 to -415 demonstrated reduced levels of upregulation compared to the wild type, but the differences were not significant; cotransfection with pPR-B (10\% -AvrII vs $17 \%$ wild type; $p=\mathrm{n} / \mathrm{s})$ and cotransfection with pPR-B in the presence of 20nM P4 (26\% -AvrII vs vs $35 \%$ wild type; $p=\mathrm{n} / \mathrm{s}$ ) (Figure 4.8 ).

Results for the PRE EMSA showed that both the PROS1 PRE probe and the consensus PRE probes bound to PR-B nuclear derived protein. Addition of $5 \mu \mathrm{g}$ of mouse antihuman PR-B Ab disrupted the interaction, but $0.5 \mu$ g did not, suggesting that the $\mathrm{Ab}$ is directed against a region of PR-B that is required for PRE interaction. Therefore, in the 
absence of a supershift, the AP1 control was included to demonstrate that the mouse anti-human PR-B was specific for the PR-B complex only. Addition of $5 \mu \mathrm{g}$ of mouse anti-human PR-B did not effect binding of the consensus AP1 probe with AP1. The PROS1(-407) PRE probe exhibited a reduced affinity for PR-B compared to the PRE consensus and PROS1 wild-type PRE (Figure 4.9).

\subsubsection{DifFERENTIAL RESPONSES TO DIFFERENT TYPES OF PROGESTINS}

It has been clinically observed that the severity of acquired PS deficiency can differ between the different generations of COCs, therefore to determine whether the type of progestin present led to a variation in the extent of hormone regulation of PROS1 promoter transcriptional activity in vitro. Once again the response experiments were repeated, this time using the testosterone derived levonorgestrel (LNG) or the progesterone derived medroxyprogesterone acetate (MPA) in place of $\mathrm{P}_{4}$. MCF-7 cells were cotransfected with $2 \mu \mathrm{g}$ pPMTR and the isoforms of progestin added at a concentration of $20 \mathrm{nM}$. Both LNG and MPA exhibited a more potent effect on the PROS1 promoter activity than $\mathrm{P}_{4}$, with MPA showing the greatest, more than doubling the response generated by $\mathrm{P}_{4}(30 \%$ vs $17 \% ; p=0.006)$ (Figure 4.10$)$.

\subsubsection{DifFERENTIAL RESPONSE TO GLUCOCORTICOID}

Progesterone receptors are members of a superfamily of receptors (see Chapter 1) that include the glucocorticoid receptors. Therefore the effect of corticosterone (CORT) was assessed to determine any effect on expression. Using the MCF-7 cell line transiently transfected with $2 \mu \mathrm{g}$ of pPMTR, 20nM of CORT upregulated PROS1 promoter activity by $20 \%(p=0.04)$ (Figure 4.11$)$. 

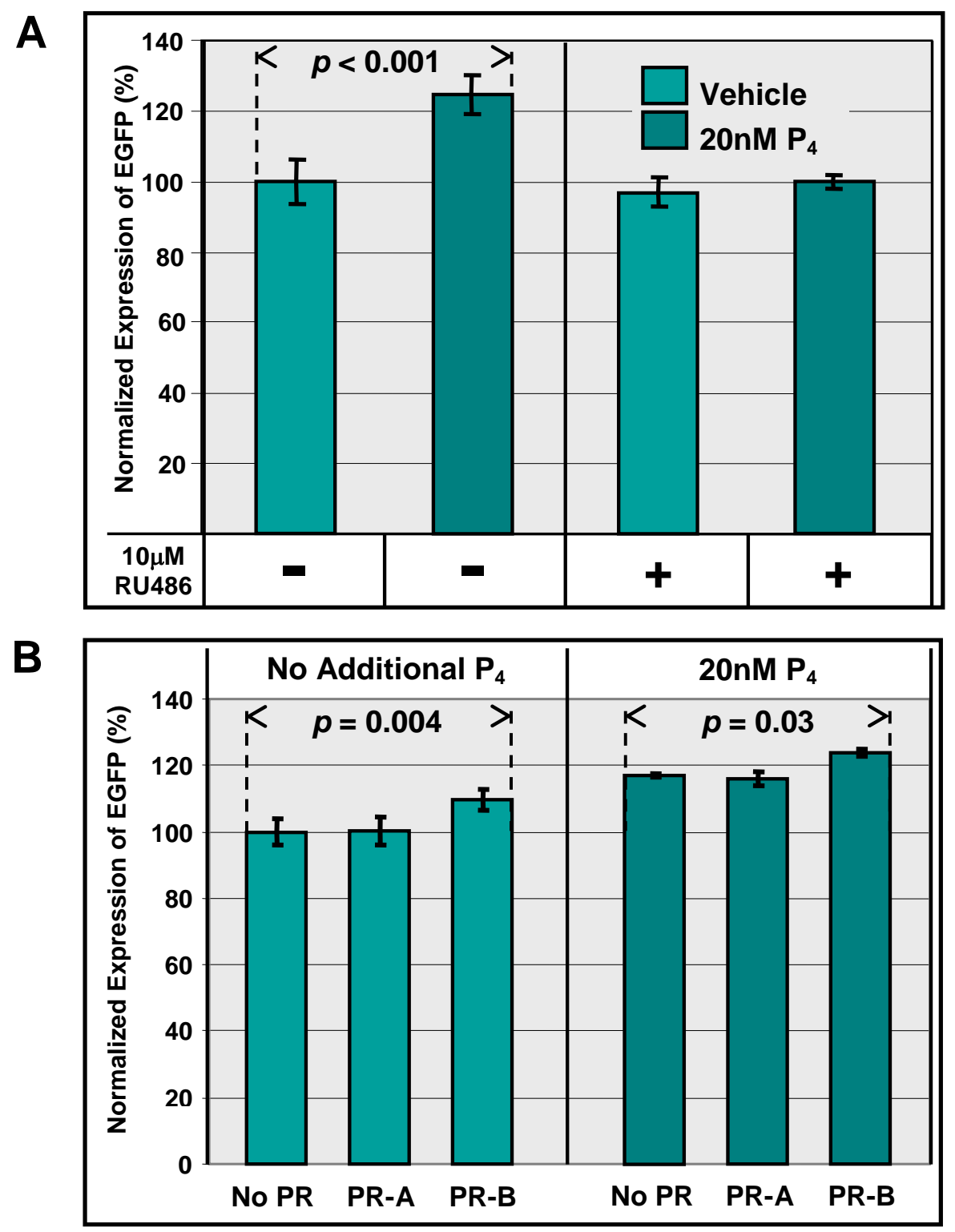

Figure 4.4 Progesterone upregulates the PROS1 promoter via a PR-B dependant mechanism. (A) MCF-7 cells transfected with pPMTR and either $10 \mu \mathrm{M}$ of the PR modulator mifepristone (RU486), or 10 $\mu \mathrm{M}$ RU486 + 20nM $\mathrm{P}_{4}$ were added; (B) MCF-7 cells transfected with pPMTR and either no cotransfection, or cotransfection with either 100ng pPR-A, or 100ng pPR-B in normal media supplemented with or without 20nM $\mathrm{P}_{4}$. Activity of the PROS1 promoter was measured as a percentage of EGFP expression normalized against constitutive DsRed2 expression over a 24h period. 
A

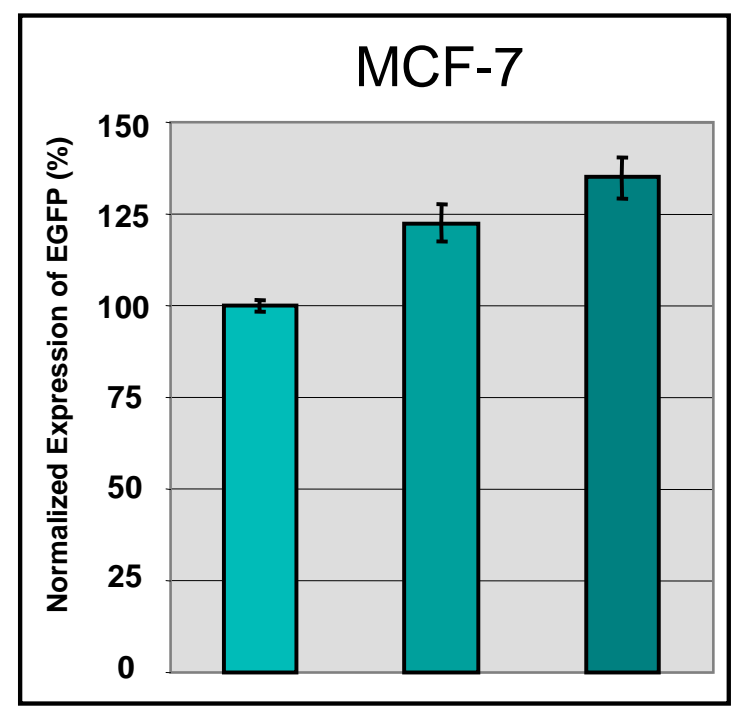

\begin{tabular}{|c|c|c|}
\hline pPMTR & pPMTR & $\begin{array}{c}\boldsymbol{p}- \\
\text { value }\end{array}$ \\
\hline Vehicle & $20 \mathrm{nM} \mathrm{P}_{4}$ & 0.03 \\
\hline Vehicle & $20 \mathrm{nM} \mathrm{P}_{4}+\mathrm{pPR}-\mathrm{B}$ & 0.01 \\
\hline
\end{tabular}

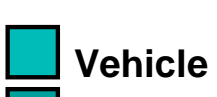

$\square$ 20nM P 4

$\square$ 20nM P 4 + pPR-B

B

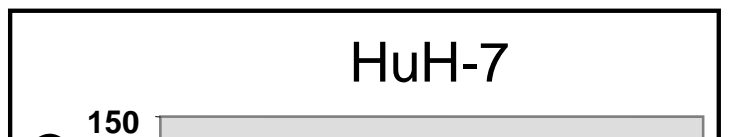

\begin{tabular}{|c|c|c|}
\hline pPMTR & pPMTR & $\begin{array}{c}\boldsymbol{p}- \\
\text { value }\end{array}$ \\
\hline Vehicle & $20 \mathrm{nM} \mathrm{P}_{4}$ & 0.008 \\
\hline Vehicle & $20 \mathrm{nM} \mathrm{P}_{4}+\mathrm{pPR}-\mathrm{B}$ & 0.04 \\
\hline
\end{tabular}

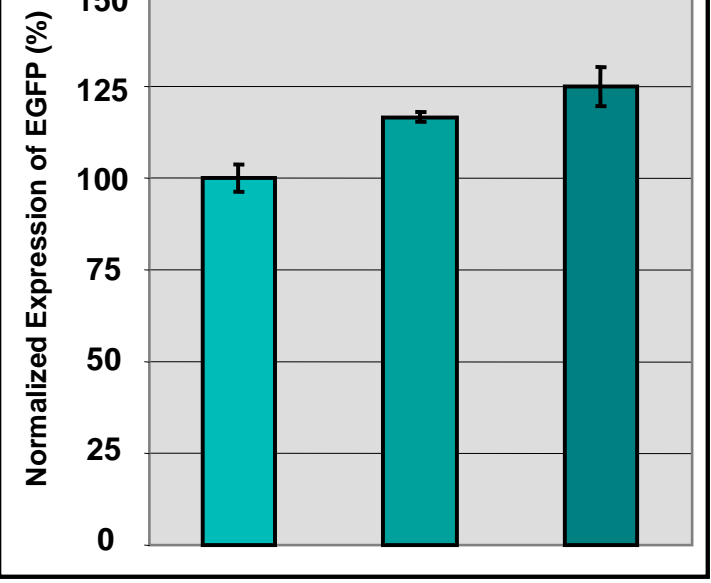

$\square$ Vehicle
$20 \mathrm{nM} \mathrm{P}_{4}$
$20 \mathrm{nM} \mathrm{P}+$ pPR-B

Figure 4.5 Progesterone upregulates the PROS1 promoter via a PR-B dependant mechanism. (A) MCF-7 cells transfected with pPMTR and either no cotransfection, or cotransfection with 100ng pPR-B in normal media supplemented with or without $20 \mathrm{nM} \mathrm{P}_{4} ;(\mathrm{B}) \mathrm{HuH}-7$ cells transfected with pPMTR and either no cotransfection, or cotransfection with 100ng pPR-B in normal media supplemented with or without 20nM $\mathrm{P}_{4}$. Activity of the PROS1 promoter was measured as a percentage of EGFP expression normalized against constitutive DsRed2 expression over a 24h period. 


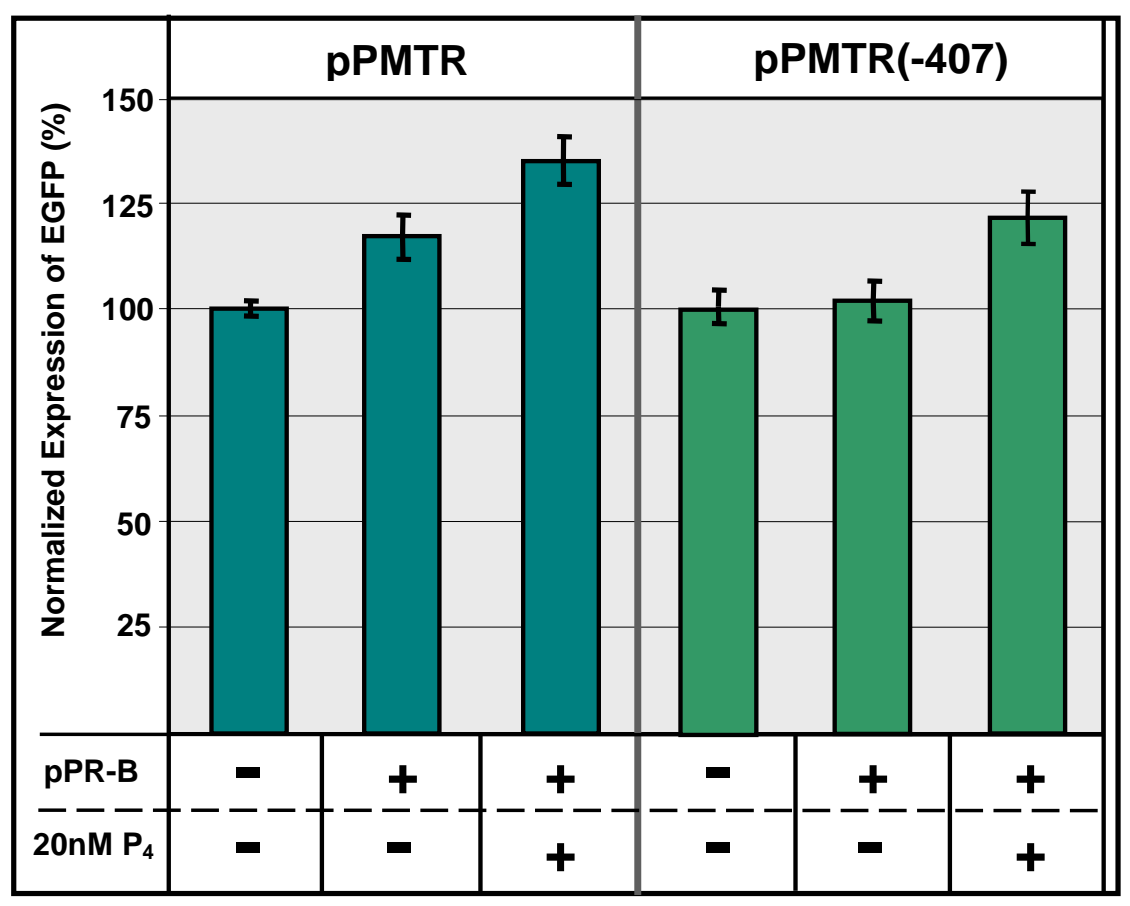

Statistical Analysis

\begin{tabular}{|c|c|c|}
\hline pPMTR & pPMTR(-407) & $\boldsymbol{p}$-value \\
\hline Vehicle + pPR-B & Vehicle + pPR-B & 0.01 \\
\hline 20nM P 4 + pPR-B & $20 \mathrm{nM} \mathrm{P}_{4}+$ pPR-B & 0.001 \\
\hline
\end{tabular}

Figure 4.6 Introduction of c-407t reduces PR-B induced upregulation. MCF-7 cells transfected with pPMTR or pPMTR(407) cotransfected with either 100ng of pPR-B, or 100ng pPR-B + 20nM P4. Activity of the PROS1 promoter was measured as a percentage of EGFP expression normalized against constitutive DsRed2 expression over a $24 \mathrm{~h}$ period. 


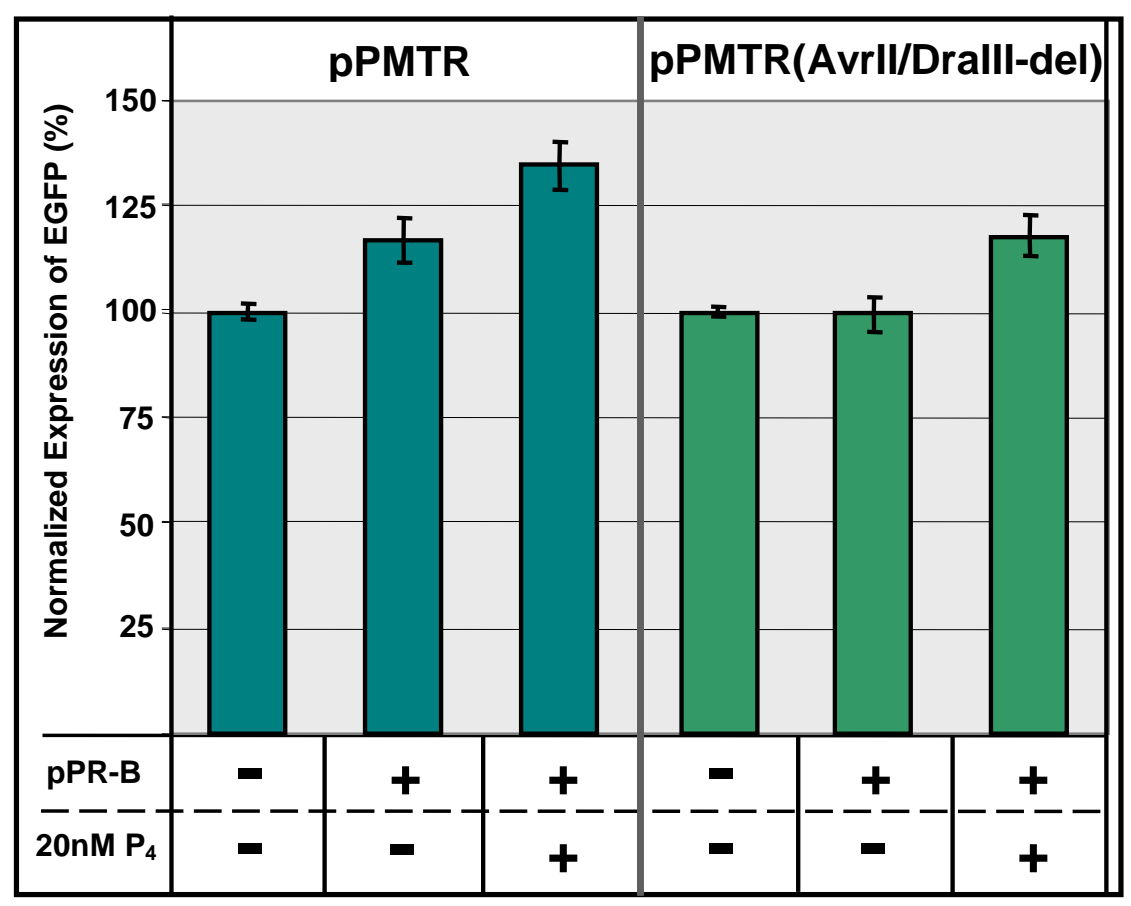

Statistical Analysis

\begin{tabular}{|c|c|c|}
\hline pPMTR & pPMTR(AvrlI/Dralll-del) & $\boldsymbol{p}$-value \\
\hline Vehicle + pPR-B & Vehicle + pPR-B & 0.003 \\
\hline $20 \mathrm{nM} \mathrm{P}_{4}+$ pPR-B & $20 \mathrm{nM} \mathrm{P}_{4}+\mathrm{pPR}-\mathrm{B}$ & $(\mathrm{n} / \mathrm{s})$ \\
\hline
\end{tabular}

Figure 4.7 Deletion of PRE reduces PR-B induced upregulation. MCF-7 cells transfected with PPMTR or pPMTR(Avrll/Dralll-del) cotransfected with either 100ng of pPR-B, or 100ng pPR-B $+20 n M P_{4}$. Activity of the PROS1 promoter was measured as a percentage of EGFP expression normalized against constitutive DsRed2 expression over a $24 \mathrm{~h}$ period. 


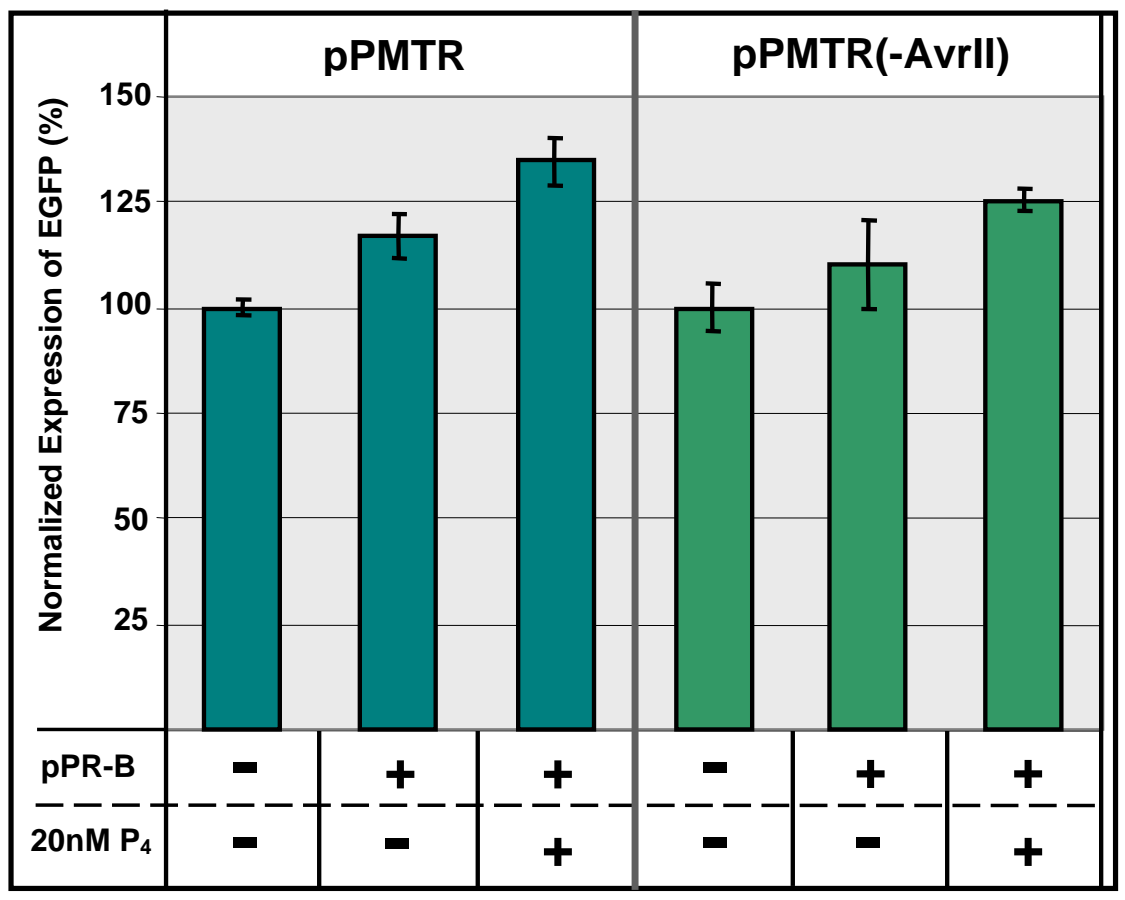

Statistical Analysis

\begin{tabular}{|c|c|c|}
\hline pPMTR & pPMTR(-Avrll) & $\boldsymbol{p}$-value \\
\hline Vehicle + pPR-B & Vehicle + pPR-B & $\mathrm{n} / \mathrm{s}$ \\
\hline 20nM $\mathrm{P}_{4}+\mathrm{pPR}-\mathrm{B}$ & $20 \mathrm{nM} \mathrm{P}_{4}+\mathrm{pPR}-\mathrm{B}$ & $\mathrm{n} / \mathrm{s}$ \\
\hline
\end{tabular}

Figure 4.8 Deletion of the nucleotides -411 to -415 at the $5^{\prime}$ terminal of the PRE reduces PR-B induced upregulation but not significantly. MCF-7 cells transfected with PPMTR or pPMTR(-AvrlI) cotransfected with either 100ng of pPR-B, or 100ng pPR-B $+20 n M P_{4}$. Activity of the PROS1 promoter was measured as a percentage of EGFP expression normalized against constitutive DsRed2 expression over a 24h period. 


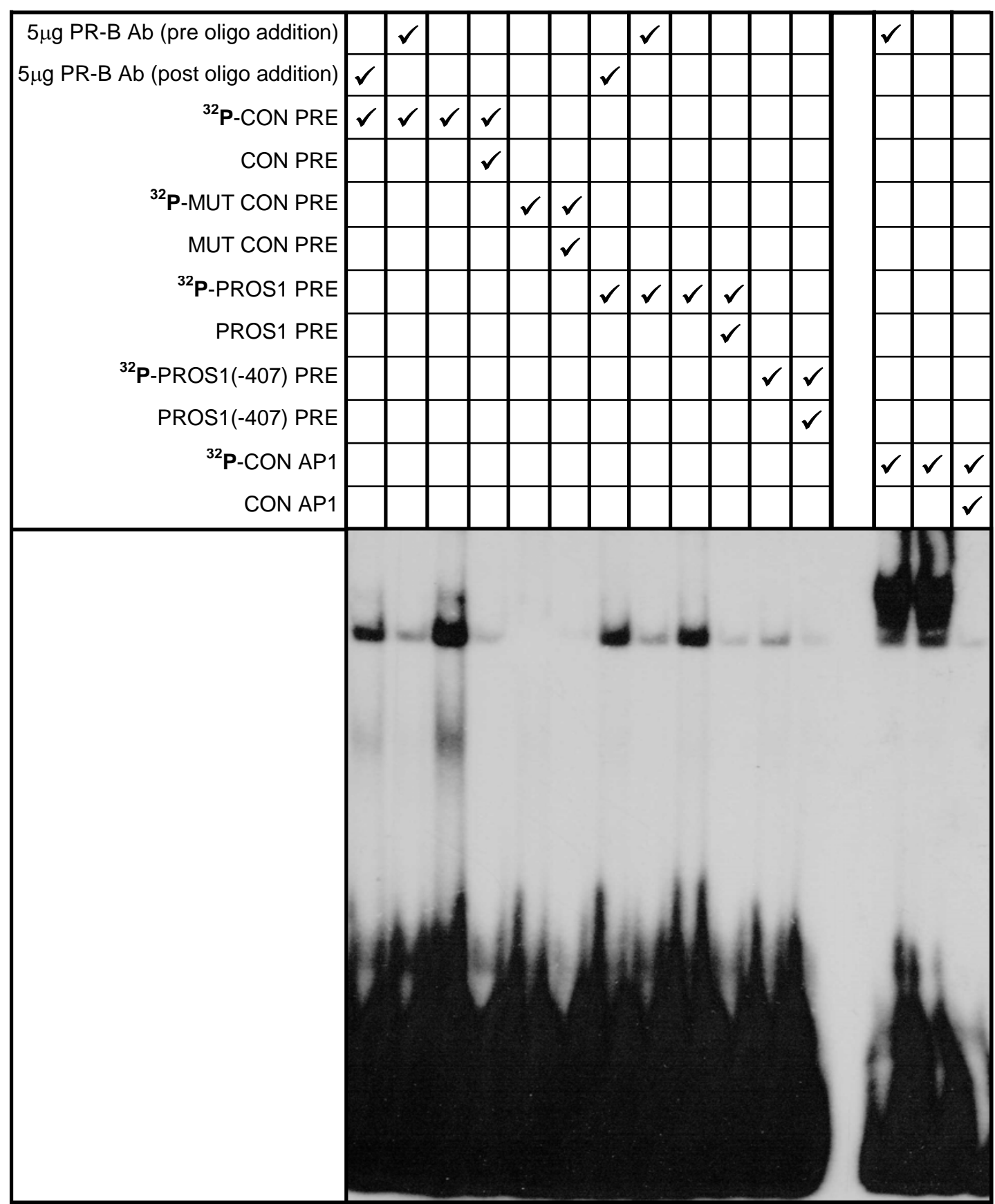

Figure 4.9 Electromobility Shift Assay (EMSA) confirmation of PR-B based mechanism. The proposed PROS1 PRE was used to probe $1 \mu \mathrm{g}$ of PR-B positive MCF-7 nuclear protein extract. The PROS1 PRE probe formed complexes identical in size to a consensus PRE probe (CON PRE). Introduction of $\mathrm{c}-407 \mathrm{t}$ variant [PROS1 (-407) PRE] diminished complex formation. PR-B binding was disrupted by the addition of $5 \mu \mathrm{g}$ of anti-PR-B prior to the addition of probe, but not after complex formation (post oligo addition). Addition of $5 \mu \mathrm{g}$ of mouse anti-human PR-B did not alter AP1 complex formation when a consensus AP1 (CON AP1) probe was used. 


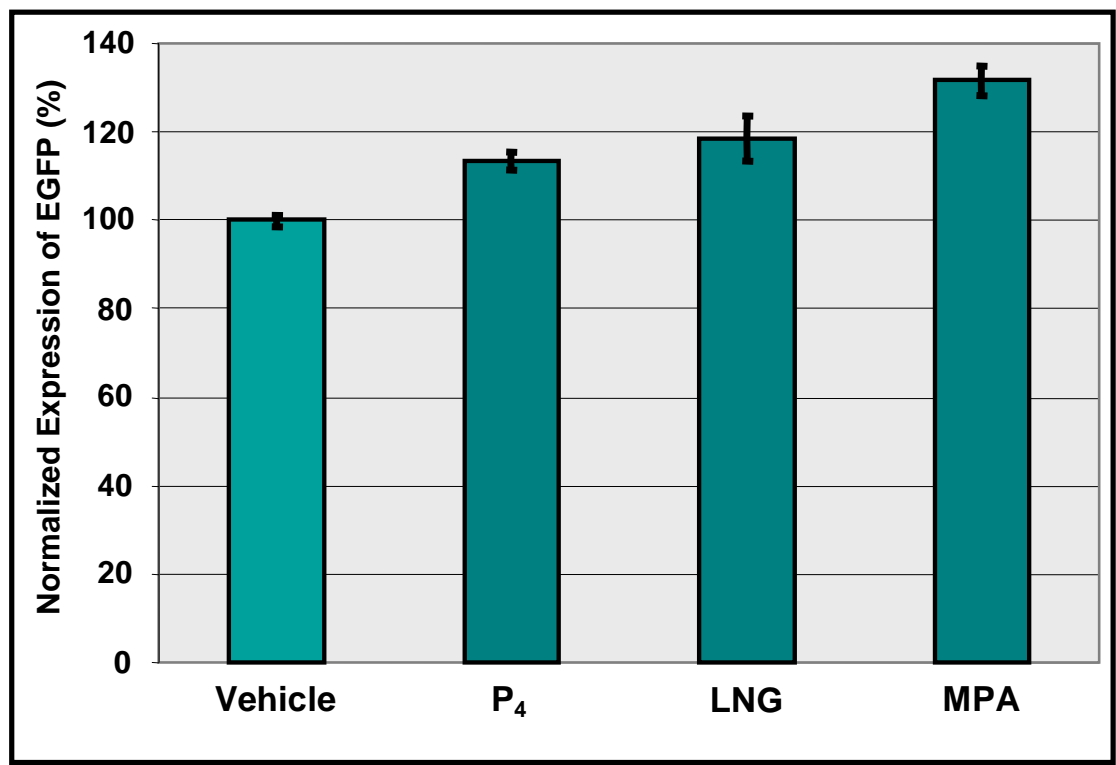

Statistical Analysis

\begin{tabular}{|c|c|c|}
\hline Condition 1 & Condition 2 & $\boldsymbol{p}$-value \\
\hline Vehicle & $\mathrm{P}_{4}$ & 0.001 \\
\hline Vehicle & LNG & 0.007 \\
\hline Vehicle & MPA & 0.0006 \\
\hline $\mathrm{P}_{4}$ & LNG & $\mathrm{n} / \mathrm{s}$ \\
\hline $\mathrm{P}_{4}$ & MPA & 0.006 \\
\hline LNG & MPA & 0.01 \\
\hline
\end{tabular}

Figure 4.10 Progestin isoforms exhibit different levels of transcriptional activation. The effect of 20nM progesterone $\left(\mathrm{P}_{4}\right)$; levonorgestrel (LNG); medroxyprogesterone acetate (MPA); on expression profile of pPMTR. Activity of the PROS1 promoter was measured as a percentage of EGFP expression normalized against constitutive DsRed2 expression over a $24 \mathrm{~h}$ period. 


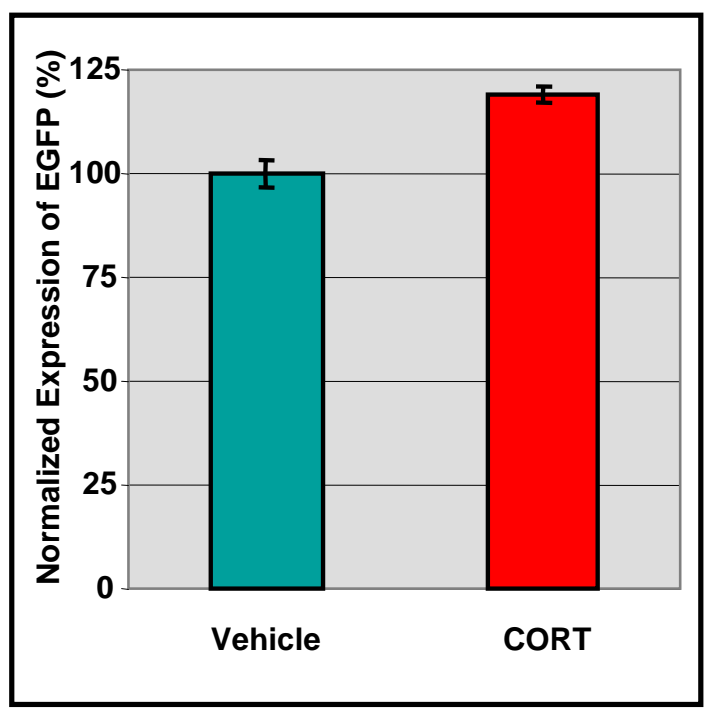

Figure 4.11 Corticosteriod upregulates the PROS1 promoter. MCF-7 cells transfected with pPMTR with and without 20nM corticosterone Activity of the PROS1 promoter was measured as a percentage of EGFP expression normalized against constitutive DsRed2 expression over a 24h period. 


\subsection{DISCUSSION}

The primary aim of this chapter was to identify an oestrogen responsive element (ERE) within the PROS1 promoter that governed the oestrogen mediated downregulation. The transient transfection method demonstrated that both ER $\alpha$ alone and in combination with $\mathrm{E}_{2}$, reduced the activity of the $950 \mathrm{bp}$ of the PROS1 promoter contained in the pPMTR vector in both the MCF-7 and $\mathrm{HuH}-7$ cell lines. Initial experiments that assessed the responsiveness of $\mathrm{E}_{2}$ only (without cotransfection with the $\mathrm{ER} \alpha$ expressing vector) using the MCF-7 cell line, also downregulated the PROS1 promoter fragment, but gradually diminished with increasing passage number. The apparent loss of ER $\alpha$ expression has previously been reported, as has the requirement for cotransfection with ER $\alpha$ expression vectors when investigation of other gene promoters using MCF-7s has been examined (Porter et al., 1997, Duan et al., 1998, Sun et al., 1998, Wang et al., 1999, Xie et al., 1999, Qin et al., 1999, Dong et al., 1999, Saville et al., 2000). Similarly, low levels of ER $\alpha$ expression in $\mathrm{HuH}-7 \mathrm{~s}$ has been reported (Cheng et al., 2006), explaining the requirement for cotransfection with $\mathrm{pER} \alpha$ when performing the transient transfection studies using that cell line.

Nevertheless, the human liver does express high levels of ER $\alpha$ in vivo (Pelletier, 2000) and although it has not been conclusively demonstrated, it is postulated that hepatic $\mathrm{ER} \alpha$ expression in humans increases in an oestrogen-dependant manner (Pinzone et al., 2004). In humans, the gene that encodes ER $\alpha$, ESR1, utilises multiple promoters in a tissue specific manner with promoter $\mathrm{E}$ the dominant form in the liver (Flouriot et al., 1998, Reid et al., 2002). Greater expression of promoter E ER $\alpha$ mRNA is observed in female liver biopsies compared to male samples (Flouriot et al., 1998). Conversely, levels of both total and free PS are lower in premenopausal women than in men 
(Goodwin et al., 2002, Koenen et al., 2005). However, total and free PS levels increase in non-OC using post-menopausal women and may be a result of the corresponding reduction in circulating oestrogen acting to reduce ER $\alpha$ expression in the liver (Goodwin et al., 2002).

The pPMTR transient transfection model demonstrated that the 950bp of the PROS1 promoter is repressed by the $\mathrm{ER} \alpha$ and $\mathrm{ER} \alpha / \mathrm{E}_{2}$, but how and where $\mathrm{ER} \alpha$ is acting is uncertain. Removing the putative ERE sequence spanning nucleotides -526 to -538 failed to reverse the inhibition, ruling out a 'classical' ER $\alpha$ mechanism. This suggests an alternative ER $\alpha$ pathway is operating via another site within the promoter region. Both the large deletion plasmids, pPMTR(AvrII/DraIII-del) and pPMTR(BclI/AvrII-del) demonstrated inhibition responses similar to the wild type. Therefore the cis-acting element is most likely located in the $324 \mathrm{bp}$ downstream from the DraIII restriction site. This contains the Sp1 elements identified by de Wolf et al. (2006). It is possible that $\mathrm{ER} \alpha$ is not binding directly to the PROS1 promoter but is instead exerting influence via interaction(s) with Sp1 transcriptional factors. A number of studies have detailed $\mathrm{Sp} 1 / \mathrm{ER} \alpha$ regulation of gene promoters; both up- and down-regulation (Safe, 2001). $\mathrm{Sp} 1 / \mathrm{ER} \alpha$ transcriptional regulation does not involve direct DNA binding by ER $\alpha$, but rather ER $\alpha$ bound $\mathrm{Sp} 1$ which binds to $\mathrm{GC}$ rich $\mathrm{Sp} 1$ sequences within the promoter. These GC rich motifs identified in the PROS1 promoter region were confirmed as Sp1 interactive domains that influence transcription to varying degrees (de Wolf et al., 2006a). To confirm that ER $\alpha$ is regulating expression via the Sp1 motifs, further investigations are required. Castro-Rivera et al. (2001) described an Sp1/ER $\alpha$ mechanism that mediated $\mathrm{E}_{2}$-responsiveness of the Cyclin D1 promoter, by performing an EMSA and a Chromatin-Immunoprecipitation (ChIP) assay. The EMSA used ERpositive cell extracts probed with consensus, mutated consensus and Cyclin D1 
promoter derived $\mathrm{Sp} 1{ }^{32} \mathrm{P}$-labelled probes, further demonstrating a supershift when an anti-Sp1 antibody was added. These results were confirmed by a ChIP assay demonstrating that both anti-Sp1 and anti-ER $\alpha$ antibodies were able to immunoprecipitate the proposed Cyclin D promoter $\mathrm{Sp} 1$ elements, post $\mathrm{E}_{2}$-induction.

For the first time, this study demonstrates that the PROS1 gene is upregulated by progesterone via a mechanism that involves binding of ligand activated PR-B to a region surrounding position -407 within the promoter. This represents a counterbalance to the effect of oestrogen and ER $\alpha$ which is important in both pregnancy and COC use settings.

The initial observation that progesterone upregulated expression of the PROS1 promoter initiated the investigation into a progestin based mechanism. The response to progesterone was stronger in the MCF-7 breast cell carcinoma line than it was in the HuH-7 liver carcinoma cell line. This may reflect differences in the PR expression between the two lines.

Neutralizing the progestin response using the progesterone receptor modulator, RU486, suggested that one of the two PR isoforms was involved and was subsequently shown to be PR-B. Identification of the PR-B binding motif originated with the investigation of the functional effects of the c- $407 \mathrm{t}$ variant, one of the two promoter region variants described in Chapter 3. The previously described variants t-397c and c-407t were detected separately in two patients with pregnancy induced high levels of oestrogen and progesterone who also had greater than normal decreases in their total (tPS), free (frPS) and functional (fuPS) PS levels at 32 weeks gestation compared to levels taken six months post partum (patient $1-39 \%, 45 \%$ and $62 \%$; patient $2-64 \%, 52 \%$ and $51 \%$; control pregnancies- $30 \%, 40 \%$ and $41 \%$ for tPS, frPS and fuPS, respectively) (data 
kindly supplied by Leesa Ivey and Kate Maslen). Therefore, it was hypothesized that the low PS levels were due to the presence of the base change(s), disrupting PR-B binding and reducing the upregulatory effect of progesterone resulting in greater PS reduction in response to the increased oestrogen. Both variants map to a highly probable $(87.5 \%)$ progesterone responsive motif (Figure 4.1 ) identified by a recently designed algorithm developed specifically for complex progesterone response elements (Stepanova et al., 2006). The in vitro observation that PR-B increased the activity of the pPMTR vector (containing the wildtype PROS1 promoter), but not the pPMTR(-407) vector, strongly suggested that c-407 forms part of a key binding site for the $\mathrm{P}_{4} / \mathrm{PR}-\mathrm{B}$ complex. The same response was apparent when the experiment was repeated with the pPMTR(AvrII/DraIII-del) plasmid in which most of the PRE is deleted. As with pPMTR(-407), there was increased activity of the PROS1 promoter when cotransfected with the pPR-B plasmid. Interestingly, both plasmids did recover a degree of increased promoter activity when $20 \mathrm{nM} \mathrm{P}_{4}$ was included with the cotransfection, suggesting PROS1 sensitivity to $\mathrm{P}_{4}$ may be conferred at more than one site. Cotransfection of the pPR-B plasmid with the pPMTR(-AvrII) upregulated expression of the PROS1 promoter marginally suggesting the $5^{\prime}$ terminus of the PRE is not required for binding pPR-B.

Surprisingly, the presence of the $-407 \mathrm{t}$ mutation enhanced the downregulatory effect of $\mathrm{E}_{2}$ on the PROS1 promoter reflecting the clinical observation of the patient's gestational response. It is well reported that $\mathrm{E}_{2}$ increases expression of the PR gene in MCF-7 cells and that the PR-B isoform is up-regulated in an ER $\alpha$ dependent manner (Schultz, et al., 2003, Mukherjee et al., 2005, Nardulli et al., 1988, Wei et al., 1988, Read et al., 1988). Thus the introduction of excess ER $\alpha$ could increase PR-B availability in both the pPMTR and pPMTR(-407) transiently transfected cell lines. The promoter containing 
the $\mathrm{c}-407 \mathrm{t}$ mutant was unable to respond to the increase of available PR-B as effectively as the wild type and therefore the downregulatory action of $E R \alpha$ and $E R \alpha / E_{2}$ was more pronounced.

The EMSA protocol reinforced the initial findings resulting from the expression studies, confirming the proposed PRE as a progesterone-responsive motif, and demonstrating that it was able to bind activated PR-B with a similar affinity to that of the consensus PRE probe. Furthermore, the PROS1(-407) PRE probe that incorporated the t-407c variant exhibited a reduced affinity for PR-B, reflecting the expression study results for the pPMTR(-407) vector.

Identifying the upregulatory effect of progestins on the PROS1 promoter is important for users of oral contraceptives. The demonstration in the present study that the testosterone derived levonorgestrel (LNG), and the progesterone derived medroxyprogesterone acetate (MPA) induce differential upregulation of PROS1 promoter transcriptional activity (MPA significantly greater than $\mathrm{P}_{4}$ ) indicates the type of progestin prescribed is important. Clinical data suggests that 3rd generation COCs are associated with significantly lower levels of free PS when compared to data for 2nd generation COCs (Kemmeren et al., 2004, Oral Contraceptive and Hemostasis Study Group, 2003). Both desogestrel (DSG) and gestodene (GSD) are still protected by patents and as such are not available for purchase. When GSD becomes available in the future (DSG is a prodrug and would not be suitable for cell culture) an interesting follow up experiment would be to compare the affect on PROS1 promoter expression with other progestins in isolation (i.e. without the presence of EE). 


\begin{tabular}{|l|c|c|c|c|}
\hline Progestin & PR & ER & GR & MR \\
\hline Progesterone & 50 & 0 & 10 & 100 \\
\hline Medroxyprogesterone acetate & 115 & 0 & 29 & 160 \\
\hline Levonorgestrel & 150 & 0 & 1 & 75 \\
\hline
\end{tabular}

Table 4.1 Relative binding affinities of three progestin isoforms for hormone receptors. The relative binding affinities of progesterone, medroxyprogesterone acetate and levonorgestrel for progesterone receptor (PR; promegestone, $100 \%)$, oestrogen receptor (ER; 17ß-oestradiol, 100\%), glucocorticoid receptor (GR; dexamethasone, 100\%) and mineralcorticoid receptor (MR; aldosterone, 100\%).

Adapted from (Kuhl, 2005)

The PROS1 promoter was also upregulated by the glucocorticoid corticosterone. This is of particular interest and suggests one of several possibilities. As discussed in Chapter 1, the PRs form part of a superfamily of nuclear receptors that includes the glucocorticoid receptor (GR) and mineralcorticoid receptors (MR). Table 4.1 details the binding affinities of $\mathrm{P}_{4}, \mathrm{MPA}$ and $\mathrm{LNG}$ for $\mathrm{PR}, \mathrm{GR}, \mathrm{MR}$ and $\mathrm{ER}$, highlighting the variability between both different progestins and receptors. The same is also true for glucocorticoid that can cross bind with PR and activate progesterone inducible genes and may explain the corticosterone effect (Leo et al., 2004).

The upregulation could be also be operating via a direct GR based mechanism. GR is highly expressed in the human liver where it regulates a wide variety of genes (Rabbitt et al., 2002). A secondary mechanism such as this could explain why both the pPMTR(407) and pPMTR(AvrII/DraIII-del) vectors demonstrated increased PROS1 promoter activity when additional $\mathrm{P}_{4}$ was added to the pPR-B cotransfection experiments. Table 4.1 details the binding affinity of $\mathrm{P}_{4}$ for GR, showing a low but significant affinity. 
Therefore the excess $\mathrm{P}_{4}$ may be driving a upregulatory responsive GRE located in the PROS1 promoter.

A large component of the work presented in this chapter are results derived from in vitro expression studies using the pPMTR vector or variations of the pPMTR vector. A criticism that may be levelled at this system is the relatively low changes in expression observed post treatment when compared to changes observed for other hormonally responsive promoter studies for example, the 17-fold change found in the investigations of the F9 gene due to the ARE disrupting point mutation (Brady et al., 1998). However, the PROS1 promoter is known to be a low activity promoter (personal correspondence with Prof. David Lane, Hammersmith Hospital, London), a phenomenon that may actually reflect translational rather than transcriptional output. The PROS1 promoter does not have a consensus Kozak sequence lacks most of the AUG flanking nucleotides required for strong ribosomal initiation (Kozak, 1987). Therefore, the low levels of hormone responsiveness may reflect the overall low level of PS production.

In summary, work detailed in this chapter demonstrates that transcription of the PROS1 gene is influenced by the presence of both oestrogen and progesterone, which downregulate and upregulate transcription, respectively. The oestrogen response is mediated via $\mathrm{ER} \alpha$, while the progesterone response requires the PR-B isoform. In addition, a region within the promoter has been identified that is involved in the binding of ligand bound PR-B receptor. Work will continue towards elucidating the ER $\alpha$ based mechanism. These findings provide an explanation for the development of acquired PS deficiency during pregnancy and in users of COCs, in particular, highlighting the importance of progesterone and synthetic progestins in both pregnancy and COC users, respectively. 
Future studies will focus on isolating the region(s) of the PROS1 promoter that direct the ER $\alpha$ mediated down-regulation by continuing with deletion studies and by performing the EMSA and ChIP assays discussed earlier in this chapter, based on the experimentals conducted by Castro-Rivera et al. (2001). 


\section{CHAPTER 5}

\section{Identification of Novel Protein S Binding \\ Partners}




\subsection{INTRODUCTION}

The interaction between the complement protein $\mathrm{C} 4 \mathrm{~b}$ binding protein $(\mathrm{C} 4 \mathrm{~b}-\mathrm{BP})$ and $\mathrm{PS}$ has been well described (Dahlback and Stenflo, 1981, Walker, 1989, Dahlback et al., 1990a, Dahlback, 1991, Nelson and Long, 1992, Fernandez et al., 1993, Fernandez and Griffin, 1994, Hardig and Dahlback, 1996, Fernandez et al., 1998). The high affinity binding relationship between the two molecules regulates levels of circulating free PS, which is the only form able to act as cofactor to activated protein C. It has been suggested that acquired PS deficiency may be a function of increased circulating levels of C4b-BP although it has not been conclusively demonstrated (Esparza-Gordillo et al., 2003). Nevertheless, it represents a possible mechanism that could limit the availability of free form PS.

Other than PS interaction with aPC, no other protein's have been directly associated with PS. The possibility of a novel protein/protein interaction involving PS may form the basis of potential hormone regulated mechanism. That is, if the concentration of a PS binding partner increased in a hormonal dependant manner, then a reduction in the availability of free PS would result. An example of this form of endocrine regulation can be seen in the relationship between insulin-like growth factor 1 (IGF-1) and its carrier IGF binding protein 1 (IGFBP1), referred to as the IGF-1/IGFBP1 axis. IGFBP1 is part of a larger family of IGF transporter proteins that are expressed by the liver (Rajaram et al., 1997). IGFBP1 inhibits IGF-1 activity by reducing availability for IGF receptor binding (Pierce et al., 2006). Rapid changes in IGFBP1 expression occur in response to glucocorticoid and insulin levels that upregulate and downregulate transcription respectively, via interactions with response elements located in the promoter region of the IGFBP1 gene (Goswami et al., 1994, Suwanichkul et al., 1994). Growth Hormone (GH) also represses IGFBP1 expression in a yet to be determined 
mechanism (Lu et al., 1999). Interestingly, levels of IGFBP1 are significantly reduced in postmenopausal women using oestrogen only forms of HRT. The reduction is attenuated by progestins that exhibit strong androgenic properties such as levonorgestrel (Heald et al., 2000, Campagnoli et al., 2003, Heald et al., 2005).

Therefore, the aim of this study is to investigate whether a similar mechanism to that of the IGF-1/IGFBP1 axis exists for PS, by determining if a novel PS binding protein exists that is itself hormonally regulated. To do this, a method successfully employed by previous investigators, the Yeast-2-Hybrid (Y-2-H) System will be used.

\subsection{THE YEAST-2-HYBRID SYSTEM}

The Y-2-H System was designed in 1980's as a technique to identify novel proteinprotein interactors when the unique properties of the yeast GAL4 transcriptional activator were recognised (Fields and Song, 1989). Fields and Song exploited the independent properties of the two key functional domains of the GAL4 protein (a Saccharomyces cerevisiae transcriptional activator), the N-terminal DNA binding domain $(\mathrm{BD})$ and the $\mathrm{C}$-terminal activation domain (AD). The $\mathrm{BD}$ interacts with a highly specific upstream activating sequence (UAS), while the AD binds to RNA polymerase. When separated, the two domains lack function but are still able to activate transcriptional activity if they physically, but not necessarily covalently, interact (Ma and Ptashne, 1988) (Figure 5.1). Therefore, if two proteins are interactors, forming fusion proteins comprised of the $\mathrm{AD}$ with protein $\mathrm{X}$ and the $\mathrm{BD}$ with protein $\mathrm{Z}$ creates a bridge between the $\mathrm{AD}$ and $\mathrm{BD}$, facilitating transcription (Figure 5.2B). If the proteins do not interact (proteins $\mathrm{X}$ and $\mathrm{Y}$; Figure 5.2A) then the reporter gene will not be transcribed. In the $\mathrm{Y}-2-\mathrm{H}$ system, specific reporter genes are used to select for positive interactors. The fusion proteins are produced by inserting the cDNA that encodes a 
protein of interest into a vector containing the coding sequence for the BD (the 'bait').

Successful expression will yield the required chimeric protein. The 'fish' chimeras are derived from cDNA libraries constructed using vectors containing the coding sequence for the $\mathrm{AD}$.

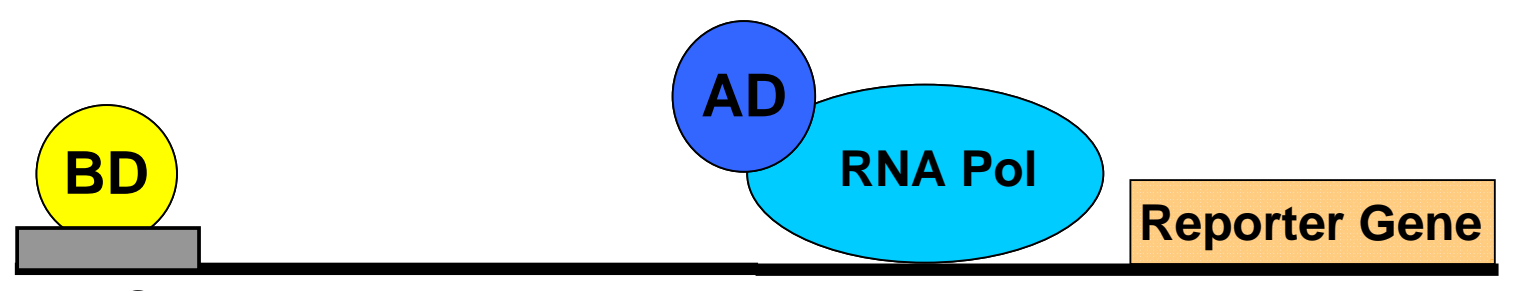

UAS

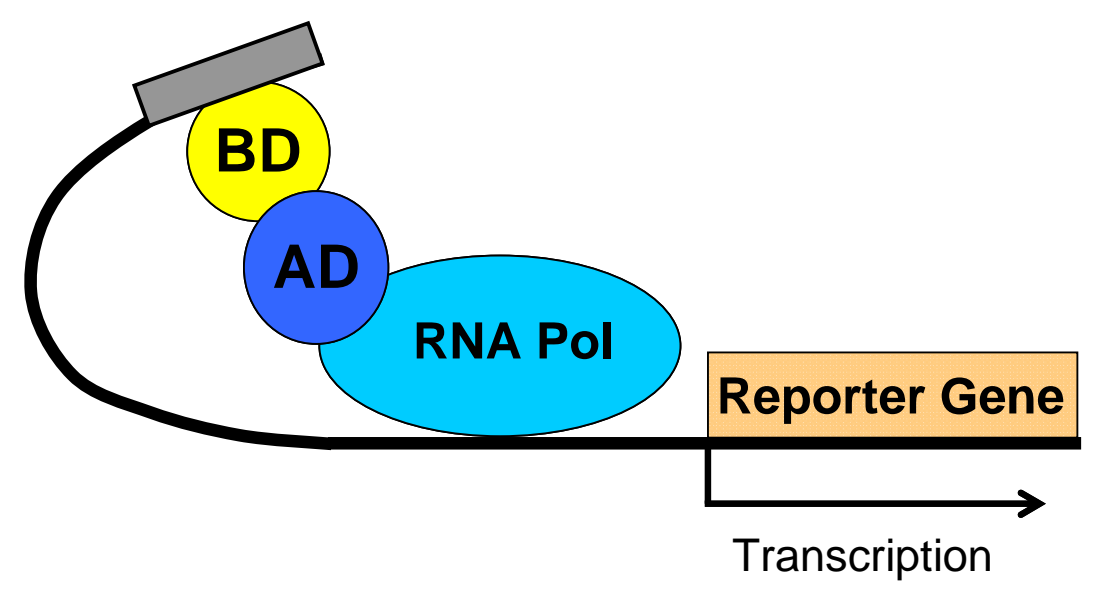

Figure 5.1 Schematic illustration of the principle underlying the mechanism of the Y-2-H system. Fields and Song (1989) discovered that the Saccharomyces cerevisiae GAL4 protein consists of two distinct domains, an N-terminal DNA binding domain (BD) and a C-terminal activation domain (AD). The BD demonstrates a high affinity for an upstream activation sequence (UAS) ciselement, while the AD interacts with RNA polymerase (RNA Pol). The two domains retain functionality, initiating transcription when they physically, but not necessarily covalently, interact. 


\section{A}

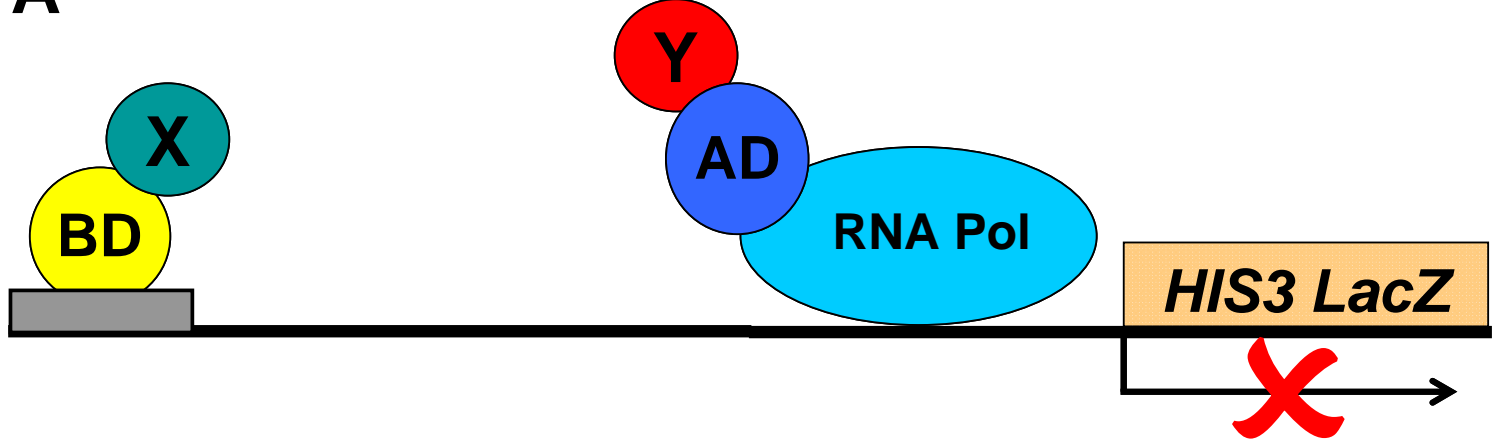

B
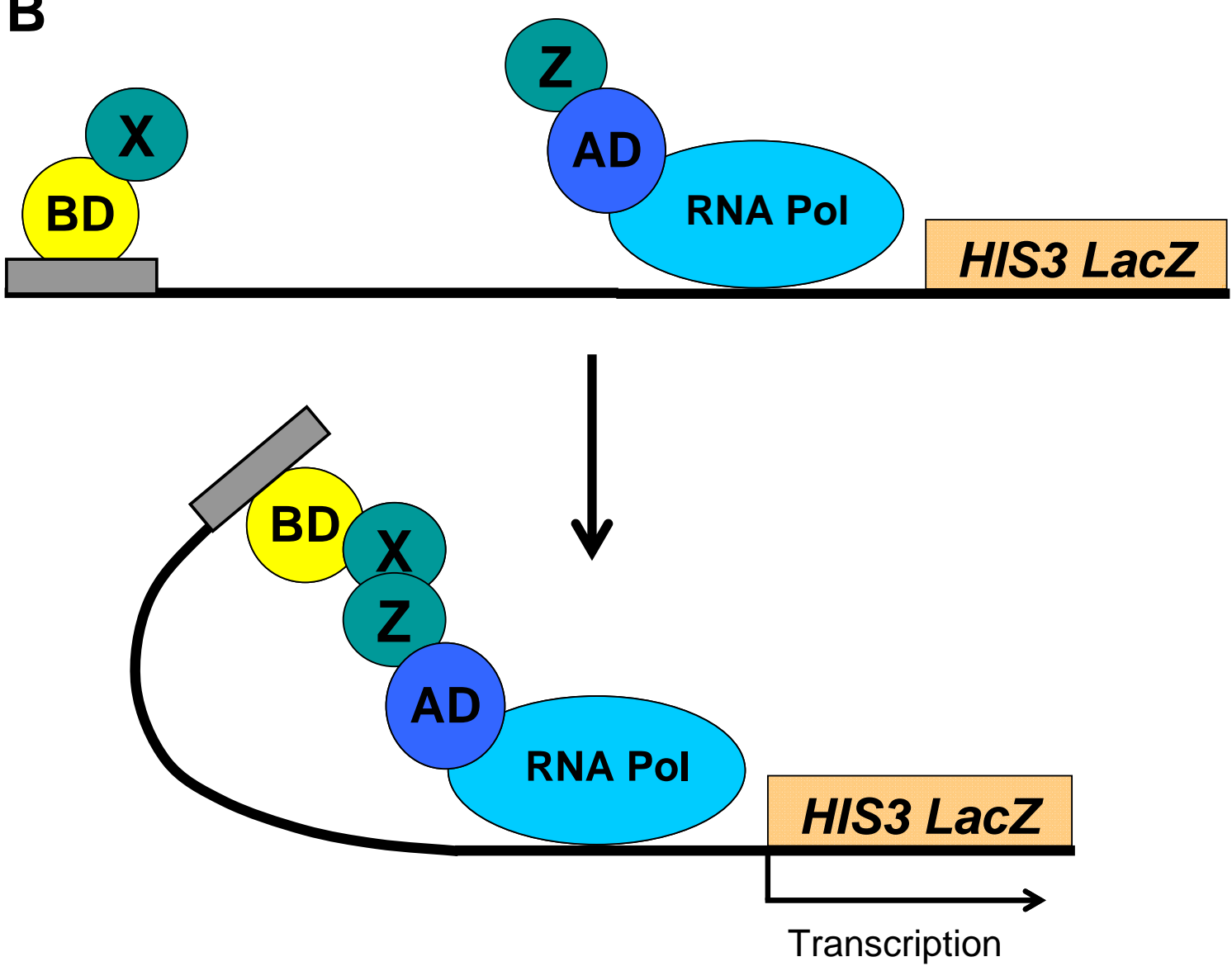

Figure 5.2 Schematic illustrating how the Y-2-H system identifies proteinprotein interactors via the creation of fusion proteins. Fusion proteins, comprising of the 'bait' (or known protein) amalgamated with the binding domain (BD) moiety and the 'fish' protein (derived from cDNA libraries for initial large scale screens) fused to the activation domain (AD) factor, will fail to activate transcription if the bait and fish are not interactors $(A)$. However, if they do interact, that will bring the $B D$ and $A D$ together, facilitating activation of RNA polymerase (RNA Pol), leading to transcription of the reporter genes, HIS3 and LacZ (B). 


\subsubsection{Limitations of the YeAst Two Hybrid Screen}

The Y-2-H system is an elegant methodology, however it does have limitations. Generation of the fusion proteins that exploit the AD and BD interaction can result in abberant folding of the protein of interest that could destroy key binding sites. The fusion proteins may also be toxic, slowing the growth of, or killing the host cell (Van Criekinge and Beyaert). Proteins, that in their native form require post-translational modifications to initiate binding, such as phosphorylation or glycosylation, may not interact with designated binding partners (Fields and Sternglanz, 1994). The major criticism of the Y-2-H system is the high number of false positives that can be identified, such as mitochondrial proteins, heat shock proteins, collagen related proteins and zinc finger proteins. However, comprehensive lists are available online that can be used to reference findings after a screen has been completed to eliminate them from follow up investigation (Van Criekinge and Beyaert).

\subsubsection{MATChMAKER YeAST-2-HYBRID SYSTEM}

The MatchMaker ${ }^{\mathrm{TM}} \mathrm{Y}-2-\mathrm{H}$ system used in this study is a dual reporter, LexA-GAL4 based process (Brent and Ptashne, 1985) which utilises a LexA BD (an E-coli repressor protein) and GAL4 AD to drive transcription of two reporter genes. The first, LacZ, encodes $\beta$-galactosidase enabling the identification of positive colonies by using $\mathrm{X}$ galactose (X-gal; 5-bromo-4-chloro-3-indolyl- $\beta$-D-galactoside) which is cleaved by $\beta$-galactosidase producing a blue by-product. The second, HIS3, enables the yeast host to manufacture endogenous histidine required for survival. Using the L40 yeast strain (genotype his34200 trp1-901 leu2-3,112 ade2 LYS2<(4lexAop-HIS3) URA3<(8lexAopLacZ) GAL4) increases the overall stringency of the method by using bait and fish plasmids that encode for the TRP1 and LEU2 genes, respectively. This allows for triple 
knock-out growth selection by using media lacking histidine, tryptophan and leucine (the TRP1 and LEU2 gene products allow the yeast to produce endogenous tryptophan and leucine).

To search for potential protein interactors with PS, the Y-2-H screen was performed using expression clones containing cDNA derived from liver and bone marrow sources. As PS is produced in both of these tissues, it was determined that these libraries would offer the best chance for identifying novel PS interactors. 


\subsection{RESULTS}

The initial large scale screen generated over 100 colonies that were able to grow on Yc agar (-His,Trp,Leu). Forty of these were subsequently assessed using the $\beta$-gal assay and for growth in the presence of 10 and $20 \mathrm{mM}$ of the histidine competitive inhibitor 3 amino-1,2,4-triazole (3AT) which left 6 viable colonies (Figure 5.3). Sequencing of each of these 6 colonies identified the coding regions of a mitochondrial isolate, two defensin isolates, a cytoskeletal talin protein and an $\alpha$-1-antichymotrypsin isolate that was detected previously in a separate study performed in this laboratory. The remaining sequence matched a previously reported sequence for the anticoagulant Protein Z, PROZ gene (Table 5.1). The PROZ fragment mapped to the 5 terminal of the PROZ gene comprising $102 \mathrm{bp}$ of promoter sequence and $25 \mathrm{bp}$ of coding sequence that included the ATG start codon. (Figure 5.4).

$\begin{array}{ccccc}\text { Colony No. } & \text { Finding } & \begin{array}{c}\text { Sequence } \\ \text { Length }\end{array} & \begin{array}{c}\text { Probable } \\ \text { False } \\ \text { Positive }\end{array} & \begin{array}{c}\text { Possible } \\ \text { Interactor }\end{array} \\ \# 2 & \text { fragment of PROZ gene } & 127 \mathrm{bp} & - & \checkmark \\ \# 112 & \alpha-1 \text {-antichymotrypsin } & 1569 \mathrm{bp} & - & \checkmark \\ \# 110 & \text { defensin } & 359 \mathrm{bp} & - & \checkmark \\ \# 111 & \text { defensin } & 664 \mathrm{bp} & - & \checkmark \\ \# 12 & \text { talin } 1 & 799 \mathrm{bp} & ? & ? \\ \# 19 & \text { mitochondrial isolate } & 519 \mathrm{bp} & \checkmark & -\end{array}$

Table 5.1- Sequencing results of positives obtained from large scale Yeast-2-Hybrid Screen. Sequences obtained from plasmid preparations of positive interactors included, a fragment that corresponded to the protein Z (PROZ) and an $\alpha$-1-antichymotrypsin and two defensin gene isolates. The talin-1 was also identified and could be an interactor, however it is structural membrane protein which is unlikely to be exposed to the extracellular environment. The mitochondrial isolate is likely to be a false positive. 
A
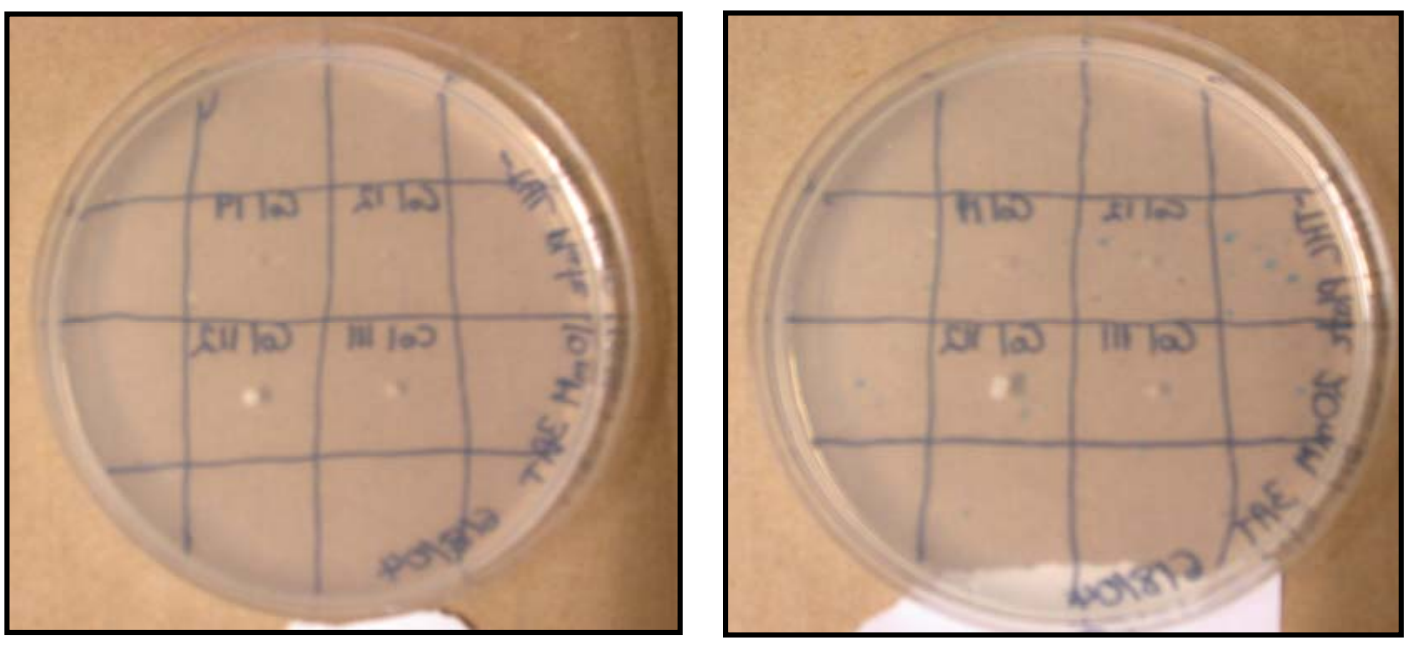

B
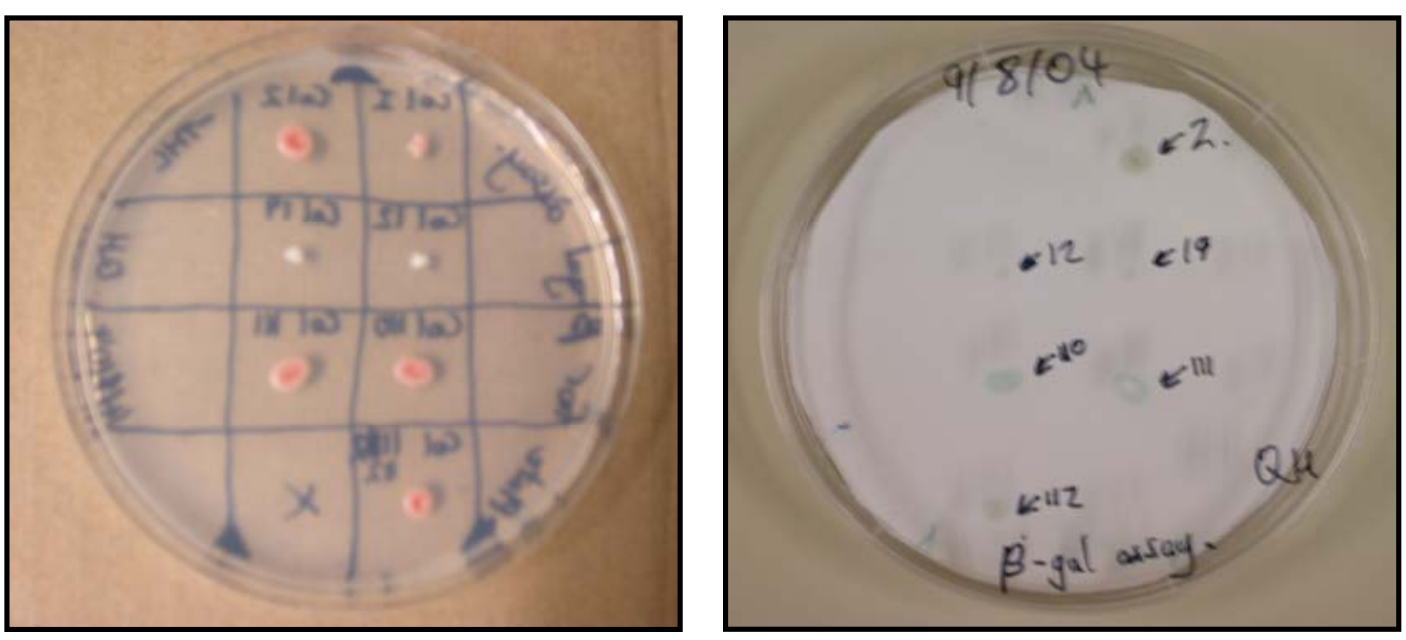

Figure 5.3- Colony screening of positives obtained from large scale Yeast-2-Hybrid Screen. Selected colonies from the large scale screen of the liver and bone marrow cDNA libraries that utilised the pBTM116/PS vector as bait, assessed for; A) growth on 10 and 20mM 3-amino-1,2,4triazole (3AT) and ; B) $\beta$-galactosidase ( $\beta$-Gal) activity. 
The small scale screen was followed up by cloning the entire PROZ cDNA into the pGADT7 vector. The decision to follow up PZ rather than any of the other isolates was based on similarities with PS as both play roles in downregulating the coagulation cascade. This was used in a cotransformation procedure with the PS/pBTM116 vector to ascertain if the full length PZ/AD fusion protein was able to interact with the PS/BD protein to drive transcription of the HIS3 and LacZ reporter genes. In excess of 200 colonies grew on Yc agar (-His,Trp,Leu) plates (Figure 5.5A) and 100 were then isolated by transferring them onto a grid Yc agar (-His,Try,Leu) plate (Figure 5.5B). Of these 100 colonies, 40 of these were able to grow in the presence of 10 and $20 \mathrm{nM} 3 \mathrm{AT}$ supplemented into Yc agar (-His, Trp, Leu) plates and 6 of these were subsequently shown to be $\beta$-Gal positive (results not shown).

PROZ Sequence acacagctgcacaggtcgtgccccgaggctcctgctgccggcacctcccccagc

PROZ Sequence ctggactttggctgtgtttgtagccctgtcccagcactccgggtgggaatggca

PROZ Sequence ggctgcgtcccactgctcc

Figure 5.4- The PROZ sequence identified in the large scale Y-2-H screen. The PROZ sequence was detected using the full length PROS1 cDNA bait (PS/pBTM116) in a large scale screen of the bone marrow and liver cDNA libraries.. Note- Bold denotes mRNA. 
A

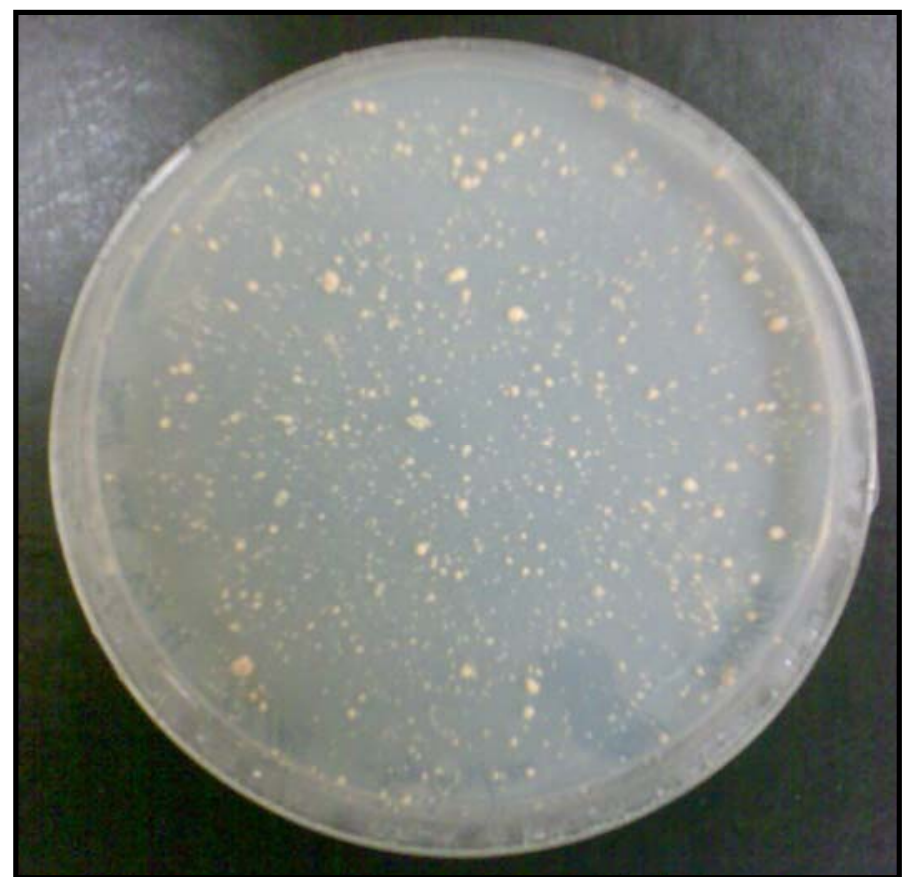

B

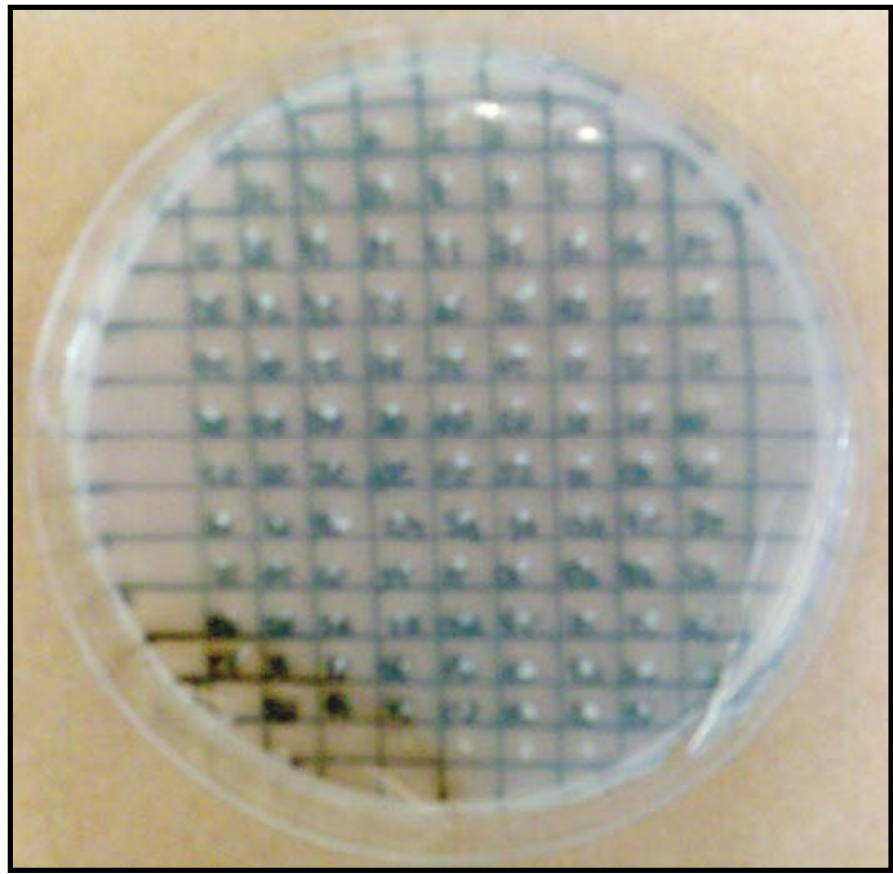

Figure 5.5 Results of small scale Yeast-2Hybrid screen. The small scale screen using the PZ/pGADT7 and PS/pBTM116 vectors generated dozens of colonies that were able to grow on Yc agar (-His, Trp, Leu) plates, A); and continued to grow after re-plating, B). 


\subsection{DISCUSSION}

The results of the initial Y-2-H liver and bone marrow cDNA library screen using the PScDNA containing pBTM116 vector identified 6 clones of interest. DNA sequencing identified these clones as; the anticoagulant PZ (or a PZ-related protein), another plasma derived protein, $\alpha$-1-antichymotrypsin; a cytoskeletal protein, talin 1; inflammatory response defensin proteins (2) and a mitochondrial isolate. All six isolates demonstrated growth in the presence of 20nM 3AT supplemented into Yc agar (-His, Trp, Leu) plates and exhibited $\beta$-Gal activity, suggesting that the protein-protein interactions were strong. Alignment of the six sequences identified found no homology between them, including the two defensin isolates (see Appendix 7)

Of the six findings, the mitochondrial isolate stands out as a definite false positive. Mitochondrial proteins are routinely isolated in many $\mathrm{Y}-2-\mathrm{H}$ screens and listed as known false positives (Van Criekinge and Beyaert). Talin-1 is a structural protein that connects intracellular actin fibres with membrane bound molecules (Senetar and McCann, 2005). Therefore the talin-1 discovery may also represent another false positive, although it is interesting to note that one study did demonstrate talin-1 androgen responsiveness in a prostatic stromal cell line (Betts et al., 1998).

The two defensin isolates are of interest as they are inflammatory mediated peptides that are predominantly produced by neutrophils (De Smet and Contreras, 2005). The role of PS in the inflammatory response was discussed in Chapter 1. In addition, a previous report has demonstrated enhanced binding of C4b-BP bound PS to the surface of neutrophils in the presence of calcium (Furmaniak-Kazmierczak et al., 1993). An 
interaction between PS and defensins may exist to anchor the antimicrobial defensins to the neutrophils, localising at site of infection and inflammation. There is no published data detailing regulation of defensin expression by hormones other that glucocorticoids (Chaly et al., 2000).

Work performed previously in this laboratory also identified an $\alpha$-1-antichymotrypsin $(\alpha 1 \mathrm{ACT})$ protein-protein interaction, in that case, with C-reactive protein (Sarich, 2002). Like PS, $\alpha 1 \mathrm{ACT}$ is involved in acute phase inflammatory responses, with plasma levels increasing 4.5 fold in response to inflammation and, is also synthesized in the liver (Kalsheker et al., 2002). $\alpha 1 \mathrm{ACT}$ is a member of the large serine protease inhibitor family, that includes antithrombin and plasminogen activator inhibitor-1, which are mediators of complement activation and blood coagulation (van Gent et al., 2003). Interestingly $\alpha 1 \mathrm{ACT}$, like the defensins, also relates to neutrophils. The primary role of $\alpha 1 \mathrm{ACT}$ is as an inhibitor of the proteinase Cathepsin $\mathrm{G}$ which is released by stimulated neutrophils (Owen et al., 1995). Cathepsin G is a potent activator of platelets and promotes the generation of thrombin via prothrombinase activation and fibrin monomer release (Goel and Diamond, 2003, Sambrano et al., 2000). Cathepsin G lacks any activity when bound to circulating $\alpha 1 \mathrm{ACT}$ (Kalsheker et al., 2002). Of particular interest is the finding that $\alpha 1 \mathrm{ACT}$ mRNA expression was induced by $\mathrm{E}_{2}$, when studied using the breast carcinoma cell line, MCF-7 (Yamamura et al., 2004). No data showing increased $\alpha 1 \mathrm{ACT}$ protein levels in response to $\mathrm{E}_{2}$ has been published. However, if $\mathrm{E}_{2}$ up-regulation of $\alpha 1 \mathrm{ACT}$ protein levels does occur and $\alpha 1 \mathrm{ACT}$ is a true interactor with PS, then a possible oestrogenic mechanism could be proposed and warrants further investigation. 
The PZ isolate was of particular interest. The positive PZ fragment was not a full length PZ cDNA but rather a fragment that corresponded to sequence of the promoter region and the 5 terminal of exon 1 . Using the pGADT7 expression vector to generate a full length PZ chimera protein resulted in growth on the selective Yc agar plates (-His,Trp,Leu/+3AT) when the full length PZ was cotransformed with the full length PScDNA/pBTM116 vector suggesting a strong interaction between the two species. Unfortunately, further confirmation experiments could not be carried out due to the inability to generate liquid cultures required for plasmid extraction and subsequent sequence analysis. Several reports discuss the phenomenon of protein toxicity whereby growth of the host yeast strain is inhibited or terminated by the overexpression of the introduced foreign protein (Van Criekinge and Beyaert, 1999). If this was the case with the full length PZ then it may explain why only the N-terminal PZ fragment was identified in the original liver and bone marrow cDNA library screen.

There are many similarities between PS and PZ that further add to the interest of an in vivo relationship. Both are anticoagulant proteins that lack proteolytic activity, acting instead as cofactors; PS as cofactor to aPC and PZ a cofactor to protein Z-dependant inhibitor (ZPI). ZPI inhibits aFX activity in a process that is increase 1000 -fold via the interaction of PZ (Han et al., 2000). However, unlike the well characterised link between low PS levels and increased thrombotic risk, the effect of low PZ in isolation, does not appear to be a risk factor for venous thrombosis (Santacroce et al., 2006, Martinelli et al., 2005, Al-Shanqeeti et al., 2005). A possible link to stroke has been suggested but is still heavily debated (Sofi et al., 2005, McQuillan et al., 2003, Heeb et al., 2002, Vasse et al., 2001).

The PS/PZ interaction is unlikely to be a hormonally responsive regulatory factor governing changes in the levels of PS seen in COC users and pregnant women. PZ 
levels are relatively consistent between the sexes, unlike PS which is significantly higher in males compared to females, and suggests that $\mathrm{PZ}$ expression is not influenced by hormonal status (Quack Loetscher et al., 2005). Interestingly, in direct contrast to PS, levels of PZ significantly increase throughout gestation and in users of COCs (AlShanqeeti et al., 2005). In both cases, the increased concentration of PZ may be a result of the oestrogen related reduction in PS levels, altering the stoichiometric ratio between the binding partners.

\subsubsection{FolLOW UP STUDIES REQUIRED TO CONFIRM THE PS/PZ INTERACTION}

Future work to confirm an interaction between PS and PZ will involve either using a GST Pull-Down assay or a co-immunoprecipitation technique. GST Pull-Down assays involve 'tagging' one of either of the proteins of interest (6xHIS-, GST, biotin) providing a means for teathering the protein to an affinity matrix (eg-glutathione). The suspected binding protein is then added followed by electrophoretic analysis SDS PAGE using silver staining, western blotting or radiographic techniques to visualise the interaction. Co-immunoprecipitation is similar, but instead of immobilising one of the proteins, monoclonal or polyclonal antibodies directed against one of the two proteins are used to pull out the protein of interest and its binding protein, which is subsequently captured using Agarose A or G beads.

These techniques should also be applied to investigate the possible PS/ $\alpha 1$ ACT interaction if a small scale study using full length PS cDNA as a bait and $\alpha 1 \mathrm{ACT}$ cDNA as the fish is positive. 


\section{CHAPTER 6}

\section{Concluding Remarks and Future Directions}


The central aim of this thesis centred on identifying a mechanism to explain why PS levels decrease in response to raised oestrogen concentrations. Several strategies were applied to determine the exact molecular process involved, including analysis of the PROS1 gene and its promoter in addition to the PS molecule itself. Investigation of the PROS1 promoter region uncovered a possible regulatory link between transcriptional regulation and oestrogen via a process involving ER $\alpha$. Although the exact mechanism is unclear the preliminary work done in this thesis provides a starting point for future experimental work detailed in Chapter 4.

However, it is the identification of progesterone as an activator of PROS1 transcription that possibly represents the greater finding, providing an important counterbalance to the downregulatory effect of oestrogen, especially in the context of oral contraceptive use. As detailed in the first chapter, combined oral contraceptive formulations comprise both an oestrogen and a progestin component. The oestrogen concentration may vary but in close to $100 \%$ of preparations is the synthetic ethinyl oestradiol (a small number contain mestranol, a prodrug that is converted to ethinyl oestradiol). As detailed in Chapter 1, the progestin component can be one of dozens of different progestin isoforms derived from parent molecules such as testosterone, progesterone and more recently spironolactone (drospirenone). It is well reported that these progesterone homologues each have separate and distinct biological profiles. Data included in this thesis reinforces this clearly, finding that the progesterone derived medroxyprogesterone significantly increased PROS1 promoter activity when compared to the parent molecule.

Therefore, it is the transcriptional activation by progestins that stands as the most significant finding of this body of work, providing an explanation for the observation that users of 3rd generation oral contraceptives have lower circulating levels of total and 
particularly free PS (Kemmeren et al., 2004). Interestingly, progestin-only formulations (progestin only pill; POP) have been shown to increase the concentration of total and free PS (Kemmeren et al., 2004). Winkler et al. (1998) found that users of POPs containing the $3^{\text {rd }}$ Generation progestin, desogestrel had greater PS increases compared to users of levonorgestrel containing POPs. However, the desogestrel concentration assessed was 2.5 stronger than that of levonorgestrel. Kemmeren et al. (2004) addressed this variance and assessed both progestins side-by-side in POP formulations and found the levonorgestrel containing form to be the more potent.

Currently, work on a new 'hormone-free' form of OC is well underway. These latest OCs will use progesterone receptor modulators (PRMs) such as RU486 (ChabbertBuffet et al., 2005, Baird et al., 2003). This thesis demonstrates a direct involvement of PR-B in the up-regulation of the PROS1 promoter, a mechanism that is blocked by RU486. Thus, the long term use of PRMs may predispose some individuals to an increased thrombotic risk, resulting from reduced PS production.

Furthermore, identification of the cis-element within the promoter that binds PR-B (nucleotides -397 to -417 ), initiating the progestin response, could explain other endocrine related PS observations. As previously discussed, unlike the oestrogen receptors, progesterone receptors share homology with other hormone receptors including mineralcorticoid, glucocorticoid and androgen receptors that interact with similar cis-elements in the promoter regions of genes. Data presented in Chapter 4 demonstrates the responsiveness of the PROS1 promoter to corticosterone and by extrapolation, could explain the clear differences between the PS levels of males and females. If the cis-element is capable of responding to ligand bound androgen receptor then the higher levels of testosterone in males could be generating greater expression of PS. 
There are several other interesting observations that can be made in regards to the finding that the PROS1 promoter is responsive to the glucocorticoid corticosterone. For example it is known that PS levels increase with age (Goodwin et al., 2002), particularly in women post-menopause (Henkens et al., 1995), a time when cortisol levels increase (Woods et al., 2006). Although the obvious reduction in oestrogen in postmenopausal women is probably the overriding hormonal change altering PS levels.

Finally, as discussed in Chapter 5, the identification of PZ as a possible PS binding partner may explain the previously described increase in PZ levels observed during pregnancy and although levels of PZ have been reported to increase in users of oral contraceptives, there is no comparative 2 nd generation/3rd generation OC data currently available.

Therefore, the work presented in this thesis describes a new interaction between the haematological and endocrine systems. However, it also details several results that will form the basis for some fascinating work to be continued in future studies. The final figure (Figure 6.1) summarises the findings of this body of work and the aspects of PS production that require further investigation. 


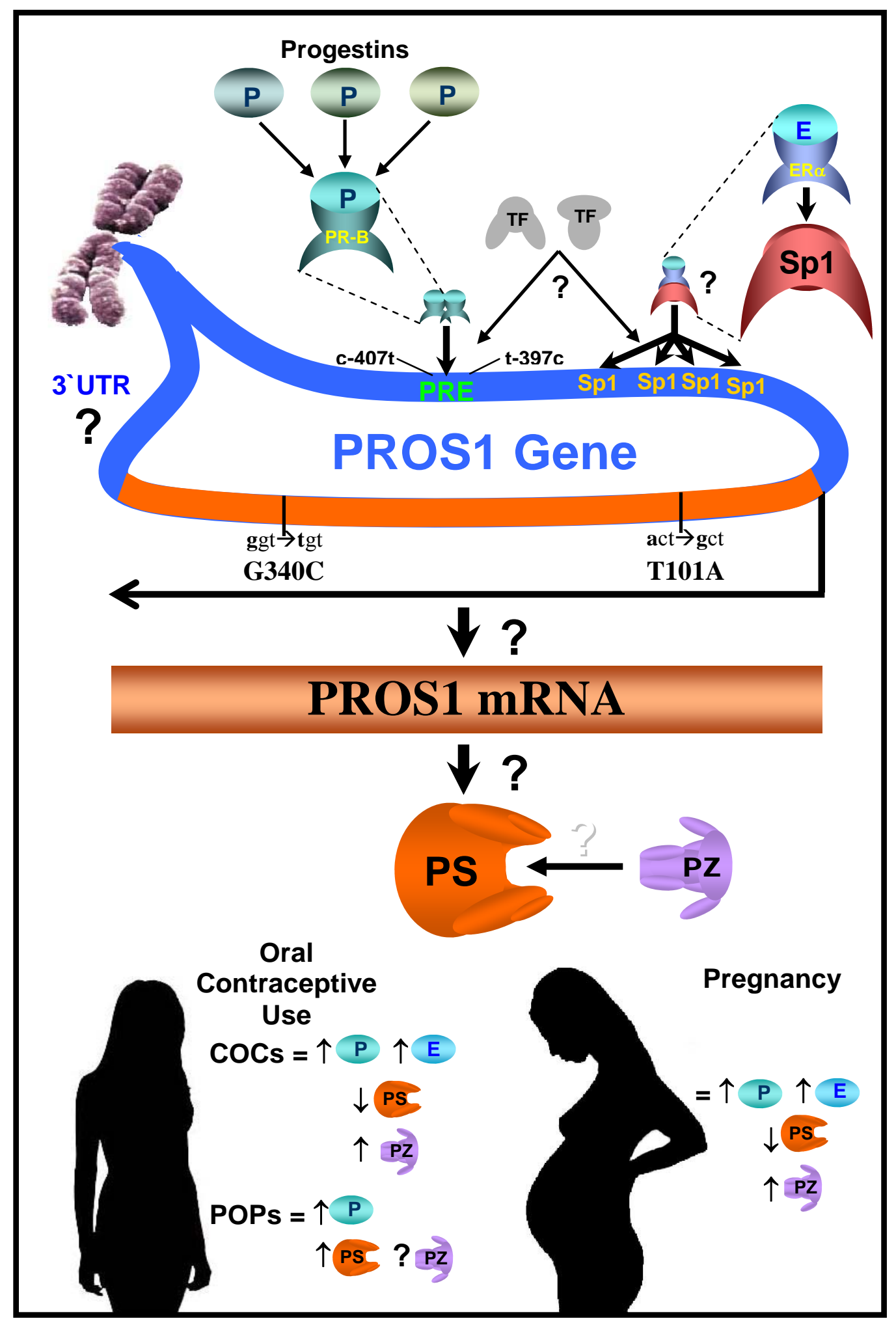

Figure 6.1 Protein S production. A summary of the work presented in this thesis and its relation to the global picture of PS production. The novel coding region T101A and G340C mutations were detected via CSHA. The CSHA also initiated the identification of the PRE/PR-B based up-regulatory mechanism within the PROS1 promoter region after the detection of the t-397c and c-407t variants. Oestrogenic down-regulation of the PROS1 promoter was also demonstrated but the exact process remains unclear, although it may involve a mechanism incorporating the Sp1 motifs previously identified by de Wolf et al. (2006). Both the progestin and oestrogen mechanisms probably require the involvement of additional transcriptional factors (TFs) that still need to be identified. The rate of upregulation of the PROS1 promoter by progestin's is isoform dependant, explaining the differential effects of 2nd and 3rd generation Combined Oral Contraceptives (COCs) on PS levels. The use of Progestin Only Pill (POPS) formulations, which lack an oestrogen component, are associated with increased PS levels. The identification of protein Z (PZ) as a possible binding partner to PS may explain the relationship in pregnancy between decreased PS and increased PZ levels. Several key questions remained unanswered such as the effects, if any, of oestrogens and progestins on the 3`Untranslated region (3`UTR) of PROS1, mRNA stability, translation and protein stability. 


\section{REFERENCES}


Adachi, T. (2005) Curr Drug Targets, 6, 585-92.

Akkawat, B. and Rojnuckarin, P. (2005) J Med Assoc Thai, 88 Suppl 4, S249-54.

Aldrighi, J. M., De Campos, L. S., Eluf Gebara, O. C., Petta, C. A. and Bahamondes, L. (2006) Gynecol Endocrinol, 22, 1-4.

Al-Farra, H. M., Al-Fahoum, S. K. and Tabbaa, M. A. (2005) Saudi Med J, 26, 1930-5.

Alhenc-Gelas, M., Plu-Bureau, Guillonneau, S., Kirzin, J. M., Aiach, M., Ochat, N. and Scarabin, P. Y. (2004) J Thromb Haemost., 2, 1594-1600.

Al-Shanqeeti, A., van Hylckama Vlieg, A., Berntorp, E., Rosendaal, F. R. and Broze, G. J., Jr. (2005) Thromb Haemost, 93, 411-3.

Anderson, H. A., Maylock, C. A., Williams, J. A., Paweletz, C. P., Shu, H. and Shacter, E. (2003) Nat.Immunol., 4, 87-91.

Anderson, H. A. and Shacter, E. (2004) Curr Pharm Des, 10, 929-37.

Baillargeon, J. P., McClish, D. K., Essah, P. A. and Nestler, J. E. (2005) J Clin Endocrinol Metab, 90, 3863-70.

Baird, D. T., Brown, A., Cheng, L., Critchley, H. O. D., Lin, S., Narvekar, N. and Williams, A. R. W. (2003) Steroids

The 2nd International Symposium on Progestins, Progesterone Receptor Modulators and Progesterone Antagonists, 68, 1099-1105.

Balmer, L. A., Beveridge, D. J., Jazayeri, J. A., Thomson, A. M., Walker, C. E. and Leedman, P. J. (2001) Mol Cell Biol, 21, 2070-84.

Bammann, B. L., Coulam, C. B. and Jiang, N. S. (1980) Am J Obstet Gynecol, 137, 293-8.

Baroni, M., Mazzola, G., Kaabache, T., Borgel, D., Gandrille, S., Vigano' D'Angelo, S., Marchetti, G., di Iasio, M. G., Pinotti, M., D'Angelo, A. and Bernardi, F. (2006) J Thromb Haemost, 4, 186-91.

Bartel, P. L. and Fields, S. (1995) Methods Enzymol, 254, 241-63.

Basurto, L., Saucedo, R., Zarate, A., Martinez, C., Gaminio, E., Reyes, E. and Hernandez, M. (2006) Gynecol Obstet Invest, 61, 61-4.

Battistelli, S., Vittoria, A., Cappelli, R., Stefanoni, M. and Roviello, F. (2005) Eur J Surg Oncol, 31, 798-802. 
Beato, M., Chavez, S. and Truss, M. (1996) Steroids, 61, 240-51.

Benzakour, O. and Kanthou, C. (2000) Blood, 95, 2008-14.

Bertina, R. M., Ploos van Amstel, H. K., van Wijngaarden, A., Coenen, J., Leemhuis, M. P., Deutz-Terlouw, P. P., van, d. L., I and Reitsma, P. H. (1990) Blood, 76, 538-548.

Betts, A. M., Collett, G. P., Neal, D. E. and Robson, C. N. (1998) FEBS Lett, 434, 6670.

Bloemenkamp, K. W. (2005) Thromb Res, 115 Suppl 1, 1-6.

Borgel, D., Duchemin, J., Alhenc-Gelas, M., Matheron, C., Aiach, M. and Gandrille, S. (1996) J Lab Clin Med, 128, 218-27.

Borgel, D., Gaussem, P., Garbay, C., Bachelot-Loza, C., Kaabache, T., Liu, W. Q., Brohard-Bohn, B., Le Bonniec, B., Aiach, M. and Gandrille, S. (2001) Biochem J, 360, 499-506.

Borgfeldt, C., Li, C. and Samsioe, G. (2004) Climacteric, 7, 78-85.

Brady, J. N., Notley, C., Cameron, C. and Lillicrap, D. (1998) Br J Haematol, 101, $273-$ 9.

Bremme, K. A. (2003) Best Pract Res Clin Haematol, 16, 153-68.

Brenner, B. (2004) Thromb.Res., 114, 409-414.

Brent, R. and Ptashne, M. (1985) Cell, 43, 729-36.

Brown, M. A., Hague, W. M., Higgins, J., Lowe, S., McCowan, L., Oats, J., Peek, M. J., Rowan, J. A. and Walters, B. N. (2000) Aust N Z J Obstet Gynaecol, 40, 133-8.

Brummel, K. E., Paradis, S. G., Butenas, S. and Mann, K. G. (2002) Blood, 100, $148-$ 52.

Campagnoli, C., Abba, C., Ambroggio, S. and Peris, C. (2003) Maturitas, 46 Suppl 1, S39-44.

Casey, M. L., MacDonald, P. C. and Andersson, S. (1994) J Clin Invest, 94, 2135-41.

Castro-Rivera, E., Samudio, I. and Safe, S. (2001) J Biol Chem, 276, 30853-61.

Ceriello, A., Giugliano, D., Quatraro, A., Marchi, E., Barbanti, M. and Lefebvre, P. (1990) Diabetes, 39, 447-9. 
Cerneca, F., Ricci, G., Simeone, R., Malisano, M., Alberico, S. and Guaschino, S. (1997) Eur J Obstet Gynecol Reprod Biol, 73, 31-6.

Chabbert-Buffet, N., Meduri, G., Bouchard, P. and Spitz, I. M. (2005) Hum Reprod Update, 11, 293-307.

Chaly, Y. V., Paleolog, E. M., Kolesnikova, T. S., Tikhonov, II, Petratchenko, E. V. and Voitenok, N. N. (2000) Eur Cytokine Netw, 11, 257-66.

Cheng, X., Shimizu, I., Yuan, Y., Wei, M., Shen, M., Huang, H., Urata, M., Sannomiya, K., Fukuno, H., Hashimoto-Tamaoki, T. and Ito, S. (2006) Life Sci.

Chou, L. S., Lyon, E. and Wittwer, C. T. (2005) Am J Clin Pathol, 124, 330-8.

Choy, Y. S., Dabora, S. L., Hall, F., Ramesh, V., Niida, Y., Franz, D., Kasprzyk-Obara, J., Reeve, M. P. and Kwiatkowski, D. J. (1999) Ann Hum Genet, 63, 383-91.

Clark, P., Brennand, J., Conkie, J. A., McCall, F., Greer, I. A. and Walker, I. D. (1998) Thromb Haemost, 79, 1166-70.

Cohen, A. T., Agnelli, G., Anderson, F. A., Arcelus, J. I., Bergqvist, D., Brecht, J. G., Greer, I. A., Heit, J. A., Hutchinson, J. L., Kakkar, A. K., Mottier, D., Oger, E., Samama, M. M. and Spannagl, M. (2007) Thromb Haemost, 98, 756-764.

Collins, P., Flather, M., Lees, B., Mister, R., Proudler, A. J. and Stevenson, J. C. (2006) Eur Heart J, 27, 2046-53.

Colosimo, A., Guida, V., Scolari, A., De Luca, A., Palka, G., Rigoli, L., Meo, A., Salpietro, D. C. and Dallapiccola, B. (2003) Genet Test, 7, 269-75.

Comp, P. C., Thurnau, G. R., Welsh, J. and Esmon, C. T. (1986) Blood, 68, 881-885.

Cordera, F. and Jordan, V. C. (2006) Semin Oncol, 33, 631-41.

Cosman, F., Baz-Hecht, M., Cushman, M., Vardy, M. D., Cruz, J. D., Nieves, J. W., Zion, M. and Lindsay, R. (2005) Thromb Res, 116, 1-13.

Cushman, M. (2007) Semin Hematol, 44, 62-9.

Dahlback, B. (1991) Thromb Haemost., 66, 49-61.

Dahlback, B., Frohm, B. and Nelsestuen, G. (1990a) J Biol Chem, 265, 16082-16087.

Dahlback, B., Hildebrand, B. and Malm, J. (1990b) J Biol Chem, 265, 8127-8135.

Dahlback, B. and Stenflo, J. (1981) Proc Natl Acad Sci U S A, 78, 2512-6. 
Dahlback, B., Wiedemer, T. and Sims, P. J. (1992) Biochemistry, 31, 12769-12777.

De Smet, K. and Contreras, R. (2005) Biotechnol Lett, 27, 1337-47.

de Wolf, C. J., Cupers, R. M., Bertina, R. M. and Vos, H. L. (2005) J Thromb Haemost., 3, 410-412.

de Wolf, C. J., Cupers, R. M., Bertina, R. M. and Vos, H. L. (2006a) J Biol Chem, 281, 17635-43.

de Wolf, C. J., Cupers, R. M., Bertina, R. M. and Vos, H. L. (2006b) Arterioscler Thromb Vasc Biol, 26, 2168-74.

Deguchi, H., Bouma, B. N., Middeldorp, S., Lee, Y. M. and Griffin, J. H. (2005) J Thromb Haemost, 3, 935-8.

DeMayo, F. J., Zhao, B., Takamoto, N. and Tsai, S. Y. (2002) Ann N Y Acad Sci, 955, 48-59; discussion 86-8, 396-406.

Denis, C. V., Roberts, S. J., Hackeng, T. M. and Lenting, P. J. (2005) Arterioscler Thromb Vasc Biol, 25, 2209-15.

Di Bitondo, R., Hall, A. J., Peake, I. R., Iacoviello, L. and Winship, P. R. (2002) Hum Mol Genet, 11, 723-31.

Dillmon, M. S., Saag, M. S., Hamza, S. H., Adler, B. K. and Marques, M. B. (2005) AIDS Res Hum Retroviruses, 21, 753-6.

Donaghue, C., Westley, B. R. and May, F. E. (1999) Mol Endocrinol, 13, 1934-50.

Dong, L., Wang, W., Wang, F., Stoner, M., Reed, J. C., Harigai, M., Samudio, I., Kladde, M. P., Vyhlidal, C. and Safe, S. (1999) J Biol Chem, 274, 32099-107.

Drakenberg, T., Ghasriani, H., Thulin, E., Thamlitz, A. M., Muranyi, A., Annila, A. and Stenflo, J. (2005) Biochemistry, 44, 8782-9.

Duan, R., Porter, W. and Safe, S. (1998) Endocrinology, 139, 1981-90.

Duchemin, J., Gandrille, S., Borgel, D., Feurgard, P., Alhenc-Gelas, M., Matheron, C., Dreyfus, M., Dupuy, E., Juhan-Vague, I. and Aiach, M. (1995) Blood, 86, 3436-3443.

Dunn, J. F., Nisula, B. C. and Rodbard, D. (1981) J Clin Endocrinol Metab, 53, 58-68.

Dykes, A. C., Walker, I. D., McMahon, A. D., Islam, S. I. and Tait, R. C. (2001) Br J Haematol, 113, 636-41. 
Eldor, A. (2002) Eur J Obstet Gynecol Reprod Biol, 104, 3-13.

Enmark, E., Pelto-Huikko, M., Grandien, K., Lagercrantz, S., Lagercrantz, J., Fried, G., Nordenskjold, M. and Gustafsson, J. A. (1997) J Clin Endocrinol Metab, 82, 4258-65.

Esmon, C. T. (1987) Science, 235, 1348-52.

Esmon, N. L., Owen, W. G. and Esmon, C. T. (1982) J Biol Chem, 257, 859-64.

Esparza-Gordillo, J., Soria, J. M., Buil, A., Souto, J. C., Almasy, L., Blangero, J., Fontcuberta, J. and de Cordoba, S. R. (2003) Immunogenetics, 54, 862-6.

Espinosa-Parrilla, Y., Morell, M., Borrell, M., Souto, J. C., Fontcuberta, J., Estivill, X. and Sala, N. (2000a) Hum Mutat, 15, 463-73.

Espinosa-Parrilla, Y., Morell, M., Souto, J. C., Tirado, I., Fontcuberta, J., Estivill, X. and Sala, N. (1999) Hum Mutat, 14, 30-9.

Espinosa-Parrilla, Y., Yamazaki, T., Sala, N., Dahlback, B. and de Frutos, P. G. (2000b) Blood, 95, 173-9.

Fair, D. S., Marlar, R. A. and Levin, E. G. (1986) Blood, 67, 1168-1171.

Farsetti, A., Misiti, S., Citarella, F., Felici, A., Andreoli, M., Fantoni, A., Sacchi, A. and Pontecorvi, A. (1995) Endocrinology, 136, 5076-83.

Farsetti, A., Narducci, M., Moretti, F., Nanni, S., Mantovani, R., Sacchi, A. and Pontecorvi, A. (2001) Endocrinology, 142, 3380-8.

Fay, P. J. (2004) Blood Rev, 18, 1-15.

Fernandez, J. A. and Griffin, J. H. (1994) J Biol Chem, 269, 2535-2540.

Fernandez, J. A., Griffin, J. H., Chang, G. T., Stam, J., Reitsma, P. H., Bertina, R. M. and Bouma, B. N. (1998) Blood Cells Mol Dis, 24, 101-112.

Fernandez, J. A., Heeb, M. J. and Griffin, J. H. (1993) J Biol Chem, 268, 16788-16794.

Fernandez-Valdivia, R., Mukherjee, A., Mulac-Jericevic, B., Conneely, O. M., DeMayo, F. J., Amato, P. and Lydon, J. P. (2005) Semin Reprod Med, 23, 22-37.

Fields, S. and Song, O. (1989) Nature, 340, 245-6.

Fields, S. and Sternglanz, R. (1994) Trends Genet, 10, 286-92. 
Flototto, T., Niederacher, D., Hohmann, D., Heimerzheim, T., Dall, P., Djahansouzi, S., Bender, H. G. and Hanstein, B. (2004) J Steroid Biochem Mol Biol, 88, 131-42.

Flouriot, G., Griffin, C., Kenealy, M., Sonntag-Buck, V. and Gannon, F. (1998) Mol Endocrinol, 12, 1939-54.

Furie, B. and Furie, B. C. (1992) N Engl J Med, 326, 800-6.

Furie, B. and Furie, B. C. (2005) J Clin Invest, 115, 3355-62.

Furmaniak-Kazmierczak, E., Hu, C. Y. and Esmon, C. T. (1993) Blood, 81, 405-11.

Gandrille, S., Borgel, D., Ireland, H., Lane, D. A., Simmonds, R., Reitsma, P. H., Mannhalter, C., Pabinger, I., Saito, H., Suzuki, K., Formstone, C., Cooper, D. N., Espinosa, Y., Sala, N., Bernardi, F. and Aiach, M. (1997) Thromb Haemost., 77, 1201 1214.

Gandrille, S., Borgel, D., Sala, N., Espinosa-Parrilla, Y., Simmonds, R., Rezende, S., Lind, B., Mannhalter, C., Pabinger, I., Reitsma, P. H., Formstone, C., Cooper, D. N., Saito, H., Suzuki, K., Bernardi, F. and Aiach, M. (2000) Thromb Haemost, 84, 918.

Gershagen, S., Fernlund, P. and Edenbrandt, C. M. (1991) J Steroid Biochem Mol Biol, 40, 763-9.

Gershagen, S., Fernlund, P. and Lundwall, A. (1987) FEBS Lett, 220, 129-135.

Gietz, D., St Jean, A., Woods, R. A. and Schiestl, R. H. (1992) Nucleic Acids Res, 20, 1425.

Gietz, R. D., Schiestl, R. H., Willems, A. R. and Woods, R. A. (1995) Yeast, 11, 35560 .

Giri, T. K., Garcia, d. F. and Dahlback, B. (2000) Thromb Haemost., 84, 413-419.

Goel, M. S. and Diamond, S. L. (2002) Blood, 100, 3797-803.

Goel, M. S. and Diamond, S. L. (2003) J Biol Chem, 278, 9458-63.

Goodwin, A. J., Rosendaal, F. R., Kottke-Marchant, K. and Bovill, E. G. (2002) Arch Pathol Lab Med, 126, 1349-66.

Goswami, R., Lacson, R., Yang, E., Sam, R. and Unterman, T. (1994) Endocrinology, 134, 736-43.

Green, S., Walter, P., Greene, G., Krust, A., Goffin, C., Jensen, E., Scrace, G., Waterfield, M. and Chambon, P. (1986) J Steroid Biochem, 24, 77-83. 
Greene, G. L., Gilna, P., Waterfield, M., Baker, A., Hort, Y. and Shine, J. (1986) Science, 231, 1150-4.

Gross, E., Arnold, N., Goette, J., Schwarz-Boeger, U. and Kiechle, M. (1999) Hum Genet, 105, 72-8.

Guiochon-Mantel, A., Loosfelt, H., Lescop, P., Sar, S., Atger, M., Perrot-Applanat, M. and Milgrom, E. (1989) Cell, 57, 1147-54.

Hackeng, T. M., Hessing, M., van 't Veer, C., Meijer-Huizinga, F., Meijers, J. C., de Groot, P. G., van Mourik, J. A. and Bouma, B. N. (1993) J Biol Chem, 268, 3993-4000.

Hackeng, T. M., Yegneswaran, S., Johnson, A. E. and Griffin, J. H. (2000) Biochem J, 349 Pt 3, 757-764.

Hall, A. J., Peake, I. R. and Winship, P. R. (2006) Br J Haematol, 135, 538-46.

Han, X., Fiehler, R. and Broze, G. J., Jr. (2000) Blood, 96, 3049-55.

Hardig, Y. and Dahlback, B. (1996) J Biol Chem, 271, 20861-20867.

Harris, K. W. and Esmon, C. T. (1985) J Biol Chem, 260, 2007-10.

Hayashi, K. and Yandell, D. W. (1993) Hum Mutat, 2, 338-46.

He, X., Shen, L., Villoutreix, B. O. and Dahlback, B. (1998) J Biol Chem, 273, 2744927458.

Heald, A., Kaushal, K., Anderson, S., Redpath, M., Durrington, P. N., Selby, P. L. and Gibson, M. J. (2005) Gynecol Endocrinol, 20, 176-82.

Heald, A., Selby, P. L., White, A. and Gibson, J. M. (2000) Am J Obstet Gynecol, 183, 593-600.

Heeb, M. J. and Griffin, J. H. (2002) Blood Cells Mol Dis, 29, 190-9.

Heeb, M. J., Koenen, R. R., Fernandez, J. A. and Hackeng, T. M. (2004) J

Thromb.Haemost., 2, 1766-1773.

Heeb, M. J., Paganini-Hill, A., Griffin, J. H. and Fisher, M. (2002) Blood Cells Mol Dis, 29, 139-44.

Heit, J. A., Ketterling, R. P., Zapata, R. E., Ordonez, S. M., Kasper, C. K. and Sommer, S. S. (1999a) Haemophilia, 5, 73-5. 
Heit, J. A., Silverstein, M. D., Mohr, D. N., Petterson, T. M., O'Fallon, W. M. and Melton, L. J., 3rd (1999b) Arch Intern Med, 159, 445-53.

Henkens, C. M., Bom, V. J., Van der, S. W., Pelsma, P. M., Sibinga, C. T., de Kam, P. J. and van der, M. J. (1995) Thromb.Haemost., 74, 1271-1275.

Hooper, W. C., Phillips, D. J. and Evatt, B. L. (1996) Thromb Res, 81, 315-26.

Hooper, W. C., Phillips, D. J. and Evatt, B. L. (1997) Thromb Haemost, 77, 1014-9.

Hooper, W. C., Phillips, D. J., Ribeiro, M., Benson, J. and Evatt, B. L. (1995) Thromb Haemost, 73, 819-24.

Hryszko, T., Suzuki, Y., Mogami, H. and Urano, T. (2005) FEBS Lett, 579, 6023-6.

Htun, H., Holth, L. T., Walker, D., Davie, J. R. and Hager, G. L. (1999) Mol Biol Cell, 10, 471-86.

Ignar-Trowbridge, D. M., Pimentel, M., Teng, C. T., Korach, K. S. and McLachlan, J. A. (1995) Environ Health Perspect, 103 Suppl 7, 35-8.

Ignar-Trowbridge, D. M., Teng, C. T., Ross, K. A., Parker, M. G., Korach, K. S. and McLachlan, J. A. (1993) Mol Endocrinol, 7, 992-8.

Ing, N. H. (2005) Biol Reprod, 72, 1290-6.

Isomaa, V. V., Ghersevich, S. A., Maentausta, O. K., Peltoketo, E. H., Poutanen, M. H. and Vihko, R. K. (1993) Ann Med, 25, 91-7.

Jaksch, M., Gerbitz, K. D. and Kilger, C. (1995) Clin Biochem, 28, 503-9.

Jensen, E. V. and Jacobsen, H. I. (1962) Recent Prog Horm Res, 18, 387-414.

Jesty, J. and Silverberg, S. A. (1979) J Biol Chem, 254, 12337-45.

Johansson, A. M., Hillarp, A., Sall, T., Zoller, B., Dahlback, B. and Hallden, C. (2005) Thromb Haemost., 94, 951-957.

Kafrissen, M. and Adashi, E. (2003) In Williams Textbook of Endocrinology(Eds, Larsen, P. R., Kronenberg, H. M., Melmed, S. and Polonsky, K. S.), pp. 665-708.

Kalsheker, N., Morley, S. and Morgan, K. (2002) Biochem Soc Trans, 30, 93-8.

Kastner, P., Krust, A., Turcotte, B., Stropp, U., Tora, L., Gronemeyer, H. and Chambon, P. (1990) Embo J, 9, 1603-14. 
Kelley, K. M., Rowan, B. G. and Ratnam, M. (2003) Cancer Res, 63, 2820-8.

Kemmeren, J. M., Algra, A. and Grobbee, D. E. (2001a) J Intern Med, 250, 441-8.

Kemmeren, J. M., Algra, A. and Grobbee, D. E. (2001b) BMJ, 323, 131-134.

Kemmeren, J. M., Algra, A., Meijers, J. C., Tans, G., Bouma, B. N., Curvers, J., Rosing, J. and Grobbee, D. E. (2004) Blood, 103, 927-33.

Kimura, R., Honda, S., Kawasaki, T., Tsuji, H., Madoiwa, S., Sakata, Y., Kojima, T., Murata, M., Nishigami, K., Chiku, M., Hayashi, T., Kokubo, Y., Okayama, A., Tomoike, H., Ikeda, Y. and Miyata, T. (2006) Blood, 107, 1737-8.

Koenen, R. R., Christella, M., Thomassen, L. G., Tans, G., Rosing, J. and Hackeng, T. M. (2005) Thromb Haemost, 93, 853-9.

Koenen, R. R., Gomes, L., Tans, G., Rosing, J. and Hackeng, T. M. (2004) Thromb Haemost, 91, 1105-14.

Kolev, K. and Machovich, R. (2003) Thromb Haemost, 89, 610-21.

Komiyama, Y., Pedersen, A. H. and Kisiel, W. (1990) Biochemistry, 29, 9418-25.

Koster, T., Rosendaal, F. R., Reitsma, P. H., van der Velden, P. A., Briet, E. and Vandenbroucke, J. P. (1994) Thromb Haemost, 71, 719-22.

Kovacs, G. T. (2003) Aust N Z J Obstet Gynaecol, 43, 4-9.

Kozak, M. (1987) Nucleic Acids Res, 15, 8125-48.

Kroegel, C. and Reissig, A. (2003) Respiration, 70, 7-30.

Kuhl, H. (2005) Climacteric, 8 Suppl 1, 3-63.

Kushner, P. J., Agard, D. A., Greene, G. L., Scanlan, T. S., Shiau, A. K., Uht, R. M. and Webb, P. (2000) J Steroid Biochem Mol Biol, 74, 311-7.

Lee, A. V., Weng, C. N., Jackson, J. G. and Yee, D. (1997) J Endocrinol, 152, 39-47.

Leo, J. C., Guo, C., Woon, C. T., Aw, S. E. and Lin, V. C. (2004) Endocrinology, 145, 1314-21.

Li, C., Briggs, M. R., Ahlborn, T. E., Kraemer, F. B. and Liu, J. (2001) Endocrinology, 142, $1546-53$.

Line, B. R. (2001) Semin Nucl Med, 31, 90-101. 
Liu, D., Guo, H., Griffin, J. H., Fernandez, J. A. and Zlokovic, B. V. (2003)

Circulation, 107, 1791-6.

Lu, D., Xie, R. L., Rydzewski, A. and Long, G. L. (1997) Thromb Haemost, 77, 115663.

Lu, N. Z., Wardell, S. E., Burnstein, K. L., Defranco, D., Fuller, P. J., Giguere, V., Hochberg, R. B., McKay, L., Renoir, J. M., Weigel, N. L., Wilson, E. M., McDonnell, D. P. and Cidlowski, J. A. (2006) Pharmacol Rev, 58, 782-97.

Lu, X., Shi, Z. and Murphy, L. J. (1999) Mol Cell Endocrinol, 149, 19-28.

Lundwall, A., Dackowski, W., Cohen, E., Shaffer, M., Mahr, A., Dahlback, B., Stenflo, J. and Wydro, R. (1986) Proc Natl Acad Sci U S A, 83, 6716-20.

Ma, J. and Ptashne, M. (1988) Cell, 55, 443-6.

Mackie, I. J., Piegsa, K., Furs, S. A., Johnson, J., Bounds, W., Machin, S. J. and Guillebaud, J. (2001) Br.J Haematol., 113, 898-904.

Malm, J., He, X. H., Bjartell, A., Shen, L., Abrahamsson, P. A. and Dahlback, B. (1994) Biochem.J., 302 ( Pt 3), 845-850.

Malm, J., Laurell, M. and Dahlback, B. (1988) Br J Haematol, 68, 437-443.

Manfioletti, G., Brancolini, C., Avanzi, G. and Schneider, C. (1993) Mol Cell Biol, 13, 4976-85.

Marnach, M. L., Ramin, K. D., Ramsey, P. S., Song, S. W., Stensland, J. J. and An, K. N. (2003) Obstet Gynecol, 101, 331-5.

Martinelli, I., Legnani, C., Bucciarelli, P., Grandone, E., De, S., V and Mannucci, P. M. (2001) Thromb Haemost., 86, 800-803.

Martinelli, I., Razzari, C., Biguzzi, E., Bucciarelli, P. and Mannucci, P. M. (2005) J Thromb Haemost, 3, 2817-9.

McQuillan, A. M., Eikelboom, J. W., Hankey, G. J., Baker, R., Thom, J., Staton, J., Yi, Q. and Cole, V. (2003) Stroke, 34, 2415-2419.

Meijer-Huizinga, F., Mertens, K. and van Mourik, J. A. (1994) Thromb Haemost, 72, 408-14.

Meinardi, J. R., Henkens, C. M., Heringa, M. P. and van der Meer, J. (1997) Blood Coagul Fibrinolysis, 8, 152-4.

Metivier, R., Reid, G. and Gannon, F. (2006) EMBO Rep, 7, 161-7. 
Middeldorp, S. (2005) Gend Med, 2 Suppl A, S3-9.

Mille-Baker, B., Rezende, S. M., Simmonds, R. E., Mason, P. J., Lane, D. A. and Laffan, M. A. (2003) Blood, 101, 1416-1418.

Miyata, T., Kimura, R., Kokubo, Y. and Sakata, T. (2006) Int J Hematol, 83, 217-23.

Molino, D., De Lucia, D., Marotta, R., Perna, A., Lombardi, C., Cirillo, M. and De Santo, N. G. (2005) Kidney Int, 68, 1223-9.

Morboeuf, O., Aiach, M. and Gandrille, S. (1998) Br J Haematol, 101, 10-5.

Morboeuf, O., Borgel, D., Gaussem, P., Vincenot, A., Pittet, J. L., Aiach, M. and Gandrille, S. (2000) Thromb Haemost., 84, 604-610.

Morgan, G. E., Rowley, G., Green, P. M., Chisholm, M., Giannelli, F. and Brownlee, G. G. (1997) Br J Haematol, 98, 79-85.

Mosselman, S., Polman, J. and Dijkema, R. (1996) FEBS Lett, 392, 49-53.

Mukherjee, K., Syed, V. and Ho, S. M. (2005) Oncogene, 24, 4388-400.

Nardulli, A. M., Greene, G. L., O'Malley, B. W. and Katzenellenbogen, B. S. (1988) Endocrinology, 122, 935-44.

Nelson, R. M. and Long, G. L. (1992) J Biol Chem, 267, 8140-8145.

Nesheim, M. E., Taswell, J. B. and Mann, K. G. (1979) J Biol Chem, 254, 10952-62.

Nicolaes, G. A. and Dahlback, B. (2002) Arterioscler Thromb Vasc Biol, 22, 530-8.

Norris, L. A. and Bonnar, J. (1996) Br J Obstet Gynaecol, 103, 261-7.

O'Brien, L. M., Mastri, M. and Fay, P. J. (2000) Blood, 95, 1714-20.

Oger, E., Alhenc-Gelas, M., Lacut, K., Blouch, M. T., Roudaut, N., Kerlan, V., Collet, M., Abgrall, J. F., Aiach, M., Scarabin, P. Y. and Mottier, D. (2003) Arterioscler Thromb Vasc Biol, 23, 1671-6.

Okada, H., Yamazaki, T., Takagi, A., Murate, T., Yamamoto, K., Takamatsu, J., Matsushita, T., Naoe, T., Kunishima, S., Hamaguchi, M., Saito, H. and Kojima, T. (2006) J Thromb Haemost, 4, 2003-9.

Olivieri, O., Friso, S., Manzato, F., Guella, A., Bernardi, F., Lunghi, B., Girelli, D., Azzini, M., Brocco, G., Russo, C. and et al. (1995) Br J Haematol, 91, 465-70. 
O'Lone, R., Frith, M. C., Karlsson, E. K. and Hansen, U. (2004) Mol Endocrinol, 18, 1859-75.

Oral Contraceptive and Hemostasis Study Group. The effects of seven monophasic oral contraceptive regimens on hemostatic variables: conclusions from a large randomized multicenter study (2003) Contraception, 67, 173-85.

Orfeo, T., Brufatto, N., Nesheim, M. E., Xu, H., Butenas, S. and Mann, K. G. (2004) J Biol Chem, 279, 19580-91.

Oruc, S., Saruc, M., Koyuncu, F. M. and Ozdemir, E. (2000) Aust N Z J Obstet Gynaecol, 40, 448-50.

Osterud, B. and Rapaport, S. I. (1977) Proc Natl Acad Sci U S A, 74, 5260-4.

Owen, C. A., Campbell, M. A., Sannes, P. L., Boukedes, S. S. and Campbell, E. J. (1995) J Cell Biol, 131, 775-89.

Owen, G. I., Richer, J. K., Tung, L., Takimoto, G. and Horwitz, K. B. (1998) J Biol Chem, 273, 10696-701.

Pelletier, G. (2000) Histol Histopathol, 15, 1261-70.

Petz, L. N., Ziegler, Y. S., Schultz, J. R., Kim, H., Kemper, J. K. and Nardulli, A. M. (2004) J Steroid Biochem Mol Biol, 88, 113-22.

Pierce, A. L., Shimizu, M., Felli, L., Swanson, P. and Dickhoff, W. W. (2006) J Endocrinol, 191, 379-86.

Pincus, G. (1958) Postgrad Med, 24, 654-60.

Pinzone, J. J., Stevenson, H., Strobl, J. S. and Berg, P. E. (2004) Mol Cell Biol, 24, 4605-12.

Pittman, D. D. and Kaufman, R. J. (1989) Thromb Haemost, 61, 161-5.

Ploos van Amstel, H. K., Reitsma, P. H., van der Logt, C. P. and Bertina, R. M. (1990) Biochemistry, 29, 7853-7861.

Porter, W., Saville, B., Hoivik, D. and Safe, S. (1997) Mol Endocrinol, 11, 1569-80.

Qin, C., Singh, P. and Safe, S. (1999) Endocrinology, 140, 2501-8.

Quack Loetscher, K. C., Stiller, R., Roos, M. and Zimmermann, R. (2005) Thromb Haemost, 93, 706-9. 
Rabbitt, E. H., Lavery, G. G., Walker, E. A., Cooper, M. S., Stewart, P. M. and Hewison, M. (2002) Faseb J, 16, 36-44.

Rajaram, S., Baylink, D. J. and Mohan, S. (1997) Endocr Rev, 18, 801-31.

Ravnik-Glavac, M., Atkinson, A., Glavac, D. and Dean, M. (2002) Hum Mutat, 19, $374-$ 83.

Read, L. D., Snider, C. E., Miller, J. S., Greene, G. L. and Katzenellenbogen, B. S. (1988) Mol Endocrinol, 2, 263-71.

Reid, G., Denger, S., Kos, M. and Gannon, F. (2002) Cell Mol Life Sci, 59, 821-31.

Rezende, S. M., Lane, D. A., Zoller, B., Mille-Baker, B., Laffan, M., Dalhback, B. and Simmonds, R. E. (2002) Thromb Haemost., 87, 258-265.

Richer, J. K., Jacobsen, B. M., Manning, N. G., Abel, M. G., Wolf, D. M. and Horwitz, K. B. (2002) J Biol Chem, 277, 5209-18.

Rock, J., Garcia, C. R. and Pincus, G. (1957) Recent Prog Horm Res, 13, 323-39; discussion 339-46.

Rosendaal, F. R., Van Hylckama Vlieg, A., Tanis, B. C. and Helmerhorst, F. M. (2003) J Thromb Haemost, 1, 1371-80.

Rosing, J., Hoekema, L., Nicolaes, G. A., Thomassen, M. C., Hemker, H. C., Varadi, K., Schwarz, H. P. and Tans, G. (1995) J Biol Chem, 270, 27852-8.

Rosing, J., Middeldorp, S., Curvers, J., Christella, M., Thomassen, L. G., Nicolaes, G. A., Meijers, J. C., Bouma, B. N., Buller, H. R., Prins, M. H. and Tans, G. (1999) Lancet, 354, 2036-40.

Rosing, J., Tans, G., Nicolaes, G. A., Thomassen, M. C., van Oerle, R., van der Ploeg, P. M., Heijnen, P., Hamulyak, K. and Hemker, H. C. (1997) Br J Haematol, 97, 233-8.

Rossetti, S., Corra, S., Biasi, M. O., Turco, A. E. and Pignatti, P. F. (1995) Mol Cell Probes, 9, 195-200.

Safe, S. (2001) Vitam Horm, 62, 231-52.

Safe, S. and Kim, K. (2004) Prog Nucleic Acid Res Mol Biol, 77, 1-36.

Sambrano, G. R., Huang, W., Faruqi, T., Mahrus, S., Craik, C. and Coughlin, S. R. (2000) J Biol Chem, 275, 6819-23.

Santacroce, R., Sarno, M., Cappucci, F., Sessa, F., Colaizzo, D., Brancaccio, V., Grandone, E. and Margaglione, M. (2006) J Thromb Haemost, 4, 2417-22. 
Saposnik, B., Borgel, D., Aiach, M. and Gandrille, S. (2003) Eur.J Biochem, 270, 545555.

Sarich, J. (2002) Murdoch University, Perth.

Saville, B., Wormke, M., Wang, F., Nguyen, T., Enmark, E., Kuiper, G., Gustafsson, J. A. and Safe, S. (2000) J Biol Chem, 275, 5379-87.

Schindler, A. E., Campagnoli, C., Druckmann, R., Huber, J., Pasqualini, J. R., Schweppe, K. W. and Thijssen, J. H. (2003) Maturitas, 46 Suppl 1, S7-S16.

Schoneveld, O. J., Gaemers, I. C. and Lamers, W. H. (2004) Biochim Biophys Acta, 1680, $114-28$.

Schultz, J. R., Petz, L. N. and Nardulli, A. M. (2003) Mol Cell Endocrinol, 201, 165-75.

Senetar, M. A. and McCann, R. O. (2005) Gene, 362, 141-52.

Sgarabotto, M., Baldini, M., Dei Cas, A., Manotti, C., Luciana Barilli, A., Rinaldi, M., Benassi, L. and Bacchi Modena, A. (2006) Thromb Res.

Shaaban, M. M. (1991) J Steroid Biochem Mol Biol, 40, 705-10.

Sheffield, V. C., Beck, J. S., Kwitek, A. E., Sandstrom, D. W. and Stone, E. M. (1993) Genomics, 16, 325-32.

Shukla, A., Shukla, G. S. and Radin, N. S. (1992) Am J Physiol, 262, F24-9.

Simmonds, R. E., Ireland, H., Kunz, G. and Lane, D. A. (1996) Blood, 88, 4195-4204.

Simmonds, R. E., Zoller, B., Ireland, H., Thompson, E., de Frutos, P. G., Dahlback, B. and Lane, D. A. (1997) Blood, 89, 4364-70.

Smith, L. H., Coats, S. R., Qin, H., Petrie, M. S., Covington, J. W., Su, M., Eren, M. and Vaughan, D. E. (2004) Circ Res, 95, 269-75.

Sofi, F., Cesari, F., Gensini, G. F., Abbate, R. and Fedi, S. (2005) Stroke, 36, 1821; author reply 1821-2.

Song, K. S., Park, Y. S. and Kim, H. K. (2000) Arthritis Rheum, 43, 557-60.

Soria, J. M. and Bertina, R. M. (1997) Thromb Haemost, 77, 755 (abstract).

Speroff, L. and Darney, P. (1996) A Clinical Guide for Contraception, Williams and Wilkins,

Baltimore. 
Staton, J. M. and Leedman, P. J. (1998) Endocrinology, 139, 1093-100.

Staton, J. M., Thomson, A. M. and Leedman, P. J. (2000) J Mol Endocrinol, 25, 17-34.

Stearns-Kurosawa, D. J., Kurosawa, S., Mollica, J. S., Ferrell, G. L. and Esmon, C. T. (1996) Proc Natl Acad Sci U S A, 93, 10212-6.

Stepanova, M., Lin, F. and Lin, V. C. (2006) Comput Biol Chem, 30, 339-47.

Stitt, T. N., Conn, G., Gore, M., Lai, C., Bruno, J., Radziejewski, C., Mattsson, K., Fisher, J., Gies, D. R., Jones, P. F. and et al. (1995) Cell, 80, 661-70.

Stossi, F., Likhite, V. S., Katzenellenbogen, J. A. and Katzenellenbogen, B. S. (2006) J Biol Chem, 281, 16272-8.

Sumino, H., Ichikawa, S., Sawada, Y., Sakamoto, H., Kumakura, H., Takayama, Y., Sakamaki, T. and Kurabayashi, M. (2005) Thromb Res, 115, 359-66.

Sun, G., Porter, W. and Safe, S. (1998) Mol Endocrinol, 12, 882-90.

Suwanichkul, A., Allander, S. V., Morris, S. L. and Powell, D. R. (1994) J Biol Chem, 269, 30835-41.

Takimoto, G. S., Tung, L., Abdel-Hafiz, H., Abel, M. G., Sartorius, C. A., Richer, J. K., Jacobsen, B. M., Bain, D. L. and Horwitz, K. B. (2003) J Steroid Biochem Mol Biol, 85, 209-19.

Tanis, B. C. and Rosendaal, F. R. (2003) Semin Vasc Med, 3, 69-84.

Tans, G., Curvers, J., Middeldorp, S., Thomassen, M. C., Meijers, J. C., Prins, M. H., Bouma, B. N., Buller, H. R. and Rosing, J. (2000) Thromb Haemost, 84, 15-21.

Tatewaki, H., Tsuda, H., Kanaji, T., Yokoyama, K. and Hamasaki, N. (2003) Thromb Haemost., 90, 1029-1039.

ten Kate, M. K., Mulder, R., Platteel, M., Brouwer, J. L., van der Steege, G. and van der Meer, J. (2006) Haematologica, 91, 1151-2.

Tsai, S. Y., Carlstedt-Duke, J., Weigel, N. L., Dahlman, K., Gustafsson, J. A., Tsai, M. J. and O'Malley, B. W. (1988) Cell, 55, 361-9.

Tung, L., Abdel-Hafiz, H., Shen, T., Harvell, D. M., Nitao, L. K., Richer, J. K., Sartorius, C. A., Takimoto, G. S. and Horwitz, K. B. (2006) Mol Endocrinol, 20, 265670.

Uchikova, E. H. and Ledjev, I. I. (2005) Eur.J Obstet.Gynecol.Reprod.Biol, 119, 185 188. 
Van Criekinge, W. and Beyaert, R., Vol. 2007, pp. Online Source.

Van Criekinge, W. and Beyaert, R. (1999) Biol Proced Online, 2, 1-38.

Van Den Bosch, M. A., Kemmeren, J. M., Tanis, B. C., Mali, W. P., Helmerhorst, F. M., Rosendaal, F. R., Algra, A. and Van Der Graaf, Y. (2003) J Thromb Haemost, 1, 439-44.

van Gent, D., Sharp, P., Morgan, K. and Kalsheker, N. (2003) Int J Biochem Cell Biol, 35, 1536-47.

van Rooijen, M., Hansson, L. O., Frostegard, J., Silveira, A., Hamsten, A. and Bremme, K. (2006) J Thromb Haemost, 4, 77-82.

Vasse, M., Guegan-Massardier, E., Borg, J. Y., Woimant, F. and Soria, C. (2001) Lancet, 357, 933-934.

Villoutreix, B. O., Garcia, d. F., Lovenklev, M., Linse, S., Fernlund, P. and Dahlback, B. (1997) Proteins, 29, 478-491.

Wakefield, T. W., Strieter, R. M., Prince, M. R., Downing, L. J. and Greenfield, L. J. (1997) Cardiovasc Surg, 5, 6-15.

Walker, F. J. (1989) J Biol Chem, 264, 17645-17648.

Wan, Y. and Nordeen, S. K. (2003) Recent Prog Horm Res, 58, 199-226.

Wang, L., Hirayasu, K., Ishizawa, M. and Kobayashi, Y. (1994) Nucleic Acids Res, 22, 1774-5.

Wang, W., Dong, L., Saville, B. and Safe, S. (1999) Mol Endocrinol, 13, 1373-87.

Wei, L. L., Krett, N. L., Francis, M. D., Gordon, D. F., Wood, W. M., O'Malley, B. W. and Horwitz, K. B. (1988) Mol Endocrinol, 2, 62-72.

Weitz, J. I. (2001) J Thromb Thrombolysis, 12, 7-17.

Wiegratz, I. and Kuhl, H. (2004) Trends Endocrinol Metab, 15, 277-85.

Wiegratz, I., Lee, J. H., Kutschera, E., Winkler, U. H. and Kuhl, H. (2004)

Contraception, 70, 97-106.

Winkler, U. H. (1998) Contraception, 57, 203-209.

Winkler, U. H. (2000) Contraception, 62, 11S-20S; discussion 37S-38S. 
Winkler, U. H., Holscher, T., Schulte, H., Zierleyn, J. P., Collet, W. and Schindler, A. E. (1996) Gynecol Endocrinol, 10, 265-71.

Woods, N. F., Carr, M. C., Tao, E. Y., Taylor, H. J. and Mitchell, E. S. (2006)

Menopause, 13, 212-21.

Woutersz, T. B. (1991) Int J Fertil, 36 Suppl 3, 26-31.

Wu, O. (2005) Gend Med, 2 Suppl A, S18-27.

Wu, O., Robertson, L., Langhorne, P., Twaddle, S., Lowe, G. D., Clark, P., Greaves, M., Walker, I. D., Brenkel, I., Regan, L. and Greer, I. A. (2005) Thromb Haemost., 94, 17-25.

Xie, W., Duan, R. and Safe, S. (1999) Endocrinology, 140, 219-27.

Yamamura, J., Miyoshi, Y., Tamaki, Y., Taguchi, T., Iwao, K., Monden, M., Kato, K. and Noguchi, S. (2004) Cancer Sci, 95, 887-92.

Yamazaki, T., Katsumi, A., Kagami, K., Okamoto, Y., Sugiura, I., Hamaguchi, M., Kojima, T., Takamatsu, J. and Saito, H. (1996) Blood, 87, 4643-50.

Yegneswaran, S., Deguchi, H. and Griffin, J. H. (2003) J Biol Chem, 278, 14614-21.

Zilliacus, J., Wright, A. P., Carlstedt-Duke, J. and Gustafsson, J. A. (1995) Mol Endocrinol, 9, 389-400.

Zoller, B., Garcia, d. F. and Dahlback, B. (1995) Blood, 85, 3524-3531. 
APPENDICES 
<smiles>CC12CCC3c4ccc(O)cc4CCC3C1CCC2O</smiles>

$17 \beta$-oestradiol $\left(E_{2}\right)$<smiles>C#CC1(O)CCC2C3CCc4cc(O)ccc4C3CCC2(C)C1(O)C#CC1CCCCCC1</smiles>

$17 \alpha$-ethinyloestradiol (EE)

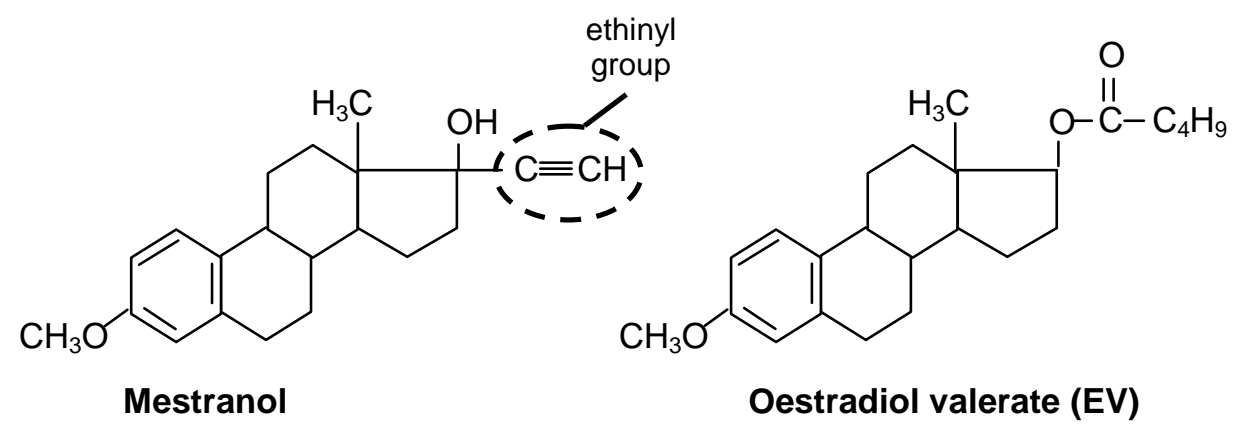

$17 \beta$-Oestradiol $\left(\mathrm{E}_{2}\right)$; the predominant isoform in vivo. $17 \alpha$-Ethinyloestradiol (EE); a synthetic oestrogen used in most COC preparations and mestranol, an isoform used in initial COC development. Both EE and mestranol have an ethinyl group attached to $\mathrm{C} 17$ that increases their half lives due to a resistance to hepatic metabolism. Oestradiol valerate (EV) is an example of an esterified oestrogen that are included in some HRT preparations. 

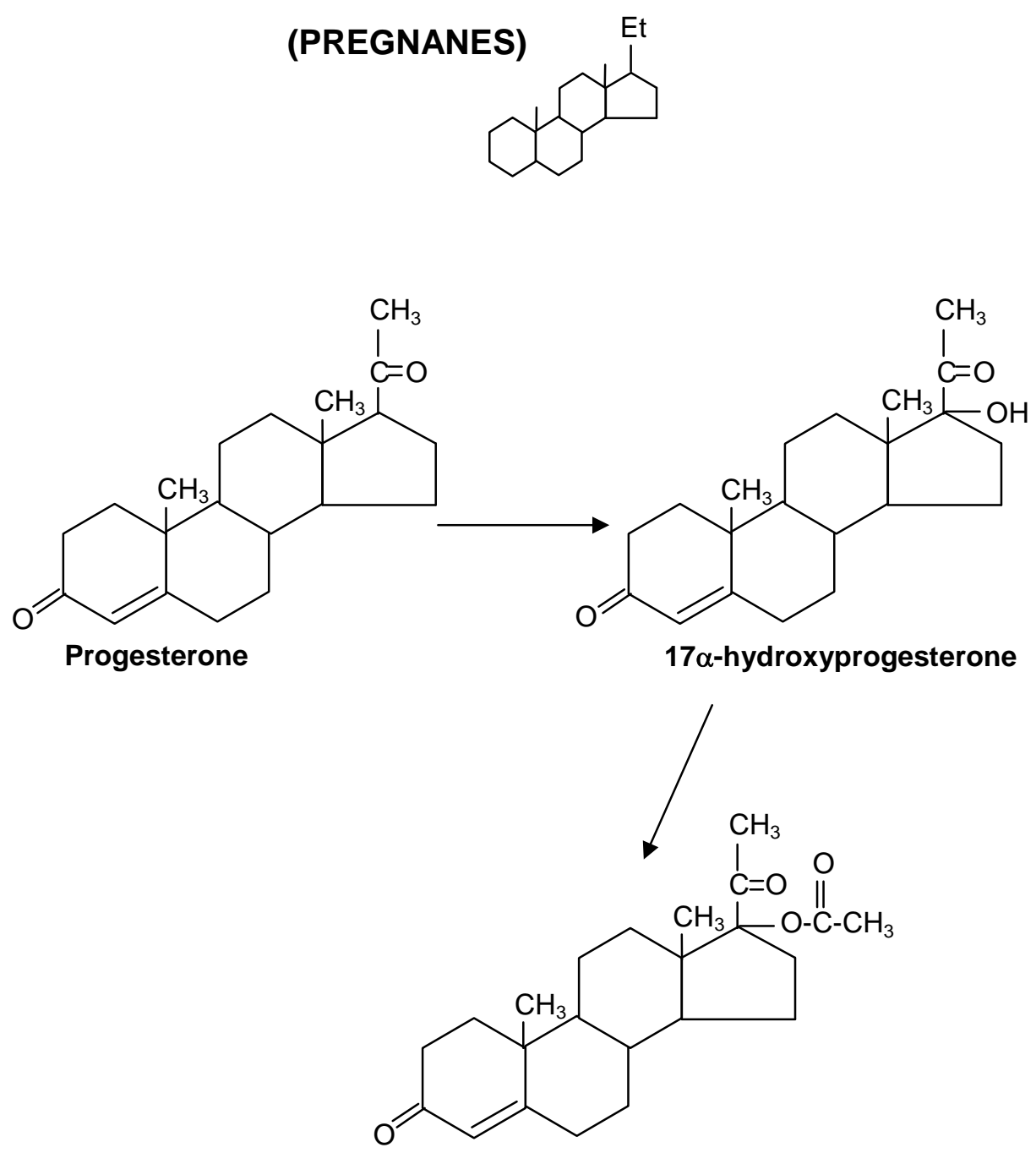

$17 \alpha$-hydroxyprogesterone acetate

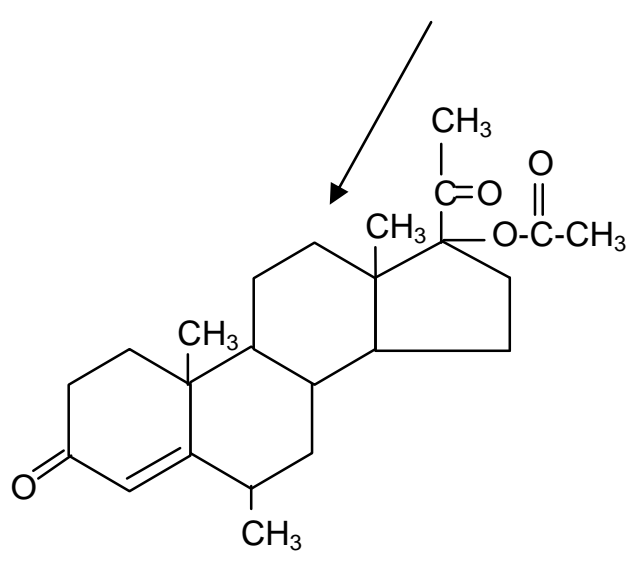

Medroxyprogesterone Acetate (MPA)<smiles>CC(=O)OC1(C(C)=O)CCC2C3CC(Cl)C4=CC(=O)C5CC5C4(C)C3CCC21C</smiles>

Cyproterone acetate

A schematic illustrating how progesterone is manipulated to form medroxyprogesterone (MPA) and cyproterone acetate. Both progestins are widely used in both COC and HRT preparations. MPA is used in many progestin-only oral contraceptives. 


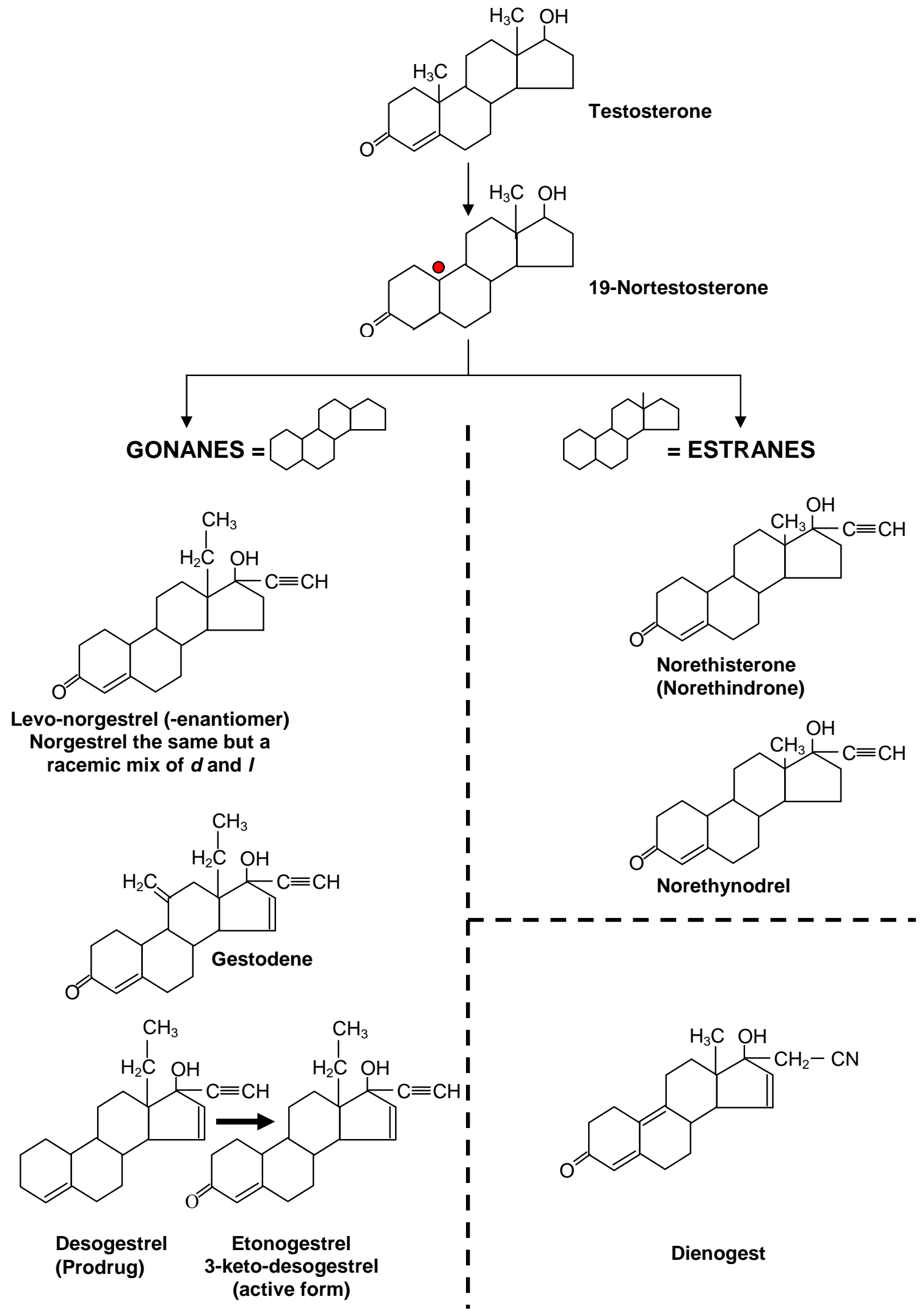

A schematic illustrating how testosterone is manipulated to form; gonanes, including the 2nd generation levonorgestrel and the 3rd generation gestodene and desogestrel; and estranes, norethisterone and dienogest 
Appendix 4- Primers used to amplify PROS1 DNA and cDNA for CSHA

\begin{tabular}{|c|c|c|c|c|}
\hline $\begin{array}{r}\text { Exon/ } \\
\text { Frag }\end{array}$ & Primer Name & $\begin{array}{c}\# \\
\text { nt }\end{array}$ & $\begin{array}{l}\mathrm{Tm} \\
\left({ }^{\circ} \mathrm{C}\right)\end{array}$ & Sequence (5'- 3') \\
\hline \multirow{2}{*}{$\begin{array}{c}5 \text { UTR } \\
\& 1\end{array}$} & PS ERE For & 20 & 50 & ACT GAA GTC TTT ATC GGA GC \\
\hline & PSintronARev & 20 & 50 & AGA AAA TCC TAC CAA CCA GG \\
\hline \multirow{2}{*}{2} & PS-2-5 & 20 & 48 & GTC ATA CAA TTC ATA GGC AG \\
\hline & PS Exon 2 Rev & 22 & 55 & AAC AGA AGG AAG TAC AGG CTG G \\
\hline \multirow{2}{*}{3} & PS Ex3 For\#2 & 21 & 46 & GGT TTG CTA AGA TAT GTT TTC \\
\hline & PS EX3 Rev\#2 & 21 & 46 & TCC CAA GGA TAA TGA AAT TAC \\
\hline \multirow{2}{*}{4} & PS Exon 4 For & 20 & 48 & CAA GTA T GT GTG TCT ACT $\underline{C T}$ \\
\hline & PS Exon 4 Rev & 20 & 48 & TCA ATT GATT GGT AGA AGT $\overline{G C}$ \\
\hline \multirow{2}{*}{$5-6$} & $P S-5 / 6-5^{\#-1}$ & 24 & 49 & GGC TTC AGG ATT TTT ATT ATA GTA \\
\hline & PS-5/6-3\# & 22 & 49 & CTA ACT GGG ATT ATT CTC ACEA I \\
\hline \multirow[b]{2}{*}{7} & PS $-7-5^{\#}$ & 21 & 50 & CAC AAA TCA AGG GTT CTT TGG \\
\hline & PS Exon 7 Rev & 22 & 53 & CA $\bar{G}$ TAA TGA TAC $\bar{C}$ CAC CAT CA $\overline{\bar{G}} \mathrm{C}$ \\
\hline \multirow{2}{*}{8} & PS Exon 8 For & 20 & 43 & ATA AGA TTG AAC ATT TAG CG \\
\hline & PS Exon 8 Rev & 18 & 43 & CAG GTG AGA AGT TAA GTA \\
\hline \multirow[b]{2}{*}{9} & PS Exon 9b For & 25 & 54 & CAC ACA AAC ATT AAG CAA TAA CCC $\underline{G}$ \\
\hline & PS Exon 9 Rev & 21 & 52 & CAT TGG TAT TGG TTC CTC ACC \\
\hline \multirow{2}{*}{10} & PS Exon 10 For & 21 & 48 & AGC ITT CTG TAT TTC TIA CCE \\
\hline & PS Exon 10 Rev & 24 & 56 & TAC ĀGA CTG CAT CAA AGT GGG ATG \\
\hline \multirow{2}{*}{11} & PS Exon 11 For & 23 & 48 & GTA ATA CTT GGT TAT TTG GTA GT \\
\hline & PS Exon 11 Rev & 20 & 48 & GAA TGA ACA AGC TTG GAT C \\
\hline \multirow{2}{*}{12} & PS Exon 12 For & 18 & 48 & AAT GCA CTC CTT GAC TCG \\
\hline & PS12Rev\#2 & 20 & 52 & TGG GCA CAC AGT AGA TAC TC \\
\hline \multirow{2}{*}{13} & PS Exon 13 For & 22 & 51 & GCA TTG AT ATG CTT CTG TTT C \\
\hline & PS Exon 13 revb & 30 & 53 & GTC CTT TGA GGT AAA TAC TGC TAT G \\
\hline \multirow{2}{*}{14} & PS Exon 14 For & 19 & 44 & ATA TTG ATT CTT TGC TCC $\underline{G}$ \\
\hline & PS Exon $14 \mathrm{Rev}$ & 19 & 44 & CTG AAT AAA AAG TAA GCA $\bar{G}$ \\
\hline \multirow{2}{*}{15} & PS Exon 15 For & 22 & 49 & GGA TTA GAA TTT GGT TGG AAA $\underline{\mathrm{C}}$ \\
\hline & PS Exon 15 Rev & 22 & 49 & TTA TAA GCA GAG AAA AGA TGC $\bar{C}$ \\
\hline \multirow{2}{*}{ F1 } & 2ndPSmRNAFor & 22 & 57 & TTC GAA ATG AGG GTC CTG GGT G \\
\hline & PSmRNAR1 & 24 & 57 & AGG AAC AGT GGT AAC TTC CAG GTG \\
\hline \multirow{2}{*}{$\mathrm{F} 2$} & PSmRNAF2 & 25 & 51 & GTG TGA ATT TGA CAT AAA TGA ATG C \\
\hline & PSmRNAR2 & 25 & 51 & AAA TCA AAT TCT GCT GAA AAT CTG C \\
\hline \multirow{2}{*}{ F3 } & PSmRNAF3 & 26 & 58 & CCA AGA TCA GAA GAG TTG TGA GGT TG \\
\hline & PSmRNAR3 & 24 & 56 & ATT CCA GAA GCT CCT TGC TTC ATC \\
\hline \multirow{2}{*}{ F4 } & PSmRNAF4 & 25 & 54 & AAC TCA AAC CGA TTA ACC CTC G \\
\hline & PSmRNAR4 & 22 & 55 & TGG CAC TGA ATG GAA CAT CTG G \\
\hline \multirow{2}{*}{ F5 } & PSMRNAF5 & 23 & 57 & CAA TCT GGA GTT GTC GAC ACC AC \\
\hline & 1stPSmRNARev & 28 & 55 & ACA CAC AAG GAA AAG GTA TTA TAA GCA G \\
\hline
\end{tabular}

\# Denotes primers previously designed by Reitsma et al. (1994).

Underlined bases denote mismatches with PROS2

Italicised bases denote penultimate mismatch base to PROS1 and PROS2

$\mathrm{F} 1 \rightarrow \mathrm{F} 5$ denotes cDNA primers. 
Appendix 5- Restriction Enzyme Combinations used for CSHA

\begin{tabular}{|c|c|c|c|c|c|c|c|c|}
\hline $\begin{array}{l}\text { Enzyme } \\
\text { (opt }{ }^{\circ} \mathrm{C} \text { ) }\end{array}$ & $\begin{array}{l}\text { ERE \& } \\
\text { Exon } 1 \\
818 \mathrm{bp}\end{array}$ & $\begin{array}{c}\text { Exons } \\
5-6 \\
363 \mathrm{bp}\end{array}$ & $\begin{array}{c}\text { Exon } \\
15 \\
332 \mathrm{bp}\end{array}$ & $\begin{array}{c}\text { Frag } \\
1 \\
562 b p\end{array}$ & $\begin{array}{c}\text { Frag } \\
2 \\
528 b p\end{array}$ & $\begin{array}{c}\text { Frag } \\
3 \\
562 b p \\
\end{array}$ & $\begin{array}{c}\text { Frag } \\
4 \\
579 b p\end{array}$ & $\begin{array}{c}\text { Frag } \\
5 \\
393 b p\end{array}$ \\
\hline $\begin{array}{c}\text { Bam HI } \\
\& \text { Sac II } \\
\left(37^{\circ} \mathrm{C}\right)\end{array}$ & $\begin{array}{l}254 \mathrm{bp} \\
342 \mathrm{bp} \\
222 \mathrm{bp}\end{array}$ & & & & & & & \\
\hline $\begin{array}{l}\text { Bst Ol } \\
\left(60^{\circ} \mathrm{C}\right)\end{array}$ & $\begin{array}{c}191 \mathrm{bp}, \\
83 \mathrm{bp}, \\
170 \mathrm{bp}, \\
230 \mathrm{bp}, \\
126 \mathrm{bp}, \\
18 \mathrm{bp}\end{array}$ & & & & & & & $\begin{array}{l}177 \mathrm{bp}, \\
216 \mathrm{bp}\end{array}$ \\
\hline $\begin{array}{c}\text { Pst I } \\
\left(37^{\circ} \mathrm{C}\right)\end{array}$ & & $\begin{array}{l}272 \mathrm{bp}, \\
233 \mathrm{bp}\end{array}$ & & & & & & \\
\hline $\begin{array}{c}\text { Bsr I } \\
\left(65^{\circ} \mathrm{C}\right)\end{array}$ & & & $\begin{array}{l}132 \mathrm{bp}, \\
127 \mathrm{bp}\end{array}$ & & & $\begin{array}{l}\text { 294bp, } \\
268 \mathrm{bp}\end{array}$ & & \\
\hline $\begin{array}{l}\text { Msp I } \\
\left(37^{\circ} \mathrm{C}\right)\end{array}$ & & & & $\begin{array}{l}232 \mathrm{bp}, \\
330 \mathrm{bp}\end{array}$ & & & & \\
\hline $\begin{array}{l}\text { Hsp92 II } \\
\left(37^{\circ} \mathrm{C}\right)\end{array}$ & & & & $\begin{array}{l}383 \mathrm{bp} \\
179 \mathrm{bp}\end{array}$ & $\begin{array}{l}295 \mathrm{bp}, \\
233 \mathrm{bp}\end{array}$ & & & \\
\hline $\begin{array}{l}\mathrm{Bfm} I \\
\left(37^{\circ} \mathrm{C}\right)\end{array}$ & & & & & $\begin{array}{l}235 \mathrm{bp}, \\
293 \mathrm{bp}\end{array}$ & & & \\
\hline $\begin{array}{l}\text { Dra III } \\
\left(37^{\circ} \mathrm{C}\right)\end{array}$ & & & & & & $\begin{array}{l}236 \mathrm{bp}, \\
326 \mathrm{bp}\end{array}$ & & \\
\hline $\begin{array}{l}\text { Dde I } \\
\left(37^{\circ} \mathrm{C}\right)\end{array}$ & & & & & & & $\begin{array}{l}199 \mathrm{bp}, \\
185 \mathrm{bp}, \\
195 \mathrm{bp}\end{array}$ & \\
\hline
\end{tabular}


Appendix 6- Sequencing, insert amplification and mutageness primer sequences

\begin{tabular}{|c|c|c|c|}
\hline Vector & $\begin{array}{l}\text { Insert or Primer } \\
\text { Information }\end{array}$ & $\begin{array}{l}\# \\
\text { nt }\end{array}$ & Sequence (5'- 3') \\
\hline \multirow{2}{*}{ PPTMR } & \multirow{2}{*}{$\begin{array}{l}\text { 950bp fragment of } \\
\text { PROS1 } 5 \text { UTR }\end{array}$} & 27 & ACG CTC GAG CAC GAT CAG GAG TTC AGA \\
\hline & & 27 & TTG AAT TCA TTC GAA GCG CGC GGA GGC \\
\hline \multirow{2}{*}{ pPTMR(-407) } & \multirow{2}{*}{$\begin{array}{l}\text { c-406t mutagenesis } \\
\text { primers }\end{array}$} & 34 & CTT CTG AAC CTA GGG ATI CTG TCC TCT TGA ACC C \\
\hline & & 34 & GGG TTC AAG AGG ACA GAA TCC CTA GGT TCA GAA G \\
\hline \multirow{2}{*}{ pPTMR(-ERE) } & \multirow{2}{*}{$\begin{array}{l}\text { Primers for removal of } \\
\text { the proposed ERE }\end{array}$} & 26 & ATT TGC TTT TAC TAT CAC CAT AGT TC \\
\hline & & 25 & CCA CAT GTT TTT TCG GTC TTG TAT G \\
\hline \multirow{4}{*}{ pPTMR related } & \multirow{7}{*}{$\begin{array}{c}\text { Primers used to confirm } \\
\text { sequences } \\
\text { of pPTMR, pPTMR(- } \\
\text { 407), pPTMR(-ERE), } \\
\text { pPTMR(-Avrll), } \\
\text { pPMTR(del-BclI/AvrII) } \\
\text { and } \\
\text { pPMTR(del-Avrll/DrallI) }\end{array}$} & 20 & ACT GAA GTC TTT ATC GGA GC \\
\hline & & 19 & GCA CGA CTT CTT CAA GTC C \\
\hline & & 19 & TGA AGT TCA CCT TGA TGC C \\
\hline & & 22 & ACC ATG GCC TCC TCC GAG AAC G \\
\hline \multirow{3}{*}{ pPTMR related } & & 22 & CTA CAG GAA CAG GTG GTG GCG G \\
\hline & & & \\
\hline & & & \\
\hline \multirow{2}{*}{ pBTM116 } & \multirow{2}{*}{$\begin{array}{l}\text { 2053bp fragment of } \\
\text { PROS1 cDNA }\end{array}$} & 27 & TTG GAT CCA AAT GAG GGT CCT GGG TGG \\
\hline & & 32 & ATC TGC AGT TAT AAG CAG AGA AAA GAT GCC TT \\
\hline \multirow{4}{*}{$\begin{array}{l}\text { pBTM116 } \\
\text { related } \\
\text { pBTM116 } \\
\text { related }\end{array}$} & \multirow{2}{*}{$\begin{array}{l}\text { Primers used to confirm } \\
\text { sequence of PROS1 }\end{array}$} & 27 & TTG GAT CCA AAT GAG GGT CCT GGG TGG \\
\hline & & 32 & ATC TGC AGA CCC AGT TTG AAA AGA GCG AAG AC \\
\hline & \multirow{4}{*}{$\begin{array}{l}\text { cDNA in pBTM116 } \\
\text { vector }\end{array}$} & 26 & TTG GAT CCA TGA CCC GGA AAC GGA TT \\
\hline & & 26 & ATC TGC AGC TTC ATT GCA TGG CAG AG \\
\hline pBTM116 & & 27 & TTG GAT CCG CTG TGT CAA TGC CAT TCC \\
\hline \multirow{5}{*}{$\begin{array}{l}\text { related } \\
\text { pBTM116 } \\
\text { related } \\
\text { pBTM116 } \\
\text { related }\end{array}$} & & 25 & ATC TGC AGG GCA CAC TGA AAC AAC C \\
\hline & & 27 & TTG GAT CCA GAA GAG TTG TGA GGT TGT \\
\hline & & 28 & ATC TGC AGT CCA GCT TCG TAT ACA TCC A \\
\hline & & 28 & TTG GAT CCA TGG ATG TAT ACG AAG CTG G \\
\hline & & 32 & ATC TGC AGT TAT AAG CAG AGA AAA GAT GCC TT \\
\hline \multirow{2}{*}{ pGADT7 } & \multirow{2}{*}{$\begin{array}{l}\text { 1225bp fragment of } \\
\text { PROZ cDNA }\end{array}$} & 25 & TTA TCG ATA TAT GGC AGG CTG CGT C \\
\hline & & 27 & GTG GGA TCC CAG TTA CTT CAT GAT CTG \\
\hline \multirow{2}{*}{ рАCT2 } & \multirow{2}{*}{$\begin{array}{l}\text { Primers used to } \\
\text { sequence } \mathrm{pACT} 2 \text { inserts }\end{array}$} & 20 & CCA GAT TAC GCT AGC TTG GG \\
\hline & & 20 & CAG TTG AAG TGA ACT TGC GG \\
\hline
\end{tabular}


Appendix 7- Sequence Alignment of Yeast-2-Hybrid Findings

Col110

Col111

Col19

Col12

Col2

Col112

GNNCCTTNNNNNNTNTGGGCCGGGGANCGAATTCGCGGCCGCGTCGACGATGAGTTNGCA 60

$\operatorname{Col} 110$

Col111

Col19

Col12

Col2

Col112

TCACTCTGNACATATTCCCTTTTTNNGGGAAGTAGGGAGCGTGCTCNTTGNGCNGCGGAT

TCACTCTGNACATATTCCCTTTTTNNGGGAAGTAGGGAGCGTGCTCNTTGNGCNGCGGAT

$\operatorname{col} 110$

$\operatorname{col} 111$

Col19

Col12

$\mathrm{Col} 2$

Col112

GCGATCCNNAANNTACACAGNGCGANGCCANCGNANTCATTCAGTNCTCCTCNTGAGNAA 180

$\operatorname{col} 110$

Col111

Col19

$\operatorname{col} 12$

$\operatorname{col} 2$

Col112

Col110

Col111

Col19

Col12

Col2

Col112

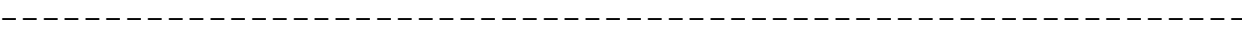

- - - - - - - - - - - - - - - - - - - - - - - - - - - - - - - - - - - - - - - - - -

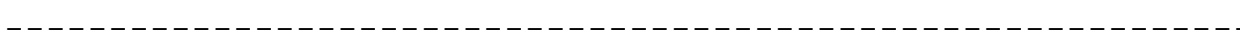

$\operatorname{col} 110$

Col111

Col19

Col12

Col2

Col112

AGATNNGATGACAGGANGTNGCAAGCTGNGCTNTTCCCNTANANCCTGNNGCGGTGGACA 240

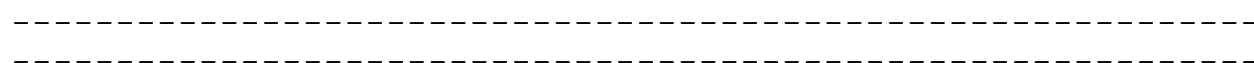

240

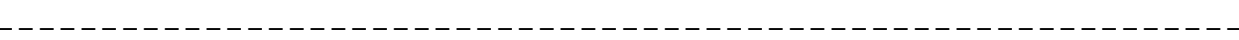

------ - - - - - - - - - - - - - - - - - - - - - - - - - - - - -

GACTCTCTGGAGTTCTGAGAGATAGGNGAGCTCTACCTGCCAAANTTTTCCATCTCGAGG $30 \odot$

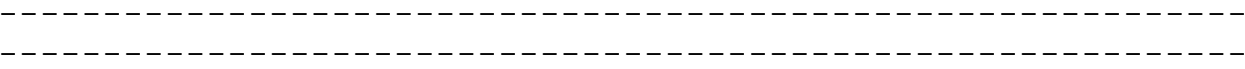

- - - - - - - - - - - - - - - - - - - - - - - - - - - - - - - - - - - - -

Col110

Col111

Col19

Col12

Col2

Col112

GACTATNACCTGAACGACNTACTTCTCCAGNTGGGNATTGAGGAAGCCTTCANCNNCNNG GACTATNACCTGAACGACNTACTTCTCCAGNTGGGNATTGAGGAAGCCTTCANCNNCNNG

Col110

Col111

Col19

Col12

Col2

Col112

GCTNACCTGNNANGGATCACAGGGGCCAGGAACCTANCNGNCTCCCANGNGGTCCATAAC

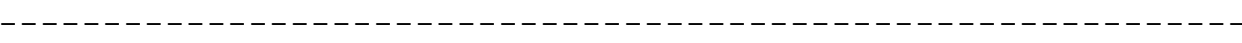

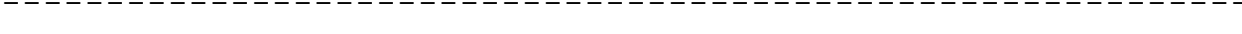

NGGTGNGCTTGATGTATNTGANGAGGGCATGAGAATNNTCTGCTGNNACTTTAGTCAAAA 480

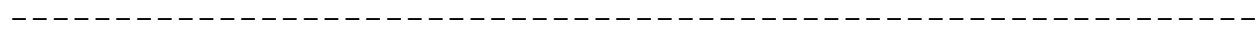
- - - - - - - - - - - - - - - - - - - - - - - - - - - - - - - - - - - - - - - - - - - - - - - - - - - - - - - - - - - - - - - - - - - - - - - - - - - - - - - - - - - - - - - - - - - 
Col110

Col111

Col19

Col12

Col2

Col112

Col110

Col111

Col19

Col12

Col2

Col112

Col110

Col111

Col19

Col12

Col2

Col112

Col110

Col111

Col19

Col12

Col2

Col112

Col110

Col111

Col19

Col12

Col2

Col112

Col110

Col111

Col19

Col12

Col2

Col112

Col110

Col111

Col19

Col12

Col2

Col112

Col110

Col111

Col19

Col12

Col2

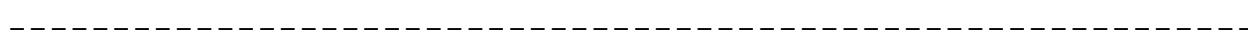
TCACCCTCCTTTNTGCATTAGTGGAGACAAGGANCATTGTGCGTTTCAANAGGNCCTTNC 540

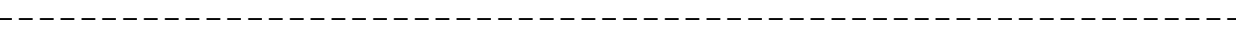
- - - - - - - - - - - - - - - - - - - - - - - - - - - - - - - - - - - - - - - - - - - -
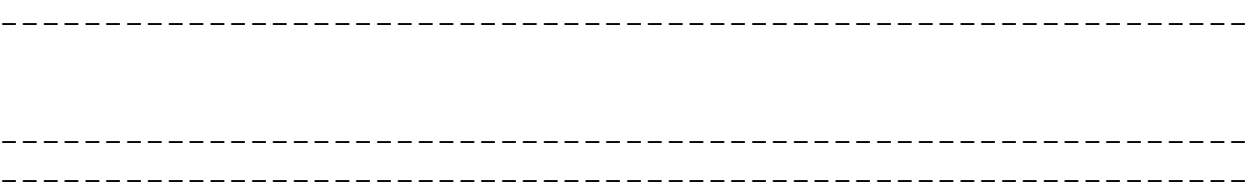
TGATGATCATTGTCCCTACAGACACCCAGAACATCTTCTTNATGAGCAAATGCNCCANTC 600
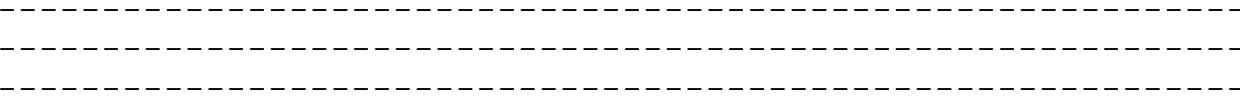
CCAAGCAAGNCTTAGAGCTTGCCATCAAGCAGTGGGGCTCTCAGTAAGGAACTTGGAATG 660
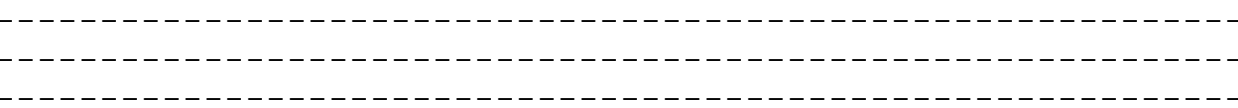
- - - - - - - - - - CAAAGCTGGATGCCTGGGTCTCTGGGGCACAGNCTGGCCCCTGTGCACCGNANTGGCCAT - - - - - - - - - - - - - - - - - - - - - - - - - - - - - - - - - 720

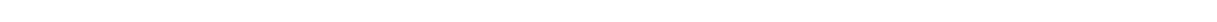
- - - - - - - - GGTATGTGTGGCCCTGNCTGCTTTTCCTTGGAAGGNGGACAGCGATTNCCCTGTGTAGCT 780 -

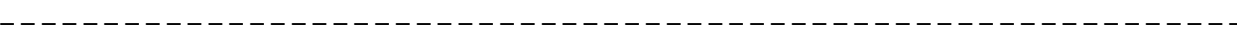

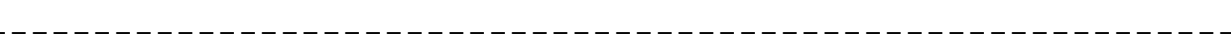

CTCACATGCACAGGGGTNCCATGGACTCTTNANNTCTGGGAGGGTCCTGGGCCTCCTGAA 840 TCGACAAGAGCAGGAGAATGAGACAGTGGTGGTGAAAGAGAAGATGGTTGGCGGCATTGC 92

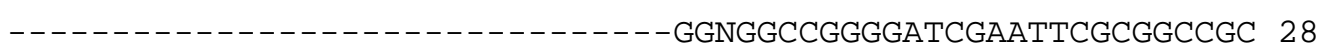
CAGCAATAAAANAATTTTCGTTGGNAGAAAAAANAAANAANAAAAAAAAAATANTGTCNG 900 CCAGATCATCGCAGCACAGGAAGAAATGCTTCGGAAGGAACGAGAGCTGGAAGAGGCGCG 152

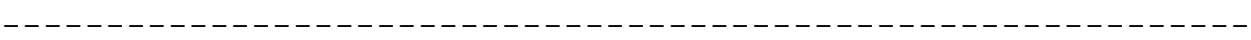

GTCGACCTGGGACAGAGGACTGCTGTCTGCCCTCTCTGGTCACCCTGCCTAGCTAGAGGA 88 TANTATTTNTTNNTNTGNNNGNANNNTTNTTATTANTTNNCANCTNTGTTNTNAANNANA 960 GAAGAAACTGGCCCAGATCCGGCAGC - -AGCAGTACAAGTTTCTGCCTTCAGAGCTTCGA 210 
Col110

Col111

Col19

Col12

Col2

Col112

Col110

Col111

Col19

Col12

Col2

Col112

Col110

Col111

Col19

Col12

Col2

Col112

Col110

Col111

Col19

Col12

Col2

Col112

Col110

Col111

Col19

Col12

Col2

Col112

Col110

Col111

Col19

Col12

Col2

Col112

Col110

Col111

Col19

Col12

Col2

Col112

Col110

Col111

Col19

Col12

TCTGTGACCCCAGCCATGAGGACCCTCGCCATCCTTGCTGCCATTCTCCTGGTGGCCCTG 148 NAAANNTNTTNTNCTNNTNATNCNCGNGTNNTGTNTNNTNNTCNAANNTNNTTNTNNATC 1020 GATGAGCACTAAAGAAGCCTCTTCTATTTAATGCAGACCCGGCCCAGAGACTGTGCGTGC 270

-GNNNNG 6

CAGGCCCAGGCTGAGCCACTCCAGGCAAGAGCTGATGAGGTTGCTGCAGCCCCGGAGCAG 208 NNNTATCNTCCTCNTTNNTGCGNTGCNTNCGNTTTTTTTTTNTTTNTTTCACCGGTANAA 1080 CACTACCAAAGCCTTCTGGGCTGTCGGGGCCCAACCTGCCCAACCCCAGCACTCCCCAAA 330

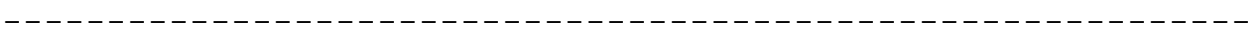
NGGNCGCGTCGACACCAAACCTACGCCAAAATCCATTTCACTATCATATTCATCGGCGTA 66

ATTGCAGCGGACATCCCAGAAGTGGTTGTTTCCCTTGCATGGGACGAAAGCTTGGCTCCA 268 NGGGTNNGNGAGTTCCCTAGCGNAGCCTNNNCATNCATNTTTNGNTNNTACNNNNCNNTT 1140 GTGCCTGCCAAACCCCAGGGCCTGGCCCCGCCCAGTCCCGCAGTACATCCCCTGTCCCCT 390 AАTCTAACTTTCTTCCC - ACAACACTTTCTCGGCCTATCCGGAATGCCCCGACGTTACT 124

AAGCATCCAGGCTCAAGGAAAACATGGCCTGCTAT - - - - AAGCATCCAGGCTCAAGGAAAAACATGGCCTGCTATTGCAGAATACCAGCGTGC - -ATTG 326 CNTNATNACCTTNTGTANNNGTGNGGNATTNTCACNTGCTNNNTNTNNGTNNACTCNNTA 1200 CCCCAACCCCAAGTGCCTTCATGCC - - CTAGGGCCCCCCAAGTGCCTGCCCCT - - - CCC 444 - - - - - - - - - - - - - - - - - - - - - - - - - - - - CGGACTACCCCGATGCATACACCACATGAAACATCCTATCATCTGTAGGCTCATTCATTT 184

ACGGAGAACGTCGCTATGGAACCTGCATCTACCAGGGAAGACTCT - - - - - - - - GG 72 CAGGAGAACGTCGCTATGGAACCTGCATCTACCAGGGAAGACTCT - $\ldots$ CNTNNNNCGNTNGCTGGNNNNNNNNTNNTCNNTNGGNGNGANCTNTCNATCANGCNTAAN 1260 CAGAGTATTAACGCTCCAAGAGTATTATTAACGCTGCTGTACCTC - - - - - GATCTGAAT 498 - - - - - - - - - - - - - - - - - - - - - - - - - - - - - - - - - - - CTCTA-ACAGCAGTAATATTAATAATTTTCATGATTTGAGAAGCC $\ldots \ldots$

GCATTCTGCTGCTGA - - GCTTGCAG - -AAAAAGAAAAATGAG - - - - - - CTCAAAATTTG 121 GCATTCTGCTGCTGA - - GCTTGCAG - - AAAAAGAAAAATGAG - - - - - - CTCAAAATTTG 422 CCNTTNNGCTNTTNCTTNNNTGCANCGNATAANANTNATNGGGTTNAATNTGNANGNTTN 1320 CTGCCGGGGCCCCAGCCCACTCCACCCTGCCAGCAGCTTCCAGCCAGTCCCCACAGCCTC 558 - - - - - - - - - - - - - - - - - - - - - - - - - - - - - - - - - - - - TCGCTTCGAAGCGAAAAGTCCTAATAGTAGAAGAACCCTCCA $\ldots \ldots$

CTTTGAGAGCTACAGGGAATTGC - TATTACTCCTGTACCTTCTGCTCAATTTCCT - TTCC 179 CTTTGAGAGCTACAGGGAATTGC - TATTACTCCTGTACCTTCTGCTCAATTTCCT - TTCC 480 TCTTNNTGTCAAAAAAGNNTANNATNNTTCTCCAANATAATAGGNNNAGTTTATNANNNN 1380 ATCAGCTCTCTTCACCGTTTTTT - -GATACTATCTTCCCCCACCCCCAGCTACCCATAGG 616 - - - gAgTGACTATATGgATgCCCCCCACCCTACCACACATTCGAAGAACCCGTATACATA 336

TCATCCCAAATAAATGCCTTGTTACAAAAAAAAAAAAAAAAAAAAAAAA-AAAAAAAAAA 238 TCATCCCAAATAAATGCCTTGTTACNAGAAAAAAAAAAAAAAAAAAAAA-AAAAAAAAAA 539 TCNTNCTATANNTNGNTGACNNTGNANNAGANCNTGTATNNGTCATGGT - CTGNCTNNTC 1439 GGCTGCAGAGTTATAAGCCCCAAACAGGTCATGCTCCAATAAAAATGATTCTACCTTCNN 676 
Col110

Col111

Col19

Col12

Col2

Col112

Col110

Col111

Col19

Col12

Col2

Col112

Col110

Col111

Col19

Col12

Col2

Col112
AAAAAAAAAAAAAA - - - AAAAAAAAAAAAAAAAAAAAAANCCCCNGGGNNNTTTTTNNN 294 AAAAAAAAAAAAAA - - - AAAAAAAAAAAAAAAAAAAAANNCCCCNGGGNNTTTTTTTNN 595 CNTNTNCTANACTA - - - - NAGCTANNAATGTAGANATGCTGGANGANATGCTNNNTTTAT 1495 AAAAAAAAAAAAAA - - - AAAAAAAAAAAAAAAAAAAAAAAACCNCNGNAANTTTTTTTT 732 - - - ACACAGCTGCA - - - CAGGTCGTGCCCCGAGGCTCCTGCTGCCGGCACCTCCCCCAG 53 GGCCTCCATGACTTTTTCAAAAAAAAAAAAAAAAAAAAAAACCNNNGGGNNTTTTNNNAN 456 *

NNNNNNNNNNAAAANCCCCNNGGGTTTTTTTTN - - - - N- - - GGGGGGGGGNNNNNNNNNN 347 NNNAAAANNAAAAAAACCCCNGGNTTTTTTTTT - - - - TTTTNGGGGGGGNNNNNNNNNNN 651 TNTTTNATGAGNNNGATCTCATNNNCCTNATCN - - - TAGTGNGTNTNNTTTCTGNTGCG 1551 TTTTNAANTTTNAAAANCCCNGGGTTTTTTTTT - - - - TTTTGGGGGGGNNNNNNNNNNNN 788 CCTGGACTTTGGCTGTGTTTGTAGCCCTGTCCCAGCACTCCGGGTGGGAATGGCAGGCTG 113 NNGAAAANNGGGAAAACCCGGGGGGNTNNTTTT - - - - TNNNGGGNGNNNNNNNNNNNNNN 512

NNNNNNNNNNNN - - - - - 359

NNNNNNNNNNNNN - - - - 664

TATCATANTNGTNTGATG 1569

NNNNNNNNNNN - - - - - 799

CGTCCCACTGCTCC - - - 127

NNNNNNN - . . . . . . 519 